LUCIENE STIVANIN

\title{
Tempo de processamento para a leitura de palavras e para a nomeação de figuras em crianças leitoras e não leitoras
}

Tese apresentada à Faculdade de Medicina da Universidade de São Paulo para obtenção do título de Doutor em Ciências

Área de Concentração: Comunicação Humana Orientadora: Prof ${ }^{a}$ Dra. Claudia Ines Scheuer

São Paulo 
Esta tese está de acordo com:

Referências: adaptado de International Committee of Medical Journals Editors (Vancouver)

Universidade de São Paulo. Faculdade de Medicina. Serviço de Biblioteca e Documentação. Guia de apresentação de dissertações, teses e monografias. Elaborado por Anneliese Carneiro da Cunha, Maria Júlia de A. L. Freddi, Maria F. Crestana, Marinalva de Souza Aragão, Suely Campos Cardoso, Valeira Vilhena. São Paulo. Serviço de Biblioteca e Documentação: 2004.

Abreviatura dos títulos dos periódicos de acordo com List of Journals Indexed in Index Medicus. 
Esta pesquisa recebeu apoio financeiro da Fundação de Amparo à Pesquisa do Estado de São Paulo - FAPESP (processo nº 05/60488-0). 


\section{DEDICATÓRIA}

Aos meus pais Gelson e Maria, humildes e sábios mestres, pelos ensinamentos e amor que me permitem ir sempre adiante.

Ao meu tio Armelindo, pelos aplausos às minhas primeiras vitórias, pela proteção quando as coisas pareciam impossíveis e pela doce lembrança de ter sido fundamental nesta grande conquista.

Às minhas irmãs e aos meus sobrinhos, por sempre compartilharem comigo os momentos de fracasso, aprendizado e sucesso.

À minha avó Ernestina, pelo exemplo de coragem e determinação. 


\section{AGRADECIMENTOS}

À Deus, por me conceder a oportunidade de estar neste caminho, rodeada por tantas pessoas especiais.

À Profa. Dra. Claudia Scheuer, brilhante profissional, por ter me mostrado os caminhos da área acadêmica e pela dedicação na orientação desta tese. Mais do que isto, agradeço pelos ensinamentos e conselhos e por ser uma grande amiga.

Aos profissionais da Escola Olavo Pezzotti, especialmente à Maria de Fátima Oliveira, Leonor Rosa e Regina Anechine, exemplos de determinação e competência na área educacional, pela recepção calorosa e pelo apoio, e por me fazerem acreditar na melhora do ensino no país.

Às crianças deste estudo, pelos momentos de alegria e aprendizado.

Às famílias das crianças, pela confiança.

À FAPESP, pelo apoio financeiro.

Ao Rafael Pasquini, pela dedicação na elaboração do programa computacional que possibilitou a realização de toda a coleta e análise de dados.

À Evelin Saffiotti, pela disposição na aplicação e análise do teste de quociente intelectual dos sujeitos.

Aos colegas fonoaudiólogos Luciana Amaro e Christian C.C. Oliveira, que participaram como juízes dos resultados. 
Ao Marcos Maeda, pelo cuidado na análise estatística deste trabalho.

À Renata Leite, pela revisão do texto e pelo incentivo.

Aos professores Drs. Francisco Baptista Assumpção Júnior, Mônica Carolina Miranda, Carla Gentile Matas e Renata Mamede Carvallo, pelas valiosas sugestões dadas nas bancas de qualificação.

Ao André Sasseron, pelo amor e apoio, por estar presente nas etapas importantes da minha vida, fazer parte de minhas decisões e ser um dos grandes motivos deste percurso.

Ao Christian Oliveira, por ser meu fiel companheiro desde os primeiros passos deste processo, por ter me ensinado tantas coisas e pela certeza de uma amizade verdadeira.

Às amigas Aline Stivanin, Alessandra Casaroto e Jacqueline Stivanin, por terem vivido comigo todas as etapas deste processo, demonstrando paciência e apoio.

Às amigas de Andradas Ana Paula Stella, Calízia Perinoto, Maria Alice Galhardo e Gisele Rossi, que mesmo distantes, estão próximas pelas recordações de todos os bons momentos vividos e pelo entusiasmo com que acompanharam este trabalho.

À Rosângela Viana Andrade, pela dedicação e carinho durante minha formação profissional e pela amizade que foi construída.

Aos colegas Adriano Predeus, Alessandra Pedraci, Ana Cristina Fernandes, Elaine Tamagnini, Fernanda Malerbi e Giovana Araújo, por compartilharem seus conhecimentos científicos e se mostrarem grandes amigos e incentivadores. 
“ Depois da aula, Hassan e eu passávamos a mão em um livro e corríamos para uma colina. Sentado ali, com as pernas cruzadas e o jogo de sombra da folhagem do pé de romã no rosto, Hassan arrancava distraído pedacinhos de grama do chão enquanto eu ia lendo as histórias que ele não podia ler sozinho. [...] Mas, apesar de ser analfabeto, ou quem sabe até por isso mesmo, Hassan era atraído pelo mistério das palavras seduzido por um mundo secreto cujo acesso the era vedado. Lia para ele poemas $e$ histórias, às vezes enigmas - embora sempre parasse de ler estes últimos quando percebia que ele tinha muito mais facilidade que eu para decifrá-los. Lia então coisas menos arriscadas. [...] Para ele, as palavras da página eram um amontoado de códigos, algo indecifrável, misterioso. Eram portas secretas e eu é que detinha todas as chaves. [...] Fiquei pasmo. Um detalhe como esse, tão óbvio que chegava a ser absolutamente estúpido, não tinha me ocorrido. Parecia que na mesma noite em que eu tinha aprendido qual era um dos objetivos da escrita, a ironia, ia ser apresentado também a uma de suas armadilhas: os furos da trama. E, entre todas as criaturas do mundo, Hassan é que foi me ensinar isso. Hassan que não sabia ler e nunca tinha escrito uma única palavra em toda a sua vida. Uma voz, fria e escura, sussurrou subitamente em meu ouvido: "Mas o que é que ele entende disso, esse hazara analfabeto?"[...] E era eu que ia ao colégio. Era eu que sabia ler e escrever. Eu era o inteligente. Hassan não era capaz de ler nem um livro de primeira série, mas podia ler com a maior facilidade...”

(Khaled Hosseini, O caçador de pipas) 


\section{SUMÁRIO}

Lista de abreviaturas

Lista de siglas

Lista de quadros

Lista de figuras

Lista de tabelas

Resumo

Abstract

1.INTRODUÇÃO

2. REVISÃO DA LITERATURA

05

2.1. Tempo de processamento da informação

06

2.2. Leitura

10

2.2.1. Leitura em voz alta de palavras isoladas

2.3. Nomeação de figuras

2.4. Relação entre a leitura de palavras e a nomeação de figuras

2.5. A leitura e seus transtornos

2.6. Nomeação de figuras em crianças com Transtorno da Leitura

3.1. Objetivo geral

3.2. Objetivos específicos

4. HIPÓTESES

\section{MÉTODOS}

5.1. Casuística

5.1.1. Crianças leitoras 
5.2. Instrumentos e procedimentos

5.2.1. Instrumentos para seleção e caracterização dos sujeito 51

5.2.2. Instrumentos para avaliação da leitura e da nomeação 55

5.2.3. Descrição do programa computacional 60

5.2.4. Participação de juízes $\quad 65$

5.3. Caracterização das amostras $\quad 67$

5.3.1. Crianças leitoras $\quad 67$

$\begin{array}{ll}\text { 5.3.2. Crianças não leitoras } & 68\end{array}$

6. RESULTADOS 72

6.1. Análise de concordância entre juízes para o tempo de 74 processamento

6.2. Crianças leitoras $\quad 75$

6.2.1. Prova de leitura de palavras $\quad 75$

$\begin{array}{ll}\text { 6.2.2. Nomeação de figuras } & 91\end{array}$

6.2.3. Comparação entre leitura de palavras e nomeação $\begin{array}{ll}\text { de figuras } & 106\end{array}$

$\begin{array}{ll}\text { 6.3. Crianças não leitoras } & 111\end{array}$

6.3.1. Comparação entre crianças leitoras e não leitoras na $\begin{array}{ll}\text { nomeação de figuras } & 111\end{array}$

$\begin{array}{ll}\text { 6.4. Sintese dos resultados } & 123\end{array}$

$\begin{array}{ll}\text { 7. DISCUSSÃO } & 124\end{array}$

$\begin{array}{lr}\text { 8. CONCLUSÃo } & 139\end{array}$

$\begin{array}{lr}\text { 9. ANEXOS } & 142\end{array}$

10. REFERÊNCIAS 


\section{LISTA DE ABREVIATURAS}

\begin{tabular}{|c|c|}
\hline et al. & e outros \\
\hline op. Cit & citados acima \\
\hline $\mathrm{AF}$ & alta freqüência \\
\hline $\mathrm{BF}$ & baixa freqüência \\
\hline $\mathrm{CV}$ & consoante-vogal \\
\hline $\mathrm{OE}$ & outras estruturas \\
\hline $\mathrm{R}$ & regular \\
\hline I & irregular \\
\hline DRO & desconhecimento da regra ortográfica \\
\hline DRA & desconhecimento da regra de acentuação \\
\hline PVF & paralexia verbal formal \\
\hline $\mathrm{R}$ & regularização \\
\hline $\mathrm{N}$ & neologismo \\
\hline NR & não resposta \\
\hline $\mathrm{RP}$ & resposta parcial \\
\hline $\mathrm{S}$ & semântico \\
\hline $\mathrm{P}$ & perceptual \\
\hline SP & semântico e perceptual \\
\hline $\mathrm{F}$ & fonológico \\
\hline $\mathrm{PF}$ & perceptual e fonológico \\
\hline NR & não resposta \\
\hline $\mathrm{C}$ & circunlocução \\
\hline SR & sem relação \\
\hline $\mathrm{R}$ & revisão \\
\hline $\mathrm{EP}$ & erro de produção \\
\hline M & média \\
\hline DP & desvio-padrão \\
\hline $\mathrm{CP}$ & correlação de Pearson \\
\hline
\end{tabular}




\title{
LISTA DE SIGLAS
}

\author{
ABIPEME Associação Brasileira de Institutos de Pesquisa de Mercado \\ IDA International Dyslexia Association \\ NICHID National Institute of Child Health and Human Development \\ DSM-IV Manual de Diagnósticos e Estatística de Transtornos Mentais \\ WISC-III Wechsler Intelligence Scale for Children
}




\section{LISTA DE QUADROS}

Quadro 1. Critérios Diagnósticos para F81.0 - 315.00:

31

Transtorno da Leitura (DSM-IV, 1995)

Quadro 2. Critérios Diagnósticos para F81.8 - 315.2:

Transtorno da Expressão Escrita - (DSM-IV, 1995)

Quadro 3. Critérios Diagnósticos para F81.2 - 315.1:

32

Transtorno da Matemática (DSM-IV, 1995)

Quadro 4. Síntese dos resultados

123 


\section{LISTA DE FIGURAS}

Figura 1. Modelo conexionista - processamento da leitura (Adams, 1994)

Figura 2. Modelo de dupla-rota-processamento da leitura (Coltheart et al., 2001)

Figura 3. Programa computacional - Janela inicial

Figura 4 Programa computacional -Cadastrar Novo Aluno

Figura 5. Programa computacional - Executar Testes

Figura 6. Programa computacional - Execução do sistema de análise

Figura 7. Programa computacional - Sistema de análise

Figura 8. Programa computacional - Arquivos individuais dos dados

Figura 9. Tempo de latência para a leitura: alta $\mathrm{x}$ baixa freqüência

Figura 10. Tempo de latência para a leitura: regulares $x$ irregulares

Figura 11. Tempo de latência para a leitura: $4 \times 6$ grafemas

Figura 12. Tempo de duração da emissão oral para a leitura: alta $\mathrm{x}$ baixa freqüência

Figura 13. Tempo de duração da emissão oral para a leitura: regulares $x$ irregulares

Figura 14. Tempo de duração da emissão oral para a leitura: 4 x 6

Figura 15. Porcentagem de acertos na leitura: alta $x$ baixa freqüência

Figura 16. Porcentagem de acertos na leitura: regulares $x$ irregulares

Figura 17. Porcentagem de acertos na leitura: $4 \times 6$ grafemas

Figura 18. Tempo de latência para a nomeação: alta $x$ baixa freqüência

Figura 19. Tempo de latência para a nomeação: regulares $x$ irregulares

Figura 20. Tempo de latência para nomeação: 4 x 6 grafemas

Figura 21. Tempo de duração da emissão oral para a nomeação: alta $x$ baixa freqüência

Figura 22. Tempo de duração da emissão oral para a nomeação: regulares $\mathrm{x}$ irregulares

Figura 23. Tempo de duração da emissão oral para a nomeação: 4 x 6 grafemas 
Figura 24. Porcentagem de acertos na nomeação: alta $x$ baixa freqüência

Figura 25. Porcentagem de acertos na nomeação: regulares $x$ irregulares

Figura 26. Porcentagem de acertos na nomeação: $4 \times 6$ grafemas

Figura 27. Tempo de latência: leitura x nomeação

Figura 28. Tempo de duração da emissão oral: leitura x nomeação

Figura 29. Porcentagem de acertos: leitura x nomeação

Figura 30. Tempo de latência para a nomeação: leitores x não leitores

Figura 31. Tempo de duração da emissão oral para a nomeação: leitores x não leitores

Figura 32. Porcentagem de acertos na nomeação: leitores $x$ não leitores 


\section{LISTA DE TABELAS}

Tabela 1. Distribuição das crianças leitoras por idade (em meses)

Tabela 2. Distribuição das crianças leitoras por gênero

Tabela 3. Distribuição das crianças leitoras por classe sócio-econômicofamiliar

Tabela 4. Distribuição das crianças não leitoras por idade (em meses) e gênero

Tabela 5. Distribuição das crianças não leitoras por classe sócioeconômico-familiar

Tabela 6. Percentis e categorias referentes aos sub-testes vocabulário e cubos e ao QI estimado (WISC-III, Weschler, 1981)

Tabela 7. Percentis e categorias de cada sub-teste da escala verbal de inteligência (WISC-III, Weschler, 1981)

Tabela 8. Caracterização das crianças não leitoras segundo sinais de Dislexia propostos pela Associação Internacional de Dislexia

Tabela 9. Concordância para tempo de latência para a leitura e nomeação

Tabela 10. Concordância para tempo de duração da emissão oral para a leitura e nomeação

Tabela 11. Média e desvio padrão em cada grupo de palavra e série para o tempo de latência (seg) na leitura de palavras

Tabela 12. p-valores - comparação do tempo de latência para a leitura: alta $\mathrm{x}$ baixa freqüência

Tabela 13. p-valores - comparação do tempo de latência para a leitura: regulares $\mathrm{x}$ irregulares

Tabela 14. p-valores - comparação do tempo de latência para a leitura: $4 \times 6$ grafemas

Tabela 15. Média e desvio padrão em cada grupo de palavra e série para o tempo de duração da emissão oral (seg) na leitura de palavras

Tabela 16. p-valores - comparação do tempo de duração da emissão oral para a leitura: alta $\mathrm{x}$ baixa freqüência

Tabela 17. p-valores - comparação do tempo de duração da emissão oral para a leitura: regulares $\mathrm{x}$ irregulares

Tabela 18. p-valores - comparação do tempo de duração da emissão oral para a leitura: 4 x 6 grafemas 
Tabela 19. Média e desvio padrão em cada grupo de palavra e série para acertos na leitura

Tabela 20. p-valores- comparação da porcentagem de acertos na leitura: alta $\mathrm{x}$ baixa freqüência

Tabela 21. p-valores- comparação da porcentagem de acertos na leitura: regulares $\mathrm{x}$ irregulares

Tabela 22. p-valores- comparação da porcentagem de acertos na leitura: $4 \times 6$ grafemas

Tabela 23. Tipos de resposta para a leitura em cada série

Tabela 24. Comparação dos tipos de resposta para a leitura em cada série

Tabela 25. Correlação entre tempo de latência e acertos na leitura

Tabela 26. Correlação entre tempo de duração da emissão oral e acertos na leitura

Tabela 27. Média e desvio padrão em cada grupo de palavra e série para o tempo de latência (seg) na nomeação de figuras

Tabela 28. p-valores - comparação do tempo de latência para a nomeação: alta $\mathrm{x}$ baixa freqüência

Tabela 29. p-valores - comparação do tempo de latência para a nomeação: regulares $\mathrm{x}$ irregulares

Tabela 30. p-valores - comparação do tempo de latência para a nomeação: 4 × 6 grafemas

Tabela 31. Média e desvio padrão em cada grupo de palavra e série para o tempo de duração da emissão oral (seg) na nomeação

Tabela 32. p-valores - comparação do tempo de duração da emissão oral para a nomeação: alta $\mathrm{x}$ baixa freqüência

Tabela 33. p-valores - comparação do tempo de duração da emissão oral para a nomeação: regulares $\mathrm{x}$ irregulares

Tabela 34. p-valores - comparação do tempo de duração da emissão oral para a nomeação: 4 × 6 grafemas

Tabela 35. Média e desvio padrão em cada grupo de palavra e série para acertos na nomeação

Tabela 36. p-valores - comparação da porcentagem de acertos na nomeação: alta $\mathrm{x}$ baixa freqüência

Tabela 37. p-valores - comparação da porcentagem de acertos 101 na nomeação: regulares $\mathrm{x}$ irregulares

Tabela 38. p-valores - comparação da porcentagem de acertos na nomeação: $4 \times 6$ grafemas 
Tabela 39. Características da nomeação em cada tipo de palavra e série

Tabela 40. Revisões e erros de produção na nomeação

Tabela 41. Correlação entre tempo de latência e acertos para a nomeação

Tabela 42. Correlação entre e tempo de duração da emissão oral 105 e acertos na nomeação

Tabela 43. p-valores: comparação do tempo de latência entre leitura e nomeação

Tabela 44. p-valores: comparação do tempo de duração da emissão oral entre leitura e nomeação

Tabela 45. p-valores: comparação da porcentagem de acertos entre leitura e nomeação

Tabela 46. Comparação do tempo de latência entre palavras de alta e baixa freqüência: leitores $\mathrm{x}$ não leitores

Tabela 47. Comparação do tempo de latência entre palavras regulares e irregulares: leitores $\mathrm{x}$ não leitores

Tabela 48. Comparação do tempo de latência entre palavras de 4 e 6 grafemas: leitores $x$ não leitores

Tabela 49. Comparação do tempo de duração da emissão oral entre palavras de alta e baixa frequencia: leitores $\mathrm{x}$ não leitores

Tabela 50. Comparação do tempo de duração da emissão oral entre palavras regulares e irregulares: leitores x não leitores

Tabela 51. Comparação do tempo de duração da emissão oral entre palavras com 4 e 6 grafemas: leitores x não leitores

Tabela 52. Comparação da porcentagem de acertos entre palavras de alta e baixa freqüência: leitores $\mathrm{x}$ não leitores

Tabela 53. Comparação da porcentagem de acertos entre palavras regulares e irregulares: leitores $\mathrm{x}$ não leitores

Tabela 54. Comparação da porcentagem de acertos entre palavras com 4 e 6 grafemas: leitores x não leitores

Tabela 55. Tipos de respostas na nomeação: leitores x não leitores

Tabela 56. Revisões e erros de produção na nomeação 


\section{RESUMO}

STIVANIN, L. Tempo de processamento para a leitura de palavras e para a nomeação de figuras em crianças leitoras e não leitoras - São Paulo, 2007. Tese (Doutorado) - Faculdade de Medicina, Universidade de São Paulo.

O desenvolvimento e o processamento da leitura de palavras e da nomeação de figuras em leitores e não leitores têm sido fundamentados em modelos cognitivos de processamento da informação. A precisão nas respostas e o tempo de processamento devem ser considerados para estas tarefas. O tempo de processamento se refere à latência e à extensão das emissões orais. $O$ objetivo deste estudo foi analisar o tempo de processamento para a leitura e a nomeação em crianças leitoras e não leitoras. Participaram 74 crianças leitoras de $2^{\mathrm{a}}$, $3^{\mathrm{a}}$ e $4^{\mathrm{a}}$ séries e 20 não leitoras de $2^{\mathrm{a}}$ série do ensino fundamental de escola pública. Os estímulos de todas as provas foram caracterizados por semelhantes variáveis psicolingüísticas do material escrito, constituindo 12 grupos de palavras e figuras equivalentes em freqüência, extensão, regularidade e complexidade silábica. Um programa computacional foi desenvolvido especialmente para esta pesquisa para registrar o tempo de processamento de cada palavra lida ou figura nomeada, com precisão numérica de 8 casas decimais. As respostas corretas e o desempenho relacionado às características de cada prova, para cada grupo de estímulo e nível escolar foram também analisados. A análise estatística foi realizada por meio da ANOVA e Correlação de Pearson. Os resultados indicaram que as propriedades das palavras exerceram influência sobre o tempo de processamento e os acertos na leitura e na nomeação, caracterizando diferentes comportamentos entre as séries. A interação entre o tipo de palavra e a série escolar indica que o grau de estabilização das representações da palavra escrita na memória depende de suas propriedades, da rota utilizada pelo leitor e das estratégias envolvidas na leitura. Este fato altera o tempo de recuperação e produção destas informações. O tempo de processamento para a leitura foi menor que o da nomeação e ambas as tarefas foram influenciadas pela freqüência da palavra escrita, mostrando um componente lexical comum a ambas as habilidades. O tempo de processamento e a influência das características psicolingüísticas na nomeação foram semelhantes entre leitores e não leitores, embora os leitores tenham sido mais eficientes. As substituições fonológicas relacionadas à complexidade fonológica dos nomes e o sistema semântico preservado conduzem à hipótese de falhas na seleção dessas representações durante a recuperação dos nomes.

Descritores: Criança. Leitura. Tempo de reação. Software. Dislexia. 


\begin{abstract}
STIVANIN, L. Processing time for word reading and picture naming in readers and non-readers children - São Paulo, 2007. Tese (Doutorado) - Faculdade de Medicina, Universidade de São Paulo.

The development and the processing of word reading and picture naming in readers and non-readers have been based on cognitive models of information processing. Accuracy of answers and processing time must be considered for reading and naming. Processing time refers to latency and length of oral emissions. The aim of this study was to analyze processing time on aloud reading of isolated words and picture naming tasks of readers and nonreaders children. Seventy-four readers attending $2^{\text {nd }}, 3^{\text {rd }}$ and $4^{\text {th }}$ grades and 20 non-readers attending $2^{\text {nd }}$ grade of public elementary school took part of this study. Stimuli for all tasks were characterized by similar psycholinguistic variables of the written material, which was composed by 12 groups of words and pictures equivalent in frequency, extension, regularity and syllabic complexity. Specific software was developed to register processing time of each word read or picture named, with an accuracy of 8-decimal places. Correct answers and performance-related characteristics to each task, for each group of stimuli and grade were also analyzed. ANOVA and Pearson's Correlation were used for analysis. Results indicate that word properties influenced the processing time and correct answers in reading and naming. Different behavior among grades was observed. Interaction between word type and school level indicates that the degree of stabilization of the written-word representation in memory depends on its properties, on the route taken by the reader and the strategies involved in reading. This fact alters retrieval time and production of the information. Processing time for reading was shorter than for naming, and both tasks were influenced by the frequency of the written word, pointing to a common lexical component. Processing time and the influence of psycholinguistic characteristics for naming were similar for readers and non-readers, although the readers were more efficient. Phonological substitutions related to the complexity of names and an intact semantic system lead to the hypothesis of failures regarding these representations during name retrieval.
\end{abstract}

Keywords: Children. Reading. Reaction time. Software. Dyslexia. 


\section{INTRODUÇÃO}




\section{INTRODUÇÃO}

Esta pesquisa, em uma óptica cognitiva, fundamentada na teoria de processamento da informação, visa estudar a leitura de palavras e a nomeação de figuras, habilidades de linguagem empregadas no cotidiano.

Para Stivanin e Scheuer (2005) "nomear figuras e ler palavras escritas é uma das formas de investigar como as informações lingüísticas vão sendo armazenadas ao longo do desenvolvimento, e como podem ser recuperadas mediante um estímulo. O tempo que a criança leva para processar e recuperar esta informação pode apontar para dificuldades na nomeação e na leitura e conduzem a hipóteses sobre o desenvolvimento cognitivo e de linguagem".

De acordo com Sprenger-Charolles et al. (2005), a eficiência em uma habilidade não pode ser determinada apenas por sua precisão, mas também pelo tempo de seu processamento e, não considerar esta medida, conduz a erros na análise do desempenho na tarefa.

A investigação sobre o tempo de processamento em determinada tarefa depende do tipo de estímulo visual (figura ou palavra escrita), das características de cada estímulo e da idade do sujeito que executa a tarefa.

Guanto ao material, na nomeação de figuras, devem ser consideradas as propriedades visuais: orientação, tamanho, traçado, cor (Johnson et al., 1996), características lexicais: freqüência e familiaridade (Snodgrass e Vandewart, 1980; Berman et al.,1989; Barry et al., 1997; Cycowicz et al.,1997; Scheuer et al., 2004) e fonológicas: extensão do nome e complexidade silábica (Cycowicz et al., 1997; Levelt et al., 1999; Béfi-Lopes e Gálea, 2000; Santiago et al., 2000). Na leitura, podem ser observadas características como freqüência (Pinheiro e 
Parente, 1999), regularidade (Lecours e Parente, 1997; Ziegler et al., 2003), extensão e complexidade silábica (Sprenger-Charolles et al., 2005).

No que se refere à idade, indivíduos mais novos apresentam tempo de processamento maior do que os mais velhos e escolarizados, em decorrência do desenvolvimento dos processos mentais e das estratégias de recuperação da informação, tanto na nomeação (Nelson, 1996) quanto na leitura (McDougall et al., 2005).

Tanto as propriedades do material quanto a idade dos sujeitos exercem diferentes influências nos diversos estágios do processamento. Assim, o tempo em tarefas verbais deve ser estudado em suas medidas referentes ao tempo de latência e ao tempo de duração da emissão oral.

A interface entre a leitura de palavras e a nomeação de figuras tem sido pesquisada no desenvolvimento típico e em crianças com transtornos de leitura, apontando para possíveis relações entre essas habilidades (Snowling, 1980; Murphy et al., 1988; Tróia et al., 1996).

Nos transtornos de leitura, a literatura internacional aponta para déficits existentes na construção das representações fonológicas conduzindo a dificuldades na nomeação de figuras (Snowling et al., 1988; Swan e Goswami, 1997; Nation e Snowling, 2001; Faust e Sharfstein-Friedman, 2003; Fowler e Swainson, 2004). Por outro lado, Trauzettel-Klosinski et al. $(2002 ; 2006)$ não observaram esta dificuldade em seus estudos sobre nomeação em crianças com transtornos de leitura.

Os estudos com crianças brasileiras, falantes do português do Brasil, envolvem a nomeação de figuras (Béfi-Lopes, 2000; Béfi-Lopes e Gálea, 2000; Miranda, 2000; Pompéia et al., 2001; Scheuer et al., 2004; Bastos, 2006); o desenvolvimento da leitura de palavras (Pinheiro, 2001; Pinheiro e Rothe-Neves; 2001; Salles e Parente, 2002; 2004); a relação da leitura com o desenvolvimento da consciência fonológica (Maluf e 
Barrera, 1997; Rego e Buarque, 1997; Salles et al., 1999; Cielo, 2002; Salles e Parente, 2002; Barrera e Maluf, 2003; Guimarães, 2003; Cárnio e Santos, 2005; Paula et al., 2005) e com a nomeação seriada rápida (Cardoso-Martins e Pennington, 2001). A relação entre leitura e nomeação no desenvolvimento típico foi recentemente estudada por Stivanin e Scheuer (2005), em um grupo piloto. Na literatura nacional consultada, não foram encontrados trabalhos sobre nomeação de figuras em crianças com transtornos de leitura, com as mesmas especificidades deste estudo.

Em decorrência das particularidades de cada língua, tanto oral quanto escrita e da escassez de trabalhos na área, torna-se importante a investigação da relação entre os processos envolvidos na nomeação de figuras e na leitura de palavras, no desenvolvimento típico da criança. Também é de grande importância determinar as características e as estratégias de nomeação utilizadas por crianças com transtornos de leitura e contribuir para avaliação e conduta clínica.

Nesta perspectiva, foram estudados o tempo de processamento, a precisão e as características da leitura e da nomeação, levando-se em conta as propriedades psicolingüísticas das palavras e a escolarização. A nomeação de figuras em crianças não leitoras foi analisada e comparada com a de leitores de mesma faixa de escolarização. 


\section{REVISÃO DA LITERATURA}




\section{REVISÃO DA LITERATURA}

Neste capítulo, são descritas informações mais detalhadas relacionadas ao tema exposto e, para tanto, foi dividido em seis tópicos:

- tempo de processamento da informação

- leitura

- leitura em voz alta de palavras isoladas

- nomeação de figuras

- relação entre a leitura de palavras e a nomeação de figuras

- a leitura e seus transtornos

- nomeação de figuras em crianças com Transtorno da Leitura

\subsection{Tempo de processamento da informação}

A teoria do processamento da informação visa explicar as relações entre o estímulo (input) e as respostas (output) e descrever atividades que ocorrem entre input e output. Ou seja, esta teoria estuda como o estímulo é manipulado e transformado para produzir uma resposta (Kail e Bisanz, 1992). De acordo com Sternberg (1992), o princípio desta teoria é compreender os processos, as estratégias e as representações mentais envolvidas em atividades cognitivas.

Os processos, estratégias e representações mentais envolvidos no processamento da informação ou em habilidades cognitivas são representados por meio de modelos. Um modelo para uma determinada tarefa envolve mecanismos específicos, incluindo mecanismos perceptuais para decodificar a informação, processos para manipular e estocar a informação, para selecionar e recuperar a informação 
armazenada e os que decidem entre alternativas. Na área da linguagem, são conhecidos modelos que explicam o processamento de uma figura representando um objeto (Johnson et al., 1996; Ferrand, 1999; Miller et al., 2001) e o processamento de palavras escritas (Adams, 1994; Coltheart et al., 1993; 2001; Ellis, 1995; Lecours e Parente, 1997).

A teoria do processamento da informação preocupa-se com diversos aspectos: qual, como e onde a informação é processada, os processos mentais envolvidos na codificação e organização das informações, a velocidade e a precisão com que os processos ocorrem e as estratégias envolvidas no acesso às representações (Sternberg, 1992).

De acordo com Posner (1980), a velocidade do processamento da informação começou a ser estudada um pouco antes de 1850, quando os astrônomos passaram a observar diferenças significativas em suas observações sobre o momento em que uma estrela estava centrada em seus telescópios. Esses atrasos eram decorrentes das diferenças nos tempos de latência apresentados por cada indivíduo. Na mesma época, os fisiologistas conseguiram demonstrar que o tempo necessário para o sistema nervoso conduzir impulsos era mensurável, contrariando a concepção anterior, que afirmava que a velocidade de condução nervosa era infinita. Reunindo estas duas informações, o fisiologista Donders, em 1969, propôs que os processos mentais pudessem ser medidos pelo tempo que exigiam.

O tempo de latência passou a ser estudado em processos envolvidos na leitura e no reconhecimento de palavras escritas (Foster e Chambers, 1973; Sprenger-Charolles et al., 2003), na compreensão da linguagem (Stanovich e West, 1983) e na nomeação de figuras (Barrow et al., 2000; Santiago et al., 2000; Bates et al., 2003; Alario et al., 2004). 
O tempo de latência ou de reação é considerado o tempo ocorrido entre estímulo e resposta (Donders, 1969) e indica o tempo de acesso à informação na memória de longo prazo (Sternberg, 1992).

$\mathrm{Na}$ nomeação de figuras, o tempo de latência refere-se à fase de reconhecimento das características visuais e semânticas do objeto representado, à seleção do nome correspondente e à programação motora (Johnson et al., 1996; Ferrand, 1999; Miller et al., 2001). No caso da leitura, o tempo de latência diz respeito ao tempo necessário para o reconhecimento da palavra escrita, acesso e seleção do nome e/ou de fonemas e/ou grupos de fonemas correspondentes aos grafemas (Coltheart et al., 1993; 2001; Ellis, 1995; Lecours e Parente, 1997).

No que se refere ao tempo de duração da emissão oral, este compreende o intervalo entre o início e o final da produção oral. Após a seleção das representações fonológicas referentes ao nome da figura ou à palavra escrita e a programação motora, ocorre a produção da palavra. Na leitura, porém, a produção pode ser mais lenta, principalmente no início do desenvolvimento da linguagem escrita, quando a palavra não é recuperada como um todo, mas por meio da conversão de grafemas para fonemas, levando à maior freqüência de segmentações (Lecours e Parente, 1997).

A velocidade do processamento se modifica com a idade. Esta mudança pode refletir a aquisição de estratégias mais eficientes para a solução de tarefas (Chi, 1977) e o conhecimento mais elaborado de domínios específicos acarretando múltiplos caminhos/rotas pelas quais a informação pode ser processada (Roth, 1983).

Outro aspecto implicado na mudança de velocidade com o decorrer da idade é que a ativação pode se dar por meio de processos automáticos ou controlados. Os processos automáticos são rápidos, iniciados sem controle voluntário, requerem pouco ou nenhum recurso 
atencional. Os processos controlados são voluntários, lentos e requerem capacidade atencional. Os processos mentais tornam-se automáticos com o desenvolvimento. Em leitores menos habilidosos, o reconhecimento de palavras é mais lento porque há necessidade da evocação de processos controlados para obter informação complementar relevante para o reconhecimento da palavra. Para os mais habilidosos, os processos são automáticos e nenhuma informação compensatória é necessária e, por isso, o tempo de processamento é menor (Schneider e Shiffrin, 1977).

Embora a eficiência em uma tarefa seja dada pela precisão e tempo de processamento (Sprenger-Charolles et al., 2005), nem sempre o tempo se correlaciona com maior precisão no desempenho. Phillips e Rabbitt (1995) apontam que alguns indivíduos podem ser mais lentos em determinadas tarefas, porém mais precisos, enquanto outros são mais rápidos e não demonstram bom desempenho.

A seguir serão descritos os processos envolvidos na leitura de palavras e na nomeação de figuras, e como o tempo se modifica com os diversos estímulos e faixas de escolarização. 


\subsection{Leitura}

Ler com eficiência, em uma óptica cognitiva, envolve a construção do significado a partir do texto escrito. A leitura depende de dois componentes: identificação fluente da palavra escrita e compreensão da linguagem. A identificação da palavra é um processo de recuperação lexical que requer reconhecimento visual de um conjunto de grafemas e ativação das formas fonológicas correspondentes. Neste caminho, a leitura pode ocorrer de forma silenciosa ou em voz alta. A compreensão envolve extrair e integrar o significado das palavras e sentenças e realizar associações com o conhecimento lingüístico e de mundo prévios para entender as idéias e conceitos explícitos ou implícitos no texto (Vellutino et al., 2004).

No presente trabalho, apenas a leitura em voz alta de palavras isoladas é tratada em maiores detalhes.

\subsubsection{Leitura em voz alta de palavras isoladas}

A leitura em voz alta envolve a transformação de uma representação visual em uma representação fonológica. Ou seja, as crianças devem aprender o código escrito usado em sua cultura para representar a fala e acessar o significado (Morais, 1995; Littlefiel e Klein, 2005; Perfetti e Liu, 2005; Ziegler e Goswami, 2005; NergardNilsen, 2006).

O desenvolvimento da leitura pode ser descrito por meio de modelos que descrevem os estágios deste desenvolvimento, caracterizando o comportamento do leitor em diversas fases. Serão 
destacados aqui modelos cognitivos e dentre eles, o modelo clássico de Frith (1985) e o proposto por Ehri e McCormick (1998).

De acordo com o modelo de Frith (1985), a criança passa por três estágios durante o desenvolvimento da leitura: o logográfico, no qual a criança trata a palavra escrita como se fosse uma representação pictoideográfica e visual do referente; o alfabético no qual, a criança aprende a fazer decodificação grafofonêmica e o ortográfico, quando a criança aprende a fazer leitura visual direta de palavras de alta freqüência.

As diversas críticas a esse modelo apontam que não se deve considerar estes estágios como sucessivos um do outro, pois a criança pode aprender a ler uma palavra por meio da aplicação de regras alfabéticas, ao mesmo tempo em que pode ler palavras por meio do acesso ao léxico (Morais, 1995; Piérart, 1997; Martinet et al., 2004).

Nesta perspectiva, Ehri e McCormick (1998) propõem um modelo composto por cinco fases, ressaltando que a criança pode utilizar as habilidades alfabéticas e as ortográficas simultaneamente. As cinco fases são: pré-alfabética, alfabética parcial, total, consolidada e a automática.

Na fase pré-alfabética, o leitor iniciante tem conhecimento limitado da estrutura de seu sistema escrito, pouco conhecimento do nome das letras e não é consciente que os grafemas representam os fonemas. $\mathrm{Na}$ fase alfabética parcial, o leitor começa a distinguir os grafemas nas palavras e a relacionar os fonemas com o nome de letras; lêem as palavras utilizando a forma e a estrutura visual das palavras, assim como suas relações grafofonéticas parciais.

$\mathrm{Na}$ fase alfabética total, a criança forma representações precisas das relações grafema-fonema que vêem nas palavras, o que possibilita que decodifique palavras que nunca vira antes, estoque na memória o resultado da análise fonética e leia outras palavras não 
familiares por comparação da estrutura previamente estocada na memória. $\quad \mathrm{Na}$ fase alfabética consolidada, a criança adquire conhecimento sobre as inflexões morfêmicas e, na fase automática, a criança desenvolve automaticidade e velocidade para identificar palavras familiares e não familiares.

Outros modelos cognitivos enfatizam como a informação escrita é processada e por meio destes, pode-se estudar o tempo dispensado na identificação da palavra. Os mais utilizados atualmente são o modelo conexionista (Seidenberg e McClelland, 1989; Adams, 1994) e o de dupla-rota (Coltheart et al., 1993; Ellis, 1995; Lecours e Parente, 1997).

Os modelos conexionistas são inspirados na arquitetura e no funcionamento do sistema nervoso. Em vez de conceber o processamento como uma série de passos, o modelo de Seidenberg e McClelland (op.cit) propõe que o cérebro dispõe de uma variedade de elementos de processamento que trabalham em paralelo e de forma cooperativa para a realização de suas atividades. O sistema é formado por um elevado número de neurônios artificiais (unidades) que são interconectados dentro e entre as camadas. Nos circuitos neurais, o input representa a forma escrita das palavras, enquanto o output a pronúncia. Quanto mais o sistema é exposto à escrita, mais consolidadas ficam as associações entre input e output, o que permite ao circuito ler novas palavras.

Baseado nestes modelos, Adams (1994) descreve o processamento da leitura em um leitor com desenvolvimento típico, para a qual existem quatro processadores, que operam interligados, em paralelo e/ou simultaneamente. O processador ortográfico contém as representações visuais das palavras escritas. À medida que a imagem da estrutura ortográfica toma forma, sinais são enviados para as unidades do processador semântico, no qual estão armazenados os 
significados de palavras familiares, permitindo a compreensão da leitura. Ao mesmo tempo, uma estimulação é enviada do processador ortográfico às unidades do processador fonológico, que contém unidades correspondentes à imagem auditiva de cada palavra, sílaba ou fonema. O processador contextual representa o conhecimento do contexto que envolve o enunciado e auxilia na interpretação da leitura. As unidades de cada processador recebem os sinais e os envia de volta ao processador de origem, o que facilita o processo de reconhecimento da palavra. O modelo pode ser observado na figura 1, a seguir:

Figura 1. Modelo conexionista - processamento da leitura (Adams, 1994)

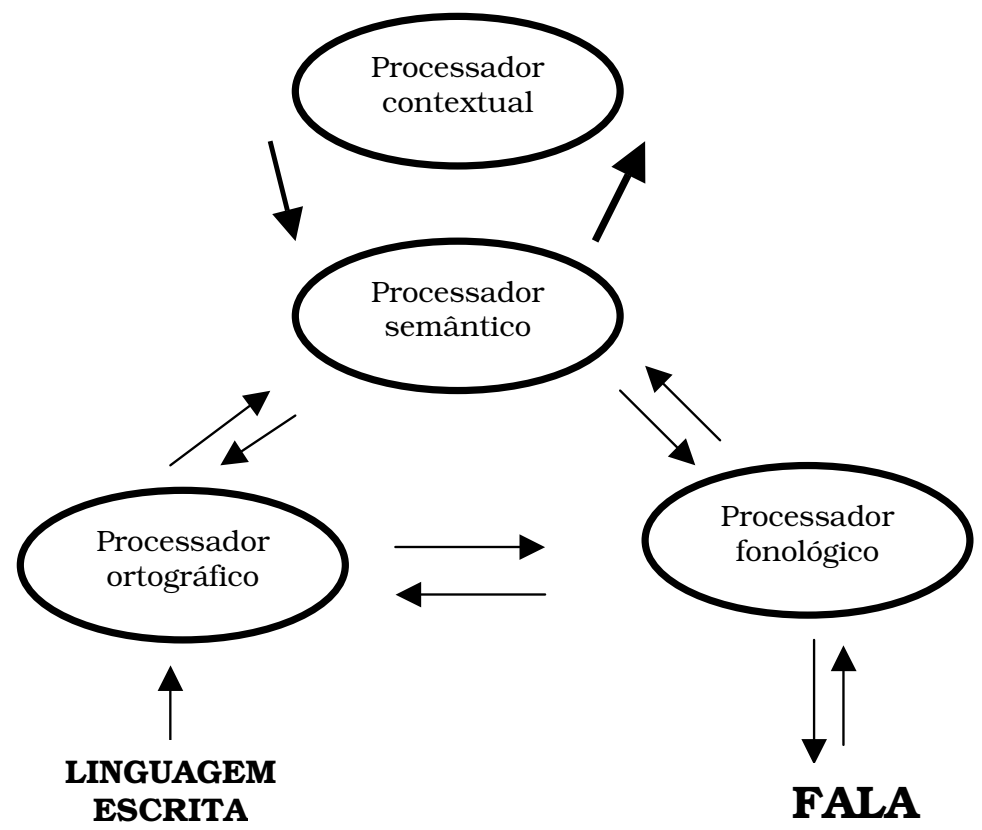

Por sua vez, o modelo de dupla-rota (figura 2) concebe que a leitura de palavras é realizada em um sistema coordenado de módulos de processamento que envolve duas rotas simultaneamente: semânticolexical ou fonológica. Ambas as rotas se iniciam com um sistema para 
análise do input visual para a construção das representações grafêmicas. A rota semântico-lexical é usada para a leitura de uma palavra previamente armazenada no léxico. Por meio deste processo, o significado da palavra e suas formas fonológicas são recuperados diretamente do léxico. A leitura realizada pela rota fonológica ou sublexical envolve a conversão grafema-fonema, para uma palavra não estocada na memória. Este processo ocorre de forma serial, traduzindo grafemas ou grupos de grafemas em fonemas, por meio da aplicação de regras. Ambas as rotas geram um output fonológico que é direcionado a um sistema comum para a produção articulatória da palavra (Coltheart et al., 1993; 2001; Ellis, 1995; Lecours e Parente, 1997).

Figura 2. Modelo de dupla-rota - processamento da leitura (Coltheart et al., 2001)
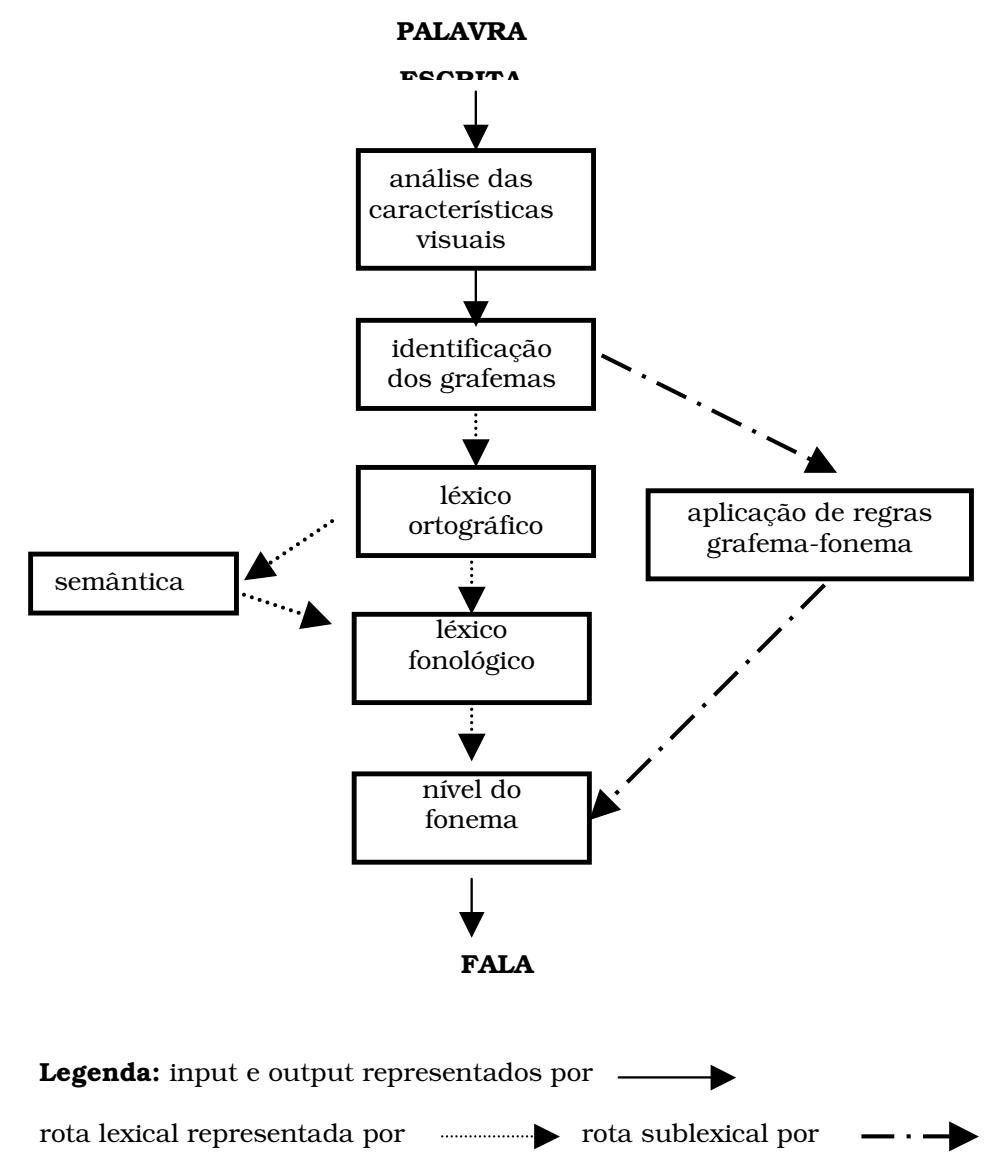
A caracterização da leitura, demonstrada pelo modelo de dupla-rota, envolve a utilização de variáveis psicolingüísticas do material escrito (Partz, 1997). Estas variáveis referem-se à lexicalidade, freqüência, concretude, regularidade, extensão e complexidade.

A variável freqüência refere-se ao número de vezes que as palavras escritas pertencentes ao vocabulário de uma língua ocorrem dentro de faixas etárias específicas, caracterizando palavras de alta e de baixa freqüência. (Pinheiro e Parente, 1999).

A irregularidade de uma palavra diz respeito às regras de conversão grafofonêmica durante a leitura, caracterizando palavras regulares e irregulares. São palavras regulares aquelas que apresentam relação unívoca entre grafema e fonema. Por outro lado, palavras irregulares são aquelas cujas relações grafofonêmicas são ambíguas durante a leitura (Lecours e Parente, 1997; Ziegler et al., 2003).

A extensão, outra característica do material escrito pode ser caracterizada pelo número de grafemas e /ou sílabas que compõem a palavra escrita (Lecours e Parente, 1997).

As palavras mais freqüentes durante o aprendizado da leitura e escrita são lidas mais rapidamente do que as menos freqüentes. Uma palavra pouco freqüente dispõe de um limiar de ativação mais elevado no léxico do que uma palavra freqüente. Espera-se, portanto, que uma palavra pouco freqüente leve mais tempo para ser ativada e que seja objeto de confusões com outras palavras visualmente semelhantes (Taft, 1991; Balota et al., 2000).

As palavras regulares são lidas mais rápida e corretamente do que as irregulares porque as rotas semântico-lexical e fonológica produzem pronúncia correta para palavras regulares e pronúncia conflitante para irregulares. Isso porque a leitura de palavras irregulares requer acesso ao léxico ortográfico (Coltheart et al., 2001). 
Em palavras de alta freqüência, não é visto o efeito de regularidade, ou seja, a precisão e o tempo de acesso são semelhantes para palavras regulares e irregulares. Isto acontece porque a pronúncia da palavra é recuperada rapidamente do léxico, antes que a informação vinda da via fonológica se torne disponível. Por outro lado, palavras irregulares de baixa freqüência são lidas mais lenta e incorretamente do que palavras regulares porque a rota fonológica não permite a construção adequada da pronúncia. Há a ativação entre dois fonemas para representar um grafema e a competição entre eles retarda a ativação da forma fonológica correta. (Coltheart et al, op. cit).

Com relação à extensão, palavras com menor número de fonemas são identificadas mais rápida e corretamente do que as com maior número de fonemas (Rey et al., 1998; Whitney e Lavidor, 2004).

O efeito de extensão, na leitura, é maior para não-palavras, menor para palavras pouco freqüentes, e quase inexistente para as de alta freqüência. Na leitura de palavras não freqüentes, esse efeito é maior, pois a palavra é lida por via não lexical, com base em um processamento serial. Assim, palavras curtas são lidas mais rápida e corretamente do que as palavras longas, pois não dependem da conversão grafema-fonema. Em contraste, quando a palavra é freqüente, o efeito de extensão é moderado pela ativação da via fonológica e da rota lexical. Então, as palavras curtas e longas podem ser recuperadas diretamente do léxico (Weekes, 1997; Coltheart et al, 2001).

Analisando-se como ocorre a leitura de palavras com diferentes características, é possível saber o tipo de rota mais utilizada por um leitor: a leitura semelhante de palavras regulares e irregulares (ausência do efeito de regularidade) fornece evidências de que o leitor está utilizando a rota lexical, pois pode recuperar diretamente do léxico as unidades ortográficas. Quando ocorre o efeito de regularidade 
(palavras regulares lidas de forma mais precisa e/ou mais rápida do que as irregulares), supõe-se o uso da rota fonológica, pois na conversão grafofonêmica, as unidades ortográficas ambíguas não podem ser lidas adequadamente.

A fonologia desempenha um papel importante no aprendizado da leitura e na construção do léxico ortográfico, pois a leitura realizada por meio da rota fonológica permite ao leitor processar palavras regulares, conhecidas ou não, e parcialmente palavras irregulares, visto que essas também contêm estruturas regulares (Coltheart et al., 2001). Pode-se dizer, então, que o processo fonológico é gerativo, isto é, permite a identificação das palavras encontradas pela primeira vez ou palavras para quais não está disponível uma representação ortográfica (Morais, 1995).

A leitura de palavras irregulares depende do reconhecimento fonológico e das habilidades semânticas. Embora o conhecimento fonológico seja necessário para mapear sons e grafemas e aprender padrões ortográficos, o conhecimento ortográfico é necessário para a leitura automática e ajuda o indivíduo a se tornar um leitor fluente. Quando as imagens ortográficas se estabilizam, os leitores acessam automaticamente a representação mental da palavra mais do que a decodificam e então, estas imagens mentais estocadas são usadas para decodificar novas palavras (Goff et al., 2005).

A habilidade para usar uma rota direta visual com um mínimo de mediação fonológica para acessar a memória semântica para obter o significado, é crucial para desenvolver o reconhecimento automático da palavra, leitura fluente e compreensão mais eficiente (Littlefield e Klein, 2005).

Com base nos modelos de processamento da informação, é possivel caracterizar o desenvolvimento da leitura, apontando as rotas utilizadas nas diversas fases. Porém, a caracterização da leitura nas 
diversas fases de seu aprendizado é dependente do sistema de escrita e do tipo de ortografia do sistema.

Crianças no início do desenvolvimento da leitura, em ortografias irregulares como no inglês e no francês, demonstram imprecisão na leitura e velocidade lenta, enquanto crianças em contato com ortografias regulares (como grego, italiano e alemão) apresentam precisão, mas velocidade lenta para palavras e não palavras (NergardNilsen, 2006).

Ziegler e Goswami (2005) sugerem que as diferenças na precisão e na velocidade da leitura em diferentes línguas refletem diferenças fundamentais na natureza do reconhecimento fonológico e nas estratégias de leitura. Assim, crianças que estão se desenvolvendo em línguas com ortografias regulares podem se apoiar na conversão grafema-fonema porque as correspondências são unívocas, enquanto as crianças aprendendo a ler em ortografias irregulares não podem usar tais estratégias tão facilmente, e desenvolvem uma série de outras estratégias.

Para caracterizar o desenvolvimento da leitura de crianças francesas, Sprenger-Charolles et al. (2003) conduziram um estudo longitudinal, no qual estas foram acompanhadas durante os quatro primeiros anos escolares. Na metade da primeira série, a leitura de palavras regulares e pseudopalavras foi melhor do que a leitura de palavras irregulares, o que indica que a leitura depende principalmente do processo sublexical ou fonológico no início da escolarização. Poucos meses após, foi observado progresso em todos os tipos de palavras, porém mais significante para palavras regulares do que para pseudopalavras, as quais foram mais bem lidas do que as irregulares. A correlação entre a precisão e o tempo de latência não foi significante para crianças mais novas, sugerindo que os leitores iniciantes 
favorecem a precisão em detrimento do tempo de latência enquanto outros adotam a estratégia oposta.

Em um estudo realizado com crianças falantes do Português do Brasil, Salles e Parente (2002) indicam que o desenvolvimento da leitura é, inicialmente, caracterizado pelo uso da rota fonológica. No início da $2^{\text {a }}$ série, a criança parece ainda não ter um extenso vocabulário identificado por via direta ou sem mediação fonológica. Crianças de $3^{\text {a }}$ série apresentam maior habilidade nas rotas fonológica e lexical, sugerindo uma evolução da primeira para a segunda rota.

Segundo McDougall et al. (2005), a idade e o tempo de experiência na leitura são fatores que contribuem para aumentar as representações no léxico ortográfico, o que acarreta o uso cada vez menor da rota fonológica e permite uma leitura mais rápida e precisa.

A velocidade de processamento, especialmente para os processos de recuperação, desempenha um papel importante para aprender a ler. Quando a leitura é mais rápida e automática, as crianças podem usar menos recursos da memória de trabalho para a decodificação e têm mais recursos para a compreensão (Ehri e McCormick, 1998; Caccamise e Snyder, 2005; Goff et al., 2005).

\subsection{Nomeação de figuras}

A nomeação envolve a conexão entre os processos perceptuais, cognitivos e lingüísticos (Wolf e Segal, 1992) e seu sucesso requer que as palavras sejam adequadamente estocadas na memória e possam ser prontamente acessadas pelo falante mediante um estímulo visual (Bjork e Bjork, 1992).

Nesta óptica, "nomear é evocar um vocábulo de uma língua em particular, marcado pela convenção e arbitrariedade, como 
referência a um objeto, pessoa, evento ou episódio. Reconhecer o significado de uma figura e nomeá-la diz respeito, em grande parte, a experiências sociais prévias e a processamentos de linguagem complexos. As vias pelas quais se processam as entradas - a auditiva e a visual - são responsáveis pela compreensão. A saída comum para todas essas vias é a fala, encarregada de dizer como a criança compreendeu e integrou as diferentes informações lingüísticas e não lingüísticas" (Scheuer et al., 2004).

Ao nomear figuras, os estágios envolvidos no processamento da informação envolvem a identificação e o reconhecimento do objeto, a ativação do nome e sua produção oral. Um objeto deve ser identificado como sendo de uma classe particular de objetos, por suas características físicas (aparência, traçado, orientação e disposição) e semânticas (funções, associações). Após a identificação das propriedades físicas e semânticas, nomes apropriados são ativados entre as palavras armazenadas no léxico mental e, finalmente, ocorre uma organização fonoarticulatória para que uma resposta específica possa ser executada. Estas operações mentais devem ocorrer rápida e eficientemente durante a fala (Johnson et al.,1996; Ferrand, 1999; Miller et al., 2001).

A nomeação envolve processos lexicais e não lexicais. Os processos não-lexicais referem-se à detecção e à percepção das informações do estímulo visual, enquanto os processos lexicais estão relacionados ao armazenamento e à recuperação das informações semânticas e das representações abstratas dos nomes (Lahey e Edwards, 1996). Enquanto a capacidade para o armazenamento de longo prazo é ilimitada, a capacidade para recuperação depende de pistas contextuais, da freqüência com que um item é acessado, da competição com outros itens do léxico e da recência do aprendizado (Bjork e Bjork, 1992). 
O reconhecimento do objeto, primeiro estágio da nomeação de figuras, depende da eficiência dos processos visuais para extrair informações do estímulo, das características das representações armazenadas sobre este e da similaridade entre o estímulo e as representações do objeto na memória (Johnson et al., 1996).

A freqüência do nome do objeto parece não exercer muita influência no processo de reconhecimento visual do estímulo, mas afeta a recuperação do seu nome. Palavras e figuras mais familiares e de alta freqüência, no cotidiano da criança, produzem respostas mais rápidas e corretas do que nomes e figuras menos familiares e de baixa freqüência (Snodgrass e Vandewart, 1980; Berman et al.,1989; Barry et al., 1997; Cycowicz et al.,1997; Scheuer et al., 2004).

As características fonológicas dos nomes também exercem um papel importante na nomeação. Um nome é produzido corretamente quando sua forma fonológica está construída e armazenada. Como esta construção é realizada em ordem seqüencial, os nomes mais curtos são produzidos mais rapidamente do que os mais longos (Levelt et al., 1999). Nomes com estruturas mais simples são produzidos mais rapidamente do que aqueles com estruturas complexas (Santiago et al., 2000).

De acordo com Béfi-Lopes e Galea (2000), os vocábulos compostos por fonemas que fazem parte do repertório fonológico da criança são armazenados mais facilmente. Portanto, o controle fonológico dos vocábulos utilizados deve favorecer o processo de aquisição lexical. Em outras palavras, é mais fácil para as crianças produzirem nomes simples e curtos, pois estes são aprendidos mais cedo e, conseqüentemente, estão mais bem representados no léxico (Cycowicz et al., 1997).

A habilidade para reconhecer e nomear figuras emerge em um desenvolvimento contínuo desde idades mais precoces e aumenta 
através dos anos escolares (Nelson, 1996). Durante a infância e a adolescência, o armazenamento de palavras melhora com novas palavras no léxico, palavras já existentes com novos significados e com novas associações entre os itens. A recuperação melhora quando as palavras são usadas com maior precisão e velocidade e quando as estratégias para facilitar a recuperação são mais freqüentes e eficientemente usadas (Nippold, 1992).

As dificuldades na nomeação podem ocorrer em função de um processamento incompleto da imagem visual ou a falhas no reconhecimento das características do objeto. Se o estágio de análise da informação visual não for completo, os estágios subseqüentes serão afetados. Neste caminho, o resultado da nomeação pode ser a produção de nomes cujos objetos são visualmente semelhantes ao objeto alvo (Barrow et al., 2000). Falhas na nomeação também podem ocorrer durante o acesso ao significado ou ao nome, principalmente quando as crianças estão no processo de organização semântica e as representações lexicais ainda não estão bem consolidadas na memória (McGregor et al., 2002). A extensão do nome influencia o estágio de organização fonológica para sua produção, podendo ocorrer nomeações com formas fonológicas similares ao nome correto (Johnson et al., 1996).

A partir das descrições sobre leitura de palavras e nomeação de figuras, o próximo tópico refere-se à relação entre estas duas habilidades. 


\subsection{Relação entre a leitura de palavras e a nomeação de figuras}

A leitura de palavras e a nomeação de figuras podem ser estudadas sob diversas perspectivas: identificação de semelhanças e diferenças em cada habilidade (Hoskyn, 2004; Valerie et al., 2004); a relação entre leitura e nomeação no curso do desenvolvimento infantil (Metsala, 1997; Laing e Hulme, 1999; Goswami, 2001; McKague et al., 2001; Valdois, 2001; Santos e Navas, 2002; Vellutino et al., 2004; Goff et al., 2005; Hayiou-Thomas et al., 2006) e no processamento dos estímulos (Theios e Amrheim, 1989; Bajo, 1998); pesquisas neurológicas objetivando determinar áreas cerebrais com funcionamento em comum para o processamento de figuras e palavras (Price et al., 2006). Estes quatro itens serão abordados, na seqüência acima apresentada.

O desenvolvimento da linguagem oral ocorre de maneira informal, relaciona-se a habilidades perceptuais, cognitivas, sociais e é facilitado pela interação entre interlocutores em uma comunidade lingüística. Por outro lado, a linguagem escrita é uma habilidade que deve ser aprendida e isto acontece, com raras exceções, antes de a criança ter completado o desenvolvido da linguagem oral (Valerie et al., 2004).

Compreender e produzir linguagem oral envolve processos que não correspondem exatamente aos da leitura e escrita. Durante uma conversação, um falante e um ouvinte se comunicam em um contexto interativo, social e imediato e em comparação, um escritor e um leitor se comunicam em contextos distantes e por meio de um código abstrato formado por símbolos escritos. Em contraste a um falante que se dirige diretamente a um ouvinte, um autor, quando escreve, pode não ter em mente um leitor específico (Hoskyn, 2004). 
Estudos sobre o desenvolvimento da linguagem apontam para relações entre as modalidades oral e escrita. Valdois (2001) ressalta que um bom domínio da linguagem oral, tanto no âmbito da produção quanto da compreensão, é importante para a criança em processo de aprendizagem da leitura. De acordo com dados pesquisados pelo National Institute of Child Health and Human Development- NICHID (2005), a habilidade de compreensão oral aos 3 anos de idade se correlaciona diretamente ao conhecimento fonológico e vocabulário aos 4,6 anos. Estas habilidades aos 4,6 anos influenciam a identificação da palavra escrita na $1^{\text {a }}$ série e a compreensão da leitura na $3^{\text {a }}$ série.

Face às propriedades estruturais do sistema alfabético, as habilidades lingüísticas desempenham diferentes pesos no desenvolvimento da leitura: as fonológicas exercem maior influência no início do desenvolvimento da leitura (quando as crianças devem decodificar e reconhecer a palavra escrita), enquanto as semânticas e sintáticas exercem maior influência em leitores em séries mais avançadas, para fins de compreensão da leitura (Vellutino et al, 2004).

Gayán e Olson (2003) apontam para forte associação genética entre consciência e decodificação fonológica, mostrando a importância do processamento fonológico (conhecimento do fonema, consciência fonológica, associação grafema-fonema) para o desenvolvimento da leitura. De acordo com Goff et al. (2005), a leitura de palavras irregulares correlaciona-se com a exposição à escrita e com o vocabulário receptivo.

O fonema, tão importante na aprendizagem da leitura, surge com a experiência da linguagem oral. No início, aparece como uma unidade perceptual implícita para o processamento básico da fala. Somente com a utilização em atividades relacionadas com a escrita e a leitura, ele torna-se uma unidade de processamento explícita (Metsala, 1997). 
No que se refere aos aspectos específicos da consciência da linguagem, especialmente a fonológica e a morfológica, estas promovem e são promovidas pelo aprendizado da leitura e escrita, estabilizando representações internas entre fonemas, sílabas e morfemas e suas representações escritas (Goswami et al., 2003).

Autores como Goswami (2001) explicam que, em fases precoces do desenvolvimento da linguagem, as crianças ouvem e percebem as palavras como única e inteira unidade e, ao falá-las, acessam sua representação fonológica como um todo. Sons similares parecem facilitar o crescimento do vocabulário. Crianças pequenas utilizam-se destas estratégias para estocar e memorizar palavras com sons similares e com diferentes significados (faca/vaca; pente/dente). Posteriormente as estratégias de recuperação da palavra mudam, as crianças processam partes e não mais o todo das palavras iniciando a construção de representações fonológicas e morfológicas.

Depreende-se, então, que o conhecimento do vocabulário está implicado na aquisição de habilidades fonológicas relacionadas à leitura. Com o crescimento do vocabulário, o número de palavras acusticamente similares também aumenta, iniciando uma pressão para implementar representações fonológicas cada vez mais detalhadas e bem definidas, o que vai auxiliar, posteriormente, no processamento fonológico (Santos e Navas, 2002). As representações fonológicas se ampliam, tornam-se altamente específicas com as mudanças no desenvolvimento do vocabulário, especialmente em palavras com propriedades fonológicas similares (Vellutino et al., 2004).

A presença de uma palavra no vocabulário oral da criança facilita a leitura da palavra correspondente quando esta é vista pela primeira vez, levando a uma melhor precisão e menor tempo de reconhecimento, por ter estabelecido representações de significado e de 
pronúncia (Laing e Hulme, 1999; McKague et al., 2001; Goff et al., 2005; Hayiou-Thomas et al., 2006).

Quanto aos processos mentais envolvidos na leitura de palavras e na nomeação de figuras, Theios e Amrheim (1989) explicam: na leitura de palavras, o sistema lingüístico identifica o estímulo, ativa as informações ortográficas, fonológicas, semânticas e articulatórias do léxico mental, resultando em uma transformação automática grafofonêmica e posterior produção da fala. No caso da figura, a imagem é processada em sistema gráfico e, logo após, ativa o sistema semântico. Após a figura ter sido identificada, um nome deve ser selecionado entre um número de nomes apropriados no léxico mental do sistema lingüístico, levando à produção da fala.

Bajo (1998) afirma que há códigos visuais mais elaborados para as figuras quando comparadas às palavras: figuras podem acessar diretamente o significado, enquanto o acesso às características fonológicas ocorre indiretamente. Por outro lado, palavras podem ser lidas antes que ativem as características do significado. Figuras e palavras diferem, então, nas suas características sensoriais, mas ambas acessam a representação semântica.

Desta forma, a leitura de palavras isoladas pode ocorrer mais rapidamente do que a nomeação das figuras correspondentes e, esta diferença, se deve a dois processos extras necessários na nomeação de figuras - o acesso ao significado da figura e a seleção do nome correto no léxico mental. Figuras podem ser identificadas diretamente por aceso ao significado e não requerem conversão grafema-fonema tampouco análise ortográfica. Durante a leitura, os leitores devem recuperar a forma fonológica correspondente ao input escrito. A informação semântico-lexical será ativada durante este processo, mas não é um pré-requisito para iniciar a resposta (Steifer, 1997). 
Trauzettel-Klosinski et al. (2006) apontam para uma correlação alta entre leitura de palavras e nomeação de figuras em bons leitores. Em estudo realizado com alunos de $2^{\mathrm{a}}$ e $4^{\mathrm{a}}$ séries $\mathrm{e}$ universitários, Marmurek e Rinaldo (1992) demonstraram que os universitários e os alunos de $4^{\text {a }}$ série lêem palavras mais rapidamente do que nomeiam objetos correspondentes, enquanto o inverso ocorreu para os alunos de $2^{\text {a }}$ série. Estes achados indicam que palavras e figuras não são necessariamente processadas pela mesma rota por todos os leitores, pois para leitores mais habilidosos, uma palavra pode ser lida antes de ocorrer o acesso ao seu significado.

Bates et al. (2001) apontam que a forma da palavra (ortografia e fonologia) influencia mais a leitura de palavras e os efeitos semânticos (familiaridade, idade de aquisição), a nomeação de figuras. Ao mesmo tempo, o achado que ambas as tarefas são afetadas pela freqüência sugere que leitura e nomeação apresentam um componente lexical comum a ambas. Roelofs (2004) indica que a construção de formas fonológicas e a programação articulatória são componentes de planejamento que ocorrem para leitura e nomeação.

Os estudos neurológicos também contribuem para a identificação de processos comuns envolvido na leitura e na nomeação. Price et al. (2006) observaram que todas as áreas cerebrais ativadas para leitura são também ativadas para a nomeação de figuras e repetição oral. Porém, durante a leitura, ocorre maior ativação em áreas associadas aos processos de produção da fala, provavelmente devido às múltiplas conexões geradas pelas unidades sublexicais das palavras escritas. Como as associações com a fonologia são mais fortes para palavras escritas do que para objetos, a ativação na área da produção da fala pode ser mais rápida e mantida por maior tempo, enquanto sinais são enviados às áreas relacionadas ao processamento semântico. Durante a nomeação de figuras, foi observado o processo inverso: as 
áreas relacionadas ao conhecimento perceptual e semântico são ativadas mais rapidamente enquanto sinais são enviados à área responsável pela produção.

Nomeação de figuras e leitura de palavras requerem, então, a recuperação da informação fonológica (Snowling, 1991) e semântica da memória de longo prazo (Bajo, 1998). Aspectos semânticos (familiaridade, freqüência e concretude) e fonológicos (extensão e complexidade articulatória) devem ser organizados na memória e acessados diante de um estímulo com características particulares.

\subsection{A leitura e seus transtornos}

De acordo com Ferraz (2002), as alterações no desenvolvimento da leitura e escrita são descritas desde 1887, passando, desde então, por várias definições e abrangendo diversos termos.

Atualmente, diversos termos e definições ainda são empregados para descrever tais alterações, constituindo-se em um problema no meio clínico e científico. Observa-se a utilização de termos como "Transtorno da Aprendizagem" (DSM-IV, 1995), "Distúrbio Específico de Aprendizagem" (Snowling et al., 1994) “dificuldades de aprendizagem” (Romero, 2004), “Dislexia” (International Dyslexia Association, 2002), entre outros.

Neste tópico, são apresentadas as concepções de alguns autores. Pode se observar ao longo das descrições de cada autor que quadros com características semelhantes podem ser designados por diversos termos. Por outro lado, observa-se, também, que diferentes quadros recebem a mesma terminologia. 
Romero (2004) utiliza o termo dificuldades na aprendizagem para descrever quadros com dificuldades mais gerais que pervadem todas as áreas do desenvolvimento ou que se referem uma área. $\mathrm{O}$ autor divide o quadro em três tipos de dificuldades:

- aprendizagem generalizada - afeta a aprendizagem em várias áreas (escolares e não escolares), prejudicando importantes aspectos do desenvolvimento (motores, lingüísticos, cognitivos, etc.), como conseqüência de alterações na estrutura e/ou funcionamento cerebral, cuja origem pode ser adquirida (durante o desenvolvimento embrionário ou em acidente após o nascimento) ou fruto de alteração genética;

- aprendizagem inespecífica - não afetam o desenvolvimento. Impedem alguma aprendizagem em particular, sem razão intelectual que as justifique. A causa instrucional e/ou ambiental exerce influência especial sobre variáveis pessoais como a motivação;

- aprendizagem específica - afeta a aprendizagem em áreas específicas, como a escolar (leitura, a escrita, a matemática), não implicam rebaixamento intelectual e podem ter como aspectos psicológicos afetados o processamento fonológico, a atenção sustentada e a memória.

De acordo com o autor acima citado, as causas das dificuldades de aprendizagem podem ser atribuídas a condições intrínsecas da pessoa (herança genética, atrasos maturacionais), circunstâncias ambientais nas quais se dá o desenvolvimento e/ou a aprendizagem (ambientes familiares e educativos pobres, projetos instrucionais inadequados, etc.) ou a uma combinação das anteriores em que as condições pessoais são influenciadas de forma positiva ou negativa pelas circunstâncias ambientais.

De acordo com Romero (2004), as dificuldades na aprendizagem (termo utilizado pelo autor) podem ser decorrentes ou 
fazer parte de um quadro maior. Este é o caso das deficiências sensoriais como as auditivas (Halliday e Bishop, 2005; Golz et al., 2006), quadros neurológicos como paralisia cerebral (Dahlgren, 2006), Síndrome de Down (Verucci et al., 2006), acidente vascular encefálico (Cardoso-Martins e Frith, 1999; Pennington et al., 2003), deficiência mental (Santa Maria e Linhares, 1999; Conners at al., 2006; Cohen et al., 2006), quadros psiquiátricos como Transtorno de Déficit de Atenção e Hiperatividade (Fletcher et al., 1999; Mayes et al., 2000), Transtorno de Conduta (Hindsaw, 1992; Bennett et al., 2003; Linares-Orama, 2005) e Transtornos de Ansiedade (Willcutt e Pennington, 2000). Assim, as dificuldades podem se apresentar apenas em uma área, como a escolar e, ainda mais especificamente, na leitura, na escrita e/ou na matemática.

A Associação Americana de Psiquiatria, no seu Manual Diagnóstico e Estatístico de Transtornos Mentais - $4^{\underline{a}}$ edição (DSM-IV, 1995), apresenta o Transtorno da Aprendizagem, denominado anteriormente de Transtornos das Habilidades Escolares. Segundo este manual, "os Transtornos de Aprendizagem são diagnosticados quando os achados do indivíduo em testes padronizados $e$ individualmente administrados de leitura, matemática ou expressão escrita estão substancialmente abaixo do esperado para sua idade, escolarização e nível de inteligência" (p.80). A seguir, serão apresentados os critérios diagnósticos para os sub-grupos do Transtorno da Aprendizagem: 
Guadro 1. Critérios Diagnósticos para F81.0 - 315.00 - Transtorno da Leitura (DSM-IV, 1995)

A. O rendimento da leitura, medido por testes padronizados, administrados individualmente, de correção ou compreensão da leitura, está acentuadamente abaixo do nível esperado, considerando a idade cronológica, a inteligência medida e a escolaridade apropriada à idade do indivíduo.

B. A perturbação no Critério A interfere significativamente no rendimento escolar ou atividades da vida diária que exigem habilidades de leitura.

C. Em presença de um déficit sensorial, as dificuldades de leitura excedem aquelas geralmente a este associadas.

Nota para a codificação: Se uma condição médica geral (por ex., neurológica) estiver presente, codificá-la no Eixo III.

Quadro 2. Critérios Diagnósticos para F81.8 - 315.2 - Transtorno da Expressão Escrita (DSM-IV, 1995)

A. As habilidades de escrita, medidas por testes padronizados, individualmente administrados (ou avaliações funcionais das habilidades de escrita), estão acentuadamente abaixo do nível esperado, considerando a idade cronológica, a inteligência medida e a escolaridade apropriada à idade do indivíduo.

B. A perturbação no Critério A interfere significativamente no rendimento escolar ou atividades da vida diária que exigem a composição de textos escritos (por ex., escrever frases gramaticalmente corretas e parágrafos organizados).

C. Em presença de um déficit sensorial, as dificuldades nas habilidades de escrita excedem aquelas habitualmente a este associadas.

Nota para a codificação: Se uma condição médica geral (por ex., neurológica) ou déficit sensorial estiverem presentes, codificar no Eixo III. 
Guadro 3. Critérios Diagnósticos para F81.2 - 315.1 - Transtorno da Matemática (DSM-IV, 1995)

A. A capacidade matemática, medida por testes padronizados, individualmente administrados, está acentuadamente abaixo do nível esperado, considerando a idade cronológica, a inteligência medida e a escolaridade apropriada à idade do indivíduo.

B. A perturbação no Critério A interfere significativamente no rendimento escolar ou atividades da vida diária que exigem habilidades em matemática.

C. Em presença de um déficit sensorial, as dificuldades na capacidade matemática excedem aquelas geralmente a este associadas.

Nota para a codificação: Caso esteja presente uma condição médica geral (por ex., neurológica) ou déficit sensorial, codificar no Eixo III.

O Transtorno da Matemática e o Transtorno da Expressão Escrita em geral estão associados ao Transtorno da Leitura, sendo relativamente rara a apresentação de qualquer destes transtornos na ausência do Transtorno da Leitura.

A categoria de Transtorno da Aprendizagem Sem Outra Especificação envolve os transtornos da aprendizagem que não satisfazem os critérios para qualquer Transtorno da Aprendizagem específico, podendo incluir problemas em todas as três áreas (leitura, matemática, expressão escrita) que, juntos, interferem significativamente no rendimento escolar, embora o desempenho nos testes que medem cada habilidade isoladamente não esteja acentuadamente abaixo do nível esperado, considerando a idade cronológica, a inteligência medida e a escolaridade apropriada à idade do indivíduo.

O Transtorno da Leitura também pode ser denominado Dislexia, de acordo com o DSM-IV. Kamhi (1997) considera, além da Dislexia, outros dois quadros de alterações na leitura: 
- "Language Learning Disabled" - presença de dificuldades na identificação da palavra escrita e na compreensão de linguagem e, conseqüentemente, na compreensão da leitura;

- Hiperlexia - a habilidade de identificação da palavra está preservada, mas há dificuldade na compreensão da linguagem, o que acarreta problemas na compreensão da leitura;

- Dislexia - ocorre dificuldade na identificação da palavra escrita, apesar de habilidades normais de compreensão e produção da linguagem. A compreensão da leitura está prejudicada devido à imprecisão ou lentidão na decodificação da palavra escrita.

Sobre a Dislexia, a International Dyslexia Association - IDA (2002) aponta que esta é uma das diversas incapacidades na aprendizagem, um distúrbio específico da linguagem, mais especificamente da linguagem escrita, de origem biológica, caracterizada por dificuldades na decodificação de palavras isoladas, que geralmente refletem habilidades insuficientes de processamento fonológico. Essas dificuldades na decodificação de palavras individuais são freqüentemente inesperadas em relação à idade ou a outras capacidades cognitivas e não são resultantes de uma incapacidade no desenvolvimento ou de um comprometimento sensorial.

A Dislexia difere dos distúrbios de aprendizagem mais gerais por se constituir em prejuízo que persiste na vida adulta, enquanto as pessoas com dificuldades de aprendizagem mais gerais apresentam soletração melhor e aritmética pior, além de fazerem progresso em programas de estimulação da leitura (Rutter e Maughan, 2005).

Embora a maioria dos indivíduos com Dislexia apresente problemas na leitura de palavras e de não palavras, alguns exibem dificuldades particulares com leitura de não palavras, enquanto a leitura de palavras irregulares está relativamente conservada. Este padrão de déficit, interpretado pelo modelo de dupla-rota como um 
prejuízo específico para adquirir a rota não lexical, é característico da dislexia designada fonológica. Por ouro lado, algumas crianças apresentam pobre desempenho na leitura de palavras irregulares enquanto a leitura de palavras regulares e não palavras está preservada, sugerindo em déficit na aquisição da rota lexical, caracterizando a dislexia de superficie (Coltheart et al., 1993).

Castles e Coltheart (1993) afirmam que 55\% das crianças com Dislexia apresentam o tipo fonológica, 30\% o de superfície e 10\% ambos os tipos.

Sobre os tipos de Dislexia expostos, Stanovitch et al. (1997) propõem que estes são causados por diferentes graus de prejuízo no processamento fonológico, combinado com a falta de exposição à escrita. Os disléxicos fonológicos sofreriam de um déficit lingüístico básico e severo, que os incapacitaria de aprender as regras de conversão grafema-fonema. Os disléxicos de superfície sofreriam do mesmo déficit, porém, mais moderado, e, neste caso, reforçado pela falta de exposição à escrita.

$\mathrm{Na}$ Dislexia, as alterações são causadas por dificuldades básicas na aprendizagem da decodificação da palavra escrita. Esta dificuldade em mapear símbolos alfabéticos em sons (princípio alfabético) depende em parte da consciência fonológica (consciência que as palavras faladas compreendem sons individuais da fala) e da consciência ortográfica (sensibilidade da criança para constatar como as letras são organizadas nas palavras escritas). Assim, pode-se dizer que os problemas na consciência fonológica, mapeamento alfabético e decodificação fonológica conduzem a dificuldades para estabilizar conexões entre sons e letras (Vellutino et al., 2004).

Há evidências de componentes genéticos e ambientais implicados nos déficits no reconhecimento de palavras no grupo de disléxicos fonológicos, enquanto nos disléxicos de superfície, o 
componente ambiental exerce maior influência (Castles et al., 1999). Conlon et al. (2006) afirmam que adolescentes com problemas de leitura apresentam cinco vezes mais possibilidade de serem de famílias com histórico de dificuldades de leitura.

Resultados do uso de técnicas de neuroimagem, em crianças e adultos com Dislexia, sugerem atividade cerebral alterada no córtex auditivo esquerdo (Trauzettel- Klosinski et al., 2006); desenvolvimento de circuitos compensatórios como observado no funcionamento no hemisfério direito e no giro frontal inferior, áreas não tão envolvidas na leitura em indivíduos com desenvolvimento típico de leitura (Shaywitz e Shaywitz, 2005) e mudanças na atividade cerebral com melhora no desempenho após intervenção terapêutica (Démonet, et al., 2004).

A seguir, são apresentados dados referentes à nomeação de figuras e outras habilidades verbais em crianças com Transtorno da Leitura. Neste estudo, será empregado o termo Transtorno da Leitura, por ser o indicado no DSM-IV (1995), utilizado internacionalmente. Porém, os termos utilizados pelos autores nos trabalhos descritos serão mantidos.

\subsection{Nomeação de figuras em crianças com Transtorno da Leitura}

Nos tópicos anteriores, foram apresentados diversos estudos sobre a relação entre linguagem oral e escrita, bem como a alteração no processamento fonológico como déficit principal no Transtorno da Leitura. Dado que a leitura de palavras e a nomeação de figuras apresentam diversos componentes de processamento em comum (Theios e Amrheim, 1989; Bajo, 1998), espera-se que os indivíduos com Transtorno da Leitura possam apresentar também dificuldades ao processar figuras. 
O problema relacionado à fonologia já foi demonstrado desde a década de 80, por Snowling (1980) e Wagner e Torgensen (1987), que atribuíram como causas do Transtorno da Leitura, as dificuldades com o sistema alfabético, ou seja, uma dificuldade para associar os estímulos visuais/grafemas aos sons correspondentes. Scarborough (1990) aponta evidências de que a aquisição do código alfabético depende do desenvolvimento da consciência fonológica.

Outros estudos demonstram a importância do vocabulário na construção de habilidades fonológicas relacionadas à leitura: uma aquisição lenta do vocabulário pode prejudicar a qualidade e a precisão das representações fonológicas estabelecidas e, a partir de então, determinar alterações no processamento fonológico em geral. Da mesma forma, alterações no processamento fonológico dificultam a construção da representação mental da estrutura fonológica e o mecanismo de acesso a essa informação (Navas, 1997; Goswami, 2001).

Como apontam Swan e Goswami (1997) "a dificuldade para encontrar e reconhecer palavras em resposta às figuras é um dos déficits encontrados no perfil lingüístico-cognitivo dos disléxicos".

Para Faust e Sharfstein-Friedman (2003), as alterações na leitura e na nomeação, presentes nas crianças com Transtorno da Leitura, parecem ser sintomas de um déficit básico na representação dos sons da fala: a leitura porque requer conversão grafema-fonema e acesso aos sons das palavras escritas e a nomeação pela dificuldade em transformar um conceito mental em uma seqüência de sons da fala.

Trabalhos realizados nas últimas duas décadas envolveram habilidades verbais, a fim de entender como a nomeação de figuras pode estar prejudicada em crianças com Transtorno da Leitura.

Em 1985, Vellutino e Scanlon avaliaram leitores de 8 e 12 anos de idade, com e sem dificuldade na leitura, em provas de recuperação espontânea de palavras concretas e abstratas. Ambos os 
grupos de sujeitos recuperaram quantidade semelhante de palavras concretas, mas os bons leitores conseguiram acessar e recuperar mais itens abstratos do que os maus leitores. Os resultados são consistentes com a hipótese de déficits verbais, que apontam lentidão para adquirir o conhecimento lexical: palavras concretas podem ser recuperadas por imagens visuais, enquanto as abstratas devem ser decodificadas verbalmente.

Katz, em 1986, investigou a nomeação de figuras em crianças de 8 anos de idade com dificuldade específica de leitura e encontrou pouca precisão na nomeação de figuras e alta freqüência de erros fonológicos, particularmente em nomes de baixa freqüência e polissilábicos. Estas crianças têm dificuldade na nomeação de objetos como conseqüência de deficiências fonológicas no estabelecimento de representações completas na memória de longo prazo e no processamento destas representações.

Em um outro estudo, em 1986, Snowling et al. aplicaram testes de repetição de não palavras e de palavras de alta e de baixa freqüência, com e sem mascaramento auditivo, em crianças disléxicas e em dois grupos controles (idade cronológica e idade de leitura). Os resultados mostraram que disléxicos não apresentaram dificuldade com o input fonológico, pois reagiram ao mascaramento de forma similar aos controles; não apresentaram problemas com o output fonológico, senão teriam dificuldade para repetir todos os tipos de palavra. Há evidências, então, de problemas na rota não lexical para a fonologia ou a existência de problemas no estágio em que as palavras faladas devem ser analisadas em seus componentes para formar programas motores/articulatórios. Crianças com dificuldades para segmentação apresentam mais problemas para estabilizar estas representações na memória de longo prazo. 
Snowling et al. (1988) analisaram em seu primeiro experimento 20 disléxicos (10,5a), 15 controles de mesma idade cronológica $(11,2 \mathrm{a})$ e 14 controles de mesmo nível de leitura $(8,6 a)$ em provas de nomeação de figuras, evocação do nome a partir de definições orais, recuperação dos itens da provas e definição de tais figuras após 6 semanas. Todos os sujeitos apresentaram desempenho semelhante para definir palavras e mais dificuldades na nomeação do que na definição de figuras; o tempo de reação para a nomeação e a definição foi semelhante entre disléxicos e controles; os disléxicos fizeram mais erros do que os controles de mesma idade cronológica e semelhante aos do mesmo nível de leitura.

No segundo experimento desses autores, participaram 11 disléxicos (9,5 a) e 30 controles (9,6a e 8,6a), em um teste de vocabulário receptivo. O desempenho foi semelhante entre os sujeitos e os autores concluíram que a dificuldade experenciada por disléxicos, para reconhecer as formas fonológicas das palavras, não é um problema no acesso, mas uma alteração na construção das representações destas palavras na memória.

Em 1997, Swan e Goswami consideraram as propriedades dos nomes, como freqüência e extensão, em provas de vocabulário receptivo e nomeação de figuras, em crianças com Dislexia e crianças de mesma idade cronológica, de mesmo nível de leitura e maus leitores (crianças com dificuldades na leitura e GI inferior à média). Os resultados indicaram que os disléxicos e os maus leitores cometeram mais erros na nomeação de figuras do que os grupos-controle (idade e leitura). Na nomeação, o maior índice de acertos nos itens curtos e/ou freqüentes do que nos longos e/ou de baixa freqüência foi observado apenas para os disléxicos. Em vocabulário receptivo, os maus leitores apresentaram pior desempenho do que todos os grupos, cometendo mais erros semânticos, enquanto os disléxicos apresentaram desempenho 
semelhante aos grupos controles. Os autores concluíram que os disléxicos apresentam dificuldades para recuperar as representações fonológicas da figura mais do que um déficit no vocabulário, enquanto os maus leitores apresentam dificuldade na recuperação devido a problemas no conhecimento lingüístico e de mundo.

Em 2001, Nation e Snowling conduziram um estudo com disléxicos e crianças com mesmo nível de leitura e constataram que os disléxicos tinham pior desempenho do que seus controles apenas quando os itens eram longos e complexos, sugerindo que a extensão da palavra pode influenciar a facilidade com que as formas fonológicas são recuperadas da memória de longo prazo.

Utilizando um instrumento que mede a posição da fóvea em relação ao estímulo para determinar o tempo de reação aos estímulos, Trauzettel-Klosinski et al. (2002) pesquisaram 14 disléxicos e 12 controles (idade), com idade média de 13,1a. Foram utilizadas 42 figuras de objetos familiares em grupos de 3 a 5, dispostas em um parágrafo com 4 linhas, assemelhando-se a um texto escrito, e três textos escritos com 8 ou 9 linhas. A velocidade de leitura diferiu entre disléxicos e controles na leitura de textos, mas não na nomeação de figuras. Os autores concluíram que a lentidão dos disléxicos deve-se ao acesso do tipo de estímulo, neste caso, os grafemas.

Mais recentemente, Faust e Sharfstein-Friedman (2003) submeteram 46 adolescentes - 23 com Dislexia de 13 anos de idade e 23 controles (mesmo nível de leitura) a uma série de provas: nomeação de figuras familiares e freqüentes. As crianças deveriam dizer se sabiam, mas não lembravam do nome ou se não conheciam o objeto das figuras que não nomearam. Se não se lembrassem do nome, deveriam dar uma informação relacionada à figura; se não conseguissem dar a informação, deveriam indicar dentre alguns fonemas, aquele que iniciava o nome da figura. 
Os resultados deste estudo mostraram que os disléxicos deram menos respostas corretas na nomeação de figuras, apresentaram mais erros fonológicos e respostas do tipo "conheço a figura, mas não me lembro do nome no momento". O número de respostas não informativas (não conheço o objeto) foi semelhante entre os grupos de sujeitos; o erro semântico foi o predominante para disléxicos e controles; a pista fonológica beneficiou mais os sujeitos do grupo controle. Os autores concluíram que os adolescentes com Dislexia apresentam dificuldades para recuperar o código fonológico dos nomes de figuras conhecidas, mais do que um déficit no vocabulário. Ou seja, apresentam conhecimento do vocabulário, mas têm alterações na construção das formas fonológicas dos nomes. Então, apesar de conhecerem o objeto representado pela figura, têm dificuldade para nomeá-lo.

Em outro estudo com crianças com e sem Transtorno da Leitura de $1^{\mathrm{a}}(\mathrm{n}=93)$ e $4^{\mathrm{a}}$ séries $(n=76)$, Fowler e Swainson (2004) investigaram o desempenho em provas de vocabulário receptivo, nomeação de figuras, correção de nomes produzidos com alterações e repetição de não palavras. Os resultados indicaram que o conhecimento fonológico impreciso, especialmente para palavras longas, contribuiu para dificuldades em todas as tarefas de nomeação.

Em 2006, Trauzettel-Klosinski et al. verificaram o tempo para a leitura em voz alta de palavras freqüentes e raras e para a nomeação de figuras em 9 crianças disléxicas e 13 controles de 9,5 anos. Os bons leitores foram mais rápidos na leitura de palavras e cometeram menos imprecisões, enquanto na prova de nomeação não foram observadas diferenças entre os grupos. Os autores concluíram que a experiência em processamento de figuras e o uso intensificado da rota visual, mesmo antes da aprendizagem das regras de conversão grafema-fonema, 
podem ter contribuído para a ausência de diferenças entre disléxicos e bons leitores na nomeação de figuras.

Recentemente, a relação entre as alterações na leitura e a dificuldade para a nomeação de figuras foi analisada também em exames de neuroimagem. McCrory et al. (2005) observaram que os disléxicos apresentam menor ativação cerebral do que seus controles normais na região occipto-temporal, apenas para a nomeação de figuras e leitura de palavras, sugerindo que a dificuldade reflete mais um déficit na recuperação fonológica do input visual do que na representação ortográfica.

Vale ressaltar que a relação entre as alterações na leitura e outras habilidades, como as fonológicas e semânticas, é diferente para cada língua, caracterizando comportamentos diferentes nas crianças com dificuldades de leitura. Disléxicos na língua inglesa apresentam maiores dificuldades nas habilidades fonológicas (porque a ortografia é irregular), enquanto os problemas de leitura em línguas mais regulares, como a italiana, estão relacionados a processos fonológicos implícitos como a recuperação do nome, prejudicando a fluência na identificação da palavra e no processamento do texto (Vellutino et al., 2004; Sprenger-Charolles et al., 2005; Zoccolotti et al., 2005).

Reunindo as informações encontradas na literatura internacional, alguns estudos apontam para ausência de diferenças na nomeação entre crianças com Transtorno da Leitura e crianças com desenvolvimento típico. Por outro lado, diversos trabalhos indicam maiores dificuldades no processamento de figuras por crianças com Transtorno da Leitura, no que diz respeito às imprecisões da nomeação e ao tempo de latência, ressaltando a importância de se considerar as características da figura e de seu nome, o que contribui para o desempenho na nomeação. 
No presente estudo, o tempo de processamento para as figuras foi investigado em crianças não leitoras, levando-se em conta características psicolingüísticas de palavras escritas correspondentes. 
3. OBJETIVOS 


\section{OBJETIVOS}

\subsection{Objetivo geral}

O objetivo deste estudo foi investigar o tempo de processamento para o material escrito e para figuras equivalentes, em crianças leitoras e não leitoras do Ensino Fundamental de escola pública.

\subsection{Objetivos específicos}

- verificar o tempo de latência e o tempo de duração da emissão oral para o processamento de palavras escritas e seus equivalentes em forma de figura;

- analisar a influência das características do material no tempo de processamento e na eficiência em provas de leitura e a nomeação;

- analisar o efeito da escolaridade no tempo de processamento e na eficiência nas provas;

- caracterizar o tipo de leitura e de nomeação;

- correlacionar tempo de processamento com eficiência nas provas;

- comparar e correlacionar leitura de palavras e nomeação de figuras;

- comparar o desempenho de leitores com o de não leitores na nomeação de figuras. 


\section{HIPÓTESES}




\section{HIPÓTESES}

- o tempo de processamento varia em função do tipo de material e da escolaridade.

- o tempo de processamento implica na eficiência da tarefa.

- leitura e nomeação sofrem influência das características da palavra escrita.

- o processamento de figuras ocorre mais rapidamente do que o da palavra escrita.

- o tempo de processamento de sujeitos não leitores é maior do que nas crianças leitoras, na nomeação de figuras. 
5. MÉTODOS 


\section{MÉTODOS}

Esta pesquisa é caracterizada por um estudo observacional e transversal, aprovado pela Comissão de Ética para Análise de Projetos de Pesquisa do Hospital das Clínicas da Faculdade de Medicina da Universidade de São Paulo (protocolo de pesquisa no 637/03) (anexo A). Responsáveis pelas crianças assinaram o Termo de Consentimento PósInformação do Hospital das Clínicas da Faculdade de Medicina da Universidade de São Paulo (anexo B).

\subsection{Casuística}

Participaram deste estudo 94 crianças do Ensino Fundamental da escola pública municipal Professor Olavo Pezzotti, localizada em São Paulo (SP). Destas crianças, 74 são leitoras e 20 não leitoras.

\subsubsection{Crianças leitoras}

O grupo de leitores foi constituído por alunos da $2^{\mathrm{a}}$, $3^{\mathrm{a}}$ e $4^{\mathrm{a}}$ séries. As crianças de $1^{\text {a }}$ série não foram incluídas nesta pesquisa por estarem no início do processo de alfabetização e ainda não identificarem um ou a maioria dos grafemas e, conseqüentemente, a palavra escrita. Por sua vez, os alunos de $5^{\text {a }}$ série não participaram porque faziam parte de outra faixa de escolarização, o Ensino Médio. Para participarem da pesquisa, foram considerados os seguintes critérios de inclusão: 


\section{Critérios de inclusão:}

- autorização do responsável legal para participação na pesquisa;

- alunos de $2^{\mathrm{a}}, 3^{\mathrm{a}}$ e $4^{\mathrm{a}}$ séries;

- classe regular e escola pública;

- idade cronológica de 7 a 12 anos, de ambos os sexos;

- crianças leitoras;

- crianças consideradas boas falantes por pais e professores;

- ausência de:

- histórico de fracasso escolar, evasão e indicação de classe especial;

- problemas neurológicos e/ou psiquiátricos;

- intercorrências no desenvolvimento;

- déficits visuais não corrigidos;

- queixas de problemas auditivos.

Durante a aplicação das provas, as crianças que apresentaram alterações fonológicas e/ou articulatórias, não identificadas por pais e professores foram excluídas da pesquisa e encaminhadas para serviços específicos. Também foram excluídas aquelas que apresentaram dificuldades na compreensão do teste e/ou que não conseguiram realizar todas as provas.

\subsubsection{Crianças não leitoras}

As crianças não leitoras foram selecionadas da $2^{\text {a }}$ série da mesma escola à qual pertencem os leitores. Optou-se pelo termo não leitores em decorrência da variedade de termos utilizados para o quadro de alterações na leitura. Foi considerada como não leitora a criança com 
dificuldades na decodificação grafofonêmica, incorrendo em impossibilidade de reconhecimento da palavra escrita.

A primeira seleção foi feita por intermédio dos professores, que identificaram as crianças que não conseguiam ler. Então, estas crianças foram submetidas à leitura de palavras simples, para excluir aquelas que conseguiam ler, mesmo com dificuldades. Outros critérios foram também levados em conta, e estão descritos a seguir:

\section{Critérios de inclusão:}

- autorização do responsável legal para participação na pesquisa;

- alunos de classe regular e escola pública;

- idade cronológica de 7 a 8:11 anos, de ambos os sexos;

- crianças não leitoras, ou seja, que não decodificam e não reconhecem a palavra escrita;

- ausência de:

- diagnóstico de problemas neurológicos e/ou psiquiátricos;

- problemas de aprendizagem em outros domínios;

- histórico de evasão e indicação de classe especial;

- déficits visuais não corrigidos;

- queixas de problemas auditivos.

- quociente de inteligência esperado - igual ou superior a 79 no WISC-III (Weschler, 1981).

- crianças consideradas boas falantes por pais e professores e com percentis dentro da normalidade em cada sub-escala verbal do WISC-III (Weschler, 1981). 


\subsection{Instrumentos e procedimentos}

A seguir, estão descritos os instrumentos, os procedimentos e a forma de análise para a seleção e caracterização dos sujeitos e para a aplicação das provas.

\subsubsection{Instrumentos para seleção e caracterização dos sujeitos}

Para a seleção/caracterização dos sujeitos deste estudo foram utilizados os seguintes instrumentos:

- Anamnese - teve como objetivo a obtenção de dados sobre o desenvolvimento e a saúde do sujeito. Contém questões sobre as condições pré, peri e pós-natais, desenvolvimento neuropsicomotor e de linguagem, audição, visão, escolarização, comportamento e saúde (doenças infantis, medicamentos e tratamentos realizados) (anexo C). Foram excluídas da pesquisa as crianças que apresentaram alterações no desenvolvimento em geral e da linguagem, queixas de problemas auditivos e visuais.

- Questionário escolar - elaborado pela pesquisadora, teve como objetivo obter informações sobre o histórico escolar do aluno quanto a dificuldades apresentadas, necessidade de reforço e comportamento. O questionário foi explicado ao professor responsável por cada série escolar e solicitado o seu preenchimento. Foram excluídos os alunos com histórico de evasão escolar, necessidade de reforço e classe especial e, somente para a 
amostra de leitores, foram excluídos também aqueles com histórico de fracasso escolar (anexo D).

- Questionário de Conners para Pais e Professores (Conners, 1968, validado por Barbosa e Gouveia, 1993) - tem por objetivo avaliar diferencialmente o hiperativo massivo (aquele que tem comportamentos identificados por pais e professores) e o situacional (só prevalece em um dos contextos: escolar ou familiar). É composto por 42 questões na versão para pais e por 40 questões na versão para professores. Dez destas questões compõem o item hiperatividade $(14,15,16,21,26,27,37,38,40$ e 42 para pais; 1 , $5,6,8,12,14,15,18,20$ e 21 para professores). As respostas possiveis são: nunca, às vezes, freqüentemente e sempre, sendo os valores da pontuação 0, 1, 2 e 3, respectivamente. Quando a pontuação total das respostas dos dez itens é 18 ou mais para pais ou 22 ou mais para professores, provavelmente trata-se de criança hiperativa. As crianças que atingiram esta pontuação foram excluídas desta pesquisa (anexo E).

- Escala de Inteligência Wechsler para crianças (WISC-III, Wechsler, 1981) - recurso psicométrico utilizado para a avaliação do funcionamento intelectual. A escala é constituída por testes bem padronizados e descritos em seu manual, sendo considerada um instrumento importante no processo diagnóstico para a compreensão do desempenho do sujeito (Rocca, 2001). O quociente de inteligência é calculado com base em duas escalas - verbal e de execução. O conjunto de subtestes vocabulário (escala verbal) e cubos (escala de execução) podem ser aplicados para a obtenção do quociente intelectual estimado. O quociente intelectual estimado tem sido muito utilizado, por necessitar de pouco tempo para a aplicação 
(cerca de 20 minutos) e são os testes que fornecem mais características psicométricas de abstração, ou seja, mostram como um indivíduo se comporta em situações menos estruturadas (Sattler, 1992):

Vocabulário - requer o conhecimento do significado do que foi ouvido (memória semântica). Este teste verifica a qualidade da linguagem e o nível de pensamento (abstrato ou não). São apresentadas palavras e o sujeito é instruído a defini-las.

Cubos - verifica organização, percepção, análise e síntese. Requer boa coordenação visuo-motora para reproduzir construtos abstratos, utilizando cubos coloridos: vermelho, branco e branco/vermelho. A prova é cronometrada. A rapidez e a facilidade com que se percebe as relações entre os cubos e o modelo desenhado fornecem indícios a respeito do nível de conceitualização visuo-espacial (Cunha, 1993). Esta prova é considerada uma boa medida de inteligência não verbal.

Todos os outros subtestes da escala de inteligência verbal também foram aplicados - informação, compreensão, aritmética e semelhanças:

Informação - relaciona-se à capacidade de reter informações (memória semântica) e é influenciada por fatores culturais e escolares. São apresentadas questões de cultura geral para que a criança responda.

Compreensão - analisa o uso de julgamento prático na vida diária, com ajustamento e maturidade social. São apresentadas questões que fazem referência ao raciocino prático. Esta prova possibilita acessar memória semântica e episódica.

Aritmética - verifica a concentração para lidar com conceitos e operações numéricas. São apresentados verbalmente problemas matemáticos para a criança resolver. 
Semelhança - requer pensamento associativo, no que se refere a estabelecer relações entre conceitos (associação semântica).

Este instrumento foi aplicado e analisado por uma psicóloga.

- Guestões para verificação de sinais de dislexia - A Associação Internacional de Dislexia - IDA (2000), apresenta uma lista para verificar sinais de dislexia, em cada série escolar. Esta lista foi entregue aos professores e lhes foi solicitado que identificassem a presença ou ausência do sinal em cada aluno não leitor (anexo F). Cada característica assinalada como presente na criança recebeu 1 ponto. Este questionário serviu para auxiliar na caracterização dos sujeitos e não como foi utilizado como critério de inclusão/exclusão.

- Escala de Avaliação do Nível Sócio-Econômico Familiar da Associação Brasileira de Institutos de Pesquisa de Mercado ABIPEME (Almeida e Wickerhauser, 1991) - teve como objetivo a classificação sócio-econômica familiar. Contém questões referentes ao nivel educacional do chefe da família e às suas posses. Cada resposta recebe uma pontuação, sendo que a soma total dos pontos indica a classe sócio-econômica-familiar a qual pertence a família (A: classe alta; B: classe média; C: classe média alta; D: classe baixa; E: classe muito baixa) (anexo G). 


\subsubsection{Instrumentos para avaliação da leitura e da nomeação}

Para a coleta dos dados foram aplicadas provas de leitura de palavras em voz alta e de nomeação de figuras. Os estímulos selecionados, a forma de aplicação das provas e os critérios de análise dos dados estão descritos abaixo:

Prova de leitura - teve como objetivo a leitura em voz alta de palavras isoladas e foi aplicada aos leitores e não leitores. No grupo de não leitores, esta prova teve como objetivo confirmar o não reconhecimento de palavras escritas.

As palavras desta prova foram selecionadas de acordo com as características psicolingüísticas do material escrito. Neste estudo, foram consideradas as variáveis: freqüência, extensão, regularidade $e$ complexidade silábica, descritos a seguir:

- Freqüência - refere-se ao número de vezes em que as palavras escritas pertencentes ao vocabulário de uma língua ocorrem dentro de faixas etárias específicas. Foram selecionadas palavras de alta e baixa freqüência de ocorrência, obtidas do trabalho desenvolvido por Pinheiro (1996), com crianças na faixa pré-escolar e séries iniciais. As palavras de baixa freqüência são caracterizadas por ocorrência de 1 a 30 vezes no material escrito enquanto as de alta freqüência, por ocorrência de 73 a 14064. Para este trabalho, as palavras de alta freqüência foram selecionadas da amostra de crianças da $2^{\text {a }}$ série do Ensino Fundamental, considerando-se que a freqüência destas tende a aumentar ao longo da escolarização, sendo então freqüentes também para a $3^{\mathrm{a}}$ e a $4^{\mathrm{a}}$ séries. Para as palavras de baixa freqüência, foram escolhidas aquelas apresentadas simultaneamente por crianças da $2^{\mathrm{a}}, 3^{\mathrm{a}}$ e $4^{\mathrm{a}}$ séries. 
- Complexidade silábica - refere-se à estrutura da palavra, ou seja, à disposição dos grafemas nas sílabas. Os nomes simples são caracterizados por estrutura silábica CV (consoante-vogal) e os nomes complexos por $\mathrm{CV}$ e outras estruturas como $\mathrm{CCV}$ (consoante-consoante-vogal) e CVC (consoante-vogal-consoante). Não foram incluídos os dígrafos.

- Extensão da palavra - refere-se ao número de grafemas que compõem uma palavra. Foram consideradas 4 e 6 grafemas para palavras de estrutura simples, e 5 ou mais grafemas para as palavras com estrutura complexa.

- Regularidade para a leitura - diz respeito às regras de conversão grafema-fonema durante a leitura, caracterizando palavras regulares e irregulares. São palavras regulares aquelas que apresentam relação unívoca entre grafema e fonema, que pode ser independente ou dependente do contexto. No primeiro caso, a relação grafema-fonema é sempre a mesma (<pato> = /pato/); no segundo, a representação sonora muda conforme a relação do grafema com os demais grafemas da palavra (<casa $>=/$ casa $/$; $<$ cesta $>=/$ cesta/). Esta conversão dependente do contexto é considerada regular por possuir regras claras e precisas. Por outro lado, palavras irregulares são aquelas cujas relações grafofonêmicas são ambíguas. No português, apenas as seguintes relações grafema-fonemas são irregulares : $\langle x\rangle-x a d r e z$, fixo, máximo e exame; $<\mathrm{e}>\mathrm{e}<\mathrm{o}>$ em posição paroxítona tônica (Lecours e Parente, 1997). 
De acordo com o balanceamento descrito, foram utilizadas 96 palavras, constituídos 12 grupos:

1 - alta freqüência, 4 grafemas, CVCV, regular: casa, galo, sapo, boné, pato, rato, vaca, vaso.

2 - alta freqüência, 4 grafemas, CVCV, irregular: bola, mesa, bolo, lixo, boca, rosa, dedo.

3 - alta freqüência, 6 grafemas, CVCVCV, regular: cavalo, girafa, sapato, macaco, jacaré, menino, menina, mágico.

4 - alta freqüência, 6 grafemas, CVCVCV, irregular: boneca, janela, raposa, cabeça.

5 - alta freqüência, extensão variável, outras estruturas, regular: livro, prato, braço, lápis, nuvem, gravata, ônibus, árvore, vestido, elefante, laranja.

6 - alta frequiência, extensão variável, outras estruturas, irregular: cobra, porta, corpo, igreja, estrela, caderno.

7 - baixa freqüiência, 4 grafemas, CVCV, regular: sofá, faca, laço, maçã, fita, jipe, taça.

8 - baixa freqüência, 4 grafemas, CVCV, irregular: bota, seta, pote, foca, táxi, selo, lobo.

9 - baixa freqüência, 6 grafemas, CVCVCV, regular: banana, barata, batata, tomate, cabide, camisa, coruja, cálice, casaco, pirata.

10 - baixa freqüência, 6 grafemas, CVCVCV, irregular: bexiga, tigela, xícara, cabelo, caneta, cebola, cereja, colete, panela, gaveta.

11 - baixa freqüência, extensão variável, outras estruturas, regular: grilo, metrô, tigre, tampa, cabrito, óculos, escada, lagarto, morango, melancia.

12 - baixa freqüência, extensão variável, outras estruturas, irregular: cofre, prego, zebra, porco, torta, frigideira, escova, martelo.

As palavras escritas foram caracterizadas por letras impressas em negrito, fonte Microsoft Sans Serif e tamanho 40. As palavras foram localizadas no centro da tela (fundo branco) de um computador e apresentadas isoladamente. A criança foi instruída a ler a palavra escrita em voz alta assim que esta aparecesse na tela.

Como acerto, considerou-se a leitura realizada de forma ortográfica, segundo Frith (1985). Os outros tipos de leitura foram classificados de acordo com os critérios propostos por Salles e Parente (2002). 
1 - Neologismo: a resposta da criança gera uma não-palavra ou uma pseudopalavra diferente do estímulo alvo (ex.: prego lido como /brego/).

2 - Regularização: a pronúncia grafema-fonema irregular de uma palavra é substituída por uma pronúncia regular (táxi lido como /táchi/).

3 - Desconhecimento da regra ortográfica: pronúncias incorretas devido ao desconhecimento de certas regras contextuais da língua (casa lido como /cassa/).

4 - Desconhecimento da regra de acentuação: a pronúncia da palavra não leva em conta as regras de acentuação (cálice lido como /calíce/).

5 - Paralexia verbal formal: substituição lexical mantendo uma semelhança de estrutura de letras, sem relação semântica (batata lida como /barata/).

6 - Lexicalização: uma pseudopalavra é lida como uma palavra real, mantendo relações de semelhança formal (exercício lido como /azercico/). Neste estudo, é impossível a ocorrência deste tipo de leitura, pois não foram utilizadas pseudopalavras, mas apenas palavras reais.

7- Não resposta: quando não foi enunciada nenhuma pronúncia ao estímulo apresentado ou foram produzidas frases como "não sei" ou outras que invalidavam a análise da leitura.

Prova de nomeação de figuras - teve como objetivo a atribuição de um nome à figura apresentada.

As figuras desta prova são equivalentes às palavras da prova de leitura. As 96 figuras foram selecionadas de um total de 400 figuras Cycowicz et al. (1997) e de sites de imagens na Internet (Google) e podem ser visualizadas no anexo $\mathrm{H}$. As figuras foram constituídas por traçado preto e fundo branco e apresentavam, em média, tamanho de $5 \mathrm{~cm} \times 5 \mathrm{~cm}$. Assim como as palavras escritas, foram apresentadas isoladamente no centro na tela do computador e a criança foi instruída a atribuir oralmente um nome à figura assim que esta aparecesse na tela. 
Cada nome corretamente atribuído à figura recebeu 1 ponto e erros 0 ponto, classificados de acordo com os critérios de Kohn e Goodglass, (1985):

1 - Perceptuais (ex.: /porta/ para casa).

2 - Semânticos (ex.: /pêssego/ para cereja).

3 - Fonológicos com palavra real (ex.: /faca/ para vaca).

4 - Fonológicos com uma não palavra (ex.: /malancia/ para melancia).

5 - Semânticos e Perceptuais (ex.: /panela/ para frigideira).

6 - Fonológicos e Perceptuais (ex.: /camisa/ para casaco).

7 - Semânticos e Fonológicos (ex.: /pato/ para gato).

8 - Perceptuais, Semânticos e Fonológicos (ex.: /galinha/ para galo).

9 - Circunlocução (ex.: função, descrição).

10 - Resposta parcial (ex.: /gidera/ para frigideira).

11 - Não resposta (ex.: não sei).

Durante a análise das respostas nas provas de leitura e de nomeação, foram criadas, pela pesquisadora, mais duas classificações:

1 - Revisão: quando a criança dava uma resposta diferente da esperada e logo após corrigia, dando a resposta adequada. Por exemplo, para a palavra /barata/ na leitura, a criança leu /barrata/ e logo após, /barata/.

2 - Erros de produção: quando a criança deu a resposta esperada, mas ocorreram fragmentações, repetições e/ou prolongamentos de fonemas ou sílabas. Por exemplo, ao ler /igreja/, produziu /i-gre-ja/. A resposta foi considerada como correta e este tipo de erro foi analisado dentro do total de acertos.

A ordem dos elementos em cada prova foi aleatória. Como as provas são extensas, cada uma foi dividida em 3 partes, a fim de evitar cansaço por parte dos sujeitos. Além dos 32 elementos contidos em cada parte, foram inicialmente inseridos 5 elementos (palavras escritas ou figuras) com o objetivo de oferecer explicações e treino para os 
sujeitos. A apresentação das provas foi aleatória, ora a de leitura ocorrendo inicialmente ora a de nomeação.

Para a aplicação de todas as provas, a criança foi posicionada de frente para a tela do computador e o microfone foi fixado à sua blusa. A avaliação foi realizada na própria escola, em uma sala destinada à pesquisa.

Os estímulos foram apresentados na tela do computador e a passagem de um estímulo ao outro ocorria por meio do pressionamento do mouse, realizado pela avaliadora.

Cada prova foi aplicada em dias diferentes, a fim de evitar contaminação de uma prova em outra. Assim, cada criança foi avaliada no mínimo duas vezes. O intervalo entre a aplicação de uma prova e outra foi de 1 semana.

\subsubsection{Descrição do programa computacional}

O tempo de processamento da palavra escrita e da figura é constituído por duas medidas: o tempo de latência e o tempo de duração da emissão oral. O tempo de latência é o tempo entre a apresentação do estímulo e o início da produção oral. O tempo de duração da emissão oral é considerado o tempo entre o início e o final da produção da palavra.

Para a obtenção das medidas do tempo de processamento, foi desenvolvido um programa especialmente para esta pesquisa elaborado pela pesquisadora e por Pasquini (2004), no Departamento de Engenharia da Computação, na Universidade de Campinas (SP). O sistema utilizado para a criação do programa foi o JAVA, uma programação muito utilizada atualmente.

As figuras 3 a 8 mostram o funcionamento ou ativação do programa computacional. 
A janela inicial (figura 3) apresenta 5 botões: Novo Aluno, Testes, Análise dos Resultados, Análise dos Resultados- 2 e Análise dos Resultados- 3. Ao pressionar cada um dos botões, abrem-se outras janelas com maior especificidade.

Novo aluno: cadastramento, dá origem à janela Cadastrar Novo Aluno.

Testes: iniciar os testes, provas de leitura, nomeação e decisão lexical, dá origem à janela Executar testes.

Análise dos Resultados: análise da onda acústica produzida pela fala da criança nas provas e para cada palavra; análise dos resultados 2 e 3 referemse a caixas independentes para os juizes; dá origem à janela Análise dos Resultados.

Figura 3. Programa computacional - Janela Inicial

\begin{tabular}{|c||c|c|}
\hline Sempo de Latência & \\
\hline Novo Aluno & Testes & Analise dos Resultados \\
\hline \hline Analise dos Resultados - 2 & Analise dos Resultados - 3 & \\
\hline \hline
\end{tabular}

Na janela Cadastrar Novo Aluno (figura 4), é realizado o cadastro de cada sujeito, nome, idade e série escolar, sendo atribuído a este um número fixo de identificação (na ID). 
Figura 4. Programa computacional -Cadastro Novo Aluno

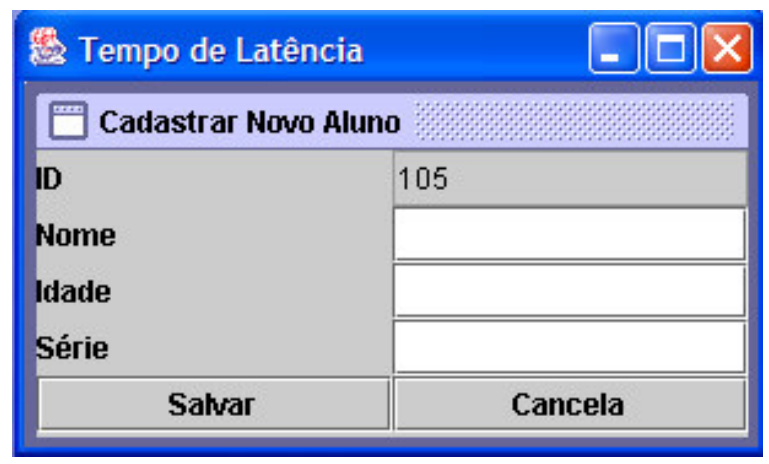

Na janela Executar Testes (figura 5) pode-se acionar os botões das provas de leitura, nomeação e decisão lexical e iniciar o teste. Em cada prova, os estímulos são apresentados no centro da tela e a passagem de um estímulo para o seguinte ocorre com o pressionamento do mouse pelo examinador. O Ok em cada prova indica que esta já foi aplicada para o aluno.

Figura 5. Programa computacional- Executar Testes

\begin{tabular}{|c|c|c|c|c|}
\hline \multicolumn{4}{|c|}{ Tempo de Latência } & $-1 \times x$ \\
\hline \multicolumn{5}{|c|}{ Executar Testes Aluno } \\
\hline \multirow{3}{*}{$\begin{array}{l}\text { ID } \\
\text { Nome } \\
\text { Idade }\end{array}$} & 4 & Leitura $10 \mathrm{~K}$ & Leitura $2 \mathrm{OK}$ & Leitura $30 \mathrm{OK}$ \\
\hline & C.N. M. & Nomeação $10 K$ & Nomeação $20 K$ & Nomeação $3 \mathrm{OK}$ \\
\hline & 8 anos & Lexical $10 \mathrm{~K}$ & Lexical $2 \mathrm{OK}$ & Lexical 3 OK \\
\hline \multirow{2}{*}{$\begin{array}{l}\text { Série } \\
\text { Pasta }\end{array}$} & $2 a$ & Atualizar & $\ll$ & $\gg$ \\
\hline & ALUNO004 & & Procurar & Sair \\
\hline
\end{tabular}

Durante a aplicação das provas, o programa é capaz de capturar os sinais emitidos pelo microfone acoplado ao computador e as bibliotecas de som convertem os sinais elétricos em valores. Estes valores são tratados e a curva referente à produção da criança é desenhada. Formam-se bancos de vozes dentro do programa. Na janela 
Análise dos Resultados (figura 6) é possível acionar o sistema de análise para cada uma das provas já realizadas pelo sujeito.

Figura 6. Programa computacional - Execução do sistema de análise

\begin{tabular}{|c|c|c|c|c|}
\hline \multicolumn{4}{|c|}{ Sempo de Latência } & $-\square x$ \\
\hline \multicolumn{5}{|c|}{ Analise dos Resultados } \\
\hline ID & 4 & \multicolumn{2}{|c|}{ Leitura } & Analise efetuada! \\
\hline Nome & C.N.M. & \multicolumn{2}{|c|}{ Nomeacao } & Analise efetuada! \\
\hline Idade & 8 anos & \multicolumn{2}{|c|}{ Lexical } & Analise efetuada! \\
\hline S?rie & $2 \mathrm{~b}$ & & & Procurar \\
\hline Pasta & ALUNO004 & $\ll$ & $\gg$ & Sair \\
\hline
\end{tabular}

Na janela Análise (figura 7), a onda de cada emissão oral é visualizada. Ao ser acionado o botão PLAY, pode-se ouvir a emissão do sujeito e visualizar a onda que a representa. Ao mesmo tempo, um marcador (linha vertical) é deslocado sobre a onda para auxiliar a visualização do início da resposta. Duas linhas podem, então, ser deslocadas manualmente e fixadas pelo pesquisador no ponto que marca o início e o final da vocalização (por meio do mouse), indicando, respectivamente, o tempo de latência e o tempo total do processamento. Cálculos são realizados pelo programa para obter o tempo de duração da emissão oral (tempo total menos o tempo de latência). Estes valores são registrados automaticamente quando o botão SALVAR é pressionado. O botão PRÓXIMO permite a visualização da onda referente ao estímulo seguinte. 
Figura 7. Programa computacional - Sistema de análise

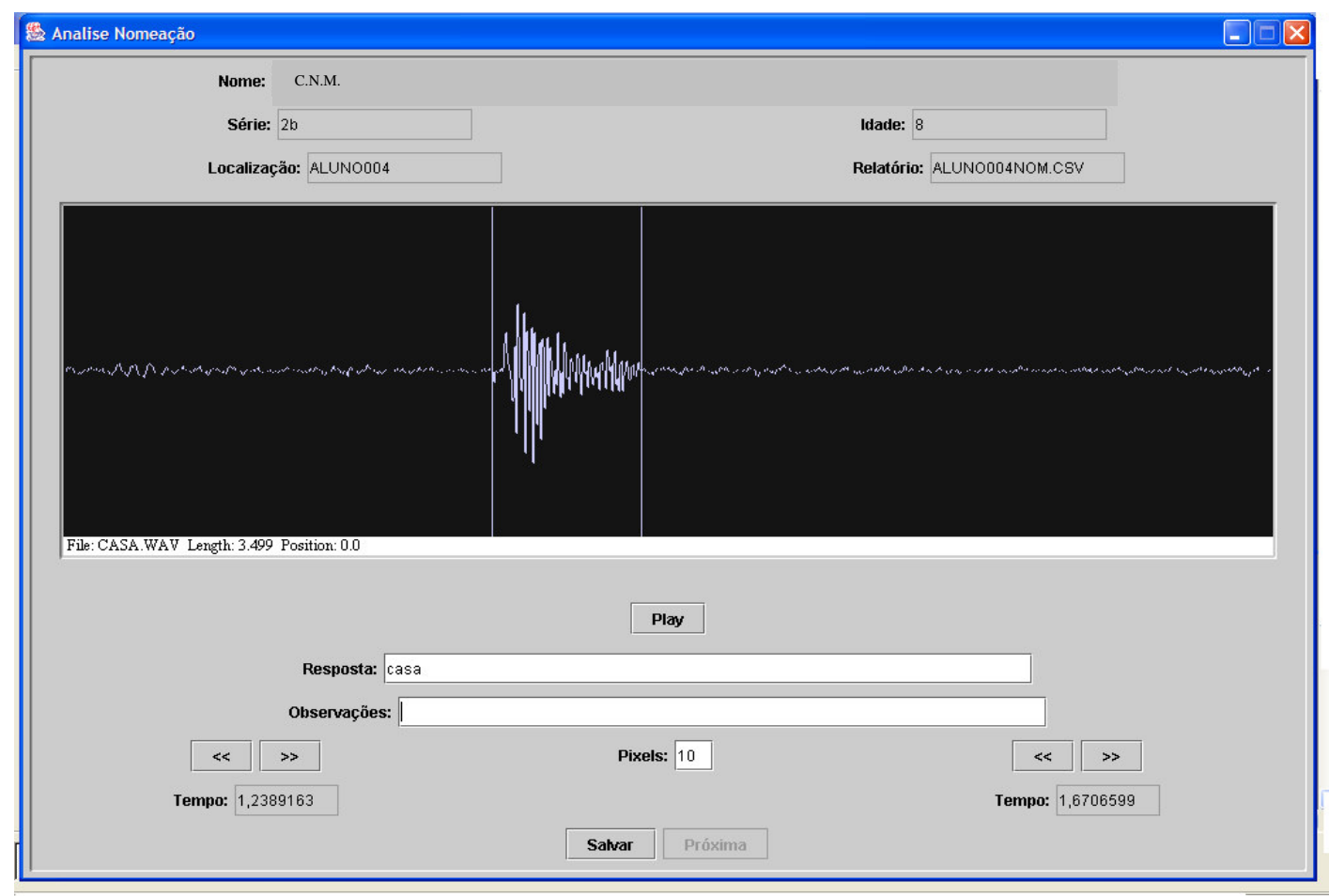

Os dados obtidos na análise ficam armazenados em arquivos individuais e podem ser acessados no Programa Excel (figura 8) que está conectado ao programa computacional. Cada arquivo contém os dados pessoais previamente cadastrados (nome, idade e série escolar), os tempos obtidos (latência, produção e total), a resposta produzida pela criança e eventuais observações. 
Figura 8. Programa computacional - Arquivos individuais dos dados

\begin{tabular}{|llll|}
\hline Aluno & B. M. R. \\
Série & $2 \mathrm{a}$ & \\
Idade & 8 anos \\
Pasta & ALUNO022 & \\
& & \\
Resultados Análise Leitura & \\
Palavra & Tempo de Latência Tempo Total Tempo de Produção Resposta Observações \\
CASA & 0,788709 & 1,499915 & 0,711206 \\
GALO & 0,978296 & 1,660529 & 0,682233 \\
SAPO & 0,785211 & 1,712018 & 0,926807 \\
BONÉ & 0,814106 & 1,412619 & 0,598513 \\
PATO & 1,019099 & 1,696799 & 0,677701 \\
\hline
\end{tabular}

O programa foi utilizado em um computador portátil com as seguintes configurações: marca HP Pavilion, modelo ze5200, processador Pentium 4, 2.4 Ghz, 512 de memória, 40 Gb, CDRW, matriz ativa 15”, rede 10/100, sistema operacional Windows XP Home; microfone Bright.

\subsubsection{Participação de juízes}

Como as medidas do tempo de processamento não foram obtidas automaticamente, mas analisadas pela pesquisadora posicionando o mouse no inicio da onda, foram necessários mais dois juizes para garantir a fidedignidade os dados.

Para selecionar os juizes, adotou-se o método proposto por Haddad (2004). Cada sujeito recebeu um número, 1 a 74 (1 a 25 para $2^{\text {a }}$ série, 26 a 49 para $3^{\text {a }}$ e 50 a 74 para a 4 a). O autor apresenta uma 
tabela de números aleatórios, retirada de Fischer e Yates (1971) (anexo I), método alternativo ao sorteio. Nesta tabela, os números podem ser selecionados na seqüência em que aparecem, seguindo-se a linha vertical ou horizontal. São incluídos os números que se apresentam dentro da amostra, ou seja, de 1 a 74 . Guando o número é superior 74 ou se repete, passa-se ao número seguinte da linha.

Para esta pesquisa, os sujeitos (10\% da amostra de cada série) foram selecionados da seqüência de números aleatórios dispostos horizontalmente, nesta tabela. Os números obtidos foram 3, 16 e 11 ( $2^{\mathrm{a}}$ série), 42, 32 e 37 ( $3^{\text {a }}$ série), 51, 73 e 62 (4ª série).

Os dados dos sujeitos correspondentes aos números obtidos foram entregues aos juízes. Os procedimentos foram explicados e os juízes analisaram, individualmente, o tempo de processamento (latência e de duração da emissão oral) para cada uma das provas e para cada uma das palavras e/ figuras.

Os resultados foram analisados estatisticamente (ANOVA), para concordância entre as 3 análises (juíz 1- pesquisadora, juíz 2 e juíz $3)$. 


\subsection{Características das amostras}

\subsubsection{Crianças leitoras}

As características referentes à idade, gênero e perfil sócioeconômico-familiar (ABIPEME, Almeida e Wickerhauser, 1991) das crianças leitoras podem ser observadas nas tabelas 1, 2 e 3, respectivamente.

Tabela 1. Distribuição das crianças leitoras por idade (em meses)

\begin{tabular}{ccccc}
\hline & \multicolumn{4}{c}{ Séries } \\
\cline { 2 - 5 } & $\mathbf{2}^{\mathbf{a}}$ & $\mathbf{3}^{\mathbf{a}}$ & $\mathbf{4}^{\mathbf{a}}$ & Total \\
\hline Média & 103,28 & 114,58 & 128,64 & 115,51 \\
Desvio padrão & 3,96 & 5,78 & 7,89 & 12,11 \\
$\mathbf{n}$ & 25 & 24 & 25 & 74 \\
\hline
\end{tabular}

Tabela 2. Distribuição das crianças leitoras por gênero

\begin{tabular}{|c|c|c|c|c|c|c|c|c|c|}
\hline & \multicolumn{6}{|c|}{ Séries } & \multirow{2}{*}{\multicolumn{2}{|c|}{ Total }} \\
\hline & & \multicolumn{2}{|r|}{$2^{a}$} & \multicolumn{2}{|c|}{$\mathbf{3}^{\mathbf{a}}$} & \multicolumn{2}{|r|}{$4^{a}$} & & \\
\hline & & $\mathbf{n}$ & $\%$ & $\mathbf{n}$ & $\%$ & $\mathbf{n}$ & $\%$ & $\mathbf{n}$ & $\%$ \\
\hline \multirow{3}{*}{ gênero } & Feminino & 13 & $52,0 \%$ & 12 & $50,0 \%$ & 14 & $56,0 \%$ & 39 & $52,7 \%$ \\
\hline & Masculino & 12 & $48,0 \%$ & 12 & $50,0 \%$ & 11 & $44,0 \%$ & 35 & $47,3 \%$ \\
\hline & Total & 25 & $100,0 \%$ & 24 & $100,0 \%$ & 25 & $100,0 \%$ & 74 & $100,0 \%$ \\
\hline
\end{tabular}

Tabela 3. Distribuição das crianças leitoras por classe sócio-econômico-familiar

\begin{tabular}{|c|c|c|c|c|c|c|c|c|c|}
\hline & & \multicolumn{6}{|c|}{ Séries } & \multirow{2}{*}{\multicolumn{2}{|c|}{ Total }} \\
\hline & & \multicolumn{2}{|r|}{$2^{\mathbf{a}}$} & \multicolumn{2}{|c|}{$\mathbf{3}^{\mathbf{a}}$} & \multicolumn{2}{|r|}{$4^{a}$} & & \\
\hline & & $\mathbf{N}$ & $\%$ & $\mathbf{N}$ & $\%$ & $\mathbf{N}$ & $\%$ & $\mathbf{N}$ & $\%$ \\
\hline \multirow{5}{*}{ ABIPEME } & $\mathbf{A}$ & & & & & 1 & $4,0 \%$ & 1 & $1,4 \%$ \\
\hline & B & 10 & $40,0 \%$ & 7 & $29,2 \%$ & 6 & $24,0 \%$ & 23 & $31,1 \%$ \\
\hline & C & 13 & $52,0 \%$ & 12 & $50,0 \%$ & 13 & $52,0 \%$ & 38 & $51,4 \%$ \\
\hline & D & 2 & $8,0 \%$ & 5 & $20,8 \%$ & 2 & $8,0 \%$ & 9 & $12,2 \%$ \\
\hline & $\mathbf{E}$ & & & & & 3 & $12,0 \%$ & 3 & $4,1 \%$ \\
\hline Total & & 25 & $100,0 \%$ & 24 & $100,0 \%$ & 25 & $100,0 \%$ & 74 & $100,0 \%$ \\
\hline
\end{tabular}

A: classe alta; B: classe média; C: classe média baixa; D: classe baixa; E: classe muito baixa 
Como apontam os dados das tabelas anteriores, aproximadamente $50 \%$ das crianças de cada classe são do gênero masculino e 50\% do feminino. A maior concentração de sujeitos encontra-se na classe sócio-econômico-familiar C (classe média baixa). Observa-se, também, um número considerável de sujeitos pertencentes à classe B (média).

\subsubsection{Crianças não leitoras}

As características das crianças não leitoras referentes à idade e gênero encontram-se na tabela 4 e as relacionadas à distribuição por classe sócio-econômico-familiar, na tabela 5.

Tabela 4 - Distribuição das crianças não leitoras por idade (em meses) e gênero

\begin{tabular}{cc}
\hline & Idade (meses) \\
\hline Média & 99,05 \\
Desvio-padrão & 4,11 \\
Feminino & $35,0 \%(\mathrm{n}=7)$ \\
Masculino & $65,0 \%(\mathrm{n}=13)$ \\
\hline
\end{tabular}

Tabela 5 - Distribuição das crianças não leitoras por classe sócio-econômicofamiliar

\begin{tabular}{llcc}
\hline & & \multicolumn{2}{c}{ Não leitores } \\
\hline & classes & $\mathbf{n}$ & $\mathbf{\%}$ \\
\hline & A & 0 & 0 \\
B & 2 & 10 \\
& C & $\mathbf{1 0}$ & $\mathbf{5 0}$ \\
& D & $\mathbf{7}$ & $\mathbf{3 5}$ \\
& E & 1 & 5 \\
\hline Total & & 20 & $100,0 \%$ \\
\hline
\end{tabular}

A: classe alta; B: classe média; C: classe média baixa; D: classe baixa; E: classe muito baixa

A idade das crianças não leitoras (99,05 meses) não difere das leitoras de $2^{\text {a }}$ série $(103,28$ meses) $(p>0,005)$. Na amostra de não leitores, a porcentagem de meninos é maior, o que está de acordo com a 
literatura, que aponta maior freqüência de alterações de leitura e escrita no gênero masculino (Snowling, 2004). Os dados da escala ABIPEME demonstram que $50 \%$ das crianças não leitoras pertencem à classe sócio-econômica $\mathrm{C}$, dado semelhante ao das crianças leitoras de $2^{\text {a }}$ série.

Na tabela 6, a seguir, podem ser observados os percentis dos testes aplicados (vocabulário e cubos- WISC-III, Weschler, 1981) para a obtenção do quociente de inteligência e as respectivas categorias, que dão informações qualitativas sobre o desempenho do sujeito (muito superior, superior, média superior, média, média inferior, limítrofe e retardo mental).

Tabela 6. Percentis e categorias referentes aos sub-testes vocabulário e cubos e ao QI estimado (WISC-III, Weschler, 1981)

\begin{tabular}{|c|c|c|c|c|c|c|}
\hline \multirow[b]{2}{*}{ Sujeitos } & \multicolumn{2}{|c|}{ Vocabulário } & \multicolumn{2}{|c|}{ Cubos } & \multirow[t]{2}{*}{$\begin{array}{c}\text { QI } \\
\text { estimado }\end{array}$} & \multirow[t]{2}{*}{ Categoria } \\
\hline & Percentil & Categoria & Percentil & Categoria & & \\
\hline 1 & 63 & $\mathrm{M}$ & 84 & MS & 112 & MS \\
\hline 2 & 75 & MS & 98 & $\mathrm{~m} \mathrm{~S}$ & 123 & $\mathrm{~S}$ \\
\hline 3 & 84 & MS & 99 & $\mathrm{~m} \mathrm{~S}$ & 129 & $\mathrm{~m} \mathrm{~S}$ \\
\hline 4 & 50 & $\mathrm{M}$ & 90 & $\mathrm{~S}$ & 112 & MS \\
\hline 5 & 95 & $\mathrm{~S}$ & 84 & MS & 123 & $\mathrm{~S}$ \\
\hline 6 & 98 & $\mathrm{~m} \mathrm{~S}$ & 84 & MS & 126 & $\mathrm{~S}$ \\
\hline 7 & 99 & $\mathrm{~m} \mathrm{~S}$ & 99 & $\mathrm{~m} \mathrm{~S}$ & 144 & $\mathrm{~m} \mathrm{~S}$ \\
\hline 8 & 50 & M & 75 & MS & 106 & $\mathrm{M}$ \\
\hline 9 & 95 & $\mathrm{~S}$ & 98 & $\mathrm{~m} \mathrm{~S}$ & 132 & $\mathrm{~m} \mathrm{~S}$ \\
\hline 10 & 37 & M & 75 & MS & 103 & M \\
\hline 11 & 99 & $\mathrm{~m} \mathrm{~S}$ & 90 & $\mathrm{~S}$ & 135 & $\mathrm{~m} \mathrm{~S}$ \\
\hline 12 & 90 & $\mathrm{~S}$ & 90 & $\mathrm{~S}$ & 123 & $\mathrm{~S}$ \\
\hline 13 & 75 & MS & 90 & $\mathrm{~S}$ & 117 & MS \\
\hline 14 & 84 & MS & 98 & $\mathrm{~m} \mathrm{~S}$ & 126 & $\mathrm{~S}$ \\
\hline 15 & 75 & MS & 84 & MS & 115 & MS \\
\hline 16 & 95 & $\mathrm{~S}$ & 84 & MS & 123 & $\mathrm{~S}$ \\
\hline 17 & 63 & $\mathrm{M}$ & 95 & $\mathrm{~S}$ & 117 & MS \\
\hline 18 & 95 & $\mathrm{~S}$ & 98 & $\mathrm{~m} \mathrm{~S}$ & 132 & $\mathrm{~m} \mathrm{~S}$ \\
\hline 19 & 98 & $\mathrm{~m} \mathrm{~S}$ & 99 & $\mathrm{~m} \mathrm{~S}$ & 141 & $\mathrm{~m} \mathrm{~S}$ \\
\hline 20 & 90 & $\mathrm{~S}$ & 98 & $\mathrm{~m} \mathrm{~S}$ & 129 & $\mathrm{~m} \mathrm{~S}$ \\
\hline
\end{tabular}

mS- muito superior; S-superior; MS- média superior; M- média; MI- média inferior

A porcentagem de crianças que apresentaram quociente intelectual estimado em cada categoria é: $35 \%(n=7)$ na categoria muito 
superior, 25\% $(n=5)$ na superior, 30\% $(n=6)$ na média superior e $10 \%$ $(n=2)$ na média. Embora o percentil dos sub-testes vocabulário e cubos indiquem categorias de inteligência média ou acima, nota-se que a pontuação obtida em cubos é maior que a do vocabulário, para a maioria as crianças.

Na tabela 7, estão os dados referentes ao quociente intelectual nos sub-testes informação, compreensão, aritmética e semelhanças da escala verbal do WISC-III (Weschler, 1981).

Tabela 7. Percentis e categorias de cada sub-teste da escala verbal de inteligência (WISC-III, Weschler, 1981)

\begin{tabular}{|c|c|c|c|c|c|c|c|c|}
\hline Sujeitos & $\begin{array}{r}\text { Infor } \\
\text { Percenti }\end{array}$ & $\begin{array}{l}\text { mação } \\
1 \text { Categoria }\end{array}$ & $\begin{array}{r}\text { Compr } \\
\text { Percentil }\end{array}$ & $\begin{array}{l}\text { reensão } \\
1 \text { Categoria }\end{array}$ & $\begin{array}{r}\text { Aritm } \\
\text { Percentil }\end{array}$ & $\begin{array}{l}\text { lética } \\
\text { Categoria }\end{array}$ & $\begin{array}{l}\text { Semel } \\
\text { Percer }\end{array}$ & $\begin{array}{l}\text { as } \\
\text { ategoria }\end{array}$ \\
\hline 1 & 50 & $\mathrm{M}$ & 37 & $\mathrm{M}$ & 25 & MI & 37 & $\mathrm{M}$ \\
\hline 2 & 63 & M & 75 & MS & 25 & MI & 95 & $\mathrm{~S}$ \\
\hline 3 & 90 & $\mathrm{~S}$ & 95 & $\mathrm{~S}$ & 16 & MI & 75 & MS \\
\hline 4 & 98 & $\mathrm{~m} \mathrm{~S}$ & 95 & $\mathrm{~S}$ & 63 & $\mathrm{M}$ & 25 & MI \\
\hline 5 & 63 & M & 95 & $\mathrm{~S}$ & 25 & MI & 95 & $\mathrm{~S}$ \\
\hline 6 & 50 & M & 95 & $\mathrm{~S}$ & 63 & $\mathrm{M}$ & 84 & MS \\
\hline 7 & 95 & $\mathrm{~S}$ & 95 & $\mathrm{~S}$ & 84 & MS & 75 & MS \\
\hline 8 & 37 & M & 50 & M & 63 & M & 75 & MS \\
\hline 9 & 84 & MS & 90 & $\mathrm{~S}$ & 90 & $\mathrm{~S}$ & 63 & $\mathrm{M}$ \\
\hline 10 & 25 & MI & 84 & MS & 25 & MI & 37 & $\mathrm{M}$ \\
\hline 11 & 75 & $\mathrm{M}$ & 98 & $\mathrm{~m} \mathrm{~S}$ & 63 & $\mathrm{M}$ & 84 & MS \\
\hline 12 & 75 & $\mathrm{M}$ & 98 & $\mathrm{~m} \mathrm{~S}$ & 63 & $\mathrm{M}$ & 84 & MS \\
\hline 13 & 63 & $\mathrm{M}$ & 99 & $\mathrm{~m} \mathrm{~S}$ & 25 & MI & 63 & $\mathrm{M}$ \\
\hline 14 & 25 & MI & 63 & $\mathrm{M}$ & 37 & $\mathrm{M}$ & 84 & MS \\
\hline 15 & 25 & MI & 75 & MS & 25 & MI & 37 & M \\
\hline 16 & 75 & MS & 98 & $\mathrm{~m} \mathrm{~S}$ & 84 & MS & 75 & MS \\
\hline 17 & 25 & MI & 90 & $\mathrm{~S}$ & 25 & MI & 25 & MI \\
\hline 18 & 75 & MS & 98 & $\mathrm{~m} \mathrm{~S}$ & 63 & M & 84 & MS \\
\hline 19 & 75 & MS & 98 & $\mathrm{~m} \mathrm{~S}$ & 63 & M & 84 & MS \\
\hline 20 & 37 & $\mathrm{M}$ & 95 & $\mathrm{~S}$ & 25 & MI & 37 & $\mathrm{M}$ \\
\hline
\end{tabular}

mS- muito superior; S- superior; MS- média superior; M- média; MI- média inferior

De acordo os dados da tabela 7, o desempenho das crianças não leitoras concentra-se nas categorias: média (para o sub-teste informação), superior (para compreensão), média e média inferior (para aritmética) e média superior (para semelhanças). 
As informações dadas pelos professores acerca da presença de sinais de dislexia (IDA, 2000) nos sujeitos não leitores são apresentadas na tabela 8 abaixo:

Tabela 8. Caracterização das crianças não leitoras segundo os sinais de Dislexia propostos pela Associação Internacional de Dislexia (IDA, 2000)

Sinais disléxicos observáveis na $2^{a}$ série $\%$ de

1. Lentidão na associação grafema-fonema alunos

2. Dificuldade na decodificação de palavras simples (leitura isolada de palavras simples)

. Dificuldade na soletração oral

4. Apóia-se em adivinhação e no contexto

5. Dificuldade para aprender novo vocabulário

6. Substituição de números de uma seqüência ou confusão com sinais aritméticos $(+-\mathrm{x} /=)$.

7. Dificuldade para relembrar fatos

8. Lentidão para aprender novas habilidades; tenta memorizar sem entender

9. Dificuldade em planejamento, organização e administração do tempo, materiais e tarefas

10. Segura o lápis de forma diferente

11. Dificuldade na coordenação motora fina (cortar papel, utilizar régua)

Observou-se que todas as crianças apresentam dificuldades na associação grafema-fonema, na decodificação de palavras e na soletração. Os outros sinais não estão presentes em todas as crianças. 
6. RESULTADOS 


\section{RESULTADOS}

Inicialmente, os resultados apresentados referem-se à
concordância entre juízes para as duas medidas do tempo de processamento, na amostra de leitores: tempo de latência e tempo de duração da emissão oral, nas provas de leitura e de nomeação.

São apresentados, posteriormente, resultados estatísticos referentes à comparação entre os tipos de estímulos e entre as séries, a correlação entre tempo e acerto, a comparação entre nomeação e leitura e entre as amostras de leitores e não leitores. O programa registra o tempo de processamento em milissegundos, com precisão de 8 casas decimais. Esta medida foi considerada na análise estatística, porém os resultados são apresentados na forma de segundos, para facilitar a visualização dos dados nas tabelas.

Para a análise estatística dos dados, foram utilizados os testes ANOVA e o coeficiente de correlação de Pearson (Maxwell e Saake, 1997).

O teste de ANOVA (Análise de Variância) é indicado para comparar três ou mais grupos de informações com nível de mensuração numérica, as amostras são independentes e/ou pareadas e deseja-se saber se, em médias, os grupos são diferentes. Pode-se testar mais de um efeito com um único modelo. O nível de significância dos testes foi de $5 \%$.

O coeficiente de correlação de Pearson (c) é um valor entre -1 e 1, que mede o grau de associação entre duas variáveis de mensuração numérica. Quanto mais próximo de -1 ou de 1 , maior o grau de associação entre as informações. Quanto mais próximo de 0 (zero), menor o grau de associação. Se o valor do coeficiente for menor que 0 , considera-se que a associação é negativa ou inversa, ou seja, quando uma informação aumenta o valor, a outra diminui. Se o valor 
do coeficiente for maior que 0 , considera-se que a associação é positiva ou direta, ou seja, quando uma informação aumenta o valor, a outra também aumenta. Determinar o valor que define uma boa correlação é inerente de cada estudo, mas de forma geral, pode-se considerar a seguinte classificação:

Se | c | 0,40 significa correlação fraca; se 0,40< | c | < 0,70 significa correlação moderada; se $0,70<1$ c $1<0,90$ significa correlação boa; se I c | > 0,90 significa correlação ótima.

\subsection{Análise de concordância entre juizes para o tempo de processamento}

Os dados estatísticos referentes à concordância entre os juízes para o tempo de latência nas provas de leitura e de nomeação encontram-se na tabela 9 e, para o tempo de duração da emissão oral, na tabela 10.

\begin{tabular}{lcc}
\multicolumn{2}{c}{ Tabela 9-Concordância para tempo de latência para a leitura e nomeação } \\
\hline Efeito & leitura & nomeação \\
\hline Palavra & $<0,0001^{*}$ & $<0,0001^{*}$ \\
Juiz & 0,1642 & $<0,0001^{*}$ \\
Palavra x juiz & 0,9449 & 0,0667 \\
\hline \multicolumn{1}{c}{ p<0.05* } & &
\end{tabular}

\begin{tabular}{|c|c|c|}
\hline Efeito & leitura & nomeação \\
\hline Palavra & $<0,0001 *$ & $<0,0001 *$ \\
\hline Juiz & 0,9314 & 0,9383 \\
\hline Palavra $\mathrm{x}$ juiz & 0,8223 & 0,9389 \\
\hline
\end{tabular}

$\mathrm{Na}$ leitura e na nomeação, houve diferença significante entre as palavras, mas não houve entre os juízes e tampouco na interação. Esse resultado mostra que o grau de concordância entre os juízes foi muito bom e o tempo medido foi uniforme entre eles. 


\subsection{Crianças leitoras}

\subsubsection{Prova de leitura de palavras}

\subsubsection{Tempo de latência}

Apresentam-se a seguir os resultados referentes à média e desvio-padrão para o tempo de latência (em segundos) na prova de leitura (tabela 11).

Tabela 11. Média e desvio padrão em cada grupo de palavra e série para o tempo de latência (seg) na leitura de palavras

\begin{tabular}{lcccc}
\hline & \multicolumn{4}{c}{ séries } \\
\cline { 2 - 5 } Tipos de palavra & $\mathbf{2}^{\text {a }}$ & $\mathbf{3}^{\mathbf{a}}$ & $\mathbf{4}^{\mathbf{a}}$ & Total \\
\hline $\mathrm{AF}, 4 \mathrm{G}, \mathrm{CV}, \mathrm{R})$ & $\mathrm{M}(\mathrm{DP})$ & $\mathrm{M}(\mathrm{DP})$ & $\mathrm{M}(\mathrm{DP})$ \\
\hline $\mathrm{AF}, 4 \mathrm{G}, \mathrm{CV}, \mathrm{I}$ & $1,20(0,35)$ & $1,06(0,46)$ & $1,10(0,45)$ & $1,12(0,42)$ \\
\hline $\mathrm{AF}, 6 \mathrm{G}, \mathrm{CV}, \mathrm{R}$ & $1,22(0,41)$ & $1,20(0,58)$ & $1,15(0,43)$ & $1,19(0,47)$ \\
\hline $\mathrm{AF}, 6 \mathrm{G}, \mathrm{CV}, \mathrm{I}$ & $1,28(0,44)$ & $1,22(0,54)$ & $1,29(0,60)$ & $1,26(0,53)$ \\
\hline $\mathrm{AF}, 5 \mathrm{e}+\mathrm{G}, \mathrm{OE}, \mathrm{R}$ & $1,27(0,37)$ & $1,14(0,41)$ & $1,16(, 45)$ & $1,19(0,41)$ \\
\hline $\mathrm{AF}, 5 \mathrm{e}+\mathrm{G}, \mathrm{OE}, \mathrm{I}$ & $1,44(0,74)$ & $1,26(0,57)$ & $1,30(0,64)$ & $1,34(0,65)$ \\
\hline $\mathrm{BF}, 4 \mathrm{G}, \mathrm{CV}, \mathrm{R}$ & $1,09(0,25)$ & $1,24(0,61)$ & $1,17(0,51)$ & $1,17(0,48)$ \\
\hline $\mathrm{BF}, 4 \mathrm{G}, \mathrm{CV}, \mathrm{I}$ & $1,28(0,42)$ & $1,26(0,58)$ & $1,19(0,55)$ & $1,24(0,51)$ \\
\hline $\mathrm{BF}, 6 \mathrm{G}, \mathrm{CV}, \mathrm{R}$ & $1,41(0,56)$ & $1,33(0,64)$ & $1,34(0,57)$ & $1,36(0,58)$ \\
\hline $\mathrm{BF}, 6 \mathrm{G}, \mathrm{CV}, \mathrm{I}$ & $1,50(0,62)$ & $1,39(0,65)$ & $1,31(0,58)$ & $1,40(0,61)$ \\
\hline $\mathrm{BF}, 5 \mathrm{e}+\mathrm{G}, \mathrm{OE}, \mathrm{R}$ & $1,35(0,50)$ & $1,30(0,52)$ & $1,31(0,61)$ & $1,32(0,54)$ \\
\hline $\mathrm{BF}, 5$ e +G, OE, I & $1,41(0,52)$ & $1,46(0,82)$ & $1,32(0,58)$ & $1,40(0,64)$ \\
\hline
\end{tabular}

$\mathrm{AF}$ : alta freqüência; $\mathrm{BF}$ : baixa freqüência; G: grafemas; CV:consoante-vogal;

OE: outras estruturas; R: regular; I:irregular; M: média; DP: desvio-padrão

Na tabela acima, observou-se diferença no tempo de latência entre os grupos de palavras e entre as séries. A comparação detalhada do tempo de latência entre os tipos de palavras nas três séries escolares é apresentada nas figuras 9, 10 e 11 e as análises estatísticas das comparações podem ser visualizadas nas tabelas 12, 13 e 14 . 
Figura 9. Tempo de latência para a leitura: alta $x$ baixa freqüência

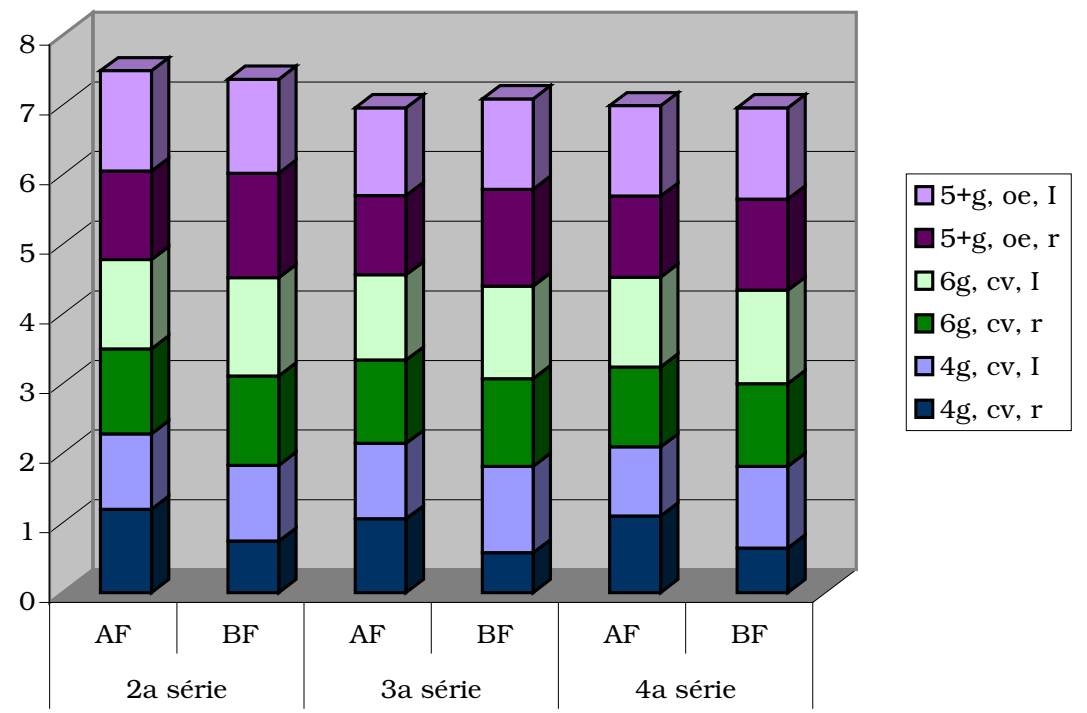

$\mathrm{AF}$ : alta freqüência, BF: baixa freqüência, g: grafemas, oe: outras estruturas, r: regular; i: irregular

Tabela 12. p-valores - comparação do tempo de latência para a leitura: alta $x$ baixa freqüência

\begin{tabular}{|c|c|c|c|}
\hline alta $x$ baixa & \multicolumn{3}{|c|}{ p-valores } \\
\hline freqüência & série & palavra & série $\mathrm{x}$ palavra \\
\hline $4 \mathrm{G}, \mathrm{CV}, \mathrm{R}$ & 0,9915 & 0,1398 & $0,0014 *$ \\
\hline $4 \mathrm{G}, \mathrm{CV}, \mathrm{I}$ & 0,6909 & $<0,0001 *$ & 0,9666 \\
\hline $6 \mathrm{G}, \mathrm{CV}, \mathrm{R}$ & 0,8602 & $<0,0001 *$ & 0,7806 \\
\hline $6 \mathrm{G}, \mathrm{CV}, \mathrm{I}$ & 0,8009 & $0,0018^{*}$ & 0,1672 \\
\hline $5 \mathrm{e}+\mathrm{G}, \mathrm{OE}, \mathrm{R}$ & 0,7694 & $<0,0001 *$ & 0,3723 \\
\hline $5 \mathrm{e}+\mathrm{G}, \mathrm{OE}, \mathrm{I}$ & 0,8051 & 0,2084 & 0,1080 \\
\hline
\end{tabular}

De acordo com os dados da tabela 12, o tempo de latência foi menor para palavras de alta freqüência do que nas de baixa $(p<0,05)$, em todos os tipos de palavra, com exceção das palavras mais simples (4 grafemas, estrutura cv e regular) e das mais complexas (5 e mais grafemas, outras estruturas e irregular). No grupo de palavras mais simples, enquanto a $3^{a}$ e a $4^{a}$ séries apresentaram tempo de latência menor para palavras de alta freqüência e maior para as de baixa, as crianças de $2^{\mathrm{a}}$ série apresentaram o comportamento inverso (interação significante entre série e palavra). 
Figura 10. Tempo de latência para a leitura: regulares $x$ irregulares

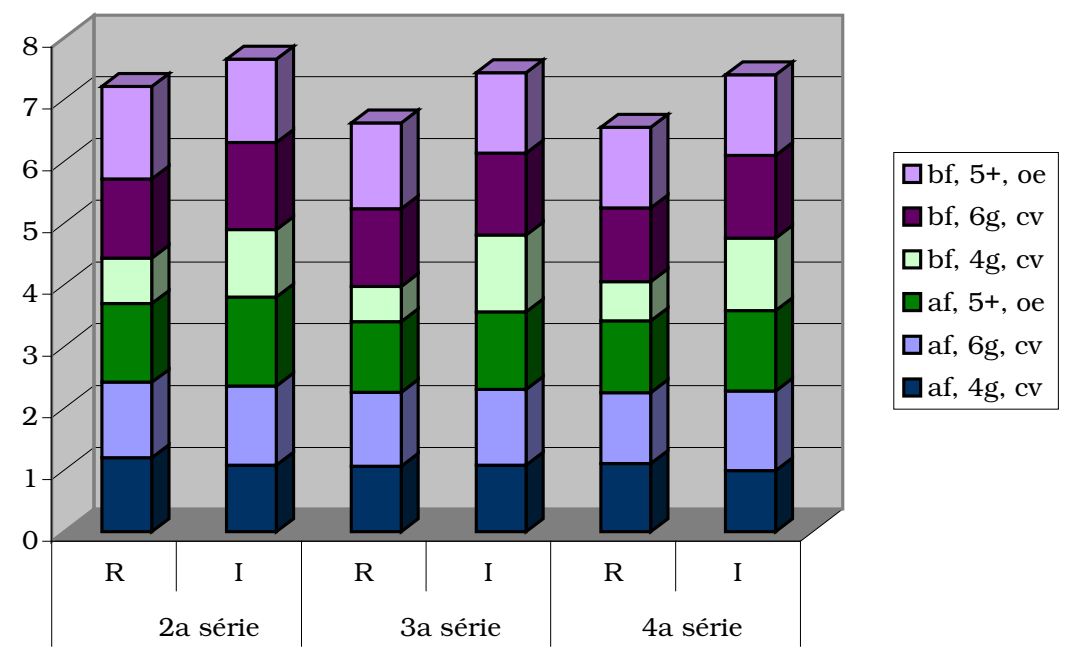

R: regular, I:irregular, af: alta freqüência, bf: baixa freqüência, g:grafemas, cv: consoante-vogal, oe:outras estruturas

Tabela 13. p-valores - comparação do tempo de latência para a leitura: regulares $x$ irregulares

\begin{tabular}{|c|c|c|c|}
\hline \multirow{2}{*}{$\begin{array}{l}\text { regulares } \mathrm{x} \\
\text { irregulares }\end{array}$} & \multicolumn{3}{|c|}{ p-valores } \\
\hline & Série & palavra & série $\mathrm{x}$ palavra \\
\hline $\mathrm{AF}, 4 \mathrm{G}, \mathrm{CV}$ & 0,5862 & 0,0632 & 0,3133 \\
\hline $\mathrm{AF}, 6 \mathrm{G}, \mathrm{CV}$ & 0,9446 & $0,0050 *$ & 0,1939 \\
\hline $\mathrm{AF}, 5 \mathrm{e}+\mathrm{G}, \mathrm{OE}$ & 0,5388 & $0,0006 *$ & 0,9021 \\
\hline $\mathrm{BF}, 4 \mathrm{G}, \mathrm{CV}$ & 0,8648 & $0,0095 *$ & $0,072 *$ \\
\hline $\mathrm{BF}, 6 \mathrm{G}, \mathrm{CV}$ & 0,7074 & $0,0295^{*}$ & $0,0462 *$ \\
\hline $\mathrm{BF}, 5 \mathrm{e}+\mathrm{G}, \mathrm{OE}$ & 0,8823 & $0,0477 *$ & $0,0281 *$ \\
\hline
\end{tabular}

p<0,05* AF: alta freqüência; $\mathrm{BF}$ : baixa freqüência, G: grafemas; $\mathrm{CV}$ : consoante- vogal; OE: outras estruturas

Conforme os dados da tabela 13, as três séries apresentaram tempo de latência maior para as palavras irregulares do que nas regulares, em dois grupos de palavras de alta freqüência (5 ou mais grafemas, estrutura cv e complexas) e em todos os de baixa freqüência.

Nos grupos de baixa freqüência, a interação série x palavra significante indica que as três séries se comportaram diferentemente com relação às palavras: nos grupos com 4 e 6 grafemas e estruturas $\mathrm{cv}$, somente a $2^{\mathrm{a}}$ série apresentou tempo maior para irregulares do que nas regulares; no grupo de palavras de baixa freqüência e mais 
complexas, apenas a $4^{\text {a }}$ série não apresentou diferenças entre palavras regulares e irregulares.

Figura 11. Tempo de latência para a leitura: $4 \times 6$ grafemas

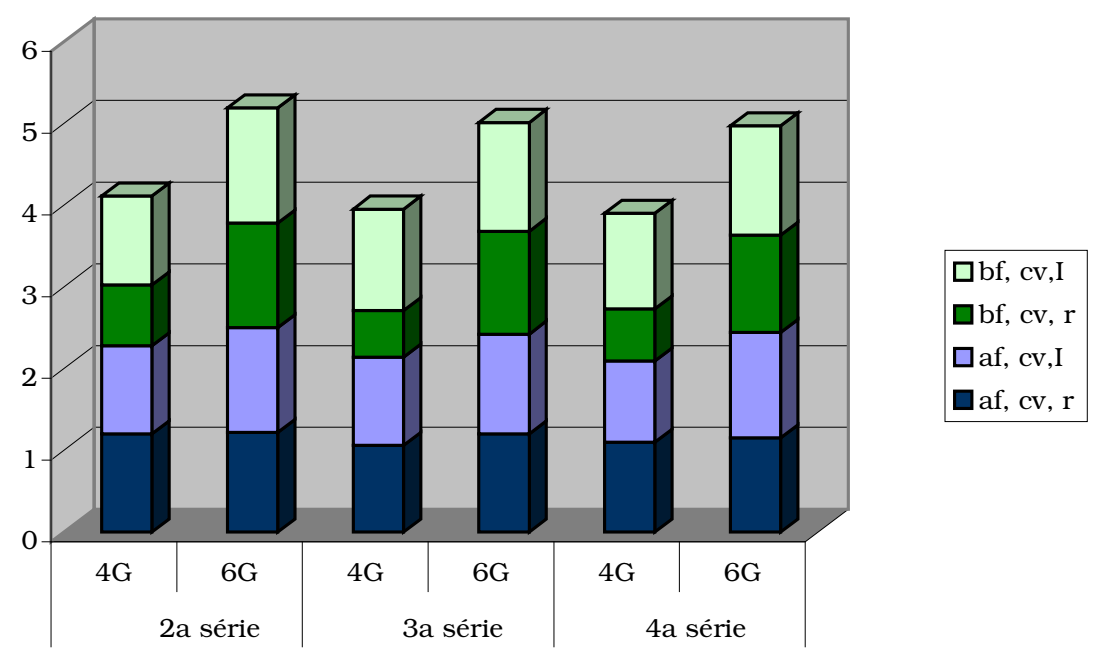

G:grafemas, af: alta freqüência, bf: baixa freqüência, cv: consoante-vogal, r:regular; i:irregular

Tabela 14. p-valores - comparação do tempo de latência para a leitura: 4 x 6 grafemas

\begin{tabular}{lccc}
\hline \multicolumn{1}{c}{$\mathbf{4}$ grafemas $\mathbf{x}$} & \multicolumn{3}{c}{ p valores } \\
$\mathbf{6}$ grafemas & Série & palavra & série $\mathbf{x}$ palavra \\
\hline $\mathrm{AF}, \mathrm{CV}, \mathrm{R}$ & 0,7204 & $\mathbf{0 , 0 3 9 6} *$ & 0,3657 \\
$\mathrm{AF}, \mathrm{CV}, \mathrm{I}$ & 0,9155 & $\mathbf{< 0 , 0 0 0 1} *$ & 0,3699 \\
$\mathrm{BF}, \mathrm{CV}, \mathrm{R}$ & 0,9731 & $<\mathbf{0 , 0 0 0 1} *$ & 0,0506 \\
$\mathrm{BF}, \mathrm{CV}, \mathrm{I}$ & 0,6753 & $\mathbf{0 , 0 0 0 1} *$ & 0,4959 \\
\hline
\end{tabular}

p<0,05* AF: alta freqüência; BF: baixa freqüência,

G: grafemas; CV: consoante-vogal; R: regular; I: irregular

De acordo com os dados da tabela acima, o tempo de latência foi maior para as palavras mais extensas (6 grafemas) do que para as mais curtas (4 grafemas), de forma semelhante entre as séries. 


\subsubsection{Tempo de duração da emissão oral}

Apresentam-se a seguir os dados referentes ao tempo de duração da emissão oral para a leitura. Na tabela 15, podem ser observados a média e o desvio-padrão.

Tabela 15. Média e desvio padrão em cada grupo de palavra e série para o tempo de duração da emissão oral (seg) na leitura de palavras

\begin{tabular}{|c|c|c|c|c|}
\hline \multirow[b]{2}{*}{ Tipos de palavra } & \multicolumn{4}{|c|}{ séries } \\
\hline & $2^{\mathbf{a}}$ & $3^{a}$ & $4^{a}$ & Total \\
\hline & $\mathrm{M}(\mathrm{DP})$ & $\mathrm{M}(\mathrm{DP})$ & $\mathrm{M}(\mathrm{DP})$ & $\mathrm{M}(\mathrm{DP})$ \\
\hline AF, 4G, CV, R & $0,67(0,15)$ & $0,59(0,08)$ & $0,64(0,11)$ & $0,63(0,12)$ \\
\hline $\mathrm{AF}, 4 \mathrm{G}, \mathrm{CV}, \mathrm{I}$ & $0,64(0,13)$ & $0,63(0,08)$ & $0,64(0,13)$ & $0,64(0,12)$ \\
\hline AF, 6G, CV, R & $0,82(0,17)$ & $0,80(0,10)$ & $0,83(0,11)$ & $0,82(0,13)$ \\
\hline $\mathrm{AF}, 6 \mathrm{G}, \mathrm{CV}, \mathrm{I}$ & $0,86(0,16)$ & $0,86(0,15)$ & $0,83(0,13)$ & $0,85(0,14)$ \\
\hline $\mathrm{AF}, 5 \mathrm{e}+\mathrm{G}, \mathrm{OE}, \mathrm{R}$ & $0,82(0,13)$ & $0,76(0,08)$ & $0,78(0,11)$ & $0,79(0,11)$ \\
\hline$\underline{\mathrm{AF}, 5 \mathrm{e}+\mathrm{G}, \mathrm{OE}, \mathrm{I}}$ & $0,78(0,16)$ & $0,76(0,18)$ & $0,76(0,16)$ & $0,77(0,16)$ \\
\hline BF, 4G, CV, R & $0,69(0,12)$ & $0,62(0,08)$ & $0,66(0,10)$ & $0,66(0,11)$ \\
\hline $\mathrm{BF}, 4 \mathrm{G}, \mathrm{CV}, \mathrm{I}$ & $0,76(0,25)$ & $0,77(0,33)$ & $0,68(0,16)$ & $0,74(0,25)$ \\
\hline BF, 6G, CV, R & $0,84(0,14)$ & $0,84(0,22)$ & $0,80(0,09)$ & $0,83(0,15)$ \\
\hline $\mathrm{BF}, 6 \mathrm{G}, \mathrm{CV}, \mathrm{I}$ & $0,93(0,22)$ & $0,90(0,23)$ & $0,87(0,14)$ & $0,90(0,20)$ \\
\hline BF, 5 e $+\mathrm{G}, \mathrm{OE}, \mathrm{R}$ & $0,86(0,19)$ & $0,82(0,14)$ & $0,79(0,13)$ & $0,82(0,15)$ \\
\hline $\mathrm{BF}, 5 \mathrm{e}+\mathrm{G}, \mathrm{OE}, \mathrm{I}$ & $0,85(0,24)$ & $0,81(0,21)$ & $0,80(0,14)$ & $0,82(0,20)$ \\
\hline
\end{tabular}

Observou-se na tabela 15, que a média do tempo de duração da emissão oral parece ser semelhante entre as séries. Entre os tipos de palavras, nos grupos de 4 grafemas com estruturas mais simples, independente da regularidade e freqüência, o tempo de duração da emissão oral foi menor do que nas outras palavras. A comparação considerando-se freqüência, regularidade e extensão, assim como as análises estatísticas, estão descritas a seguir (figuras 12, 13 e 14 e tabelas 16,17 e 18). 
Figura 12. Tempo de duração da emissão oral para a leitura: alta $\mathbf{x}$ baixa freqüência

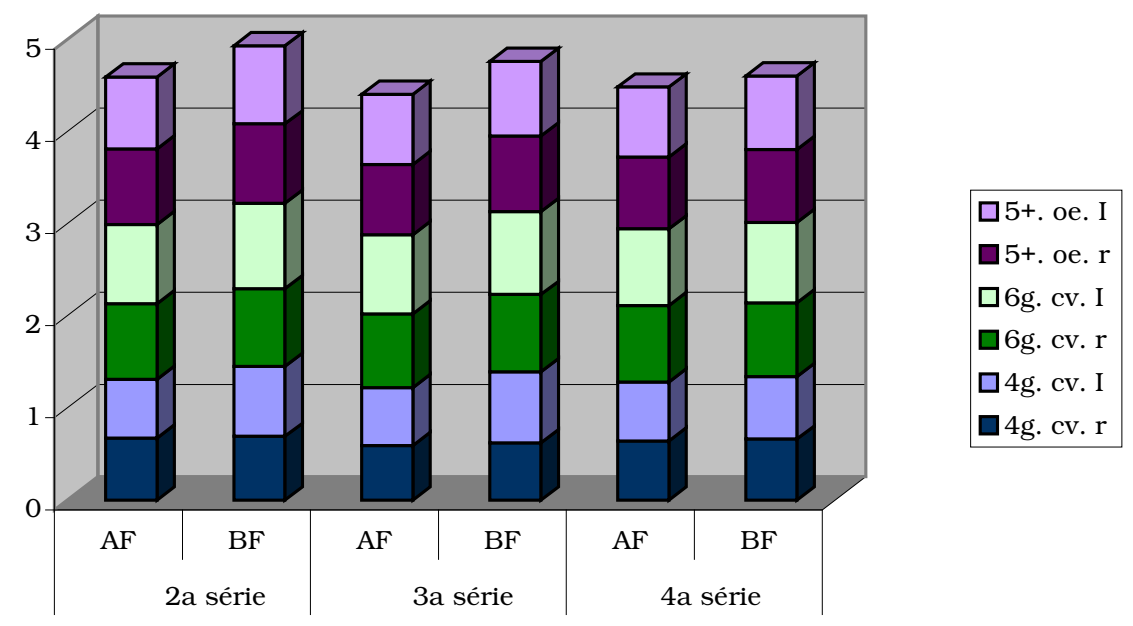

AF: alta freqüência, BF: baixa freqüência, oe: outras estruturas, cv: consoante-vogal, g: grafemas, r:regular; i: irregular

Tabela 16. p-valores - comparação do tempo de duração da emissão oral para a leitura: alta $x$ baixa freqüência

\begin{tabular}{|c|c|c|c|}
\hline \multirow{2}{*}{$\begin{array}{l}\text { alta } \times \text { baixa } \\
\text { freqüência }\end{array}$} & \multicolumn{3}{|c|}{ p-valores } \\
\hline & série & palavra & série $\mathrm{x}$ palavra \\
\hline$\overline{4 \mathrm{G}, \mathrm{CV}, \mathrm{R}}$ & 0,0478* & 0,0151* & 0,8615 \\
\hline $4 \mathrm{G}, \mathrm{CV}, \mathrm{I}$ & 0,6569 & $0,0002 *$ & 0,2386 \\
\hline $6 \mathrm{G}, \mathrm{CV}, \mathrm{R}$ & 0,8755 & 0,5351 & 0,2497 \\
\hline $6 \mathrm{G}, \mathrm{CV}, \mathrm{I}$ & 0,5570 & $0,0453^{*}$ & 0,8671 \\
\hline $5 \mathrm{e}+\mathrm{G}, \mathrm{OE}, \mathrm{R}$ & 0,2619 & $0,0065 *$ & 0,3252 \\
\hline 5 e $+\mathrm{G}, \mathrm{OE}, \mathrm{I}$ & 0,7642 & $0,0034 *$ & 0,7787 \\
\hline
\end{tabular}

A média do tempo de duração da emissão oral foi menor para as palavras de alta freqüência, em todas as séries. No grupo de palavras mais simples (4 grafemas, estrutura cv e regular), a média do tempo diminuiu entre a $2^{\underline{a}}$ e a $3^{\underline{a}}$ séries e aumentou entre a $3^{\underline{a}}$ e a $4^{\underline{a}}$ séries. 
Figura 13. Tempo de duração da emissão oral para a leitura: regulares $\mathrm{x}$ irregulares

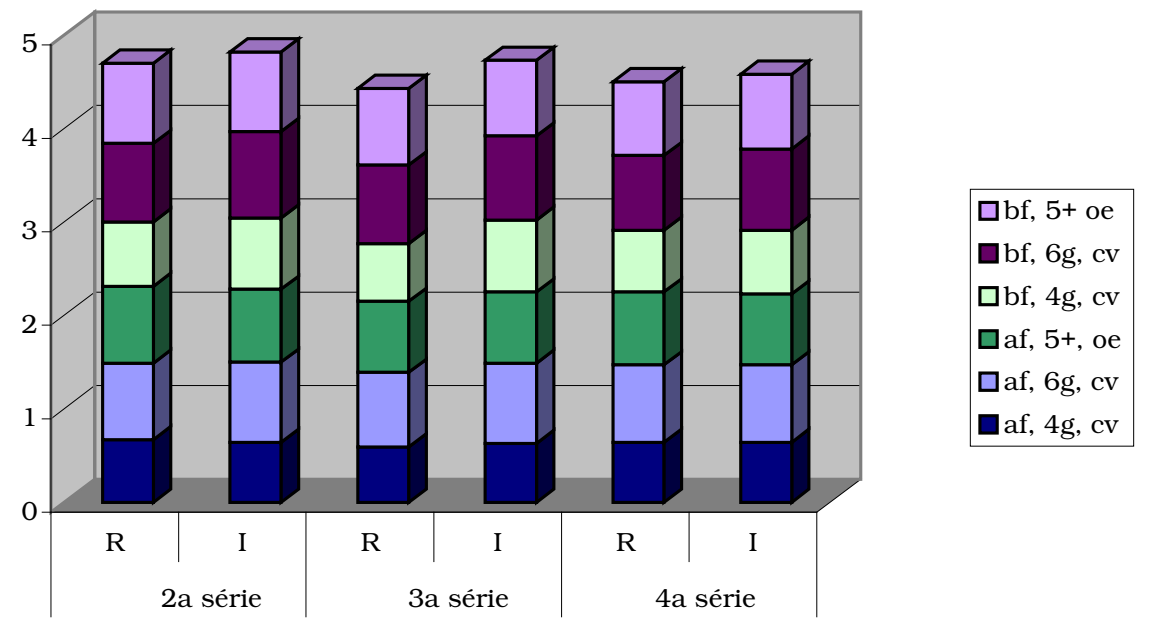

R:regular, I:irregular, af: alta freqüência, bf: baixa freqüência, g:grafemas, cv:consoante-vogal, oe:outras estruturas

Tabela 17. p-valores - comparação do tempo de duração da emissão oral para a leitura: regulares $x$ irregulares

\begin{tabular}{lccc}
\hline \multicolumn{1}{c}{ regulares x } & \multicolumn{3}{c}{ p-valores } \\
irregulares & série & palavra & série x palavra \\
\hline $\mathrm{AF}, 4 \mathrm{G}, \mathrm{CV}$ & 0,3304 & 0,8457 & $\mathbf{0 , 0 4 3 0 *}$ \\
$\mathrm{AF}, 6 \mathrm{G}, \mathrm{CV}$ & 0,9111 & $\mathbf{0 , 0 2 3 9}$ & 0,3500 \\
$\mathrm{AF}, 5 \mathrm{e}+\mathrm{G}, \mathrm{OE}$ & 0,5498 & 0,2235 & 0,6578 \\
$\mathrm{BF}, 4 \mathrm{G}, \mathrm{CV}$ & 0,5053 & $\mathbf{0 , 0 0 3 1}$ & 0,1372 \\
$\mathrm{BF}, 6 \mathrm{G}, \mathrm{CV}$ & 0,5467 & $\mathbf{0 , 0 0 0 7}$ & 0,9057 \\
$\mathrm{BF}, 5 \mathrm{e}+\mathrm{G}, \mathrm{OE}$ & 0,4595 & 0,8395 & 0,8313 \\
\hline
\end{tabular}

p<0,05* AF: alta freqüência; $\mathrm{BF}$ : baixa freqüência,

G: grafemas; CV: consoante- vogal; R: regular; I: irregular

De acordo com os dados da tabela 17, as palavras regulares foram lidas mais rapidamente em três grupos: alta freqüência, 6 grafemas e estrutura cv; baixa freqüência, 4 e 6 grafemas, estrutura cv. A significância na interação série $\mathrm{x}$ palavra no grupo de palavras mais simples se deve a um comportamento invertido entre os tipos de palavras nas $2^{\underline{a}}$ e $3^{\underline{a}}$ séries: na $2^{\text {a }}$ série, o tempo foi maior para palavras regulares e na $3^{a}$, para as irregulares. 
Figura 14. Tempo de duração da emissão oral para a leitura: 4 x 6 grafemas

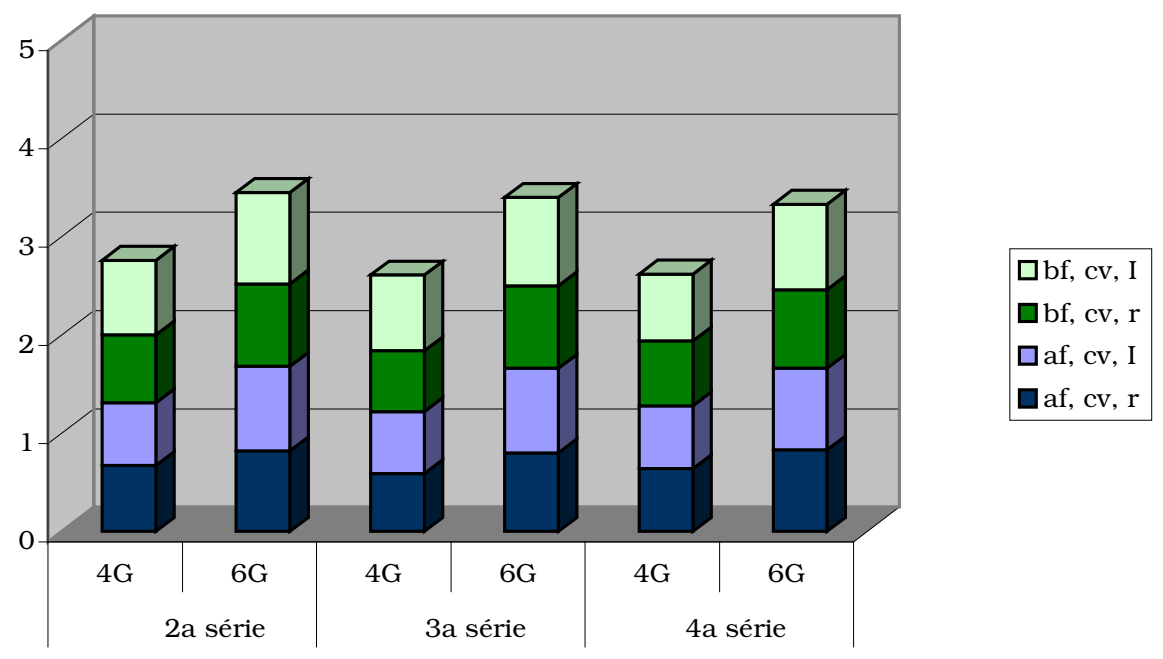

G:grafemas, af: alta freqüência, bf: baixa freqüência, cv: consoante-vogal, r:regular, i:irregular

Tabela 18 - p-valores - comparação do tempo de duração da emissão oral para a leitura: $4 \times 6$ grafemas

\begin{tabular}{lccc}
\hline \multicolumn{1}{c}{ 4 grafemas x } & \multicolumn{3}{c}{ p valores } \\
\multicolumn{1}{c}{ grafemas } & série & palavra & série x palavra \\
\hline $\mathrm{AF}, \mathrm{CV}, \mathrm{R}$ & 0,2909 & $<\mathbf{0 , 0 0 0 1}^{*}$ & 0,1279 \\
$\mathrm{AF}, \mathrm{CV}, \mathrm{I}$ & 0,9168 & $<\mathbf{0 , 0 0 0 1}^{*}$ & 0,3755 \\
$\mathrm{BF}, \mathrm{CV}, \mathrm{R}$ & 0,4656 & $<\mathbf{0 , 0 0 0 1}^{*}$ & 0,1264 \\
$\mathrm{BF}, \mathrm{CV}, \mathrm{I}$ & 0,3835 & $<\mathbf{0 , 0 0 0 1}^{*}$ & 0,7697 \\
\hline
\end{tabular}

p<0,05* AF: alta freqüência; BF: baixa freqüência,

G: grafemas; CV: consoante- vogal; R: regular; I: irregular

O tempo de duração da emissão oral foi maior para as palavras mais (6 grafemas) do que para as menos extensas (4 grafemas), em todas as séries. 


\subsubsection{Acertos}

A média e o desvio-padrão da porcentagem de acertos na prova de leitura são apresentados na tabela 19, abaixo:

Tabela 19. Média e desvio padrão em cada grupo de palavra e série
para acertos na leitura de palavras
\begin{tabular}{lcccc}
\hline & \multicolumn{4}{c}{ séries } \\
\cline { 2 - 5 } Tipos de palavra & $\mathbf{2}^{\mathbf{a}}$ & $\mathbf{3}^{\mathbf{a}}$ & $\mathbf{4}^{\mathbf{a}}$ & Total \\
\hline & $\mathrm{M}(\mathrm{DP})$ & $\mathrm{M}(\mathrm{DP})$ & $\mathrm{M}(\mathrm{DP})$ & $\mathrm{M}(\mathrm{DP})$ \\
\hline $\mathrm{AF}, 4 \mathrm{G}, \mathrm{CV}, \mathrm{R}$ & $93,0(9,6)$ & $100,0(0,0)$ & $97,5(5,1)$ & $98,6(4,4)$ \\
\hline $\mathrm{AF}, 4 \mathrm{G}, \mathrm{CV}, \mathrm{I}$ & $96,0(6,5)$ & $95,2(8,1)$ & $96,0(7,7)$ & $97,1(5,8)$ \\
\hline $\mathrm{AF}, 6 \mathrm{G}, \mathrm{CV}, \mathrm{R}$ & $97,0(5,4)$ & $99,0(3,5)$ & $97,0(6,5)$ & $99,5(2,5)$ \\
\hline $\mathrm{AF}, 6 \mathrm{G}, \mathrm{CV}, \mathrm{I}$ & $97,0(8,3)$ & $97,9(7,1)$ & $97,0(8,3)$ & $98,6(5,7)$ \\
\hline $\mathrm{AF}, 5$ e +G, OE, R & $96,7(6,4)$ & $98,5(35)$ & $97,8(6,0)$ & $98,5(4,3)$ \\
\hline $\mathrm{AF}, 5$ e +G, OE, I & $96,0(11,1)$ & $97,2(8,0)$ & $94,0(14,3)$ & $97,5(6,6)$ \\
\hline $\mathrm{BF}, 4 \mathrm{G}, \mathrm{CV}, \mathrm{R}$ & $95,4(9,9)$ & $98,2(4,8)$ & $95,4(9,9)$ & $96,9(7,2)$ \\
\hline $\mathrm{BF}, 4 \mathrm{G}, \mathrm{CV}, \mathrm{I}$ & $85,1(16,2)$ & $90,5(11,7)$ & $86,9(15,4)$ & $90,9(11,7)$ \\
\hline $\mathrm{BF}, 6 \mathrm{G}, \mathrm{CV}, \mathrm{R}$ & $90,8(6,4)$ & $83,3(8,2)$ & $94,8(5,1)$ & $94,5(6,4)$ \\
\hline $\mathrm{BF}, 6 \mathrm{G}, \mathrm{CV}, \mathrm{I}$ & $89,6(12,4)$ & $80,8(16,7)$ & $93,6(10,8)$ & $96,9(6,6)$ \\
\hline $\mathrm{BF}, 5$ e +G, OE, R & $91,2(11,3)$ & $80,4(10,0)$ & $93,2(6,9)$ & $96,1(5,9)$ \\
\hline $\mathrm{BF}, 5$ e +G, OE, I & $94,0(7,3)$ & $94,3(9,7)$ & $94,0(8,9)$ & $98,3(4,3)$ \\
\hline
\end{tabular}

$\mathrm{AF}$ : alta freqüência; BF: baixa freqüência; G: grafemas;CV:consoante-vogal; OE: outras estruturas; R: regular; I:irregular; M: média; DP: desvio-padrão

Nas figuras seguintes $(15,16$ e 17), estão os valores da comparação entre palavras e séries para acertos, e podem ser observadas as variáveis freqüência, regularidade e extensão. Nas tabelas 20, 21 e 22, estão as análises estatísticas destas comparações. 
Figura 15. Porcentagem de acertos na leitura: alta $\mathbf{x}$ baixa freqüência

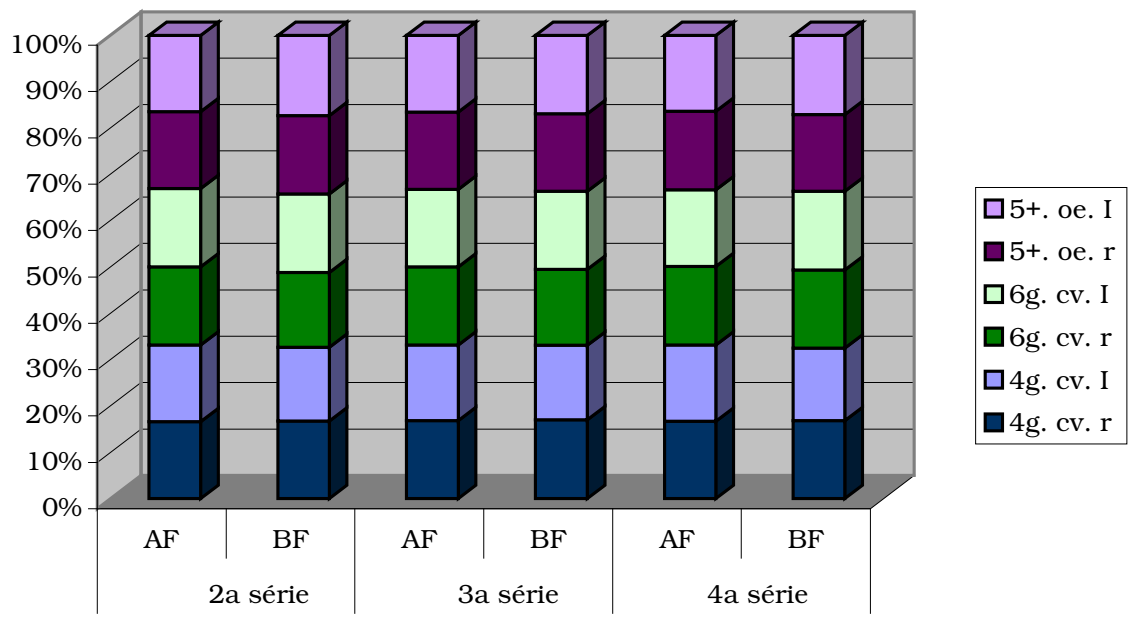

$\mathrm{AF}$ : alta freqüência, BF: baixa freqüência, cv: consoante-vogal, g: grafemas, oe: outras estruturas, r: regular; i: irregular

Tabela 20. p-valores - comparação da porcentagem de acertos na leitura: alta $x$ baixa freqüência

\begin{tabular}{lccc}
\hline $\begin{array}{c}\text { alta x baixa } \\
\text { freqüência }\end{array}$ & série & \multicolumn{2}{c}{ p-valores } \\
palavra & série x palavra \\
\hline $4 \mathrm{G}, \mathrm{CV}, \mathrm{R}$ & 0,2019 & 0,0514 & 0,9793 \\
$4 \mathrm{G}, \mathrm{CV}, \mathrm{I}$ & 0,8436 & $<\mathbf{0 , 0 0 0 1} *$ & 0,4139 \\
$6 \mathrm{G}, \mathrm{CV}, \mathrm{R}$ & 0,0505 & $<\mathbf{0 , 0 0 0 1} *$ & 0,2065 \\
$6 \mathrm{G}, \mathrm{CV}, \mathrm{I}$ & 0,9587 & $\mathbf{0 , 0 2 5 8 *}$ & 0,6301 \\
$5 \mathrm{e}+\mathrm{G}, \mathrm{OE}, \mathrm{R}$ & 0,9509 & $\mathbf{0 , 0 0 8 0 ^ { * }}$ & 0,2249 \\
$5 \mathrm{e}+\mathrm{G}, \mathrm{OE}, \mathrm{I}$ & 0,7168 & 0,3414 & 0,4383 \\
\hline
\end{tabular}

p<0,05* G: grafemas, CV: consoante-vogal;

R: regular; I: irregular; OE: outras estruturas

Analisando os dados da tabela 20, houve, assim como para o tempo de latência, maior quantidade de acertos nas palavras de alta do que nas de baixa freqüência, com exceção das mais simples (4 grafemas, estrutura cv e regular) e das mais complexas (5 e mais grafemas, ouras estruturas e irregular). O comportamento entre as séries foi semelhante. 
Figura 16. Porcentagem de acertos na leitura:regulares $x$ irregulares

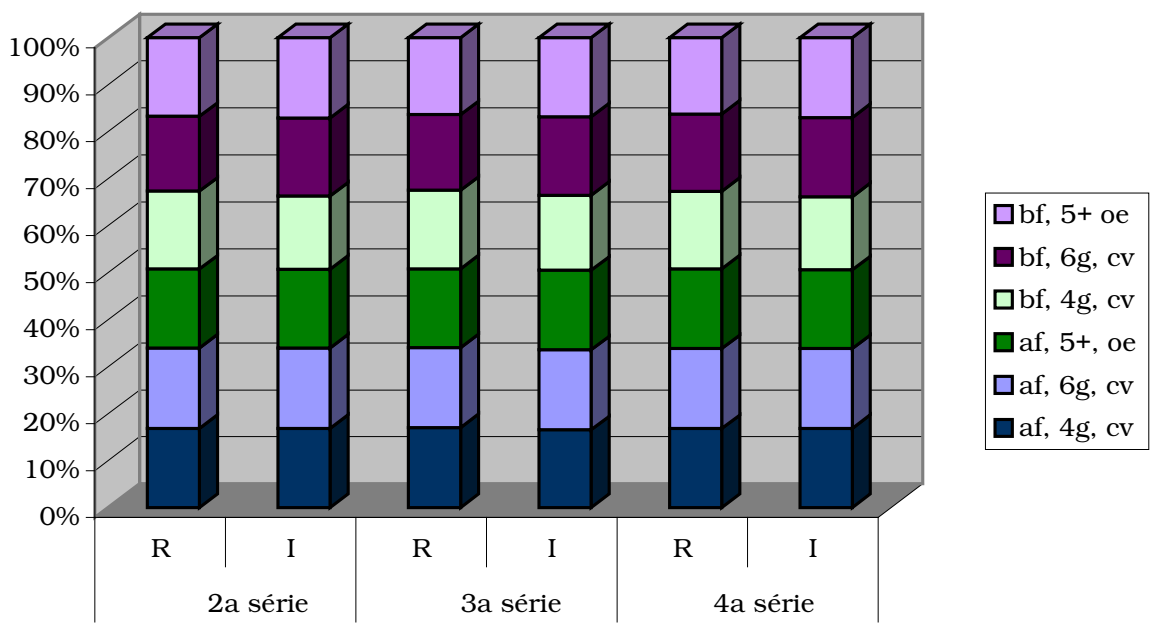

R: regular, I: irregular, af: alta freqüência, bf: baixa freqüência, g: grafemas, cv: consoante-vogal, oe: outras estruturas

Tabela 21. p-valores - comparação da porcentagem de acertos na leitura: regulares $x$ irregulares

\begin{tabular}{lccc}
\hline \multicolumn{1}{c}{$\begin{array}{c}\text { regulares } \mathbf{x} \\
\text { irregulares }\end{array}$} & série & p-valores \\
palavra & série x palavra \\
\hline $\mathrm{AF}, 4 \mathrm{G}, \mathrm{CV}$ & 0,8347 & 0,0729 & 0,2083 \\
$\mathrm{AF}, 6 \mathrm{G}, \mathrm{CV}$ & 0,7030 & 0,2570 & 0,6970 \\
$\mathrm{AF}, 5 \mathrm{e}+\mathrm{G}, \mathrm{OE}$ & 0,6073 & 0,2594 & 0,2755 \\
$\mathrm{BF}, 4 \mathrm{G}, \mathrm{CV}$ & 0,4817 & $<\mathbf{0 , 0 0 0 1} *$ & 0,8916 \\
$\mathrm{BF}, 6 \mathrm{G}, \mathrm{CV}$ & 0,2240 & $\mathbf{0 , 0 1 7 3}$ & 0,4237 \\
$\mathrm{BF}, 5 \mathrm{e}+\mathrm{G}, \mathrm{OE}$ & 0,4551 & $\mathbf{0 , 0 1 1 8 ^ { * }}$ & 0,8659 \\
\hline
\end{tabular}

p<0,05* AF: alta freqüência; BF: baixa freqüência,

G: grafemas; CV: consoante-vogal; OE: outras estruturas

Na tabela 21, verificou-se maior quantidade de acertos para as palavras regulares do que nas irregulares. Esta diferença foi observada apenas nas palavras de baixa freqüência. O comportamento entre as séries também foi semelhante. 
Figura 17. Porcentagem de acertos na leitura de palavras: 4 x 6 grafemas

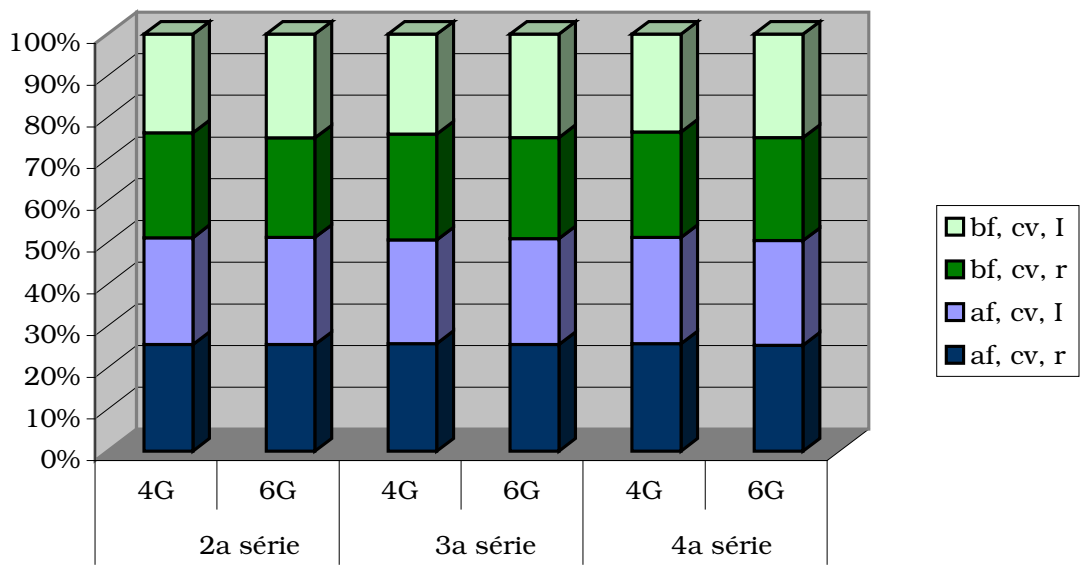

G: grafemas, af: alta freqüência, bf: baixa freqüência, cv: consoante-vogal, r: regular, i: irregular

Tabela 22. p-valores - comparação da porcentagem de acertos na leitura: $4 \times 6$ grafemas

\begin{tabular}{lccc}
\hline \multicolumn{1}{c}{ 4 grafemas x } & \multicolumn{3}{c}{ p valores } \\
\multicolumn{1}{c}{ grafemas } & Série & Palavra & Série x palavra \\
\hline AF, CV, R & $\mathbf{0 , 0 4 2 9}^{*}$ & 0,1757 & 0,5978 \\
AF, CV, I & 0,7744 & 0,1017 & 0,7552 \\
BF, CV, R & 0,1828 & $\mathbf{0 , 0 2 7 3}^{*}$ & 0,3359 \\
BF, CV, I & 0,7062 & $<\mathbf{0 , 0 0 0 1}^{*}$ & 0,6252 \\
\hline
\end{tabular}

p<0,05* AF: alta freqüência; $B F$ : baixa freqüência,

G: grafemas; CV: consoante-vogal; R: regular; I: irregular

De acordo com os dados acima, houve maior quantidade de acertos para as palavras de 4 grafemas do que nas de 6 , apenas nas de baixa freqüência. A diferença entre as séries no grupo de palavras AF, $\mathrm{CV}$ e $\mathrm{R}$ ocorreu porque a $3^{\mathrm{a}}$ série apresentou $100 \%$ de acerto, o que causou a diferença em relação às demais séries. 


\subsubsection{Características da leitura de palavras}

As características da leitura também foram qualitativamente analisadas. $\mathrm{Na}$ tabela 23 , constam as características observadas na leitura nas três séries. Calculou-se a porcentagem de cada tipo de leitura. Para cada tipo destas respostas, tabulou-se a porcentagem de erros de produção (fragmentações, repetição de sílabas, de fonemas e de palavras) e de revisões (correção da leitura após a resposta dada) associados. Devido à baixa incidência, não houve teste estatístico aplicável.

Tabela 23. Tipos de resposta para a leitura em cada série

\begin{tabular}{|c|c|c|c|c|c|c|}
\hline \multirow[t]{2}{*}{$\begin{array}{l}\text { Tipos de } \\
\text { resposta }\end{array}$} & \multicolumn{2}{|c|}{$2^{a}$ série } & \multicolumn{2}{|c|}{$3^{a}$ série } & \multicolumn{2}{|c|}{$4^{\mathrm{a}}$ série } \\
\hline & $\mathbf{N}$ & $\%$ & $\mathbf{N}$ & $\%$ & $\mathbf{N}$ & $\%$ \\
\hline \multicolumn{7}{|l|}{ DRO } \\
\hline & 1 & 1,25 & 0 & 0,00 & 3 & 4,35 \\
\hline $\mathbf{D R O}+\mathbf{r}$ & 6 & 7,50 & 6 & 10,00 & 4 & 5,80 \\
\hline DRO + ep & 4 & 5,00 & 0 & 0,00 & 0 & 0,00 \\
\hline DRA & 19 & 23,75 & 10 & 16,67 & 7 & 10,14 \\
\hline $\mathbf{D R A}+\mathbf{r}$ & 2 & 2,50 & 1 & 1,67 & 0 & 0,00 \\
\hline DRA+ ep & 2 & 2,50 & 2 & 3,33 & 0 & 0,00 \\
\hline PVF & 15 & 18,75 & 6 & 10,00 & 11 & 15,94 \\
\hline $\mathbf{P V F}+\mathbf{r}$ & 4 & 5,00 & 7 & 11,67 & 13 & 18,84 \\
\hline PVF+ ep & 0 & 0,00 & 0 & 0,00 & 0 & 0,00 \\
\hline $\mathbf{R}$ & 17 & 21,25 & 5 & 8,33 & 8 & 11,59 \\
\hline $\mathbf{R}+\mathbf{r}$ & 1 & 1,25 & 5 & 8,33 & 2 & 2,90 \\
\hline $\mathbf{R}+\mathbf{e p}$ & 1 & 1,25 & 3 & 5,00 & 3 & 4,35 \\
\hline $\mathbf{N}$ & 4 & 5,00 & 5 & 8,33 & 11 & 15,94 \\
\hline $\mathbf{N r}$ & 1 & 1,25 & 8 & 13,33 & 6 & 8,70 \\
\hline Nep & 1 & 1,25 & 1 & 1,67 & 1 & 1,45 \\
\hline NR & 2 & 2,50 & 1 & 1,67 & 0 & 0,00 \\
\hline
\end{tabular}

DRO: desconhecimento da regra ortográfica; DRA: desconhecimento da regra de acentuação, PVF: paralexia verbal formal; R: regularização; N: neologismo; NR: não resposta; ep:erros de produção; r: revisão

Agrupando-se os tipos de respostas, sem considerar os erros de produção e as revisões realizadas, foi possível a aplicação de testes estatísticos. Da mesma forma, os erros de produção e as revisões foram 
computados no total das respostas. Os resultados encontram-se na tabela abaixo:

24. Comparação dos tipos de resposta para a leitura em cada série

\begin{tabular}{ccccccc}
\hline Tipos de resposta & \multicolumn{2}{c}{$\mathbf{2}^{\mathbf{a}}$ série } & \multicolumn{2}{c}{$\mathbf{3}^{\mathbf{a}}$ série } & \multicolumn{2}{c}{$\mathbf{4}^{\mathbf{a}}$ série } \\
\cline { 2 - 7 } & $\mathbf{N}$ & $\mathbf{\%}$ & $\mathbf{N}$ & $\mathbf{\%}$ & $\mathbf{N}$ & $\mathbf{\%}$ \\
\hline DRO & 11 & 14,10 & 6 & 10,17 & 7 & 10,14 \\
DRA & $\mathbf{2 3}$ & $\mathbf{2 9 , 4 9}$ & 13 & 22,03 & $\mathbf{7}$ & $\mathbf{1 0 , 1 4}$ \\
PVF & $\mathbf{1 9}$ & $\mathbf{2 4 , 3 6}$ & 13 & 22,03 & $\mathbf{2 4}$ & $\mathbf{3 4 , 7 8}$ \\
$\mathbf{R}$ & 19 & 24,36 & 13 & 22,03 & 13 & 18,84 \\
$\mathbf{N}$ & $\mathbf{6}$ & $\mathbf{7 , 6 9}$ & 14 & 23,73 & $\mathbf{1 8}$ & $\mathbf{2 6 , 0 9}$ \\
\hline Erros de produção & $\mathbf{7}$ & $\mathbf{8 , 9 7}$ & 5 & 8,47 & $\mathbf{3}$ & 4,34 \\
\hline Revisões & $\mathbf{1 4}$ & $\mathbf{1 7 , 9 4}$ & 28 & 47,45 & $\mathbf{2 5}$ & 36,23 \\
\hline
\end{tabular}

Teste de Qui-quadrado $(p)=0,0211^{*}$.

DRO: desconhecimento da regra ortográfica; DRA: desconhecimento da regra de acentuação, PVF: paralexia verbal formal; R: regularização; N: neologismo

Observou-se nas características da leitura (tabelas 23 e 24) que DRO (desconhecimento da regra ortográfica), DRA (desconhecimento da regra de acentuação) e R (regularização) foram apresentados em maior quantidade pelas crianças da $2^{\text {a }}$ série, enquanto PVF (paralexia verbal formal) e $\mathrm{N}$ (Neologismo) ocorreram em maior porcentagem na $4^{\text {a }}$ série.

As diferenças significantes foram observadas entre as $2^{\underline{a}}$ e $4^{\underline{a}}$ séries (negrito). Considerando-se a concentração de respostas, estas passam de uma concentração em DRA (desconhecimento da regra de acentuação) na $2^{\text {a }}$ série para uma concentração em PVF (paralexia verbal formal) e $\mathrm{N}$ (neologismo) na $4^{\underline{a}}$ série.

As crianças da $4^{\text {a }}$ série apresentaram menor quantidade de fragmentações nas respostas (erros de produção), de forma estatisticamente significante. Por outro lado, os alunos de $3^{\text {a }}$ e $4^{\text {a }}$ séries realizaram mais revisões nas suas respostas do que a $2^{\text {a }}$ série. 
A porcentagem de erros de produção ocorridos durante a leitura adequada das palavras não foi estatisticamente diferente entre as séries $(\mathrm{p}=0,0612)$.

\subsubsection{Correlação entre tempo de latência e acertos}

A correlação entre tempo de latência e acertos pode ser observada na tabela 25 .

Tabela 25. Correlação entre tempo de latência e acertos na leitura

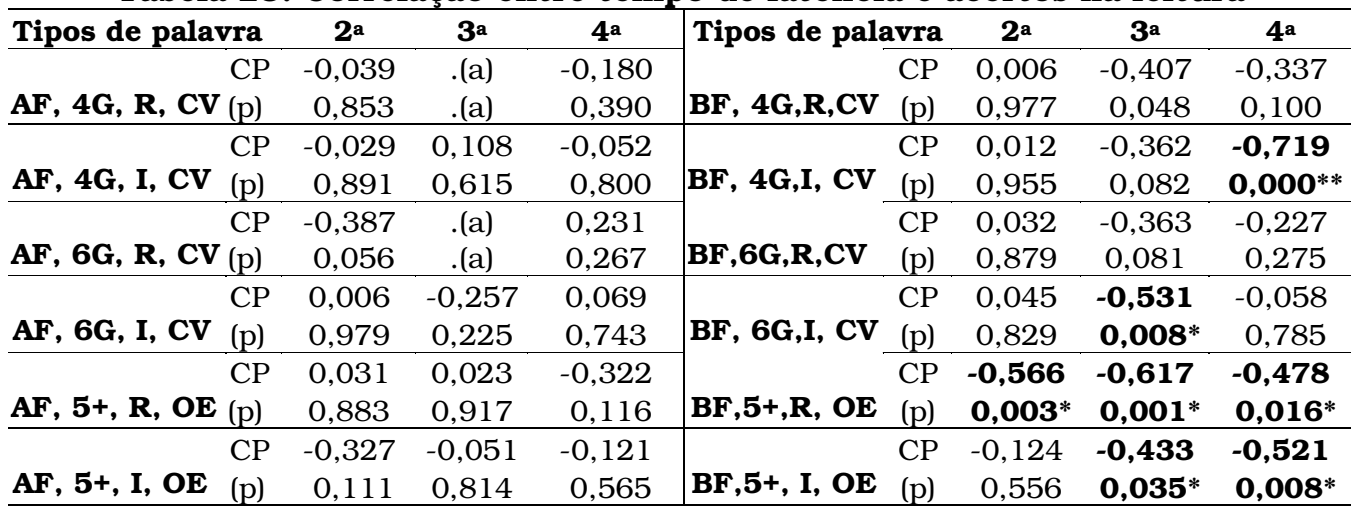

$\mathrm{AF}$ : alta freqüência; $\mathrm{BF}$ : baixa freqüência; G: grafemas; $\mathrm{CV}$ :consoante-vogal; OE: outras estruturas; R: regular; I:irregular; CP: correlação e Pearson; .(a): não aplicável, uma das variáveis é constantes;

* - correlação moderada; ** - correlação boa

Os resultados indicaram correlação negativa entre acertos e tempo de latência de forma significante, apenas nos grupos de baixa freqüência. Para as palavras de alta freqüência, não houve correlação significante. A correlação negativa nas palavras de baixa freqüência indica associação entre tempo de latência maior e menor eficiência na leitura. A única correlação considerada boa foi observada na $4^{a}$ série, para as palavras de baixa freqüência, 4 grafemas, irregulares e estrutura consoante-vogal, enquanto as demais foram consideradas moderadas. 


\subsubsection{Correlação entre tempo de duração da emissão oral e acertos}

Na tabela 26 abaixo, pode ser visualizada a correlação entre tempo de duração da emissão oral e acertos na leitura de palavras.

Tabela 26. Correlação entre tempo de duração da emissão oral e acertos na leitura

\begin{tabular}{|c|c|c|c|c|c|c|c|c|}
\hline alavra & $2^{a}$ & $3^{\mathbf{a}}$ & $\mathbf{4}^{\mathbf{a}}$ & \multirow{3}{*}{\multicolumn{2}{|c|}{ 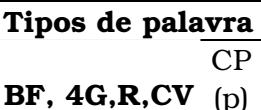 }} & $2^{a}$ & J" & $\mathbf{4}^{\mathbf{a}}$ \\
\hline \multirow[b]{2}{*}{$\mathrm{AF}, \mathbf{4 G}, \mathrm{R}, \mathrm{CV}$} & & & & & & & & \\
\hline & & (a) & & & & & & \\
\hline \multirow[b]{2}{*}{$\mathrm{AF}, \mathbf{4 G}, \mathrm{I}, \mathrm{CV}$} & & & & \multirow[b]{2}{*}{ BF, 4G, I, CV } & & & & \\
\hline & & & & & (p) & & & \\
\hline \multirow{2}{*}{$A, 6 G, R, C V$} & & & & \multirow[b]{2}{*}{$\mathrm{B}, \mathbf{6 G}, \mathrm{R}, \mathrm{CV}$} & & & & \\
\hline & & (a) & & & (p) & & & \\
\hline \multirow[b]{2}{*}{$\mathrm{AF}, \mathbf{6 G}, \mathbf{I}, \mathbf{C V}(\mathrm{p})$} & & & & \multirow[b]{2}{*}{$\mathrm{BF}, 6 \mathrm{G}, \mathrm{I}, \mathrm{CV}$} & $\mathrm{CP}$ & & & \\
\hline & & & & & (p) & & & \\
\hline \multirow[b]{2}{*}{ AF, 5+,R, OE } & & & & \multirow[b]{2}{*}{ BF, 5+, R, OE } & $\mathrm{CP}$ & & & \\
\hline & & & & & (p) & & & \\
\hline $\mathrm{CP}$ & & & & & & $-0,521$ & $-0,630$ & \\
\hline
\end{tabular}

$\mathrm{AF}$ : alta freqüência; BF: baixa freqüência; G: grafemas;CV:consoante-vogal; OE: outras estruturas; R: regular; I:irregular; CP: correlação e Pearson; .(a): não aplicável, uma das variáveis é constante

* - correlação moderada; ** - correlação boa

No grupo de palavras mais simples (alta freqüência, 4 grafemas, regular e estrutura cv), as crianças da $4^{\text {a }}$ série apresentaram correlação negativa e significante, o que indica que as palavras lidas corretamente foram produzidas em menor intervalo de tempo.

Foram observadas, também, correlações em todas as séries, para as palavras irregulares com estruturas mais complexas de alta e de baixa freqüência. Isto quer dizer que houve menor porcentagem de acertos nestas palavras e um tempo de duração da emissão prolongado. 


\subsubsection{Prova de nomeação de figuras}

\subsubsection{Tempo de latência}

Os valores referentes ao tempo de latência (segundos) para a nomeação, como média e desvio-padrão, podem ser visualizados na tabela 27.

Tabela 27. Média e desvio padrão em cada grupo de palavra e série para o tempo de latência (seg) na nomeação de figuras

\begin{tabular}{|c|c|c|c|c|}
\hline \multirow[b]{2}{*}{ Tipos de palavra } & \multicolumn{4}{|c|}{ séries } \\
\hline & $\mathbf{2}^{\mathbf{a}}$ & $\mathbf{3}^{\mathbf{a}}$ & $4^{a}$ & Total \\
\hline & $\mathrm{M}(\mathrm{DP})$ & $\mathrm{M}(\mathrm{DP})$ & $\mathrm{M}(\mathrm{DP})$ & $\mathrm{M}(\mathrm{DP})$ \\
\hline $\mathrm{AF}, 4 \mathrm{G}, \mathrm{CV}, \mathrm{R}$ & $1,52(0,32)$ & $1,43(0,45)$ & $1,64(0,72)$ & $1,53(0,53)$ \\
\hline $\mathrm{AF}, 4 \mathrm{G}, \mathrm{CV}, \mathrm{I}$ & $1,47(0,42)$ & $1,36(0,41)$ & $1,47(0,49)$ & $1,44(0,44)$ \\
\hline $\mathrm{AF}, 6 \mathrm{G}, \mathrm{CV}, \mathrm{R}$ & $1,54(0,36)$ & $1,59(0,72)$ & $1,62(0,54)$ & $1,58(0,55)$ \\
\hline $\mathrm{AF}, 6 \mathrm{G}, \mathrm{CV}, \mathrm{I}$ & $2,59(1,45)$ & $2,46(1,34)$ & $2,42(1,34)$ & $2,49(1,36)$ \\
\hline $\mathrm{AF}, 5 \mathrm{e}+\mathrm{G}, \mathrm{OE}, \mathrm{R}$ & $1,99(0,69)$ & $1,64(0,39)$ & $1,76(0,51)$ & $1,80(0,56)$ \\
\hline $\mathrm{AF}, 5 \mathrm{e}+\mathrm{G}, \mathrm{OE}, \mathrm{I}$ & $1,78(0,34)$ & $1,74(0,60)$ & $1,67(0,54)$ & $1,73(0,50)$ \\
\hline $\mathrm{BF}, 4 \mathrm{G}, \mathrm{CV}, \mathrm{R}$ & $2,06(0,87)$ & $1,93(0,71)$ & $1,96(0,86)$ & $1,98(0,81)$ \\
\hline $\mathrm{BF}, 4 \mathrm{G}, \mathrm{CV}, \mathrm{I}$ & $2,76(1,05)$ & $2,14(0,69)$ & $2,47(1,10)$ & $2,46(0,98)$ \\
\hline $\mathrm{BF}, 6 \mathrm{G}, \mathrm{CV}, \mathrm{R}$ & $2,17(0,67)$ & $2,31(1,01)$ & $2,48(1,09)$ & $2,32(0,93)$ \\
\hline $\mathrm{BF}, 6 \mathrm{G}, \mathrm{CV}, \mathrm{I}$ & $2,67(1,07)$ & $2,66(1,33)$ & $2,49(1,13)$ & $2,60(1,17)$ \\
\hline $\mathrm{BF}, 5 \mathrm{e}+\mathrm{G}, \mathrm{OE}, \mathrm{R}$ & $2,58(1,66)$ & $2,16(, 95)$ & $2,05(0,65)$ & $2,26(1,17)$ \\
\hline $\mathrm{BF}, 5 \mathrm{e}+\mathrm{G}, \mathrm{OE}, \mathrm{I}$ & $2,23(1,04)$ & $2,11(0,92)$ & $2,20(1,05)$ & $2,18(0,99)$ \\
\hline
\end{tabular}

A seguir, encontram-se os valores estatísticos das comparações entre os tipos de palavras e entre as séries para o tempo de latência na nomeação, no que diz respeito à freqüência, regularidade e extensão. Estes resultados estão nas tabelas 28, 29 e 30, respectivamente. 
Figura 18. Tempo de latência para a nomeação: alta $\mathbf{x}$ baixa freqüência

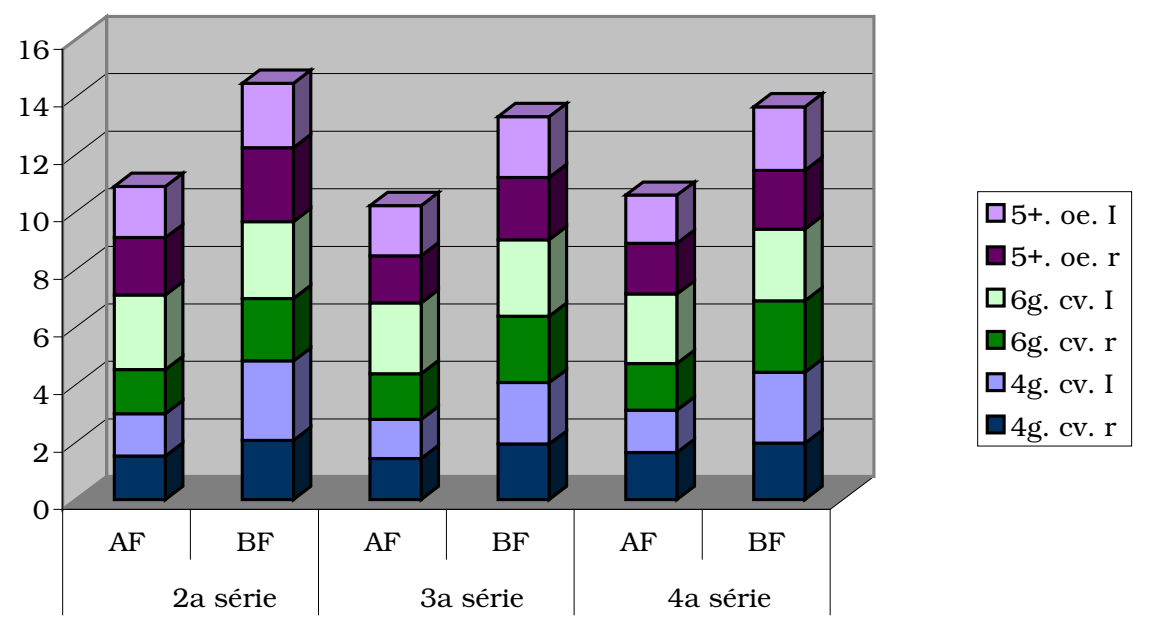

$\mathrm{AF}$ : alta freqüência, $\mathrm{BF}$ : baixa freqüência, g:grafemas, cv:consoante-vogal, oe:outras estruturas, r: regular; i: irregular

Tabela 28. p-valores - comparação do tempo de latência para a nomeação: alta $\mathbf{x}$ baixa freqüência

\begin{tabular}{lccc}
\hline $\begin{array}{c}\text { alta x baixa } \\
\text { freqüência }\end{array}$ & série & $\begin{array}{c}\text { p-valores } \\
\text { palavra }\end{array}$ & série x palavra \\
\hline $4 \mathrm{G}, \mathrm{CV}, \mathrm{R}$ & 0,6842 & $<\mathbf{0 , 0 0 0 1} *$ & 0,6446 \\
4G, CV, I & 0,1064 & $<\mathbf{0 , 0 0 0 1} *$ & 0,1314 \\
6G, CV, R & 0,6309 & $<\mathbf{0 , 0 0 0 1} *$ & 0,4397 \\
6G, CV, I & 0,8371 & $0,5151^{*}$ & 0,9426 \\
5 e + G, OE, R & 0,1087 & $\mathbf{0 , 0 0 0 5} *$ & 0,6011 \\
5 e +G, OE, I & 0,8923 & $\mathbf{0 , 0 0 0 1} *$ & 0,8330 \\
\hline \multicolumn{2}{c}{ p<0,05* G: grafemas, CV: consoante-vogal; } \\
R:regular; I: irregular; OE: outras estruturas
\end{tabular}

Conforme os dados da tabela 28, o tempo de latência foi menor para as figuras cujos nomes são mais freqüentes. Isto quer dizer as figuras, cujos nomes são mais freqüentes, foram nomeadas mais rapidamente do que as figuras com nomes pouco freqüentes. Este dado oferece indícios da existência de uma relação entre a freqüência das palavras escritas e dos nomes das figuras. 
Figura 19. Tempo de latência para a nomeação: regulares $x$ irregulares

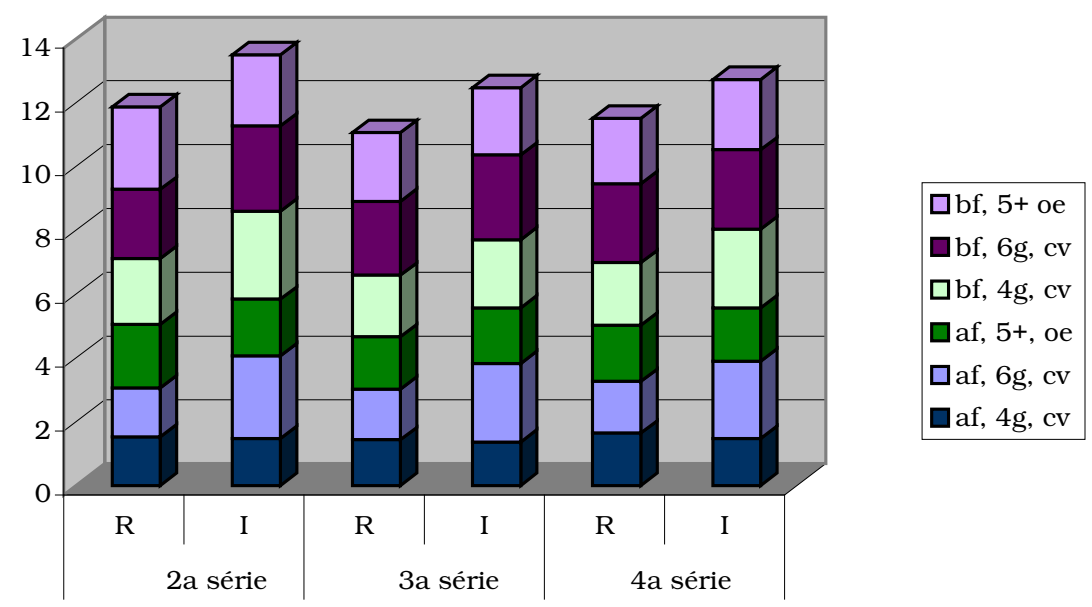

R: regular, I: irregular, af: alta freqüência; bf: baixa freqüência, g: grafemas, cv: consoante-vogal, oe: outras estruturas

Tabela 29. p-valores - comparação do tempo de latência para a nomeação: regulares $x$ irregulares

\begin{tabular}{|c|c|c|c|}
\hline \multirow{2}{*}{$\begin{array}{l}\text { regulares } x \\
\text { irregulares }\end{array}$} & \multicolumn{3}{|c|}{ p-valores } \\
\hline & série & palavra & série $\mathrm{x}$ palavra \\
\hline $\mathrm{AF}, 4 \mathrm{G}, \mathrm{CV}$ & 0,3533 & 0,1422 & 0,7236 \\
\hline $\mathrm{AF}, 4 \mathrm{G}, \mathrm{CV}$ & 0,9785 & $<0,0001 *$ & 0,7922 \\
\hline $\mathrm{AF}, 5 \mathrm{e}+\mathrm{G}, \mathrm{OE}$ & 0,2703 & 0,2541 & 0,1324 \\
\hline $\mathrm{BF}, 4 \mathrm{G}, \mathrm{CV}$ & 0,2040 & $0,0002 *$ & 0,2373 \\
\hline $\mathrm{BF}, 4 \mathrm{G}, \mathrm{CV}$ & 0,9606 & $0,0445 *$ & 0,3417 \\
\hline $\mathrm{BF}, 5 \mathrm{e}+\mathrm{G}, \mathrm{OE}$ & 0,5137 & 0,4760 & 0,2217 \\
\hline
\end{tabular}

De acordo com os dados da tabela 29, o tempo de latência foi menor para nomes cuja escrita foi regular, em três grupos de palavras, não havendo equivalência com as características observadas na leitura. 
Figura 20. Tempo de latência para a nomeação: 4 x 6 grafemas

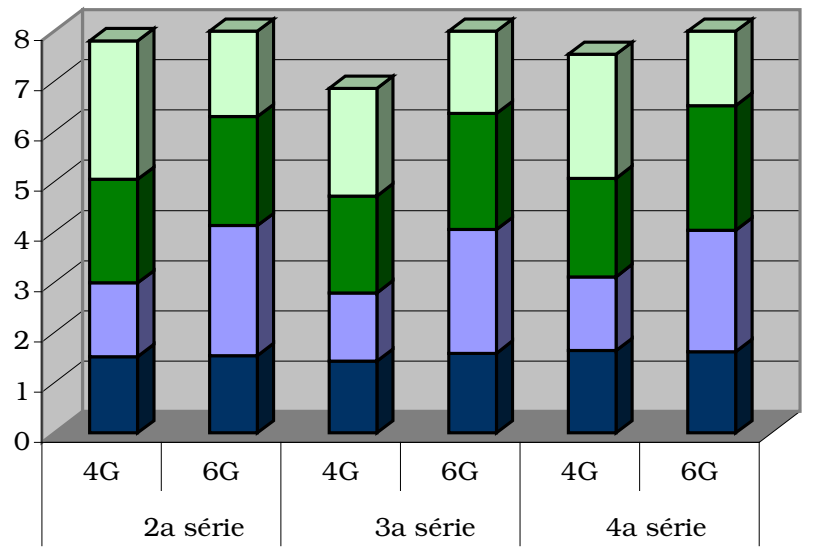

$\square \mathrm{bf}, \mathrm{cv}, \mathrm{I}$ $\square \mathrm{bf}, \mathrm{cv}, \mathrm{r}$ $\square$ af, cv, I

$\square \mathrm{af}, \mathrm{cv}, \mathrm{r}$

G: grafemas, af: alta freqüência, bf: baixa freqüência, cv:consoante-vogal, r: regular; i: irregular

Tabela 30. p-valores - comparação do tempo de latência para a nomeação: 4 × 6 grafemas

\begin{tabular}{lccc}
\hline \multicolumn{1}{c}{$\mathbf{4}$ grafemas $\mathbf{x}$} & \multicolumn{3}{c}{ p valores } \\
$\mathbf{6}$ grafemas & série & palavra & série x palavra \\
\hline $\mathrm{AF}, \mathrm{CV}, \mathrm{R}$ & 0,5895 & 0,5072 & 0,5825 \\
$\mathrm{AF}, \mathrm{CV}, \mathrm{I}$ & 0,8678 & $<\mathbf{0 , 0 0 0 1} *$ & 0,8851 \\
$\mathrm{BF}, \mathrm{CV}, \mathrm{R}$ & 0,8428 & $\mathbf{0 , 0 0 5 2}$ & $*$ \\
$\mathrm{BF}, \mathrm{CV}, \mathrm{I}$ & 0,4128 & 0,3145 & 0,3636 \\
\hline
\end{tabular}

p<0,05* AF: alta freqüência; $B F$ : baixa freqüência,

G: grafemas; CV: consoante-vogal; R: regular; I: irregular

Para a variável extensão, observou-se menor tempo de latência na nomeação de figuras cujos nomes são mais curtos do que longos. As crianças das três séries apresentaram o mesmo comportamento. 


\subsubsection{Tempo de duração da emissão oral}

Na tabela 31, a seguir, estão os valores referentes à média e desvio-padrão do tempo de duração da emissão oral, para cada tipo de palavra e em cada série.

Tabela 31. Média e desvio padrão em cada grupo de palavra e série para o tempo de duração da emissão oral (seg) na nomeação

\begin{tabular}{lcccc} 
Tipos de palavra & \multicolumn{4}{c}{ séries } \\
\cline { 2 - 5 } & $\mathbf{2}^{\mathrm{a}}$ & $\mathbf{3}^{\mathbf{a}}$ & $\mathbf{4}^{\mathbf{a}}$ & Total \\
\hline $\mathrm{M}(\mathrm{DP})$ & $\mathrm{M}(\mathrm{DP})$ & $\mathrm{M}(\mathrm{DP})$ & $\mathrm{M}(\mathrm{DP})$ \\
\hline $\mathrm{AF}, 4 \mathrm{G}, \mathrm{CV}, \mathrm{R}$ & $0,65(0,15)$ & $0,71(0,37)$ & $0,61(0,09)$ & $0,66(0,24)$ \\
\hline $\mathrm{AF}, 4 \mathrm{G}, \mathrm{CV}, \mathrm{I}$ & $0,64(0,11)$ & $0,73(0,44)$ & $0,59(0,11)$ & $0,65(0,27)$ \\
\hline $\mathrm{AF}, 6 \mathrm{G}, \mathrm{CV}, \mathrm{R}$ & $0,78(0,11)$ & $0,85(0,34)$ & $0,77(0,11)$ & $0,80(0,21)$ \\
\hline $\mathrm{AF}, 6 \mathrm{G}, \mathrm{CV}, \mathrm{I}$ & $0,76(0,15)$ & $0,83(0,47)$ & $0,72(0,09)$ & $0,77(0,28)$ \\
\hline $\mathrm{AF}, 5 \mathrm{e}+\mathrm{G}, \mathrm{OE}, \mathrm{R}$ & $0,78(0,14)$ & $0,78(0,38)$ & $0,74(0,10)$ & $0,76(0,23)$ \\
\hline $\mathrm{AF}, 5 \mathrm{e}+\mathrm{G}, \mathrm{OE}, \mathrm{I}$ & $0,67(0,11)$ & $0,73(0,37)$ & $0,68(0,09)$ & $0,69(0,22)$ \\
\hline $\mathrm{BF}, 4 \mathrm{G}, \mathrm{CV}, \mathrm{R}$ & $0,67(0,11)$ & $0,67(0,34)$ & $0,61(0,09)$ & $0,65(0,21)$ \\
\hline $\mathrm{BF}, 4 \mathrm{G}, \mathrm{CV}, \mathrm{I}$ & $0,71(0,12)$ & $0,81(0,60)$ & $0,66(0,13)$ & $0,72(0,36)$ \\
\hline $\mathrm{BF}, 6 \mathrm{G}, \mathrm{CV}, \mathrm{R}$ & $0,75(0,16)$ & $0,82(0,41)$ & $0,72(0,10)$ & $0,76(0,26)$ \\
\hline $\mathrm{BF}, 6 \mathrm{G}, \mathrm{CV}, \mathrm{I}$ & $0,74(0,10)$ & $0,81(0,33)$ & $0,73(0,09)$ & $0,76(0,20)$ \\
\hline $\mathrm{BF}, 5$ e +G, OE, R & $0,75(0,15)$ & $0,81(0,49)$ & $0,74(0,12)$ & $0,77(0,29)$ \\
\hline $\mathrm{BF}, 5$ e +G, OE, I & $0,73(0,1)$ & $0,77(0,47)$ & $0,70(0,13)$ & $0,73(0,29)$ \\
\hline
\end{tabular}

$\mathrm{AF}$ : alta freqüência; $\mathrm{BF}$ : baixa freqüência; G: grafemas;CV:consoante-vogal; OE: outras estruturas; R: regular; I:irregular; M: média; DP: desvio-padrão

Nas figuras 21, 22 e 23, podem ser visualizadas as comparações entre os tipos de palavras e séries. Nas tabelas 32, 33 e 34, encontram-se as análises estatísticas. 
Figura 21. Tempo de duração da emissão oral para a nomeação: alta $\mathbf{x}$ baixa freqüência

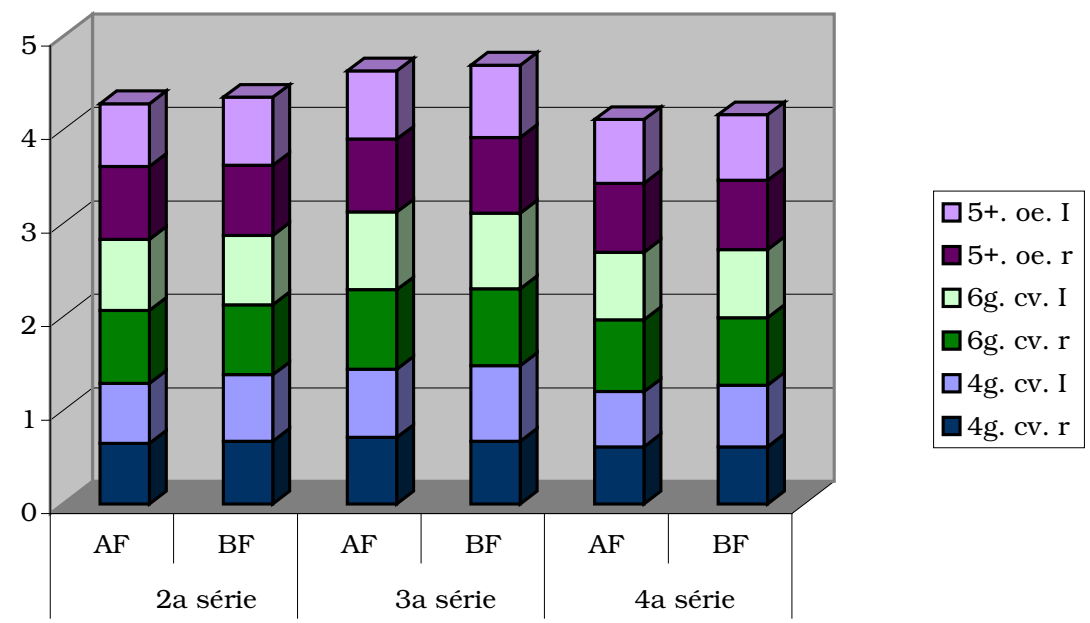

AF: alta freqüência, BF: baixa freqüência, cv:consoante-vogal, g:grafemas, oe: outras estruturas, r: regular, i: irregular

Tabela 32. p-valores - comparação do tempo de duração da emissão oral para a nomeação: alta $x$ baixa freqüência

\begin{tabular}{|c|c|c|c|}
\hline \multirow{2}{*}{$\begin{array}{l}\text { alta } \mathbf{x} \text { baixa } \\
\text { freqüêencia }\end{array}$} & \multicolumn{3}{|c|}{ p-valores } \\
\hline & série & palavra & série $x$ palavra \\
\hline $4 \mathrm{G}, \mathrm{CV}, \mathrm{R}$ & 0,3691 & 0,5226 & 0,3557 \\
\hline $4 \mathrm{G}, \mathrm{CV}, \mathrm{I}$ & 0,1564 & 0,0782 & 0,9961 \\
\hline $6 \mathrm{G}, \mathrm{CV}, \mathrm{R}$ & 0,3682 & $0,0154 *$ & 0,6227 \\
\hline $6 \mathrm{G}, \mathrm{CV}, \mathrm{I}$ & 0,3589 & 0,6263 & 0,7506 \\
\hline $5 \mathrm{e}+\mathrm{G}, \mathrm{OE}, \mathrm{R}$ & 0,7813 & 0,9368 & 0,4136 \\
\hline $5 \mathrm{e}+\mathrm{G}, \mathrm{OE}, \mathrm{I}$ & 0,6751 & $0,0053^{*}$ & 0,5173 \\
\hline
\end{tabular}

G: grafemas; CV: consoante-vogal; R: regular; I: irregular

O tempo de duração da emissão oral foi maior para as palavras de baixa freqüência na nomeação de dois tipos de figuras: nomes com 6 grafemas, estrutura cv e regulares e nomes com 5 ou mais grafemas, outras estruturas e irregulares. 
Figura 22. Tempo de duração da emissão oral para a nomeação: regulares e irregulares

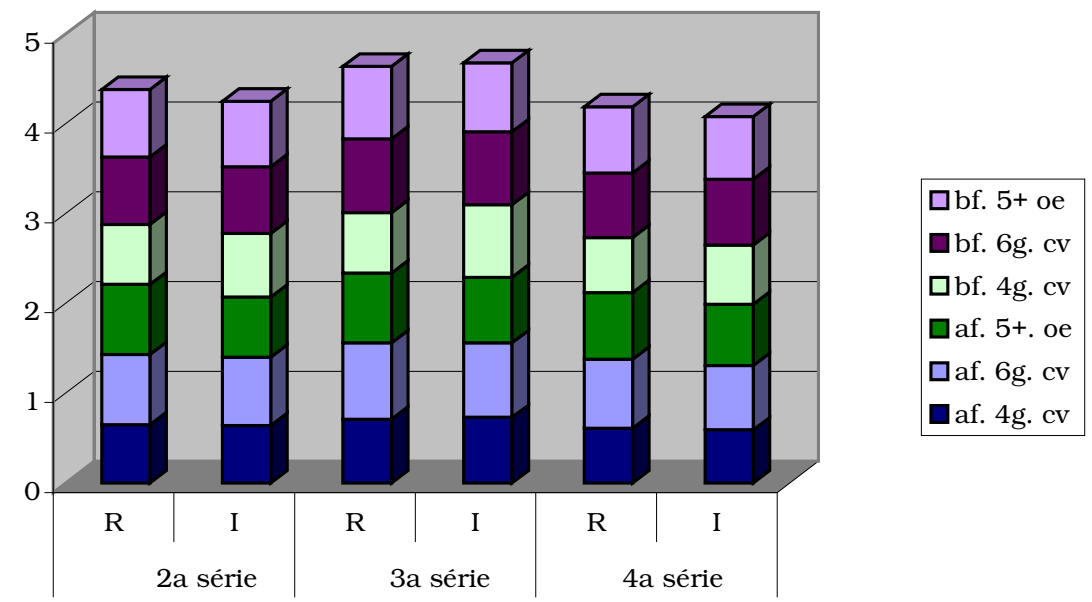

R: regular, I: irregular, af: alta freqüência, bf: baixa freqüência, g: grafemas, cv: consoante-vogal, oe: outras estruturas

Tabela 33. p-valores - comparação do tempo de duração da emissão oral para a nomeação: regulares $x$ irregulares

\begin{tabular}{lccc}
\hline \multicolumn{1}{c}{ regulares x } & \multicolumn{3}{c}{ p-valores } \\
irregulares & série & palavra & série x palavra \\
\hline $\mathrm{AF}, 4 \mathrm{G}, \mathrm{CV}$ & 0,1308 & 0,9269 & 0,8441 \\
$\mathrm{AF}, 6 \mathrm{G}, \mathrm{CV}$ & 0,4114 & $\mathbf{0 , 0 4 2 2} *$ & 0,5685 \\
$\mathrm{AF}, 5 \mathrm{e}+\mathrm{G}, \mathrm{OE}$ & 0,7857 & $<\mathbf{0 , 0 0 0 1} *$ & 0,0745 \\
$\mathrm{BF}, 4 \mathrm{G}, \mathrm{CV}$ & 0,3874 & $\mathbf{0 , 0 0 1 7}$ & 0,2070 \\
$\mathrm{BF}, 6 \mathrm{G}, \mathrm{CV}$ & 0,3251 & 0,9589 & 0,6998 \\
$\mathrm{BF}, 5 \mathrm{e}+\mathrm{G}, \mathrm{OE}$ & 0,7023 & $\mathbf{0 , 0 2 4 9 *}$ & 0,9288 \\
\hline
\end{tabular}

p<0,05* AF: alta freqüência; BF: baixa freqüência,

G: grafemas; CV: consoante-vogal; R: regular; I: irregular

Com exceção dos grupos de alta freqüência/4 grafemas/consoante-vogal e baixa freqüência/6 grafemas/consoantevogal, o tempo de duração da emissão oral foi maior na produção de nomes equivalentes a palavras irregulares para a leitura do que naquelas correspondentes às regulares. 
Figura 23. Tempo de duração da emissão oral para a nomeação: 4 x 6 grafemas

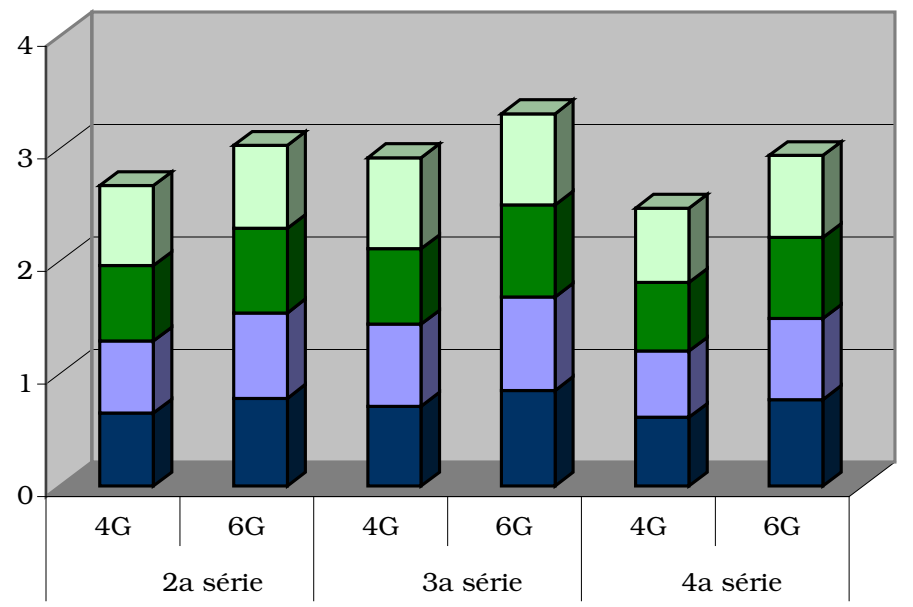

G:grafemas, af: alta freqüência, bf: baixa freqüência, r: regular, i: irregular; cv:consoante-vogal, oe:outras estruturas,

Tabela 34. p-valores - comparação do tempo de duração da emissão oral para a nomeação: 4 × 6 grafemas

\begin{tabular}{lccc}
\hline \multicolumn{1}{c}{$\begin{array}{c}\text { 4 grafemas } \mathbf{x} \\
\mathbf{6} \text { grafemas }\end{array}$} & série & \multicolumn{2}{c}{ p valores } \\
palavra & série x palavra \\
\hline $\mathrm{AF}, \mathrm{CV}, \mathrm{R}$ & 0,3320 & $<\mathbf{0 , 0 0 0 1}$ & 0,4203 \\
$\mathrm{AF}, \mathrm{CV}, \mathrm{I}$ & 0,1981 & $\mathbf{0 , 0 0 0 5}^{*}$ & 0,8609 \\
$\mathrm{BF}, \mathrm{CV}, \mathrm{R}$ & 0,4279 & $<\mathbf{0 , 0 0 0 1}$ & 0,2581 \\
$\mathrm{BF}, \mathrm{CV}, \mathrm{I}$ & 0,3022 & 0,1137 & 0,4961 \\
\hline
\end{tabular}

p<0,05* AF: alta freqüência; BF: baixa freqüência,

G: grafemas; CV: consoante-vogal; R: regular; I: irregular

O tempo de duração da emissão oral foi maior na nomeação de figuras com nomes mais extensos (6 grafemas) do que naquelas com nomes de 4 grafemas, na maioria dos tipos de palavra, com exceção das de baixa freqüência, irregular e com estrutura consoante-vogal. 


\subsubsection{Acertos}

Na tabela 35, abaixo, apresentam-se a média e o desviopadrão para os acertos, na nomeação.

Tabela 35. Média e desvio padrão em cada grupo de palavra e série para acertos na nomeação de figuras

\begin{tabular}{|c|c|c|c|c|}
\hline \multirow[t]{2}{*}{ Tipos de palavra } & \multicolumn{4}{|c|}{ séries } \\
\hline & $\mathbf{2}^{\mathbf{a}}$ & $\mathbf{3}^{\mathbf{a}}$ & $4^{a}$ & Total \\
\hline & M (DP) & M (DP) & M (DP) & $\mathrm{M}(\mathrm{DP})$ \\
\hline $\mathrm{AF}, 4 \mathrm{G}, \mathrm{CV}, \mathrm{R}$ & $83,5(13,8)$ & $85,9(10,6)$ & $81,0(12,6)$ & $83,4(12,4)$ \\
\hline $\mathrm{AF}, 4 \mathrm{G}, \mathrm{CV}, \mathrm{I}$ & $90,3(9,9)$ & $87,5(10,6)$ & $88,6(11,7)$ & $88,8(10,6)$ \\
\hline $\mathrm{AF}, 6 \mathrm{G}, \mathrm{CV}, \mathrm{R}$ & $98,0(4,7)$ & $95,3(8,1)$ & $94,5(8,9)$ & $95,9(7,5)$ \\
\hline $\mathrm{AF}, 6 \mathrm{G}, \mathrm{CV}, \mathrm{I}$ & $55,0(25,0)$ & $56,3(29,7)$ & $54,0(23,6)$ & $55,1(25,8)$ \\
\hline $\mathrm{AF}, 5 \mathrm{e}+\mathrm{G}, \mathrm{OE}, \mathrm{R}$ & $86,5(9,5)$ & $86,0(11,7)$ & $83,6(8,7)$ & $85,4(10,0)$ \\
\hline $\mathrm{AF}, 5 \mathrm{e}+\mathrm{G}, \mathrm{OE}, \mathrm{I}$ & $84,0(16,3)$ & $79,2(14,1)$ & $84,7(13,5)$ & $82,7(14,7)$ \\
\hline $\mathrm{BF}, 4 \mathrm{G}, \mathrm{CV}, \mathrm{R}$ & $74,3(14,3)$ & $83,9(12,1)$ & $80,0(14,3)$ & $79,3(14,0)$ \\
\hline $\mathrm{BF}, 4 \mathrm{G}, \mathrm{CV}, \mathrm{I}$ & $61,1(16,2)$ & $70,8(16,0)$ & $62,3(17,9)$ & $64,7(17,1)$ \\
\hline $\mathrm{BF}, 6 \mathrm{G}, \mathrm{CV}, \mathrm{R}$ & $76,8(15,2)$ & $73,8(15,6)$ & $74,0(13,8)$ & $74,9(14,7)$ \\
\hline $\mathrm{BF}, 6 \mathrm{G}, \mathrm{CV}, \mathrm{I}$ & $69,6(12,7)$ & $73,3(16,9)$ & $80,0(15,0)$ & $74,3(15,4)$ \\
\hline $\mathrm{BF}, 5 \mathrm{e}+\mathrm{G}, \mathrm{OE}, \mathrm{R}$ & 74,8 9,96) & $76,7(12,4)$ & $72,8(11,0)$ & $74,7(11,0)$ \\
\hline $\mathrm{BF}, 5 \mathrm{e}+\mathrm{G}, \mathrm{OE}, \mathrm{I}$ & $66,0(14,2)$ & $77,6(15,6)$ & $76,0(14,8)$ & $73,1(15,6)$ \\
\hline
\end{tabular}

Nas figuras 24, 25 e 26, podem ser observadas as porcentagens de acertos em cada tipo de palavra e nas tabelas 36, 37 e 38, o tratamento estatístico das comparações. 
Figura 24. Porcentagem de acertos na nomeação: alta $x$ baixa freqüência

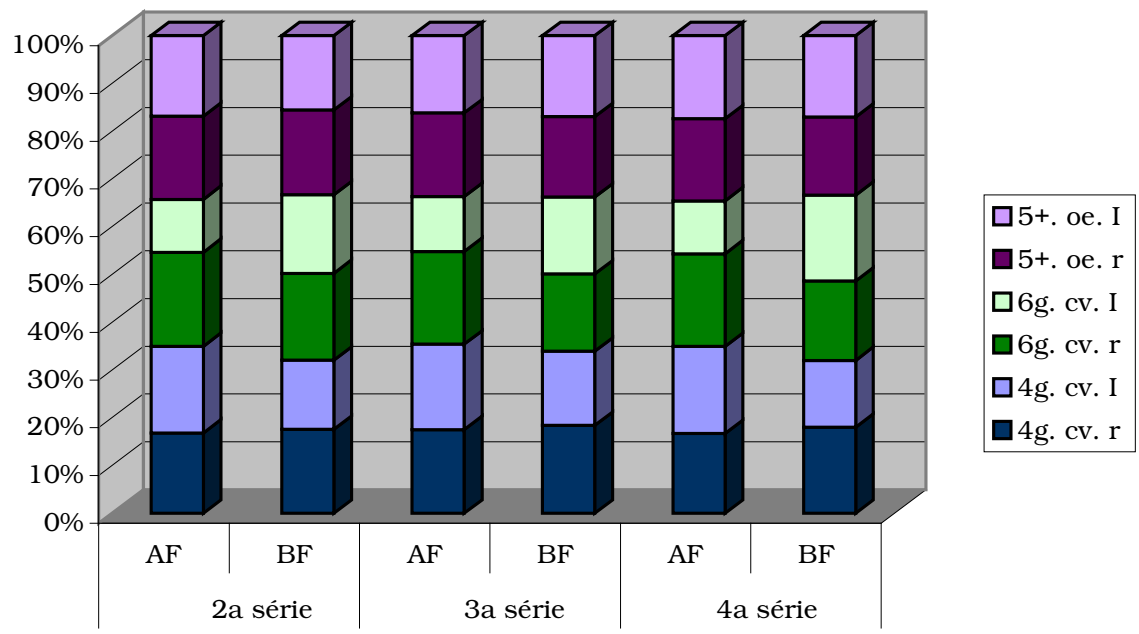

AF: alta freqüência, BF: baixa freqüência, cv:consoante-vogal, oe: outras estruturas, r: regular; i: irregular;g: grafemas,

Tabela 36. p-valores - comparação da porcentagem de acertos na nomeação: alta $x$ baixa freqüência

\begin{tabular}{lccc}
\hline $\begin{array}{c}\text { alta x baixa } \\
\text { freqüência }\end{array}$ & série & palavra $^{\text {p-valores }}$ & série x palavra \\
\hline $4 \mathrm{G}, \mathrm{CV}, \mathrm{R}$ & 0,0999 & $\mathbf{0 , 0 3 9 8}$ & 0,1754 \\
$4 \mathrm{G}, \mathrm{CV}, \mathrm{I}$ & 0,4625 & $<\mathbf{0 , 0 0 0 1} *$ & $\mathbf{0 , 0 2 0 1}$ \\
6G, CV, R & 0,4176 & $<\mathbf{0 , 0 0 0 1} *$ & 0,9666 \\
$6 \mathrm{G}, \mathrm{CV}, \mathrm{I}$ & 0,5621 & $<\mathbf{0 , 0 0 0 1} *$ & 0,3600 \\
$5 \mathrm{e}+\mathrm{G}, \mathrm{OE}, \mathrm{R}$ & 0,3010 & $<\mathbf{0 , 0 0 0 1} *$ & 0,8512 \\
$5 \mathrm{e}+\mathrm{G}, \mathrm{OE}, \mathrm{I}$ & 0,2681 & $<\mathbf{0 , 0 0 0 1} *$ & $\mathbf{0 , 0 0 9 3}$ \\
\hline \multicolumn{1}{c}{ p<0,05* } & G: grafemas, CV: consoante-vogal; \\
R:regular; I: irregular; OE: outras estruturas
\end{tabular}

De forma semelhante ao tempo de latência, os acertos (tabela 36) foram predominantes na nomeação de figuras com nomes de alta freqüência. Houve diferença no comportamento entre as séries na nomeação de dois tipos de figuras (nomes com 4 grafemas, estrutura cv e irregular e nomes com 5 ou mais grafemas, outras estruturas e irregular): a diferença entre alta e baixa freqüência foi mais evidente na $2^{\mathrm{a}}$ e na $4^{\mathrm{a}}$ séries. 
Figura 25. Porcentagem de acertos na nomeação: regulares $x$ irregulares

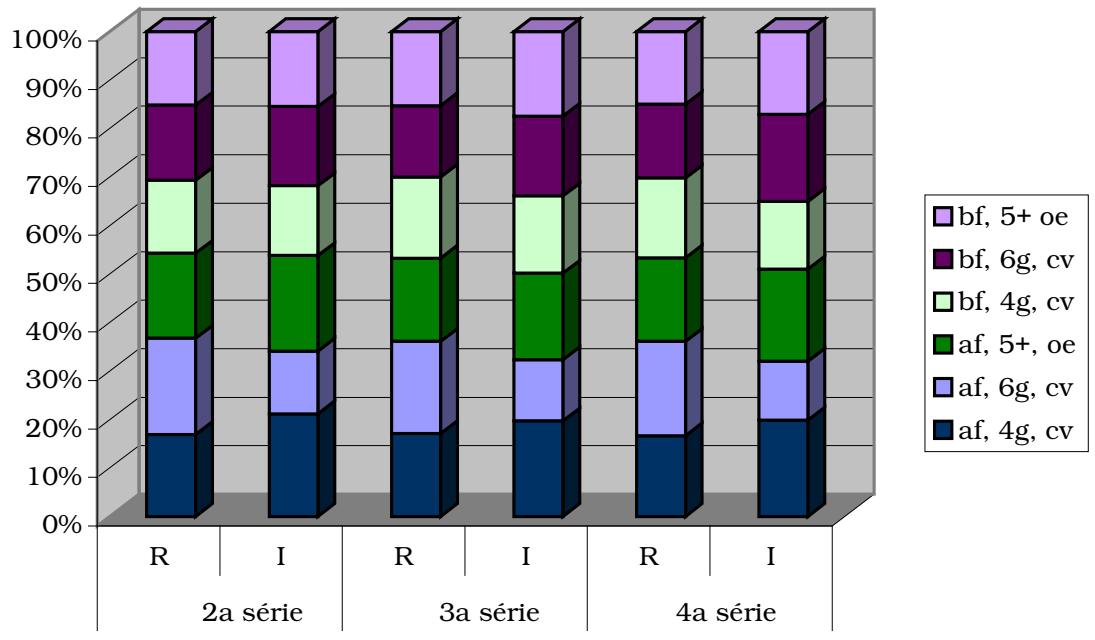

R: regular, I: irregular, af: alta freqüência, bf: baixa freqüência, g: grafemas, cv: consaonte-vogal, oe: outras estruturas

Tabela 37. p-valores - comparação da porcentagem de acertos na nomeação: regulares $x$ irregulares

\begin{tabular}{lccc}
\hline \multicolumn{1}{c}{$\begin{array}{c}\text { regulares } \mathbf{x} \\
\text { irregulares }\end{array}$} & série & p-valores \\
palavra & série x palavra \\
\hline $\mathrm{AF}, 4 \mathrm{G}, \mathrm{CV}$ & 0,6619 & $\mathbf{0 , 0 0 2 5} *$ & 0,2998 \\
$\mathrm{AF}, 6 \mathrm{G}, \mathrm{CV}$ & 0,8499 & $\mathbf{< , 0 0 0 1} *$ & 0,8650 \\
$\mathrm{AF}, 5 \mathrm{e}+\mathrm{G}, \mathrm{OE}$ & 0,5936 & 0,1663 & 0,2804 \\
$\mathrm{BF}, 4 \mathrm{G}, \mathrm{CV}$ & $\mathbf{0 , 0 2 4 4} *$ & $<\mathbf{0 , 0 0 0 1} *$ & 0,5950 \\
$\mathrm{BF}, 6 \mathrm{G}, \mathrm{CV}$ & 0,4501 & 0,8033 & $\mathbf{0 , 0 4 8 0} *$ \\
$\mathrm{BF}, 5 \mathrm{e}+\mathrm{G}, \mathrm{OE}$ & 0,0866 & 0,3938 & $\mathbf{0 , 0 1 9 3} *$ \\
\hline
\end{tabular}

p<0,05* AF: alta freqüência; $\mathrm{BF}$ : baixa freqüência,

G: grafemas; CV: consoante-vogal; OE: outras estruturas

Verificou-se acima (tabela 37) que a diferença no comportamento entre as séries foi predominante na nomeação de figuras com nomes de baixa freqüência, 5 ou mais grafemas, estrutura cv e mais complexas: enquanto a $2^{\text {a }}$ série apresentou predomínio de acertos nos nomes regulares, a $4^{\underline{a}}$ série apresentou o comportamento inverso. Porém, a diferença de acertos entre nomes equivalentes às palavras regulares e irregulares nestas séries não foi estatisticamente significante. 
Figura 26. Porcentagem de acertos na nomeação: 4 e 6 grafemas

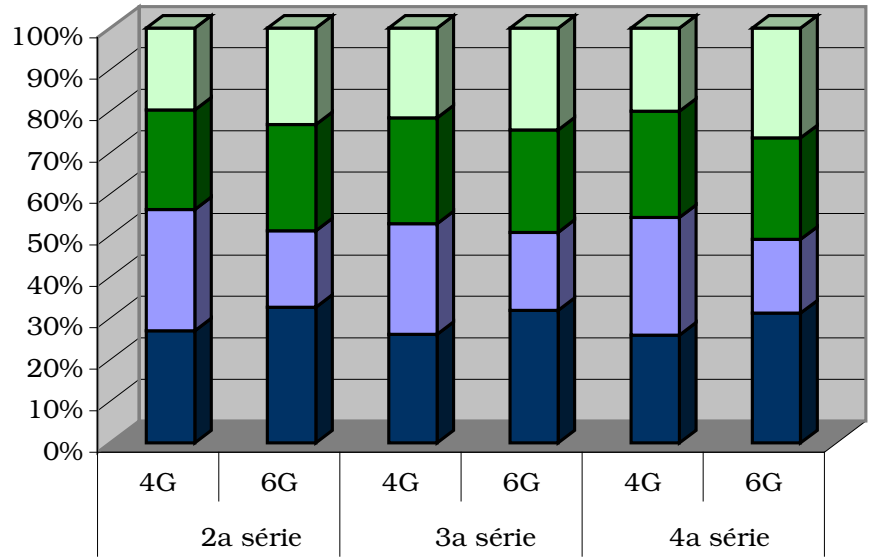

G: grafemas, af: alta freqüência, bf: baixa freqüência, cv: consoante-vogal, r: regular; i: irregular

Tabela 38. p-valores - comparação da porcentagem de acertos

\begin{tabular}{|c|c|c|c|}
\hline \multirow{2}{*}{$\begin{array}{l}\text { grafemas } x \\
6 \text { grafemas }\end{array}$} & \multicolumn{3}{|c|}{ p valores } \\
\hline & série & palavra & série $\mathbf{x}$ palavra \\
\hline $\mathrm{AF}, \mathrm{CV}, \mathrm{R}$ & 0,3290 & $<0,0001 *$ & 0,3456 \\
\hline $\mathrm{AF}, \mathrm{CV}, \mathrm{I}$ & 0,9499 & $<0,0001 *$ & 0,8516 \\
\hline $\mathrm{BF}, \mathrm{CV}, \mathrm{R}$ & 0,5582 & $0,0426 *$ & 0,0637 \\
\hline $\mathrm{BF}, \mathrm{CV}, \mathrm{I}$ & 0,1766 & $<0,0001 *$ & $0,0071 *$ \\
\hline
\end{tabular}

p<0,05* AF: alta freqüência; $\mathrm{BF}$ : baixa freqüência,

G: grafemas; CV: consoante-vogal; R: regular; I: irregular

As figuras com nomes formados por 4 grafemas apresentaram mais acertos do que as com 6, apontando para a ocorrência do efeito extensão. Esta diferença foi observada em todas as séries, com exceção da $3^{\text {a }}$, para as figuras com nomes mais complexos (baixa freqüência, irregular e estrutura consoante-vogal) (efeito série $x$ palavra significante). 


\subsubsection{Características da nomeação de figuras}

As figuras que não receberam seu nome usual foram analisadas qualitativamente. Devido à quantidade de categorias de classificação e à baixa incidência destas, não foi possível aplicar testes estatísticos. As estratégias apresentadas durante a nomeação de figuras são apresentadas na tabela 39.

Tabela 39- Características da nomeação em cada tipo de palavra e série

\begin{tabular}{c|cccccc}
\hline Tipos de resposta & \multicolumn{2}{c}{$\mathbf{2}^{\mathbf{a}}$ série } & \multicolumn{2}{c}{$\mathbf{3}^{\mathbf{a}}$ série } & \multicolumn{2}{c}{$\mathbf{4}^{\mathbf{a}}$ série } \\
\cline { 2 - 7 } & $\mathbf{N}$ & $\mathbf{N}$ & $\mathbf{N}$ & $\mathbf{0}$ & $\mathbf{N}$ & $\%$ \\
\hline $\mathbf{S}$ & & & & & & \\
$\mathbf{P}$ & 153 & 27,37 & 165 & 35,41 & 172 & 44,22 \\
$\mathbf{F}$ & 156 & 27,91 & 114 & 24,46 & 125 & 32,13 \\
$\mathbf{S P}$ & 9 & 1,61 & 2 & 0,43 & 6 & 1,54 \\
$\mathbf{S F}$ & 142 & 25,40 & 128 & 27,47 & 12 & 3,08 \\
$\mathbf{P F}$ & 1 & 0,18 & 0 & 0,00 & 0 & 0,00 \\
$\mathbf{N R}$ & 5 & 0,89 & 0 & 0,00 & 0 & 0,00 \\
$\mathbf{C I R}$ & 81 & 14,49 & 39 & 8,37 & 51 & 13,11 \\
$\mathbf{S R}$ & 0 & 0,00 & 3 & 0,64 & 1 & 0,26 \\
& 0 & 0,00 & 1 & 0,21 & 4 & 1,03 \\
\hline
\end{tabular}

Teste de Qui-quadrado (p)=0,0411. S: semântico; P:perceptual; SP: semântico e perceptual; F: fonológico; PF: perceptual e fonológico; NR: não resposta; CIR: circunlocução; SR: sem relação; NR: não resposta.

Observou-se aumento progressivo do percentual de erros semânticos com a escolarização e redução no percentual de erros semântico-perceptuais na $4^{\underline{a}}$ série.

As revisões realizadas (correção da resposta) podem ser visualizadas na tabela 40, assim como os erros de produção (fragmentações, repetição de sílabas e fonemas, prolongamentos) ocorridos durante a nomeação esperada (EP nos acertos) ou durante a substituição do nome alvo por outro (EP nos erros).

Tabela 40. Revisões e erros de produção na nomeação 


\begin{tabular}{l|ccccccc}
\hline \multirow{2}{*}{ Tipos de resposta } & \multicolumn{2}{c}{ 2a série } & \multicolumn{2}{c}{ 3a série } & \multicolumn{2}{c}{ 4a série } \\
\cline { 2 - 7 } & $\mathbf{N}$ & $\mathbf{\%}$ & $\mathbf{N}$ & $\mathbf{\%}$ & $\mathbf{N}$ & $\mathbf{\%}$ \\
\hline revisões & 12 & 2,15 & 14 & 3,00 & 18 & 4,63 \\
EP nos acertos & 10 & 0,53 & 7 & 0,38 & 9 & 0,47 \\
EP nos erros & 0 & 0 & 3 & 0,64 & 5 & 0,97 \\
\hline
\end{tabular}

Teste de Qui-quadrado: 0,7817

EP: erros de produção

De acordo com os dados da tabela 40, não houve diferença estatisticamente significante entre as séries no que se refere à porcentagem de revisões e de erros de produção realizados na nomeação de figuras.

\subsubsection{Correlação entre tempo de latência e acertos}

A correlação entre o percentual de acertos e a média do tempo de latência em cada grupo de estímulos e séries pode ser observada na tabela 41, abaixo:

\section{Tabela 41. Correlação entre tempo de latência e acertos}

\section{para a nomeação}

\begin{tabular}{|c|c|c|c|c|c|c|c|}
\hline Tipos de palavra & $2^{a}$ & $3^{a}$ & $4^{a}$ & Tipos de palavra & $\mathbf{2}^{\mathrm{a}}$ & $3^{a}$ & $4^{\mathrm{a}}$ \\
\hline \multirow[b]{2}{*}{$A F, 4 G, R, C V$} & $-0,132$ & $-0,337$ & $-0,11$ & \multirow{2}{*}{$B F, 4 G, R, C V$} & & $-0,234$ & $-0,407$ \\
\hline & & & & & 0,026* & 0,27 & $0,043^{*}$ \\
\hline \multirow[b]{2}{*}{$\mathrm{AF}, \mathbf{4 G}, \mathrm{I}, \mathrm{CV}$} & & & & \multirow[b]{2}{*}{$\mathrm{BF}, 4 \mathrm{G}, \mathrm{I}, \mathrm{CV}$} & & $-0,518$ & $-0,438$ \\
\hline & & & & & & 9* & \\
\hline \multirow[b]{2}{*}{$\mathrm{AF}, \mathbf{6 G}, \mathrm{R}, \mathrm{CV}$} & -0 & $-0,771$ & $-0,2$ & \multirow[b]{2}{*}{ BF, 6G, R,CV (p) } & 87 & -0, & \\
\hline & & & & & & 0,0 & \\
\hline \multirow[b]{2}{*}{$\mathrm{AF}, 6 \mathrm{G}, \mathrm{I}, \mathrm{CV}$} & $-0,1$ & $-0,1$ & 0,134 & \multirow[b]{2}{*}{$\mathrm{BF}, \mathbf{6 G}, \mathrm{I}, \mathrm{CV}$} & 66 & $-0,3$ & $-0,5$ \\
\hline & & 0,44 & 0,522 & & 19* & 0,107 & \\
\hline \multirow[b]{2}{*}{$A F, 5+G, R, O E$} & $-0,209$ &,- 216 & $-0,164$ & \multirow[b]{2}{*}{$\mathbf{B F}, \mathbf{5 + G}, \mathbf{R}, \mathbf{O E}(\mathrm{p})$} & $-0,352$ & $-0,602$ & $-0,078$ \\
\hline & & & 0,434 & & & 0,002* & \\
\hline \multirow[b]{2}{*}{$\mathrm{AF}, 5+\mathrm{G}, \mathrm{I}, \mathrm{OE}$} & 0,162 & $-0,118$ & $-0,018$ & \multirow[b]{2}{*}{ BF,5+G,I,OE } & $-0,228$ & $-0,223$ & $-0,288$ \\
\hline & 0,438 & 0,583 & 0,932 & & 0,274 & 0,295 & 0,162 \\
\hline
\end{tabular}

$\mathrm{AF}$ : alta freqüência; $\mathrm{BF}$ : baixa freqüência; G: grafemas;CV:consoante-vogal; OE: outras estruturas; R: regular; I:irregular; CP: correlação e Pearson

* - correlação moderada; ** - correlação boa 
Os dados indicaram correlações negativas e estatisticamente significantes nas três séries, principalmente nos grupos de baixa freqüência. Todas as correlações significantes são moderadas, com exceção da correlação observada na $3^{\text {a }}$ série, para as palavras de alta freqüência, 6 grafemas, regulares e com estrutura consoante-vogal, que foi considerada boa.

\subsubsection{Correlação entre tempo de duração da emissão oral e acertos}

A análise estatística referente à correlação entre acertos e tempo de duração da emissão oral pode ser visualizada na tabela seguinte.

Tabela 42. Correlação entre tempo de duração da emissão oral e acertos para a nomeação

\begin{tabular}{|c|c|c|c|c|c|c|c|c|c|}
\hline \multicolumn{2}{|c|}{ Tipos de palavra } & $\mathbf{2}^{\mathbf{a}}$ & $3^{\mathbf{a}}$ & $4^{a}$ & \multicolumn{2}{|c|}{ Tipos de palavra } & \multirow{2}{*}{$\frac{2^{a}}{-0,556}$} & \multirow{2}{*}{$\frac{\mathbf{3}^{\mathbf{a}}}{-0,066}$} & \multirow{2}{*}{$\frac{\mathbf{4}^{\mathbf{a}}}{-0,138}$} \\
\hline & $\mathrm{CP}$ & $-0,422$ & $-0,019$ & $-0,522$ & & $\mathrm{CP}$ & & & \\
\hline $\mathrm{AF}, \mathbf{4 G}, \mathbf{R}, \mathbf{C V}$ & (p) & $0,035^{*}$ & 0,930 & $0,007^{*}$ & BF, 4G, R, CV & (p) & $0,004^{*}$ & 0,758 & 0,511 \\
\hline \multirow[b]{2}{*}{$\mathrm{AF}, \mathbf{4 G}, \mathrm{I}, \mathrm{CV}$} & $\mathrm{CP}$ & $-0,316$ & 0,348 & 0,077 & \multirow{3}{*}{ BF, 4G, I, CV } & $\mathrm{CP}$ & $-0,105$ & $-0,251$ & $-0,156$ \\
\hline & (p) & 0,124 & 0,095 & 0,716 & & (p) & 0,619 & 0,237 & 0,457 \\
\hline \multirow[b]{2}{*}{$\mathrm{AF}, \mathbf{6 G}, \mathrm{R}, \mathrm{CV}$} & $\mathrm{CP}$ & 0,227 & $-0,039$ & $-0,391$ & & $\mathrm{CP}$ & & $-0,131$ & $-0,508$ \\
\hline & (p) & 0,276 & 0,858 & 0,053 & $\mathrm{BF}, \mathbf{6 G}, \mathrm{R}, \mathrm{CV}$ & (p) & 0,179 & 0,540 & $0,009^{*}$ \\
\hline \multirow[b]{2}{*}{$\mathrm{AF}, \mathbf{6 G}, \mathrm{I}, \mathrm{CV}$} & $\mathrm{CP}$ & 0,062 & 0,171 & 0,155 & \multirow{4}{*}{$\begin{array}{l}\mathrm{BF}, \mathbf{6 G}, \mathbf{I}, \mathrm{CV} \\
\mathrm{BF}, \mathbf{5}+\mathrm{G}, \mathrm{R}, \mathrm{OE}\end{array}$} & $\mathrm{CP}$ & $-0,083$ & 0,174 & $-0,250$ \\
\hline & (p) & 0,767 & 0,425 & 0,458 & & (p) & 0,694 & 0,416 & 0,228 \\
\hline \multirow[b]{2}{*}{$A F, 5+G, R, O E$} & $\mathrm{CP}$ & 0,106 & 0,008 & $-0,445$ & & $\mathrm{CP}$ & $-0,338$ & 0,012 & $-0,190$ \\
\hline & (p) & 0,613 & 0,971 & $0,026^{*}$ & & (p) & 0,099 & 0,957 & 0,363 \\
\hline \multirow[b]{2}{*}{$\mathrm{AF}, 5+\mathrm{G}, \mathrm{I}, \mathrm{OE}$} & $\mathrm{CP}$ & 0,601 & 0,322 & 0,141 & \multirow[b]{2}{*}{ BF,5+G, I, OE } & $\mathrm{CP}$ & $-0,295$ & 0,245 & $-0,183$ \\
\hline & (p) & $0,002 *$ & 0,125 & 0,500 & & (p) & 0,153 & 0,248 & 0,381 \\
\hline
\end{tabular}

$\mathrm{AF}$ : alta freqüência; $\mathrm{BF}$ : baixa freqüência; G: grafemas; CV:consoante-vogal;

OE: outras estruturas; R: regular; I:irregular; CP: correlação e Pearson;

* - correlação moderada; ** - correlação boa

Para a nomeação, foram encontradas correlações negativas e moderadas entre acertos e tempo de duração da emissão oral. 


\subsubsection{Comparação entre leitura de palavras e nomeação de figuras}

Os próximos resultados referem-se à comparação entre leitura de palavras e nomeação de figuras, nos grupos de crianças leitoras, considerando-se cada grupo de palavras e cada série. Os três subitens dizem respeito à comparação quanto ao tempo de latência, tempo de duração da emissão oral e acertos, respectivamente.

\subsubsection{Tempo de latência}

A figura 27 apresenta a média do tempo de latência (seg) para a leitura e para a nomeação e a tabela 43 , os p valores da comparação entre as duas provas.

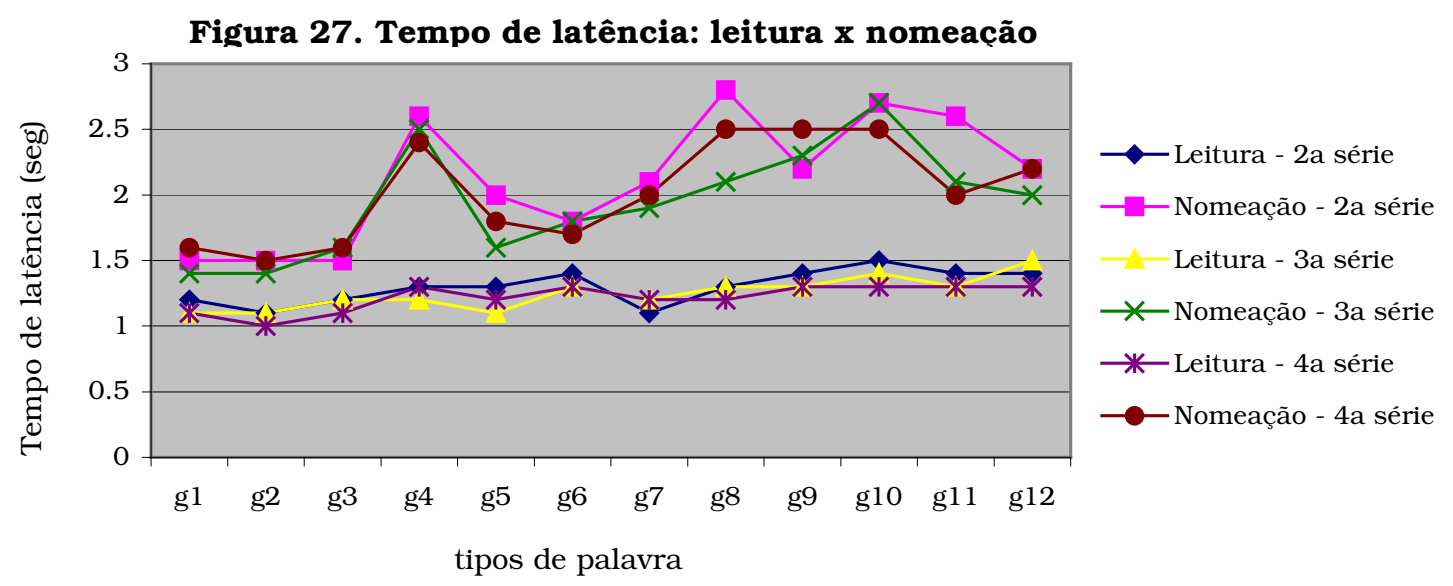

g1: alta freqüência, 4 grafemas, regular, consoante-vogal g2: alta freqüência, 4 grafemas, irregular, consoante-vogal g3: alta freqüência, 6 grafemas, regular, consoante-vogal g4: alta freqüência, 6 grafemas, irregular, consoante-vogal g5: alta freqüência, 5 e mais grafemas, regular, estruturas mais complexas g6: alta freqüência, 5 e mais grafemas, irregular, estruturas mais complexas g7: baixa freqüência, 4 grafemas, regular, consoante-vogal g8: baixa freqüência, 4 grafemas, irregular, consoante-vogal g9: baixa freqüência, 6 grafemas, regular, consoante-vogal g10: baixa freqüência, 6 grafemas, irregular, consoante-vogal g11: baixa freqüência, 5 e mais grafemas, regular, estruturas mais complexas g12: baixa freqüência, 5 e mais grafemas, irregular, estruturas mais complexas 
Observou-se que o tempo de latência para a leitura de palavras foi menor do que na nomeação de figuras, nas três séries. A diferença entre a leitura e a nomeação foi maior, principalmente nos grupos de estímulos de baixa freqüência.

Tabela 43. p-valores: comparação do tempo de latência entre leitura e nomeação

\begin{tabular}{|c|c|c|c|}
\hline \multirow[b]{2}{*}{$\begin{array}{l}\text { Características } \\
\text { psicolingüisticas }\end{array}$} & \multicolumn{3}{|c|}{ p-valores } \\
\hline & Série & Prova & Série $\mathrm{x}$ prova \\
\hline $\mathrm{AF}, 4 \mathrm{G}, \mathrm{CV}, \mathrm{R}$ & 0,4310 & $<0,0001 *$ & $<0,4168$ \\
\hline $\mathrm{AF}, 4 \mathrm{G}, \mathrm{CV}, \mathrm{I}$ & 0,7814 & $<0,0001 *$ & 0,3955 \\
\hline $\mathrm{AF}, 6 \mathrm{G}, \mathrm{CV}, \mathrm{R}$ & 0,9908 & $<0,0001 *$ & 0,6481 \\
\hline $\mathrm{AF}, 6 \mathrm{G}, \mathrm{CV}, \mathrm{I}$ & 0,9217 & $<0,0001 *$ & 0,8996 \\
\hline $\mathrm{AF}, 5 \mathrm{e}+\mathrm{G}, \mathrm{OE}, \mathrm{R}$ & 0,0677 & $<0,0001 *$ & 0,4984 \\
\hline $\mathrm{AF}, 5 \mathrm{e}+\mathrm{G}, \mathrm{OE}, \mathrm{I}$ & 0,5487 & $<0,0001 *$ & 0,7771 \\
\hline $\mathrm{BF}, 4 \mathrm{G}, \mathrm{CV}, \mathrm{R}$ & 0,9873 & $<0,0001 *$ & 0,5184 \\
\hline $\mathrm{BF}, 4 \mathrm{G}, \mathrm{CV}, \mathrm{I}$ & 0,1782 & $<0,0001 *$ & 0,1221 \\
\hline $\mathrm{BF}, 6 \mathrm{G}, \mathrm{CV}, \mathrm{R}$ & 0,7823 & $<0,0001 *$ & 0,3719 \\
\hline $\mathrm{BF}, 6 \mathrm{G}, \mathrm{CV}, \mathrm{I}$ & 0,6132 & $<0,0001 *$ & 0,9213 \\
\hline $\mathrm{BF}, 5 \mathrm{e}+\mathrm{G}, \mathrm{OE}, \mathrm{R}$ & 0,2833 & $<0,0001 *$ & 0,2718 \\
\hline $\mathrm{BF}, 5 \mathrm{e}+\mathrm{G}, \mathrm{OE}, \mathrm{I}$ & 0,9183 & $<0,0001 *$ & 0,4979 \\
\hline
\end{tabular}

p<0,05 AF: alta freqüência; BF: baixa freqüência; G: grafemas;

$\mathrm{CV}$ :consoante-vogal; OE: outras estruturas; R: regular; I:irregular

Constatou-se na tabela 43, na coluna prova, que os p-valores indicaram diferença estatisticamente significante entre leitura e nomeação para todos os tipos de palavras, com o tempo de latência menor para a leitura do que na nomeação. Na coluna série, observou-se a ausência de diferença significante entre as três séries estudadas e na coluna série $x$ prova, os $\mathrm{p}$-valores indicaram que a diferença entre ambas as provas ocorre da mesma forma em todas as séries, ou seja, tempo de leitura menor do que o de nomeação. 


\title{
6.2.3.2.Tempo de duração da emissão oral
}

\author{
$\mathrm{Na}$ figura 28, pode ser visualizado o tempo de duração da \\ emissão oral para leitura e nomeação e, na tabela 44, a comparação \\ entre as duas provas.
}

Figura 28.Tempo de duração da emissão oral: leitura x nomeação

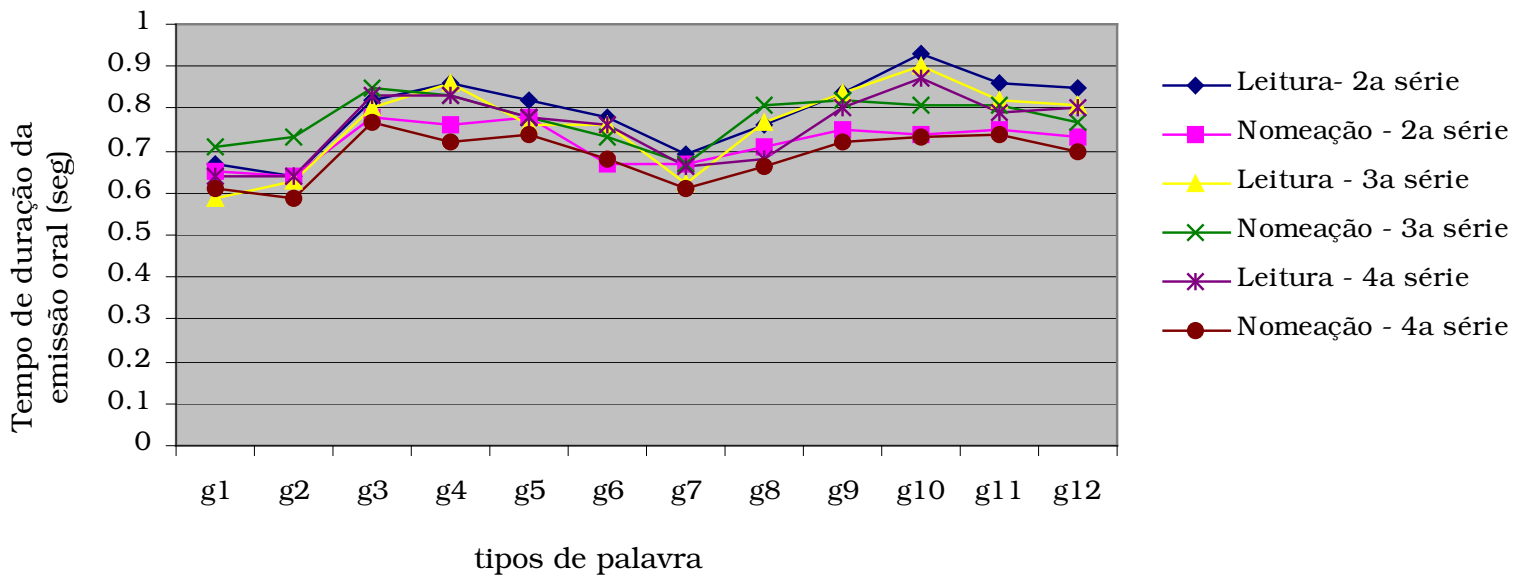

g1: alta freqüência, 4 grafemas, regular, consoante-vogal g2: alta freqüência, 4 grafemas, irregular, consoante-vogal g3: alta freqüência, 6 grafemas, regular, consoante-vogal g4: alta freqüência, 6 grafemas, irregular, consoante-vogal g5: alta freqüência, 5 e mais grafemas, regular, estruturas mais complexas g6: alta freqüência, 5 e mais grafemas, irregular, estruturas mais complexas g7: baixa freqüência, 4 grafemas, regular, consoante-vogal g8: baixa freqüência, 4 grafemas, irregular, consoante-vogal g9: baixa freqüência, 6 grafemas, regular, consoante-vogal g10: baixa freqüência, 6 grafemas, irregular, consoante-vogal g11: baixa freqüência, 5 e mais grafemas, regular, estruturas mais complexas g12: baixa freqüência, 5 e mais grafemas, irregular, estruturas mais complexas 
Tabela 44. p-valores: comparação do tempo de duração da emissão oral entre leitura e nomeação

\begin{tabular}{|c|c|c|c|}
\hline \multirow[b]{2}{*}{$\begin{array}{l}\text { Caracteristicas } \\
\text { psicolingüisticas }\end{array}$} & \multicolumn{3}{|c|}{ p-valores } \\
\hline & Série & Prova & Série $x$ prova \\
\hline$\overline{\mathrm{AF}}, 4 \mathrm{G}, \mathrm{CV}, \mathrm{R}$ & 0,6143 & 0,3889 & 0,0510 \\
\hline $\mathrm{AF}, 4 \mathrm{G}, \mathrm{CV}, \mathrm{I}$ & 0,3521 & 0,5481 & 0,1144 \\
\hline $\mathrm{AF}, 6 \mathrm{G}, \mathrm{CV}, \mathrm{R}$ & 0,7453 & 0,4655 & 0,2181 \\
\hline $\mathrm{AF}, 6 \mathrm{G}, \mathrm{CV}, \mathrm{I}$ & 0,4719 & 0,0094* & 0,5308 \\
\hline $\mathrm{AF}, 5 \mathrm{e}+\mathrm{G}, \mathrm{OE}, \mathrm{R}$ & 0,6297 & 0,4468 & 0,6897 \\
\hline $\mathrm{AF}, 5 \mathrm{e}+\mathrm{G}, \mathrm{OE}, \mathrm{I}$ & 0,7966 & $0,0170 *$ & 0,5217 \\
\hline $\mathrm{BF}, 4 \mathrm{G}, \mathrm{CV}, \mathrm{R}$ & 0,4498 & 0,6964 & 0,2363 \\
\hline $\mathrm{BF}, 4 \mathrm{G}, \mathrm{CV}, \mathrm{I}$ & 0,1677 & 0,8213 & 0,7277 \\
\hline $\mathrm{BF}, 6 \mathrm{G}, \mathrm{CV}, \mathrm{R}$ & 0,3840 & $0,0370 *$ & 0,5562 \\
\hline $\mathrm{BF}, 6 \mathrm{G}, \mathrm{CV}, \mathrm{I}$ & 0,4291 & $<0,0001^{*}$ & 0,3915 \\
\hline $\mathrm{BF}, 5 \mathrm{e}+\mathrm{G}, \mathrm{OE}, \mathrm{R}$ & 0,5784 & 0,0089* & 0,5933 \\
\hline $\mathrm{BF}, 5$ e $+\mathrm{G}, \mathrm{OE}, \mathrm{I}$ & 0,7424 & $0,0211^{*}$ & 0,6826 \\
\hline
\end{tabular}

$\mathbf{p}<\mathbf{0 , 0 5} \mathrm{AF}$ : alta freqüência; $\mathrm{BF}$ : baixa freqüência; G: grafemas;

CV:consoante-vogal; OE: outras estruturas; R: regular; I:irregular

$\mathrm{Na}$ figura 28 e na tabela 44 , notou-se que, na $2^{\mathrm{a}}$ e na $4^{\mathrm{a}}$ séries, o tempo de duração da emissão oral foi maior para a leitura do que para a nomeação em todos os grupos de palavras. Já a $3^{a}$ série apresentou maior tempo de duração da emissão oral para a nomeação do que para a leitura nos grupos de palavras $1,2,3,5,7$ e 8 .

De forma estatisticamente significante, o tempo para a leitura foi maior do que para a nomeação nos grupos 4, 6 e de 9 a 12 , nas três séries. Entre as séries, este comportamento foi semelhante (ausência de interação série x prova).

\subsubsection{Acertos}

$\mathrm{Na}$ figura 29 e na tabela 45, podem ser visualizados a porcentagem de acertos para leitura e para nomeação e a análise estatística da comparação entre ambas. 
Figura 29. Porcentagem de acertos: leitura x nomeação

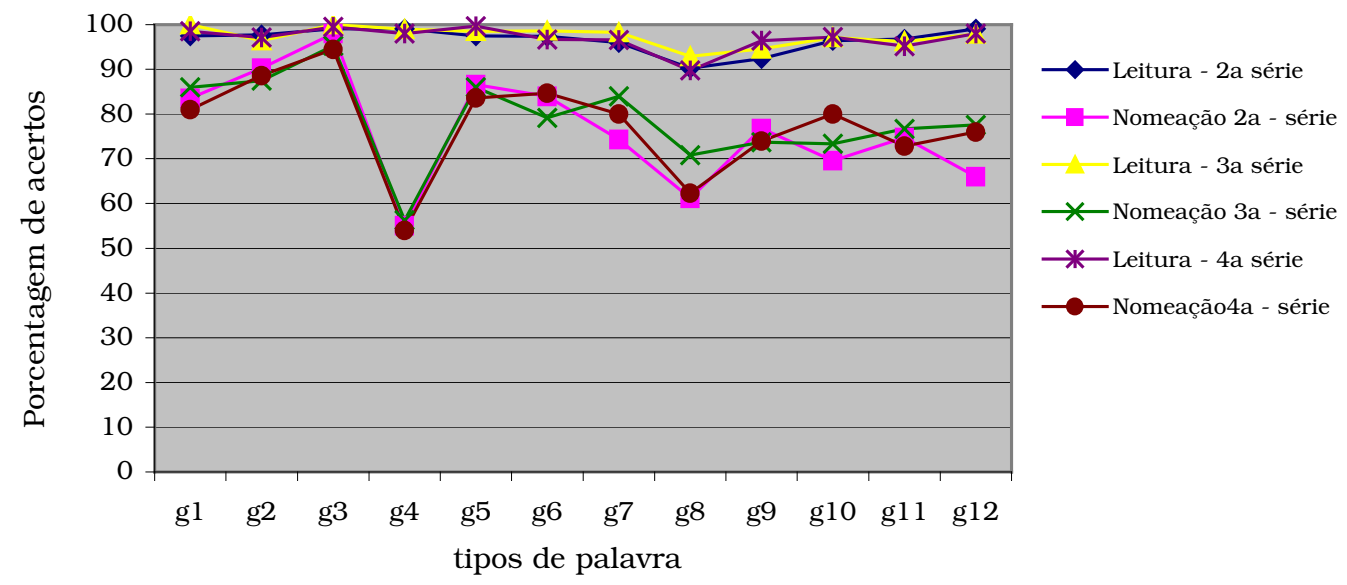

g1: alta freqüência, 4 grafemas, regular, consoante-vogal g2: alta freqüência, 4 grafemas, irregular, consoante-vogal g3: alta freqüência, 6 grafemas, regular, consoante-vogal g4: alta freqüência, 6 grafemas, irregular, consoante-vogal g5: alta freqüência, 5 e mais grafemas, regular, estruturas mais complexas g6: alta freqüência, 5 e mais grafemas, irregular, estruturas mais complexas g7: baixa freqüência, 4 grafemas, regular, consoante-vogal g8: baixa freqüência, 4 grafemas, irregular, consoante-vogal g9: baixa freqüência, 6 grafemas, regular, consoante-vogal g10: baixa freqüência, 6 grafemas, irregular, consoante-vogal g11: baixa freqüência, 5 e mais grafemas, regular, estruturas mais complexas g12: baixa freqüência, 5 e mais grafemas, irregular, estruturas mais complexas

Tabela 45. p-valores: comparação da porcentagem de acertos entre leitura e nomeação

\begin{tabular}{|c|c|c|c|}
\hline $\begin{array}{l}\text { Caracteristicas } \\
\text { psicolingüisticas }\end{array}$ & Série & $\begin{array}{l}\text { p-valores } \\
\text { Prova }\end{array}$ & $\begin{array}{c}\text { Série } \mathbf{x} \\
\text { prova }\end{array}$ \\
\hline $\mathrm{AF}, 4 \mathrm{G}, \mathrm{CV}, \mathrm{R}$ & 0,2015 & $<0,0001^{*}$ & 0,5753 \\
\hline $\mathrm{AF}, 4 \mathrm{G}, \mathrm{CV}, \mathrm{I}$ & 0,4945 & $<0,0001^{*}$ & 0,9069 \\
\hline $\mathrm{AF}, 6 \mathrm{G}, \mathrm{CV}, \mathrm{R}$ & 0,3832 & $<0,0003^{*}$ & 0,1574 \\
\hline $\mathrm{AF}, 6 \mathrm{G}, \mathrm{CV}, \mathrm{I}$ & 0,9072 & $<0,0001^{*}$ & 0,9827 \\
\hline $\mathrm{AF}, 5 \mathrm{e}+\mathrm{G}, \mathrm{OE}, \mathrm{R}$ & 0,9282 & $<0,0001^{*}$ & 0,2409 \\
\hline $\mathrm{AF}, 5$ e +G, OE, I & 0,6984 & $<0,0001 *$ & 0,2044 \\
\hline $\mathrm{BF}, 4 \mathrm{G}, \mathrm{CV}, \mathrm{R}$ & 0,0594 & $<0,0001 *$ & 0,1497 \\
\hline $\mathrm{BF}, 4 \mathrm{G}, \mathrm{CV}, \mathrm{I}$ & 0,0837 & $<0,0001^{*}$ & 0,4241 \\
\hline $\mathrm{BF}, 6 \mathrm{G}, \mathrm{CV}, \mathrm{R}$ & 0,9139 & $<0,0001 *$ & 0,2579 \\
\hline $\mathrm{BF}, 6 \mathrm{G}, \mathrm{CV}, \mathrm{I}$ & 0,0559 & $<0,0001 *$ & 0,1160 \\
\hline $\mathrm{BF}, 5 \mathrm{e}+\mathrm{G}, \mathrm{OE}, \mathrm{R}$ & 0,3427 & $<0,0001 *$ & 0,7159 \\
\hline $\mathrm{BF}, 5$ e $+\mathrm{G}, \mathrm{OE}, \mathrm{I}$ & 0,0556 & $<0,0001^{*}$ & $0,0063^{*}$ \\
\hline
\end{tabular}

p<0,05 AF: alta freqüência; $\mathrm{BF}$ : baixa freqüência; G: grafemas;

R: regular;I:irregular; CV:consoante-vogal; OE: outras estruturas; 
Como pode ser observado, houve maior porcentagem de acertos na leitura de palavras do que na nomeação de figuras, de forma estatisticamente significante. Observou-se que esta diferença foi maior nos grupos 4 (alta freqüência, 6 grafemas, estrutura CV, irregular) e nos grupos de 8 a 12 (baixa freqüência).

Este comportamento foi semelhante entre as séries na maioria dos grupos de estímulos, com exceção do grupo 12 (baixa freqüência, 5 e mais grafemas, estrutura silábica complexa e irregular), que é o de maior complexidade ( $\left.\mathrm{p}=0,0063^{*}\right)$. Esta interação entre série e prova se deve ao comportamento das crianças de $2^{\text {a }}$ série na prova de nomeação, que foi inferior ao das crianças de $3^{\mathrm{a}}$ e de $4^{\mathrm{a}}$ séries.

\subsection{Crianças não leitoras}

\subsubsection{Comparação entre leitores e não leitores na nomeação de figuras}

A seguir, são apresentados os resultados da comparação entre leitores e não leitores de $2^{\underline{a}}$ série, na prova de nomeação de figuras, com relação ao tempo de latência, tempo de duração da emissão oral e acertos. 


\subsubsection{Tempo de latência}

A média do tempo de latência para cada grupo de figuras referente ao grupo de leitores e não leitores pode ser visualizada na figura 30. As análises estatísticas referentes à freqüência, regularidade e extensão encontram-se nas tabelas 46, 47 e 48.

\section{Figura 30. Tempo de latência para a nomeação: leitores $x$ não leitores}

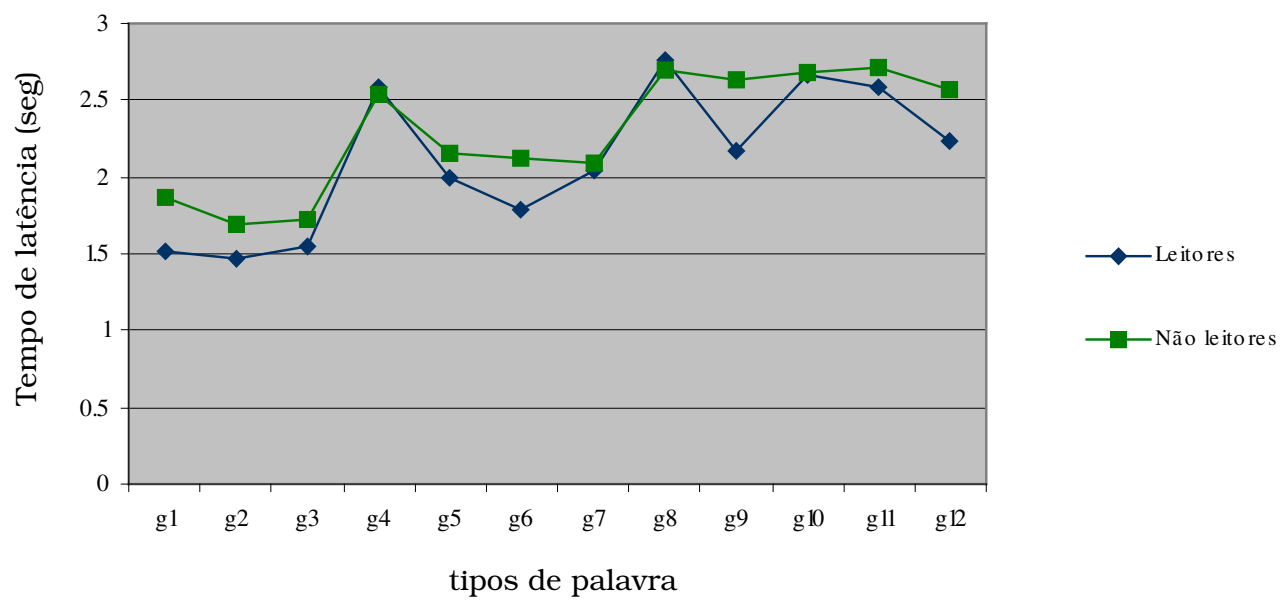

g1: alta freqüência, 4 grafemas, regular, consoante-vogal g2: alta freqüência, 4 grafemas, irregular, consoante-vogal g3: alta freqüência, 6 grafemas, regular, consoante-vogal g4: alta freqüência, 6 grafemas, irregular, consoante-vogal g5: alta freqüência, 5 e mais grafemas, regular, estruturas mais complexas g6: alta freqüência, 5 e mais grafemas, irregular, estruturas mais complexas g7: baixa freqüência, 4 grafemas, regular, consoante-vogal g8: baixa freqüência, 4 grafemas, irregular, consoante-vogal g9: baixa freqüência, 6 grafemas, regular, consoante-vogal g10: baixa freqüência, 6 grafemas, irregular, consoante-vogal

g11: baixa freqüência, 5 e mais grafemas, regular, estruturas mais complexas g12: baixa freqüência, 5 e mais grafemas, irregular, estruturas mais complexas 
Tabela 46. Comparação do tempo de latência entre palavras de alta e baixa freqüência: leitores $x$ não leitores

\begin{tabular}{|c|c|c|c|c|c|c|}
\hline $\begin{array}{l}\text { Tipos de } \\
\text { palavra }\end{array}$ & Freqüuência & leitores & $\begin{array}{c}\text { não } \\
\text { leitores }\end{array}$ & sujeito & palavra & $\begin{array}{c}\text { sujeito } \mathbf{X} \\
\text { palavra }\end{array}$ \\
\hline \multirow[b]{2}{*}{$4 \mathrm{G}, \mathrm{CV}, \mathrm{R}$} & alta & 1,52 & 1,86 & & & \\
\hline & baixa & 2,05 & 2,09 & 0,3115 & $0,0006^{*}$ & 0,1595 \\
\hline \multirow{3}{*}{$4 \mathrm{G}, \mathrm{CV}, \mathrm{I}$} & alta & 1,47 & 1,69 & & & \\
\hline & baixa & 2,76 & 2,69 & 0,7003 & $<0,0001^{*}$ & 0,3819 \\
\hline & alta & 1,54 & 1,73 & & & \\
\hline \multirow[t]{2}{*}{$6 \mathrm{G}, \mathrm{CV}, \mathrm{R}$} & baixa & 2,17 & 2,64 & 0,0887 & $<0,0001 *$ & 0,2736 \\
\hline & alta & 2,59 & 2,54 & & & \\
\hline \multirow[t]{2}{*}{$6 \mathrm{G}, \mathrm{CV}, \mathrm{I}$} & baixa & 2,67 & 2,48 & 0,6579 & 0,9597 & 0,7466 \\
\hline & alta & 1,99 & 2,16 & & & \\
\hline \multirow[t]{2}{*}{$5 \mathrm{e}+\mathrm{G}, \mathrm{OE}, \mathrm{R}$} & baixa & 2,58 & 2,71 & 0,5744 & $0,0094 *$ & 0,9232 \\
\hline & alta & 1,78 & 2,13 & & & \\
\hline 5 e $+\mathrm{G}, \mathrm{OE}, \mathrm{I}$ & baixa & 2,23 & 2,57 & 0,1069 & $0,0259 *$ & 0,9719 \\
\hline
\end{tabular}

Os dados da tabela acima mostraram que não houve diferença estatisticamente significante para o tempo de latência entre leitores e não leitores. O tempo de latência para as figuras com nomes de alta freqüência foi menor do que nas de baixa, nos dois grupos de sujeitos.

Tabela 47. Comparação do tempo de latência entre palavras regulares e irregulares: leitores $x$ não leitores

\begin{tabular}{|c|c|c|c|c|c|c|}
\hline $\begin{array}{l}\text { Tipos de } \\
\text { palavra }\end{array}$ & Regularidade & leitores & $\begin{array}{c}\text { não } \\
\text { leitores }\end{array}$ & sujeito & palavra & $\begin{array}{c}\text { sujeito X } \\
\text { palavra }\end{array}$ \\
\hline \multirow[b]{2}{*}{$\mathrm{AF}, 4 \mathrm{G}, \mathrm{CV}$} & regular & 1,52 & 1,86 & & & \\
\hline & irregular & 1,47 & 1,69 & 0,0504 & 0,2032 & 0,5042 \\
\hline \multirow[b]{2}{*}{$\mathrm{AF}, 6 \mathrm{G}, \mathrm{CV}$} & regular & 1,54 & 1,73 & & & \\
\hline & irregular & 2,59 & 2,54 & 0,7831 & $<0,0001 *$ & 0,5021 \\
\hline \multirow{3}{*}{$\mathrm{AF}, 5+\mathrm{G}, \mathrm{OE}$} & regular & 1,99 & 2,16 & & & \\
\hline & irregular & 1,78 & 2,13 & 0,1393 & 0,4033 & 0,5088 \\
\hline & regular & 2,05 & 2,09 & & & \\
\hline \multirow[t]{2}{*}{$\mathrm{BF}, 4 \mathrm{G}, \mathrm{CV}$} & irregular & 2,76 & 2,69 & 0,9402 & $0,0005^{*}$ & 0,7555 \\
\hline & regular & 2,17 & 2,64 & & & \\
\hline \multirow[t]{2}{*}{$\mathrm{BF}, 6 \mathrm{G}, \mathrm{CV}$} & irregular & 2,67 & 2,48 & 0,5707 & 0,2805 & $0,0401 *$ \\
\hline & regular & 2,58 & 2,71 & & & \\
\hline $\mathrm{BF}, 5+\mathrm{G}, \mathrm{OE}$ & irregular & 2,23 & 2,57 & 0,4942 & 0,1595 & 0,5428 \\
\hline
\end{tabular}

AF; alta freqüência; BF: baixa freqüência; G: grafemas; CV:consoante-vogal; OE: outras estruturas

Como pode ser observado na tabela 47, o tempo de latência para a nomeação de figuras com nomes irregulares foi maior do que nas 
regulares apenas no grupo de alta freqüência, com 6 grafemas e estrutura silábica consoante-vogal. Este comportamento foi semelhante entre leitores e não leitores. A interação sujeito x palavra no grupo de figuras com nomes de baixa freqüência, com 6 grafemas e estrutura silábica consoante-vogal indicou que, enquanto no grupo de leitores, o tempo de latência foi maior para a recuperação de nomes equivalentes às palavras irregulares, para os não leitores ocorreu o comportamento inverso.

Tabela 48. Comparação do tempo de latência entre palavras de 4 e 6 grafemas: leitores $x$ não leitores

\begin{tabular}{|c|c|c|c|c|c|c|}
\hline $\begin{array}{c}\text { Tipos de } \\
\text { palavra }\end{array}$ & Extensão & leitores & $\begin{array}{c}\text { não } \\
\text { leitores }\end{array}$ & sujeito & palavra & $\begin{array}{c}\text { sujeito } X \\
\text { palavra }\end{array}$ \\
\hline \multirow[b]{2}{*}{$\mathrm{AF}, \mathrm{CV}, \mathrm{R}$} & 4 grafemas & 1,52 & 1,86 & & & \\
\hline & 6 grafemas & 1,54 & 1,73 & 0,0540 & 0,5617 & 0,4341 \\
\hline \multirow{3}{*}{$\mathrm{AF}, \mathrm{CV}, \mathrm{I}$} & 4 grafemas & 1,47 & 1,69 & & & \\
\hline & 6 grafemas & 2,59 & 2,54 & 0,7244 & $<0,0001^{*}$ & 0,4904 \\
\hline & 4 grafemas & 2,05 & 2,09 & & & \\
\hline \multirow[t]{2}{*}{$\mathrm{BF}, \mathrm{CV}, \mathrm{R}$} & 6 grafemas & 2,17 & 2,64 & 0,2569 & $0,0261 *$ & 0,1419 \\
\hline & 4 grafemas & 2,76 & 2,69 & & & \\
\hline $\mathrm{BF}, \mathrm{CV}, \mathrm{I}$ & 6 grafemas & 2,67 & 2,48 & 0,5951 & 0,3945 & 0,7301 \\
\hline
\end{tabular}

O tempo de latência para nomes de 6 foi maior do que nos de 4 grafemas, na nomeação de palavras de alta freqüência/regular e de baixa freqüência/irregular. Não houve diferença entre leitores e não leitores. Nos nomes de alta freqüência/regulares e de baixa freqüência/irregulares, não houve diferença no tempo de latência para a extensão: leitores e não leitores apresentaram tempo de latência semelhante para a nomeação destas figuras. 


\subsubsection{Tempo de duração da emissão oral}

As médias do tempo de duração da emissão oral para a nomeação de figuras, no grupo de leitores e não leitores, são apresentadas na figura 31 , a seguir.

Figura 31. Tempo de duração da emissão oral para a nomeação: leitores x não leitores

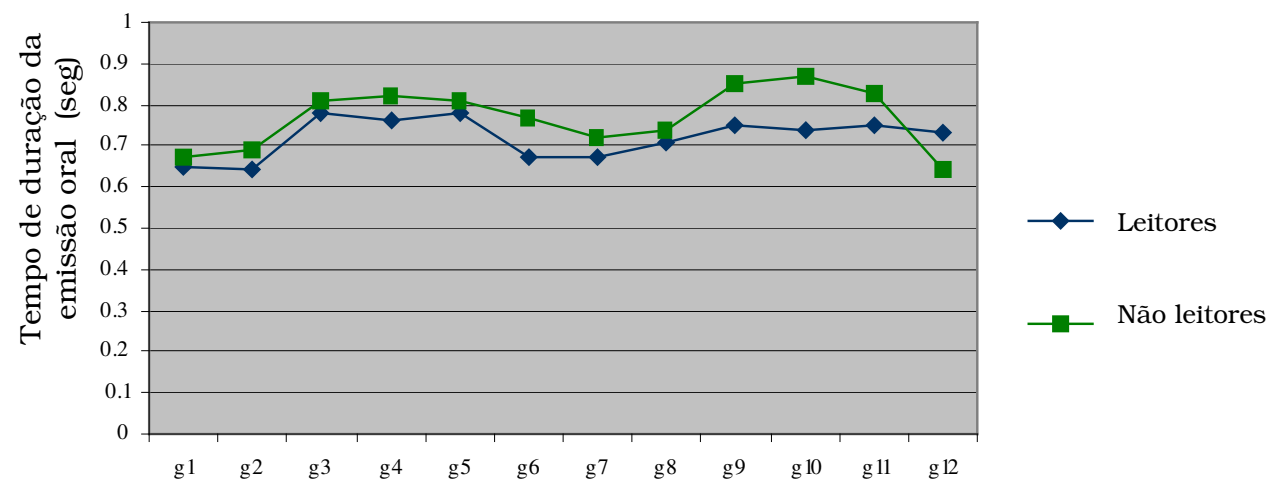

tipos de palavra

g1: alta freqüência, 4 grafemas, regular, consoante-vogal g2: alta freqüência, 4 grafemas, irregular, consoante-vogal g3: alta freqüência, 6 grafemas, regular, consoante-vogal g4: alta freqüência, 6 grafemas, irregular, consoante-vogal g5: alta freqüência, 5 e mais grafemas, regular, estruturas mais complexas g6: alta freqüência, 5 e mais grafemas, irregular, estruturas mais complexas g7: baixa freqüência, 4 grafemas, regular, consoante-vogal g8: baixa freqüência, 4 grafemas, irregular, consoante-vogal g9: baixa freqüência, 6 grafemas, regular, consoante-vogal g10: baixa freqüência, 6 grafemas, irregular, consoante-vogal g11: baixa freqüência, 5 e mais grafemas, regular, estruturas mais complexas g12: baixa freqüência, 5 e mais grafemas, irregular, estruturas mais complexas

Os dados da figura 31 indicaram que o comportamento dos leitores e não leitores para a produção dos diferentes tipos de nomes foi semelhante. Porém, o tempo de duração da emissão oral parece ser menor para os leitores. As análises estatísticas considerando-se as variáveis freqüência, regularidade e extensão podem ser visualizadas nas tabelas 49, 50 e 51. 
Tabela 49. Comparação do tempo de duração da emissão oral entre palavras de alta e baixa frequiência: leitores x não leitores

\begin{tabular}{|c|c|c|c|c|c|c|}
\hline $\begin{array}{c}\text { Tipos de } \\
\text { palavra }\end{array}$ & Freqüência & leitores & $\begin{array}{c}\text { não } \\
\text { leitores } \\
\end{array}$ & sujeito & palavra & $\begin{array}{l}\text { série } X \\
\text { palavra }\end{array}$ \\
\hline & alta & 0,65 & 0,67 & & & \\
\hline \multirow[t]{2}{*}{$4 \mathrm{G}, \mathrm{CV}, \mathrm{R}$} & baixa & 0,67 & 0,72 & 0,3405 & 0,2105 & 0,4700 \\
\hline & alta & 0,64 & 0,69 & & & \\
\hline \multirow[t]{2}{*}{$4 \mathrm{G}, \mathrm{CV}, \mathrm{I}$} & baixa & 0,71 & 0,74 & 0,1096 & 0,140 & 0,7205 \\
\hline & alta & 0,78 & 0,81 & & & \\
\hline \multirow[t]{2}{*}{$6 \mathrm{G}, \mathrm{CV}, \mathrm{R}$} & baixa & 0,75 & 0,85 & 0,0970 & 0,7396 & 0,1829 \\
\hline & alta & 0,76 & 0,82 & & & \\
\hline \multirow[t]{2}{*}{$6 \mathrm{G}, \mathrm{CV}, \mathrm{I}$} & baixa & 0,74 & 0,87 & $0,0161 *$ & 0,5554 & 0,0991 \\
\hline & alta & 0,78 & 0,81 & & & \\
\hline \multirow[t]{2}{*}{5 e $+\mathrm{G}, \mathrm{OE}, \mathrm{R}$} & baixa & 0,75 & 0,83 & 0,2383 & 0,9886 & 0,5710 \\
\hline & alta & 0,67 & 0,77 & & & \\
\hline $5 \mathrm{e}+\mathrm{G}, \mathrm{OE}, \mathrm{I}$ & baixa & 0,73 & 0,64 & 0,8700 & 0,5774 & 0,1365 \\
\hline
\end{tabular}

O tempo de duração da emissão oral para nomes freqüentes e pouco freqüentes foi semelhante. Observou-se diferença entre leitores e não leitores apenas no grupo de nomes com 6 grafemas, estrutura consoante-vogal e irregular (alta e baixa freqüência).

Tabela 50. Comparação do tempo de duração da emissão oral entre palavras regulares e irregulares: leitores $x$ não leitores

\begin{tabular}{|c|c|c|c|c|c|c|}
\hline $\begin{array}{l}\text { Tipos de } \\
\text { palavras }\end{array}$ & Regularidade & leitores & $\begin{array}{c}\text { não } \\
\text { leitores }\end{array}$ & sujeito & palavra & $\begin{array}{c}\text { sujeito } X \\
\text { palavra }\end{array}$ \\
\hline \multirow[b]{2}{*}{$\mathrm{AF}, 4 \mathrm{G}, \mathrm{CV}$} & regular & 0,65 & 0,67 & & & \\
\hline & irregular & 0,64 & 0,69 & 0,2894 & 0,9936 & 0,3642 \\
\hline \multirow[b]{2}{*}{$\mathrm{AF}, 6 \mathrm{G}, \mathrm{CV}$} & regular & 0,78 & 0,81 & & & \\
\hline & irregular & 0,76 & 0,82 & 0,2654 & 0,8758 & 0,5686 \\
\hline \multirow[b]{2}{*}{$\mathrm{AF}, 5+\mathrm{G}, \mathrm{OE}$} & regular & 0,78 & 0,81 & & & \\
\hline & irregular & 0,67 & 0,77 & 0,0546 & $<0,0001^{*}$ & $0,0130 *$ \\
\hline \multirow{3}{*}{$\mathrm{BF}, 4 \mathrm{G}, \mathrm{CV}$} & regular & 0,67 & 0,72 & & & \\
\hline & irregular & 0,71 & 0,74 & 0,1475 & 0,1619 & 0,7928 \\
\hline & regular & 0,75 & 0,85 & & & \\
\hline \multirow[t]{2}{*}{$\mathrm{BF}, 6 \mathrm{G}, \mathrm{CV}$} & irregular & 0,74 & 0,87 & $0,0036 *$ & 0,9146 & 0,3804 \\
\hline & regular & 0,75 & 0,83 & & & \\
\hline $\mathrm{BF}, 5+\mathrm{G}, \mathrm{OE}$ & irregular & 0,73 & 0,64 & 0,9972 & 0,0665 & 0,1634 \\
\hline
\end{tabular}

AF: alta freqüência; BF: baixa freqüência; G: grafemas;CV:consoante-vogal;

$\mathrm{OE}$ : outras estruturas 
De acordo com os dados da tabela 50, o tempo de duração da emissão oral foi maior na nomeação de figuras com nomes regulares do que nos irregulares, no grupo de alta freqüência, 5 e mais grafemas com estruturas complexas. Esta diferença foi observada apenas para os leitores, causando a interação significante sujeito x palavra.

Nas palavras de baixa freqüência com 6 grafemas e estrutura consoante-vogal, o tempo de duração da emissão oral foi estatisticamente maior para os não leitores.

Notou-se que, no grupo de baixa freqüência, irregular, com 5 e mais grafemas e estruturas mais complexas, os não leitores apresentaram tempo de duração menor do que os leitores. Este fato pode ser atribuído ao alto índice de erros neste tipo de figura, como substituição da palavra alvo por palavras de menor extensão.

Tabela 51. Comparação do tempo de duração da emissão oral entre palavras com 4 e 6 grafemas: leitores $x$ não leitores

\begin{tabular}{ccccccc}
\hline $\begin{array}{c}\text { Tipos de } \\
\text { palavra }\end{array}$ & Extensão & leitores & $\begin{array}{c}\text { não } \\
\text { leitores }\end{array}$ & sujeito & palavra & $\begin{array}{c}\text { sujeito X } \\
\text { palavra }\end{array}$ \\
\hline & 4 grafemas & 0,65 & 0,67 & & & \\
AF, CV, R & 6 grafemas & 0,78 & 0,81 & 0,4702 & $<\mathbf{0 , 0 0 0 1 *}$ & 0,6956 \\
\hline & 4 grafemas & 0,64 & 0,69 & & & \\
AF, CV, I & 6 grafemas & 0,76 & 0,82 & 0,1303 & $<\mathbf{0 , 0 0 0 1 *}$ & 0,8965 \\
\hline & 4 grafemas & 0,67 & 0,72 & & & \\
BF, CV, R & 6 grafemas & 0,71 & 0,74 & 0,0646 & $<\mathbf{0 , 0 0 0 1 *}$ & 0,3788 \\
\hline & 4 grafemas & 0,71 & 0,74 & & & \\
BF, CV, I & 6 grafemas & 0,74 & 0,87 & $\mathbf{0 , 0 0 5 1}^{*}$ & $\mathbf{0 , 0 0 0 1}^{*}$ & $\mathbf{0 , 0 1 9 7}$ \\
\hline
\end{tabular}

$\mathrm{AF}$ : alta freqüência; $\mathrm{BF}$ : baixa freqüência;CV:consoante-vogal; R: regular; I:irregular

Os nomes mais curtos (4 grafemas) foram produzidos mais rapidamente do que os mais extensos (6 grafemas), em todos os tipos de palavra. Os não leitores apresentaram maior tempo de duração do que os leitores na produção de nomes de baixa freqüência, irregular e com estrutura consoante-vogal, e esta diferença foi maior nos nomes de 6 grafemas (interação significante sujeito x palavra). 
6.3.1.3. Acertos

A porcentagem de acertos para leitores e não leitores na nomeação podem ser visualizados na figura 32 e as análises estatísticas das comparações, nas tabelas 52, 53 e 54.

\section{Figura 32. Porcentagem de acertos na nomeação: leitores x não leitores}

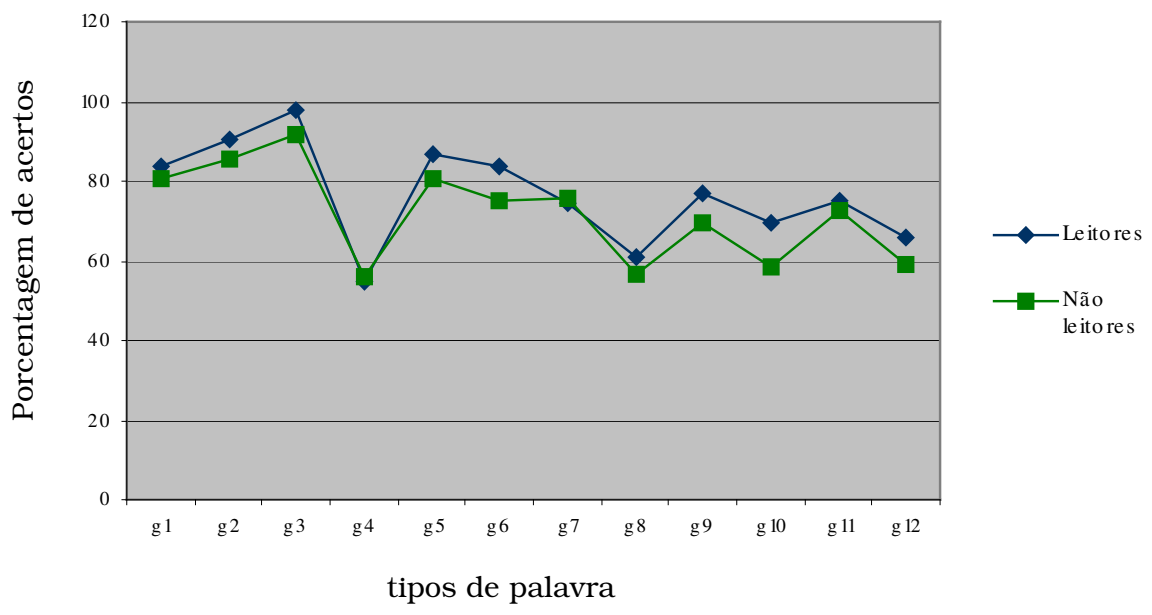

g1: alta freqüência, 4 grafemas, regular, consoante-vogal g2: alta freqüência, 4 grafemas, irregular, consoante-vogal g3: alta freqüência, 6 grafemas, regular, consoante-vogal g4: alta freqüência, 6 grafemas, irregular, consoante-vogal

g5: alta freqüência, 5 e mais grafemas, regular, estruturas mais complexas g6: alta freqüência, 5 e mais grafemas, irregular, estruturas mais complexas g7: baixa freqüência, 4 grafemas, regular, consoante-vogal

g8: baixa freqüência, 4 grafemas, irregular, consoante-vogal g9: baixa freqüência, 6 grafemas, regular, consoante-vogal g10: baixa freqüência, 6 grafemas, irregular, consoante-vogal g11: baixa freqüência, 5 e mais grafemas, regular, estruturas mais complexas g12: baixa freqüência, 5 e mais grafemas, irregular, estruturas mais complexas 
Tabela 52. Comparação da porcentagem de acertos entre palavras de alta e baixa freqüência: leitores $x$ não leitores

\begin{tabular}{|c|c|c|c|c|c|c|}
\hline $\begin{array}{c}\text { Tipos de } \\
\text { palavra }\end{array}$ & Freqüência & leitores & $\begin{array}{c}\text { não } \\
\text { leitores }\end{array}$ & sujeito & palavra & $\begin{array}{c}\text { sujeito } X \\
\text { palavra }\end{array}$ \\
\hline & alta & 83,5 & 80,6 & & & \\
\hline \multirow[t]{2}{*}{$4 \mathrm{G}, \mathrm{CV}, \mathrm{R}$} & baixa & 74,3 & 75,7 & 0,8398 & $0,0153^{*}$ & 0,4459 \\
\hline & alta & 90,3 & 85,7 & & & \\
\hline \multirow[t]{2}{*}{$4 \mathrm{G}, \mathrm{CV}, \mathrm{I}$} & baixa & 61,1 & 56,4 & 0,1521 & $<0,0001^{*}$ & 0,9738 \\
\hline & alta & 98,0 & 91,9 & & & \\
\hline \multirow[t]{2}{*}{$6 \mathrm{G}, \mathrm{CV}, \mathrm{R}$} & baixa & 76,8 & 69,5 & $0,0061 *$ & $<0,0001^{*}$ & 0,8145 \\
\hline & alta & 69,6 & 56,3 & & & \\
\hline \multirow[t]{2}{*}{$6 \mathrm{G}, \mathrm{CV}, \mathrm{I}$} & baixa & 55,0 & 58,5 & $0,0255^{*}$ & $0,0362 *$ & 0,1204 \\
\hline & alta & 86,5 & 80,5 & & & \\
\hline \multirow[t]{2}{*}{5 e $+\mathrm{G}, \mathrm{OE}, \mathrm{R}$} & baixa & 74,8 & 72,5 & $0,0277^{*}$ & $0,0003^{*}$ & 0,4555 \\
\hline & alta & 84,0 & 75,0 & & & \\
\hline $5 \mathrm{e}+\mathrm{G}, \mathrm{OE}, \mathrm{I}$ & baixa & 66,0 & 58,8 & 0,0414 & $<0,0001^{*}$ & 0,7880 \\
\hline
\end{tabular}

Como pode ser visualizado na tabela 52, todos os sujeitos apresentaram maior porcentagem de acertos na nomeação de figuras com nomes de alta freqüência do que nos de baixa. Os leitores apresentaram mais acertos do que os não leitores na maioria dos grupos de palavras, com exceção dos nomes de 4 grafemas, independente da freqüência.

Tabela 53. Comparação da porcentagem de acertos entre palavras regulares e irregulares: leitores $x$ não leitores

\begin{tabular}{|c|c|c|c|c|c|c|}
\hline $\begin{array}{c}\text { Tipos de } \\
\text { palavra }\end{array}$ & Regularidade & leitores & $\begin{array}{c}\text { não } \\
\text { leitores }\end{array}$ & sujeito & palavra & $\begin{array}{c}\text { sujeito } \mathbf{X} \\
\text { palavra }\end{array}$ \\
\hline \multirow[b]{2}{*}{$\mathrm{AF}, 4 \mathrm{G}, \mathrm{CV}$} & regular & 83,5 & 80,6 & & & \\
\hline & irregular & 90,3 & 85,7 & 0,2055 & $0,0190 *$ & 0,7295 \\
\hline \multirow{3}{*}{$\mathrm{AF}, 6 \mathrm{G}, \mathrm{CV}$} & regular & 98,0 & 91,9 & & & \\
\hline & irregular & 55,0 & 56,3 & 0,5229 & $<0,0001^{*}$ & 0,3235 \\
\hline & regular & 86,5 & 80,5 & & & \\
\hline \multirow[t]{2}{*}{$\mathrm{AF}, 5+\mathrm{G}, \mathrm{OE}$} & irregular & 84,0 & 75,0 & $0,0181 *$ & 0,1996 & 0,6381 \\
\hline & regular & 74,3 & 75,7 & & & \\
\hline \multirow[t]{2}{*}{$\mathrm{BF}, 4 \mathrm{G}, \mathrm{CV}$} & irregular & 61,1 & 56,4 & 0,6430 & $<0,0001$ * & 0,3004 \\
\hline & regular & 76,8 & 69,5 & & & \\
\hline \multirow[t]{2}{*}{$\mathrm{BF}, 6 \mathrm{G}, \mathrm{CV}$} & irregular & 69,6 & 58,5 & $0,0120 *$ & $0,0002 *$ & 0,3934 \\
\hline & regular & 74,8 & 72,5 & & & \\
\hline $\mathrm{BF}, 5+\mathrm{G}, \mathrm{OE}$ & irregular & 66,0 & 58,8 & 0,1547 & $0,0001 *$ & 0,3515 \\
\hline
\end{tabular}

$\mathrm{AF}$ : alta freqüência; $\mathrm{BF}$ : baixa freqüência; G:grafemas;CV:consoante-vogal; $\mathrm{OE}$ : outras estruturas 
Conforme os dados da tabela 53, as figuras com nomes correspondentes às palavras irregulares para a leitura apresentaram menor porcentagem de acertos do que as irregulares. A diferença entre leitores e não leitores foi observada nos grupos de alta freqüência, 5 e mais grafemas e outras estruturas (regulares e irregulares) e de baixa freqüência, 6 grafemas e estrutura consoante-vogal (regulares e irregulares).

Tabela 54. Comparação da porcentagem de acertos entre palavras com 4 e 6 grafemas: leitores $x$ não leitores

\begin{tabular}{|c|c|c|c|c|c|c|}
\hline $\begin{array}{l}\text { Tipos de } \\
\text { palavra }\end{array}$ & Extensão & leitores & $\begin{array}{c}\text { não } \\
\text { leitores }\end{array}$ & sujeito & palavra & $\begin{array}{c}\text { sujeito } X \\
\text { palavra }\end{array}$ \\
\hline \multirow[b]{2}{*}{$\mathrm{AF}, \mathrm{CV}, \mathrm{R}$} & 4 grafemas & 83,5 & 80,6 & & & \\
\hline & 6 grafemas & 98,0 & 91,9 & 0,0883 & $<0,0001^{*}$ & 0,4312 \\
\hline \multirow[b]{2}{*}{$\mathrm{AF}, \mathrm{CV}, \mathrm{I}$} & 4 grafemas & 90,3 & 85,7 & & & \\
\hline & 6 grafemas & 55,0 & 56,3 & 0,7040 & $<0,0001^{*}$ & 0,4163 \\
\hline \multirow{3}{*}{$\mathrm{BF}, \mathrm{CV}, \mathrm{R}$} & 4 grafemas & 74,3 & 75,7 & & & \\
\hline & 6 grafemas & 76,8 & 69,5 & 0,4425 & 0,4850 & 0,1039 \\
\hline & 4 grafemas & 61,1 & 56,4 & & & \\
\hline $\mathrm{BF}, \mathrm{CV}, \mathrm{I}$ & 6 grafemas & 69,6 & 58,5 & 0,0268* & $0,0229 *$ & 0,1598 \\
\hline
\end{tabular}

$\mathrm{Na}$ nomeação, a porcentagem de acertos foi maior para as figuras com nomes mais curtos (4 grafemas) do que mais extensos (6 grafemas), para todos os tipos de palavras, com exceção das palavras de baixa freqüência, regulares e com estrutura consoante-vogal.

No grupo de baixa freqüência, irregular e com estrutura consoante-vogal, os não leitores apresentaram menos acertos do que os leitores. 


\subsubsection{Características da nomeação de figuras}

$\mathrm{Na}$ tabela 55 abaixo, pode-se visualizar os tipos de nomeação apresentados pelas crianças não leitoras, em comparação com as leitoras.

Tabela 55. Tipos de resposta na nomeação: leitores $x$ não leitores

\begin{tabular}{c|cccc}
\hline Tipos de resposta & \multicolumn{2}{c}{ leitores } & \multicolumn{2}{c}{ não leitores } \\
\cline { 2 - 5 } & $\mathbf{N}$ & $\mathbf{\%}$ & $\mathbf{N}$ & $\mathbf{\%}$ \\
\hline S & 153 & 27,37 & 136 & 25,26 \\
$\mathbf{P}$ & 156 & 27,91 & 161 & 30,26 \\
$\mathbf{F}$ & $\mathbf{9}$ & $\mathbf{1 , 6 1}$ & $\mathbf{2 5}$ & $\mathbf{4 , 6 9}$ \\
SP & 142 & 25,40 & 57 & 10,71 \\
SF & 1 & 0,18 & 4 & 0,75 \\
PF & 5 & 0,89 & 0 & 0 \\
NR & 81 & 14,49 & 83 & 15,60 \\
CIR & 0 & 0,00 & 7 & 1,31 \\
SR & 0 & 0,00 & 10 & 1,87 \\
\hline
\end{tabular}

Teste de Qui-quadrado (p)=0,001*. S: semântico; P:perceptual;

SP: semântico e perceptual; F: fonológico; PF: perceptuale fonológico; NR: não resposta; CIR: circunlocução; SR: sem relação

De acordo com a análise estatística dos dados acima, a principal diferença entre leitores e não leitores na caracterização da nomeação refere-se à maior porcentagem de substituições fonológicas realizadas pelos não leitores. Os outros tipos de respostas foram apresentados em quantidade semelhante por ambas as amostras.

A porcentagem de revisões (correção da resposta) pode ser visualizada na tabela 56, assim como os erros de produção (fragmentações, repetição de sílabas e fonemas, prolongamentos) 
ocorridos durante a nomeação esperada (EP nos acertos) ou a substituição do nome alvo por outro (EP nos erros).

Tabela 56. Revisões e erros de produção na nomeação

\begin{tabular}{c|cccc}
\hline \multirow{2}{*}{ Tipos de respostas } & \multicolumn{2}{c}{ leitores } & \multicolumn{2}{c}{ Não leitores } \\
\cline { 2 - 5 } & $\mathbf{N}$ & $\mathbf{\%}$ & $\mathbf{N}$ & $\mathbf{\%}$ \\
\hline revisões & 12 & 2,15 & 22 & 4,13 \\
EP nos acertos & 10 & 0,53 & 15 & 2,81 \\
EP nos erros & 0 & 0 & 10 & 1,87 \\
\hline
\end{tabular}

Teste de Qui-quadrado: 0,0781

EP: erros de produção

Observou-se que os não leitores apresentaram mais revisões e erros de produção do que os leitores, embora na haja diferença estatisticamente significante. 


\subsection{Sintese dos resultados}

Para facilitar a compreensão dos resultados, os aspectos mais importantes foram enfocados e podem ser visualizados nos quadro abaixo:

\section{Quadro 4. Sintese dos resultados}

\begin{tabular}{|c|c|}
\hline LEITURA & 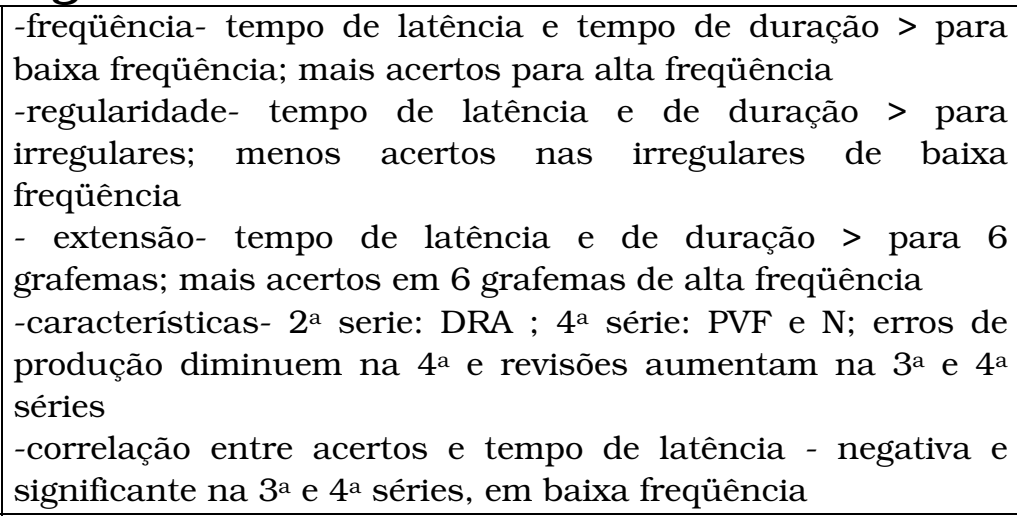 \\
\hline NOMEAÇÃO & $\begin{array}{l}\text {-freqüência- tempo de latência > e menos acertos para baixa } \\
\text { freqüência; tempo de duração variável } \\
\text {-regularidade- tempo de latência e de duração > e menos } \\
\text { acertos em } 3 \text { tipos de palavras } \\
\text { - extensão- tempo de latência e de duração > e menos acertos } \\
\text { para } 6 \text { grafemas } \\
\text {-características- aumentam erros S e diminuem SP com a } \\
\text { escolarização } \\
\text {-correlação entre acertos e tempo de latência- negativa e } \\
\text { significante, principalmente em baixa freqüência }\end{array}$ \\
\hline $\begin{array}{c}\text { LEITURA } \\
x \text { NOMEAÇÃo }\end{array}$ & $\begin{array}{l}\text {-tempo de latência- nomeação > leitura } \\
\text {-tempo de duração da emissão oral- leitura > nomeação na 2a } \\
\text { e 4a série } \\
\text {-acertos- leitura > nomeação }\end{array}$ \\
\hline $\begin{array}{c}\text { LEITORES } \\
x \\
\text { NÀO LEITORES }\end{array}$ & $\begin{array}{l}\text {-tempo de latência semelhante } \\
\text {-tempo de duração da emissão oral- maior para não leitores } \\
\text { nas palavras: baixa freqüência, regular e irregular, com } 6 \\
\text { grafemas e estrutura cv. } \\
\text {-acertos- semelhante para as palavras de } 4 \text { grafemas, } \\
\text { independente da freqüência e da regularidade; nos outros } \\
\text { grupos, a porcentagem foi maior para os leitores. } \\
\text {-características- predomínio maior de erros fonológicos, } \\
\text { revisões e erros de produção para os não leitores. }\end{array}$ \\
\hline
\end{tabular}


7. DISCUSSÃO 


\section{DISCUSSÃO}

Este capítulo apresenta reflexões sobre os dados obtidos nas tarefas de leitura e de nomeação, relacionados às propriedades do material visual e às características do desenvolvimento típico e não típico de leitura.

Alguns aspectos não foram os mesmos observados em estudos internacionais, provavelmente em decorrência das características próprias de cada língua e por questões metodológicas. Talvez os dados não possam ser totalmente generalizados para a população de outras escolas, face ao tipo de ensino e às condições sócio-culturais de cada comunidade, fatores não analisados no presente estudo. Entretanto, podem servir como parâmetros para análise em estudos similares.

O ponto de partida desta discussão é a leitura de palavras. Em muitos dos estudos sobre o tema, o critério de análise envolve apenas acertos e erros. Duas questões sobre este critério merecem reflexão. Primeiro, processar a palavra escrita rápida ou lentamente interfere no acesso e na recuperação da palavra. A literatura aponta que o reconhecimento da palavra escrita deve ser realizado em tempo suficiente para diminuir a sobrecarga na memória de trabalho e permitir à criança se dedicar aos processos de compreensão da mensagem escrita (Ehri e McCormick, 1998; Caccamise e Snyder, 2005; Goff et al., 2005). Então, considerar o reconhecimento da palavra escrita como correto ou não e, não levar em conta o tempo de seu processamento, dificulta a interpretação do real desempenho da criança.

Outra questão importante relaciona-se à definição de acerto e erro. Quando se estuda desenvolvimento, neste caso o da leitura, definir 
acerto ou erro para o reconhecimento da palavra escrita depende da fase de aprendizagem em que a criança se encontra. $O$ tipo de estratégia que o leitor usa durante a leitura aponta as características da aprendizagem.

Desta forma, as medidas de tempo de processamento e sua interação com o tipo de material, a escolarização e os tipos de leitura fornecem dados mais fidedignos sobre o desenvolvimento da criança ao longo da escolarização.

Considerando a relação do tempo de processamento com a eficiência na leitura, uma hipótese desta pesquisa não foi confirmada. Portanto, recuperar mais rápido a palavra escrita não determina uma leitura mais precisa, pois as crianças podem ser mais rápidas e se confundir, enquanto podem (ou necessitam) ler mais lentamente para realizar o reconhecimento preciso da palavra escrita.

Ao ler a palavra "galo", a pesquisa ao léxico pode ter como resultado "gato" e "galo". Ao conferir, a criança tem que perceber e resolver que é a palavra com /1/ que corresponde ao grafema da palavra escrita. Crianças mais novas podem ser rápidas neste processo e selecionar a palavra errada, enquanto as mais escolarizadas podem ser mais lentas e mais eficientes. Um tempo maior para recuperar uma palavra determinando a imprecisão na leitura indica que suas representações não estão estáveis.

Outros estudos que envolvem a velocidade de processamento da leitura utilizam métodos diferentes, dentre eles o tempo de leitura de um texto (Salles e Parente, 2002). Este procedimento permite outras análises, como as estratégias envolvidas na leitura de texto, as características semânticas e sintáticas e os processos de revisão realizados com o objetivo de compreensão.

O tempo de processamento, analisado para cada palavra isoladamente, no presente estudo, permitiu verificar a influência das 
variáveis psicolingüísticas das palavras escritas (freqüência, regularidade e extensão) que determinaram diferentes médias de tempo. Ou seja, as palavras de alta freqüência, as regulares e as mais curtas foram recuperadas (tempo de latência) e produzidas (tempo de duração da emissão oral) mais rapidamente do que as palavras pouco freqüentes, as irregulares e as mais longas.

A análise de duas medidas do tempo de processamento possibilitou informações diferentes. No que se refere ao tempo de latência, enquanto a criança aumenta a freqüência do contato com a palavra escrita e aprende as regras ortográficas, as representações (fonológicas, ortográficas e de significado) se estabilizam e possibilitam uma recuperação cada vez mais automática e rápida desta informação. Por outro lado, ao ler palavras novas ou pouco freqüentes, extensas, com irregularidades, ainda não aprendidas ou em fase de aprendizagem, a criança tem que utilizar regras de conversão entre grafemas e fonemas e/ou realizar uma pesquisa no léxico à procura da representação correspondente ao input, o que lentifica o tempo de recuperação.

Diferentemente do tempo de latência, determinado pela estabilização das representações das palavras que ocorrem durante a aprendizagem da leitura e o desenvolvimento da criança, o tempo de produção possibilitou verificar o quanto as estratégias empregadas pelas crianças diminuem ou estendem o tempo de processamento. Para palavras menos freqüentes, irregulares e extensas, o contato permanente com o input visual permite ao leitor acessar o léxico e/ou realizar regras de conversão grafofonêmica e realizar processos como revisões, segmentações e prolongamentos até obter o resultado final, aumentando o tempo da duração da leitura.

Deve-se ressaltar que, embora as palavras mais extensas levem mais tempo para serem produzidas (resultado encontrado neste 
estudo), uma análise mais fidedigna deve levar em conta o tempo de produção de cada fonema isoladamente, o que não foi realizado no presente estudo. Por exemplo, "trem" é uma palavra de 4 grafemas, constituída por encontro consonantal e caracterizada por uma emissão nasal final. Esta palavra poderia hipoteticamente ser produzida em tempo semelhante à palavra "batata", formada por 6 grafemas e estrutura simples.

Um aspecto relevante é que as três variáveis psicolingüísticas consideradas neste estudo não podem ser analisadas isoladamente, pois elas interagem causando efeitos no processamento das palavras escritas. Como descrito por Coltheart et al. (2001), palavras de alta freqüência, regulares e curtas podem ser recuperadas rapidamente do léxico, sem a necessidade da ativação da via fonológica. Porém, as palavras menos freqüentes e extensas necessitam da aplicação de regras grafofonêmicas porque não estão estabilizadas na memória; se estas possuírem associações irregulares, ocorre a ativação entre dois fonemas para representar um grafema e a competição entre eles retarda a ativação da forma fonológica correta.

Os dados obtidos a partir de características das palavras escritas mostram a necessidade da construção de listas balanceadas durante a avaliação da leitura. Não considerar estes critérios, pode conduzir a uma interpretação errônea do desempenho do sujeito, por considerar palavras que ainda não fazem parte do material escrito ou cujas relações fonológicas e /ou ortográficas ainda não foram ensinadas. Ao se estudar apenas uma característica (por exemplo, a freqüência), deve se ter cuidado em controlar as outras variáveis, ou seja, garantir que a regularidade, a extensão e a complexidade sejam a mesma, observadas nas palavras de alta e de baixa freqüência.

A análise das variáveis psicolingüísticas para o tempo de processamento de cada série escolar possibilitou verificar as rotas de 
leitura utilizadas. Neste sentido, verificou-se que as crianças menos escolarizadas de $2^{\text {a }}$ série utilizam preferencialmente a rota fonológica, o que explica a leitura caracterizada por substituições ortográficas (como "casa" lida como /cassa/), desconhecimento da regra de acentuação ("barata” lida como /baratá/), regularizações ("táxi” lido como /táchi/) e erros de produção (segmentações, repetições, pausas). Este perfil é o mesmo observado em outros estudos sobre o desenvolvimento da leitura (Salles e Parente, 2002; Sprenger-Charolles et al., 2003).

Com a escolarização e o desenvolvimento, a criança aprende e estabiliza as relações ortográficas, o que permite a recuperação automática e adequada da palavra e conduz ao uso menos freqüente da rota fonológica. A rota lexical torna-se mais utilizada e o perfil da leitura muda: as paralexias verbais e os neologismos (Salles e Parente, 2002) tornam-se mais freqüentes, além do uso de revisões que se desenvolvem com o amadurecimento do indivíduo. Assim, na tentativa de recuperar a palavra diretamente do léxico, as crianças deixam de regularizá-la e de segmentá-la, incorrendo na seleção de palavras com estrutura fonológica similar ("livro" lido /vidro/ ou "pipoca” lida como /popoca/). As revisões indicam que as crianças mais velhas e escolarizadas são capazes de perceber que a pronúncia realizada não existe e/ou não corresponde à palavra escrita.

No entanto, estas crianças mais velhas e escolarizadas ainda utilizam a rota fonológica na leitura de palavras mais complexas. De acordo com a literatura, a rota lexical está mais desenvolvida a partir da $3^{\text {a }}$ série (Salles e Parente, op. cit), porém a rota fonológica continua a ser utilizada na leitura de palavras mais complexas juntamente à rota lexical, mesmo na vida adulta, quando o leitor se depara com palavras desconhecidas ou pouco vistas (Sprenger-Charolles, op. cit).

Assim, do ponto de vista da escolarização, crianças de primeira série estão em fase de aprendizagem do sistema alfabético e 
teoricamente devem ser capazes de decodificar e reconhecer palavras escritas até o final desta série. Isto não quer dizer que as crianças de $2^{\text {a }}$ série sejam eficientes na leitura, pois as regras, não apenas as de conversão grafofonêmica, mas também as regras ortográficas e o ensino da utilização de pistas semânticas e contextuais durante a leitura, continuam a ser aprendidas e utilizadas nos anos seguintes.

Nesta perspectiva, as crianças deste estudo, mais ou menos escolarizadas, foram capazes de reconhecer as palavras escritas, mas utilizam estratégias diferentes. Ressalta-se mais uma vez, que se fosse considerado apenas o critério acerto/erro, todos os escolares teriam comportamento semelhante.

A leitura foi caracterizada a partir do tempo de processamento e de sua interação com os tipos de palavra e a escolaridade, confirmando a hipótese sobre a relação destes fatores. Contudo, para a nomeação, que envolve outro tipo de análise visual, formulam-se algumas questões: o processamento de outros estímulos visuais, como uma figura, apresentaria as mesmas etapas do processamento da palavra escrita? E seria igualmente influenciado pelas características do material?

Os dados da comparação entre leitura e nomeação, obtidos nesta pesquisa, apontaram tanto para semelhanças como para diferenças entre o processamento destas duas tarefas. Palavras escritas e figuras são estímulos visuais e o resultado final ocorre por meio da fala. O processamento da figura se inicia com a representação de um objeto e o da palavra escrita, por uma seqüência de símbolos arbitrários que devem ser aprendidos formalmente. O tipo de estímulo visual, figura ou palavra escrita pode ser determinante de tempos de processamento diferentes entre as tarefas e, as características das palavras escritas podem ou não afetar a nomeação das figuras. 
O fato de a leitura apresentar menor tempo de latência e maior porcentagem de acertos do que a nomeação pode ser explicado pelas rotas envolvidas em cada tarefa: ao ler, o indivíduo pode acessar o léxico, recuperar a forma fonológica da palavra e produzi-la. O leitor também tem à disposição os processos de transformação entre grafemas e fonemas, aprendidos desde o início da escolarização, para a leitura de palavras novas (Coltheart et al., 1993; Ellis, 1995; Lecours e Parente, 1997).

Por outro lado, a nomeação de figuras requer sempre o acesso ao significado para a posterior produção do nome (Theios e Amrhein, 1989; Johnson et al., 1996). Reconhecer e nomear uma figura não é uma habilidade aprendida formalmente e sofre muito mais do que a leitura, a influência da cultura e das experiências do indivíduo.

Uma criança pode reconhecer a palavra escrita "cabrito" porque conhece as relações entre os grafemas e os fonemas correspondentes ou entre a palavra como um todo e sua forma fonológica. No entanto, o acesso ao significado pode ou não ocorrer. Ao se deparar com a figura de um cabrito, por nunca ter visto ou visto muito pouco, o tempo de pesquisa ao léxico aumenta e a criança pode acessar nomes de animais visualmente semelhantes, como "bezerro". Controlar para uma pesquisa a freqüência de ocorrência dos nomes é muito complexo em decorrência das variáveis culturais e lingüísticas.

$\mathrm{O}$ fato de a leitura ter sido mais rápida do que a nomeação em todos os grupos de sujeitos difere do perfil observado nas pesquisas de Marmurek e Rinaldo (1992): alunos de $4^{\text {a }}$ série podem ler palavras mais rapidamente do que nomear objetos correspondentes, enquanto o inverso é observado para os alunos de $2^{\text {a }}$ série. Este fato pode ser explicado por diferenças metodológicas entre os dois estudos e por diferenças particulares de cada língua e da cultura, que influenciam o desenvolvimento da leitura e da nomeação. 
Outro dado importante refere-se à equivalência das características do estímulo entre as palavras escritas e as figuras. Os dados indicaram que os efeitos de freqüência e de extensão ocorreram de forma semelhante para a leitura e para a nomeação, enquanto o de regularidade foi diferente.

A presença do efeito "freqüência" sugere que as palavras escritas mais utilizadas na fase de escolarização referem-se a objetos em maior experiência, uso e contato com a criança. $O$ fato de ambas as tarefas serem afetadas pela freqüência, sugere que leitura e nomeação apresentam um componente lexical em comum, como também indicado por Bates (2001) e se influenciam mutuamente durante o desenvolvimento (Goswami, 2001). Por sua vez, esse efeito não foi observado no tempo de duração da emissão oral, indicando que após a criança recuperar o nome, este pode ser produzido oralmente como um todo. Já na leitura, a aplicação de regras de conversão ou o acesso ao léxico determinam diferenças no tempo de produção entre palavras de alta e de baixa freqüência.

No que se refere à influência das características fonológicas, apesar do efeito "extensão" ter sido semelhante para a nomeação e a leitura, cabe ressaltar que o caminho desta influência é diferente para ambas. Na leitura, a extensão é intrínseca ao estímulo visual, ou à palavra escrita. Já na nomeação, a partir da identificação das propriedades visuais e do acesso ao significado, é que a extensão da forma fonológica afeta o processamento da figura.

O efeito "regularidade", diferente para a nomeação e leitura, era esperado, porque a regularidade se aplica somente a palavras escritas e não a figuras, daí os resultados apontarem que, para este critério não há equivalência entre palavras e figuras. Buando as palavras irregulares são lidas isoladamente, o tempo para reconhecê-las pode ser maior, pois a leitura deste tipo de palavra depende do contexto 
(frase ou sentença) para não gerar pronúncias conflitantes. (/bolo/ e /bólo/). Por outro lado, a nomeação é diretamente derivada do objeto representado, enquanto durante ou após a leitura é que o objeto se constitui mentalmente (Stivanin e Scheuer, in press).

Partindo do principio que leitura e nomeação apresentam semelhanças, a nomeação também estaria em defasagem para aquelas crianças cuja leitura é uma tarefa difícil ou para os não leitores deste estudo?

Sobre este tema, os trabalhos encontrados na literatura (Snowling et al., 1988; Swan e Goswami, 1997; Nation e Snowling, 2001; Faust e Sharfstein-Friedman, 2003; Fowler e Swainson, 2004; Trauzettel-Klosinski et al., 2002; 2006) apresentam dados conflitantes o que levou ao interesse por essa pesquisa sobre nomeação de figuras em crianças não leitoras, falantes do português do Brasil.

No entanto, houve alguns obstáculos para a formação da amostra de não leitores. O primeiro foi o que considerar como alterações na leitura. Dificuldades na leitura podem ser encontradas e esperadas nas diversas fases da escolarização, porque fazem parte do processo de aprendizagem da leitura. Ainda, podem ser dificuldades não esperadas em determinadas fases, mas que se devem a um atraso no desenvolvimento e serão superadas em breve. Optou-se, então, por selecionar crianças não leitoras e que, na $2^{\text {a }}$ série, ainda não conseguem reconhecer a palavra escrita.

O segundo obstáculo foi determinar a causa da impossibilidade de reconhecimento da palavra escrita. O procedimento deveria envolver uma avaliação multidisciplinar, com avaliação neurológica, psicológica, oftalmológica, audiológica, fonoaudiológica, dentre outras. Porém, em decorrência das dificuldades para encaminhar os sujeitos a serviços públicos que realizam tais procedimentos, o 
processo desta pesquisa se tornaria longo e contaria com menor número de sujeitos.

Decidiu-se que informações detalhadas dadas por pais e professores e a realização do teste de inteligência WISC-III (Weschler, 1981) seriam procedimentos importantes para excluir os escolares cujo desempenho em leitura (e em nomeação de figuras) fosse conseqüência de déficits sensoriais, atencionais e intelectuais. Da mesma forma, os resultados obtidos na escala verbal do WISC -III garantiu que as alterações na leitura não fossem decorrentes de atraso intelectual e/ou distúrbio na linguagem oral.

Completando a análise da amostra, os sinais de dislexia (disponíveis no site da Associação Internacional de Dislexia), apresentados pelos não leitores, forneceram características sobre a amostra, mas não conduzem à hipótese diagnóstica, por não fazerem parte de um instrumento validado para a língua.

Particularmente, quanto aos resultados da nomeação, os não leitores processaram as figuras em tempo semelhante aos leitores de mesma série, mas não foram tão eficientes. Este grupo sofreu influência da extensão e da complexidade das figuras, o que facilitou ou dificultou a nomeação e produziram mais substituições fonológicas.

Diante destes dados, algumas explicações podem ser dadas. Primeiro, o tempo de processamento semelhante entre leitores e não leitores, para a nomeação de figuras, indica que a menor eficiência nesta tarefa pode ser explicada porque o tempo de recuperação do nome não foi suficiente ou adequado. Levanta-se como hipótese, a necessidade de um processamento mais lento para que o acesso e/ou recuperação dos nomes das figuras ocorra adequadamente, embora os dados obtidos neste estudo não garantam este fato.

Outra explicação aponta para uma falha nos processos que envolvem a fonologia. As crianças não leitoras são mais ou menos 
eficientes de acordo com as características fonológicas dos nomes das figuras. Conforme aumenta a extensão e a complexidade do nome, surgem as nomeações não esperadas, caracterizadas por substituições fonológicas: /vidro/ x /vrido/, /cobra/ x /croba/, /batata/ x /barata/, resultando em novas palavras ou pseudopalavras. Isto mostra que a dificuldade não está na análise das características visuais e nem semânticas das figuras. Caso contrário, as substituições seriam caracterizadas por outros tipos de nomes.

Esta hipótese, sobre dificuldades no processamento fonológico, foi estudada nas últimas duas décadas (Snowling, 1980; Wagner e Torgensen, 1987; Scarborough, 1990; Navas, 1997; Goswami, 2001) e envolvem a análise do comportamento da criança em várias tarefas de repetição de palavras, retenção de itens verbais em curto prazo, consciência fonológica e nomeação seriada rápida. A capacidade prejudicada para estabilizar representações fonológicas, acessá-las e recuperá-las seria a causa de dificuldades para ler e nomear.

Neste sentido, Snowling (2004) aponta que crianças com Transtorno da Leitura têm um comprometimento específico no processamento fonológico, enquanto outros sistemas de linguagem se encontram relativamente intactos. Estas crianças, as com Transtorno da Leitura, podem usar muito bem a linguagem para a finalidade de comunicação, mas apresentam dificuldades sutis no processamento dos sons que, aparentemente, interferem na aquisição de um sistema de linguagem escrita.

Depreende-se que o problema na nomeação pode não ser percebido, pois diante de outras alternativas para fins de comunicação, as crianças com Transtorno da Leitura podem utilizar definições e explicações de palavras quando o acesso ao nome do que desejam falar não ocorre (observado no estudo de Faust e Sharfstein-Friedman, 2003). Isto pode causar modificações na comunicação, como aumento 
da extensão da mensagem e/ou falta de motivação para prosseguir, implicando em incoerência ou falta de detalhes na transmissão da informação.

Partindo do pressuposto que as crianças não leitoras do presente estudo apresentam déficit na nomeação por uma falha na estabilização de representações fonológicas e na recuperação desta informação, uma questão merece reflexão: o que causa esta falha? Estão descartados aqui os déficits intelectuais e os de linguagem oral.

Para explicar esta questão, alguns pesquisadores enfatizam a importância de fatores genéticos (Castles et al., 1999; Conlon et al., 2006), alguns indicam o papel do ambiente (Snowling, 2004) e outros defendem a interação da genética e do ambiente (Stanovitch et al., 1997).

A partir da explicação genética para as alterações no Transtorno da Leitura, a criança nasceria com este déficit específico (Castles et al., 1999; Conlon et al., 2006) o qual pode ser observado nos exames de neuroimagem (Démonet, et al., 2004; Shaywitz e Shaywitz, 2005; Trauzettel- Klosinski et al., 2006). Estes exames demonstram prejuízos em áreas relacionadas à fonologia e o desenvolvimento de rotas neurais compensatórias em tarefas como leitura, repetição e nomeação.

Evidenciando o papel do ambiente, Snowling (2004) tenta explicar esta questão. A autora aponta que o pior desempenho de crianças com Transtorno da Leitura em provas de nomeação deve-se às alterações na leitura, o que causaria e diminuiria o menor contato com determinados tipos de palavras. As representações fonológicas destas palavras, desconhecidas ou pouco vistas, não estariam disponíveis ou mal especificadas, prejudicando o armazenamento lexical e, conseqüentemente, a nomeação de figuras. No presente estudo, porém, as crianças não leitoras tiveram problemas para processar figuras de 
baixa e de alta freqüência também. Então, o problema pode ter influência, mas não está especificamente na falta de exposição ao material escrito.

Integrando as duas explicações acima, Stanovitch et al. (1997) acreditam na influência genética, que compromete o processamento fonológico, caracterizando uma leitura difícil por dificuldades na conversão grafofonêmica e na memorização destas relações. Por outro lado, o papel do ambiente, como falta de exposição ao material escrito pode determinar dificuldades na formação do léxico de palavras escritas, contribuindo para o déficit na leitura.

$\mathrm{Na}$ presente pesquisa, foi possível caracterizar o perfil dos não leitores para a nomeação de figuras e refletir sobre os processos cognitivos implicados neste comportamento. Porém, determinar as causas depende da realização de exames neurológicos e do estudo da exposição à leitura, não realizados aqui.

Finalizando, cabe discutir a importância do programa computacional para corroborar os achados deste estudo.

Considerar as medidas do tempo de processamento foi possivel devido à construção do programa computacional. A aplicação das provas por meio do programa é prática. Embora seja um processo lento, a análise dos dados é precisa, porque permitir ouvir e visualizar a onda acústica referente à fala. Contudo, a análise da concordância entre juízes foi essencial para garantir a fidedignidade das diversas análises deste estudo.

Existem programas que permitem um reconhecimento automático da fala, mas sofrem a influência de ruídos externos, conduzindo a erros no registro do tempo. Além disso, são mais utilizados com adultos, pois as crianças muitas vezes não atendem às solicitações e hesitam, fazem perguntas, tossem antes de ler ou nomear. 
O programa pode se tornar mais prático com a diminuição do número de palavras a serem analisadas. Mas, o mais interessante, é que alguns pesquisadores estão estudando meios de reconhecimento preciso da voz humana, o que possibilitará construir programas capazes de discriminar sons da fala de outros sons, automaticamente.

A análise do tempo de processamento, possível por meio da construção do programa computacional, serve como meio de avaliação diagnóstica e de evolução terapêutica. Os procedimentos podem se estender a outros tipos de tarefas lingüísticas e também a outras populações, como os quadros neurológicos e psiquiátricos. 
8. CONCLUSÃo 


\section{CONCLUSÃo}

Este estudo permitiu concluir que:

- na leitura de palavras, o tempo de processamento não foi determinante da eficiência na leitura da maioria das palavras, com exceção das mais complexas, nas quais a lentidão no processamento está associada a menor eficiência da leitura.

- a influência das variáveis psicolingüísticas para o tempo de processamento e precisão das respostas caracterizou-se pela interação entre freqüência, regularidade, extensão e complexidade silábica das palavras escritas.

- as crianças mais novas e menos escolarizadas utilizam preferencialmente a rota fonológica, enquanto os escolares mais velhos fazem uso mais freqüente da rota lexical, embora as duas rotas estejam disponíveis para todos os escolares em função da complexidade da palavra escrita.

- a interação entre estes fatores (tipos de palavras e faixas escolares) indica que o grau de estabilização das representações da palavra escrita na memória depende de suas propriedades, da rota utilizada pelo leitor e das estratégias envolvidas na leitura. Este fato altera o tempo de recuperação e produção destas informações.

- a nomeação apresentou maior tempo de processamento do que a leitura, denotando que a análise visual da figura e a necessidade de acesso ao significado para a adequada produção do nome são processos 
que levam mais tempo do que a análise ortográfica e/ou fonológica da palavra escrita, na faixa de escolaridade estudada.

- a característica freqüência exerceu efeito semelhante entre a leitura e a nomeação, indicando um componente lexical em comum para o processamento de palavras e de figuras.

- os efeitos de freqüência, regularidade e extensão nos grupos de figuras produziram semelhantes comportamentos lingüísticos entre crianças leitoras e não leitoras.

- apesar da influência das características do material e o tempo de processamento terem sido semelhantes entre as amostras, os não leitores foram menos eficientes do que os leitores de mesma faixa de escolarização. A freqüência de substituições fonológicas na nomeação, em oposição ao sistema semântico preservado, conduz à hipótese de falhas na seleção das representações fonológicas das figuras. 
9. ANEXOS 
ANE

HOSPITAL DAS CLÍNICAS

DA FACULDADE DE MEDICINA DA UNIVERSIDADE DE SÃo PAULO

CAIXA POSTAL, 8091 - SÃO PAULO - BRASIL

DIRETORIA CLÍNICA

Comissão de Ética para Análise de Projetos de Pesquisa

\section{APROVACẼO}

A Comissão de Ética para Análise de

Projetos de Pesquisa - CAPPesq da Diretoria Clínica do Hospital das Clínicas e da Faculdade de Medicina da Universidade de São Paulo, em sessão de 08.10.03, APROVOU o Protocolo de Pesquisa $n^{\circ} 637 / 03$. intitulado: "Tempo de Latência para a Nomeação e para a Leitura em Crianças de $2^{a}$ a $4^{a}$ Séries" apresentado pela ÁREA DE FISIOPATOLOGIA EXPERIMENTAL, inclusive $\triangle$ Termo de Consentimento Livre e Esclarecido.

Pesquisador(a) Responsável: PROFA. DRA. CLÁUDIA INES SCHEUER

Pesquisador(a) Executante: SRA. LUCIENE STIVANIN

CAPPesq, 08 de Outubro de 2003.

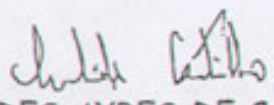

PROF. DR. EUCLIDES AYRES DE CASTILHO

Presidente da Comissão de Ética para Análise de Projetos de Pesquisa

incaminhe-se à CPG-FMUSP

ara as devidas pronidencias.

P., 10,0 S

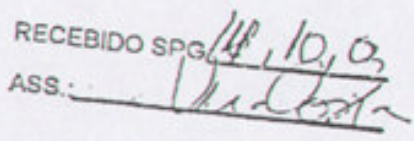

OBSERVAÇÃO: Cabe ao pesquisador elaborar e apresentar à CAPPesq, os relatórios parciais e final sobre a pesquisa (Resolução do Conselho Nacional de Saúde $n^{\circ} 196$, de 10.10.1996, inciso IX.2, letra " $c$ ")

D) / 


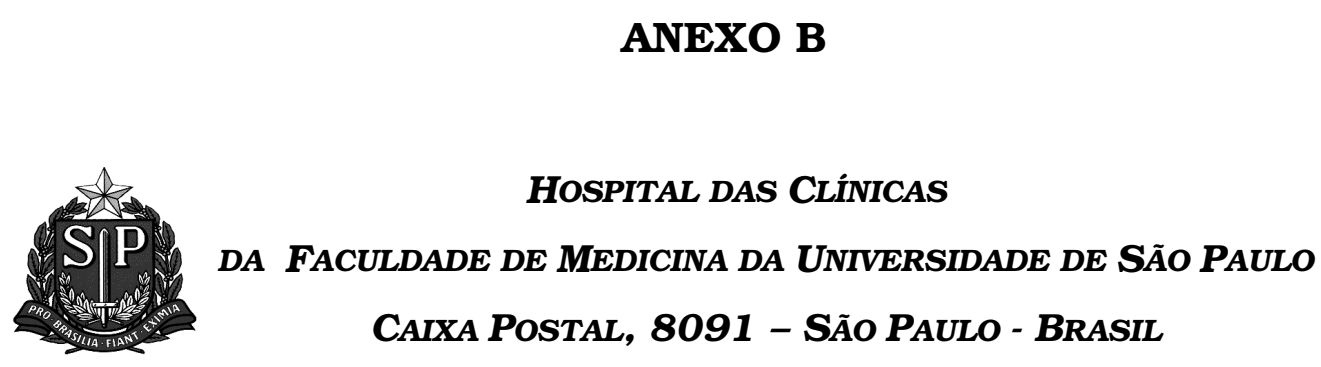

TERMO DE CONSENTIMENTO LIVRE E ESCLARECIDO

\section{I - DADOS DE IDENTIFICAÇÃO DO SUJEITO DA PESGUISA OU RESPONSÁVEL LEGAL}

\section{NOME DO PACIENTE:}

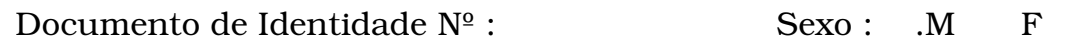

Data de Nascimento:

Endereço

Bairro:

Cep

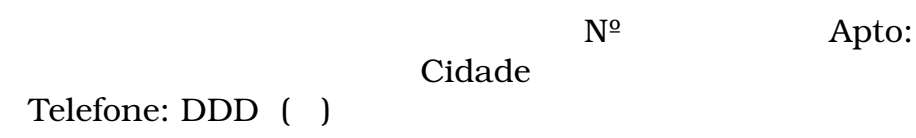

\section{RESPONSÁVEL LEGAL:}

Natureza (grau de parentesco, tutor, curador etc.)

Documento de identidade

Sexo: M $\mathrm{F}$ ]

Data de Nascimento.:

Endereço:

Bairro:

Cep:

Telefone: DDD ( )

Cidade:

№ $\quad$ Apto:

\section{II - DADOS SOBRE A PESQUISA CIENTÍFICA}

1. TÍtUlo do PROTOCOlO DE PESQUISA Tempo de processamento para a leitura e para a nomeação em crianças leitoras e não leitoras

2. PESgUISADOR RESPONSÁVEL: Dra. Cláudia Scheuer

PESQUISADOR EXECUTANTE: Luciene Stivanin

CARGO/FUNÇÃO: Fonoaudióloga INSCRIÇÃO CONSELHO REGIONAL № 14.385/SP

UNIDADE DO HCFMUSP: Laboratório de Investigação Fonoaudiológica e Linguagem Infantil e Cognição do Curso de Fonoaudiologia- Cidade Universitária

3. AVALIAÇÃo DO RISCO DA PESgUISA: RISCO MÍNIMO (cansaço) - (probabilidade de que o indivíduo sofra algum dano como consequência imediata ou tardia do estudo)

4.DURAÇÃO DA PESQUISA : 24 meses

\section{III - REGISTRO DAS EXPLICAÇÕES DO PESgUISADOR AO PACIENTE OU SEU REPRESENTANTE LEGAL SOBRE A PESQUISA CONSIGNANDO:}

1. justificativa e os objetivos da pesquisa: a fala e a escrita estão relacionadas, de acordo com vários estudos. Como não há trabalhos sobre a relação entre ler palavras e dizer o nome de figuras, os objetivos deste trabalho serão medir o tempo que a criança leva para ler palavras, para nomear e apontar objetos, verificar o número de acertos da criança e os tipos de erros em cada prova. 
2. Procedimentos: os pais responderão a perguntas sobre o desenvolvimento da criança e as condições econômicas, para saber se a criança poderá fazer parte da pesquisa.. As crianças realizarão 3 provas: ler palavras em voz alta, nomear figuras e apontar o objeto pedido pela pesquisadora. Serão anotados o tempo que a criança leva para ler e nomear, o número de acertos e quais erros foram cometidos. $\mathrm{O}$ objetivo é saber sobre o desenvolvimento normal e a relação entre e leitura e nomeação.

3. desconfortos e riscos esperados: o risco esperado é mínimo, ou seja, a criança pode se cansar.

4. benefícios que poderão ser obtidos: com os resultados, serão obtidos dados sobre o desenvolvimento normal de leitura, que servirão para avaliar posteriormente onde estão as dificuldades das crianças com baixo rendimento escolar e assim, planejar a intervenção.

5. procedimentos alternativos que possam ser vantajosos para o indivíduo: se for encontrado algum tipo de alteração, a criança será encaminhada para atendimento.

\section{V - ESCLARECIMENTOS DADOS PELO PESQUISADOR SOBRE GARANTIAS DO SUJEITO DA PESQUISA CONSIGNANDO:}

1. O reponsável pelo participante da pesquisa terá acesso, a qualquer momento, às informações sobre procedimentos, riscos e benefícios relacionados à pesquisa, inclusive quanto apresentar dúvidas.

2. O reponsável pelo participante da pesquisa terá a liberdade de retirar seu consentimento a qualquer momento e de deixar de participar do estudo, sem que isto traga prejuízo à continuidade da assistência.

3. Os dados pessoais do particpante da pesquisa são confidenciais e assim, não serão revelados. Para a pesquisa, há confidencialidade, sigilo e privacidade.

4. Se o participante da pesquisa apresentar danos à saúde por ter particpado da pesquisa, receberá assistência gratuita no HCFMUSP.

5. O participante da pesquisa será indeniizado se sofrer danos à saúde decorrentes da pesquisa.

\section{INFORMAÇÕES DE NOMES, ENDEREÇOS E TELEFONES DOS RESPONSÁVEIS PELO ACOMPANHAMENTO DA PESQUISA, PARA CONTATO EM CASO DE INTERCORRÊNCIAS CLÍNICAS E REAÇÕES ADVERSAS.}

Luciene Stivanin- Rua Teodoro Sampaio , 632 apto. 52 Pinheiros Cep: 05406-000

São Paulo-SP

Tel.: Cel: (11)9338-8535

e-mail: stivanin@usp.br

Cláudia Inês Scheuer- Rua Cipotânea, 51 Butantâ Cep: 05360-160 São Paulo-SP

Tel: (11)30917455

\section{VI - CONSENTIMENTO PÓS-ESCLARECIDO}

Declaro que, após convenientemente esclarecido pelo pesquisador e ter entendido o que me foi explicado, consinto em participar do presente Protocolo de Pesquisa

São Paulo,

de

de

assinatura do sujeito da pesquisa

ou responsável legal assinatura do pesquisador (carimbo ou nome Legivel) 
ANEXO C

\section{ANAMNESE FONOAUDIOLÓGICA}

Nome da criança:

D.N.: $\quad$ Idade: Escolaridade: Data:

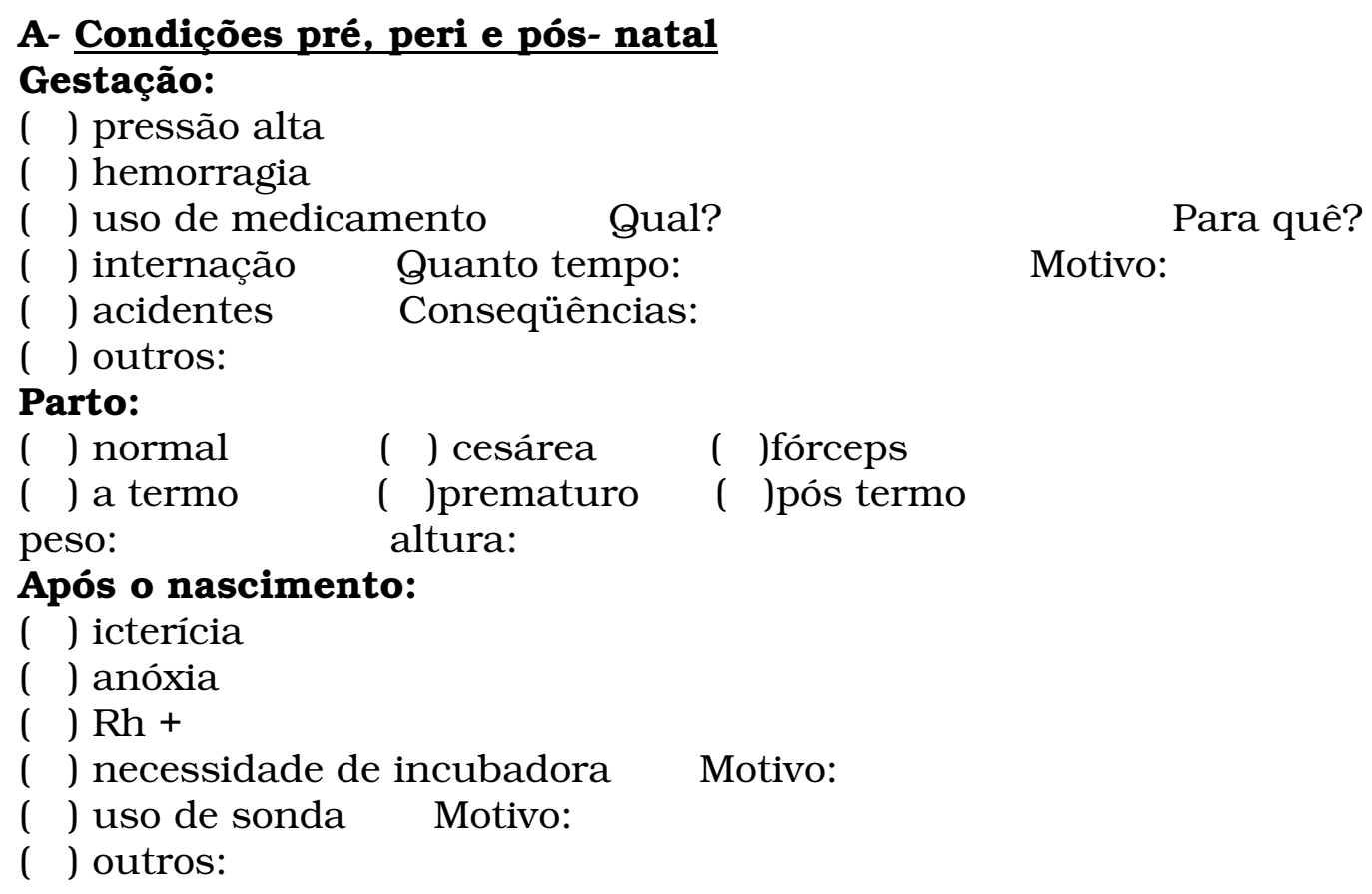

\section{B- Dados sobre o desenvolvimento} Desenvolvimento Neuropsicomotor Idade em que controlou a cabeça:

Idade em que sentou:

Idade em que engatinhou:

Idade em que andou:

Idade em que controlou urina: diurno: noturno: Idade em que controlou fezes: diurno:

noturno:

Necessitou de tratamento para algum dos itens acima? Qual(is)? Por quê?:

\section{Desenvolvimento de linguagem:}

Idade em que falou as primeiras palavras:

Idade em que falou as primeiras frases:

Conta histórias? Conta o que aconteceu com ele (a)?

Compreende o que ouve?

Entende piadas?

Entende expressão facial? 
Apresentou (ou apresenta) troca de sons na fala? Quais? Quando? Por quanto tempo?

Inicia a comunicação?

Mantém diálogo?

A comunicação é diferente fora de casa e com pessoas não familiares? Como é? Por quê?

Interage bem com os amigos da escola?

Prefere ficar sozinho? Por quê?

Já fez tratamento fonoaudiológico por problemas na fala? Quando?

Por quanto tempo?

\section{Audição}

Ouve bem?

Já fez exame audiológico? Por quê? Quando? Quais os resultados?

\section{Visão}

Enxerga bem?

Usa óculos? Há quanto tempo?

Qual é o problema visual?

\section{C- Escolarização}

Quando ingressou à escola?

Ficou ano sem estudar? Qual? Por quê?

Já repetiu de ano? Qual? Por quê?

Sabe ler?

Sabe escrever?

Consegue fazer cópia?

Apresentou dificuldades escolares? Quais? Quando? Como foi solucionado? Ainda apresenta algum tipo de dificuldade?

Precisa de ajuda para fazer o ver de casa? Por quê? Quem ajuda?

\section{D- Saúde}

Doenças infantis:

Já fez exames? Quais? Por que? Quais os resultados?

Já ficou internado? Quando? Por quanto tempo? Por quê?

Fez ou faz uso de remédios? Quais? Para que?

Fez ou faz algum tipo de tratamento? Qual (is)? Por que

\section{E- Comportamento}

Seu filho é:

( ) desatento

( ) ansioso

( ) hiperativo

( ) hipoativo

( ) agressivo

Outros: 
F- Observações: 


\section{ANEXO D \\ QUESTIONÁRIO ESCOLAR}

O (a) aluno (a):

( ) tem dificuldade motora para manipular os materiais (escrever, apagar, recortar)

( ) esforça-se para enxergar (se não usar óculos)

( ) tem dificuldade para ouvir

( ) tem dificuldade para entender o que ouve

( ) tem dificuldade para falar

( ) tem dificuldade para ler

( ) tem dificuldade para escrever

( ) tem dificuldade para compreender o que lê ou escreve

( ) apresenta dificuldade para aprender

O quê principalmente?

Como você descreveria a dificuldade?

O que você considera como causa desta dificuldade?

( ) tem dificuldade com matemática porque não entende as noções de quantidade e as relações envolvidas

( ) tem dificuldade com matemática porque não consegue ler ou compreender oralmente o problema matemático

( ) tem dificuldade para aprender o conteúdo das disciplinas porque tem dificuldade de compreensão

( ) tem dificuldade para aprender o conteúdo das disciplinas porque não consegue ler a matéria

( ) está mais atrasado que a maioria dos alunos

( ) já necessitou ou necessita de exercícios de reforço para acompanhar a classe

( ) já freqüentou ou tem necessidade de freqüentar escola especial

( ) já foi reprovado

( ) ficou algum ano afastado da escola Motivo:

( ) não deveria estar cursando esta série

( ) o desempenho escolar é inferior à idade

( ) é desatento

( ) é agitado

( ) é agressivo

( ) esquece facilmente as coisas

( ) apresenta comportamentos diferentes. Descreva:

Você sabe se ele toma algum medicamento ou faz tratamento? Descreva:

Observações (outras características importantes não descritas aqui):

Nome da professora: 


\section{ANEXO E}

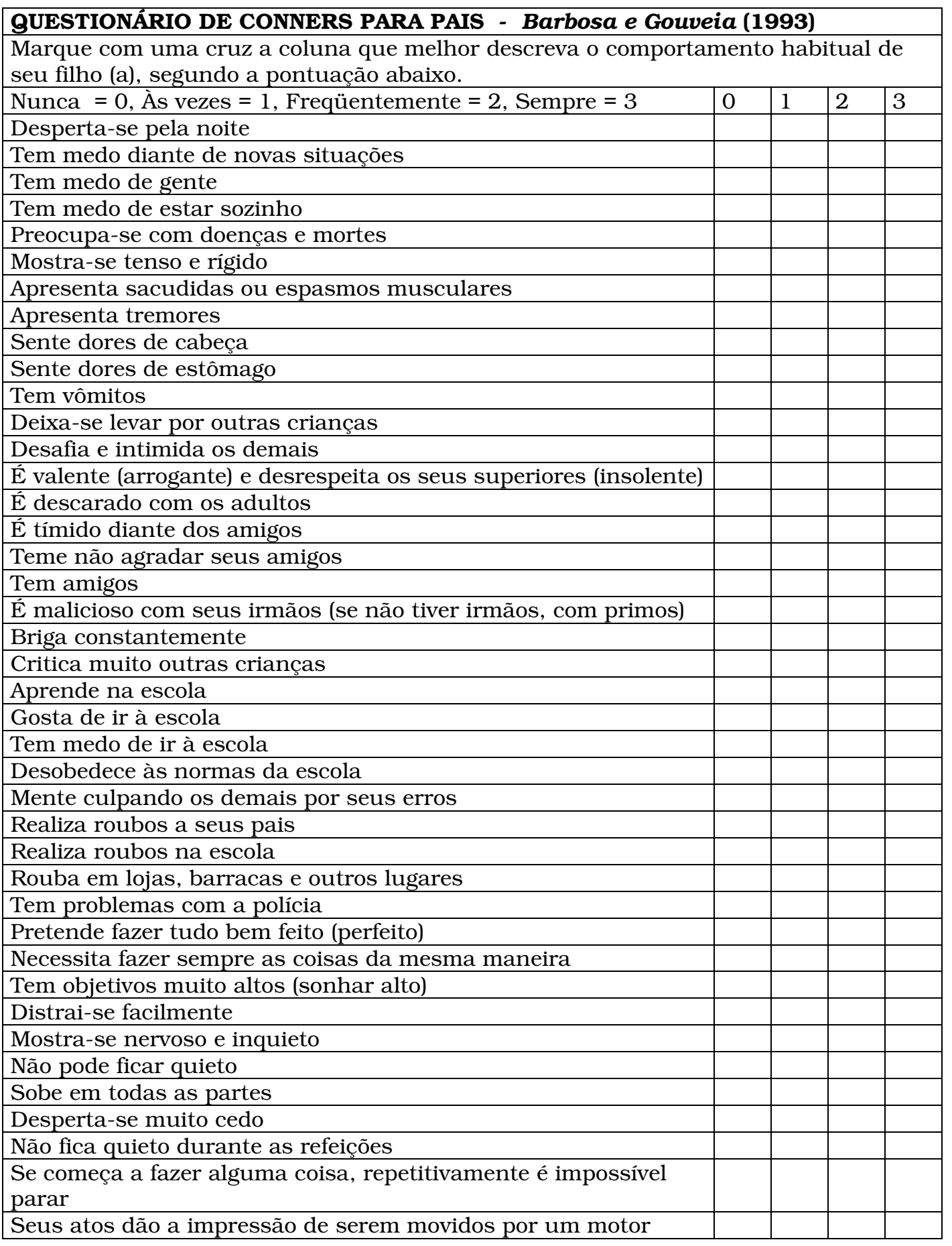




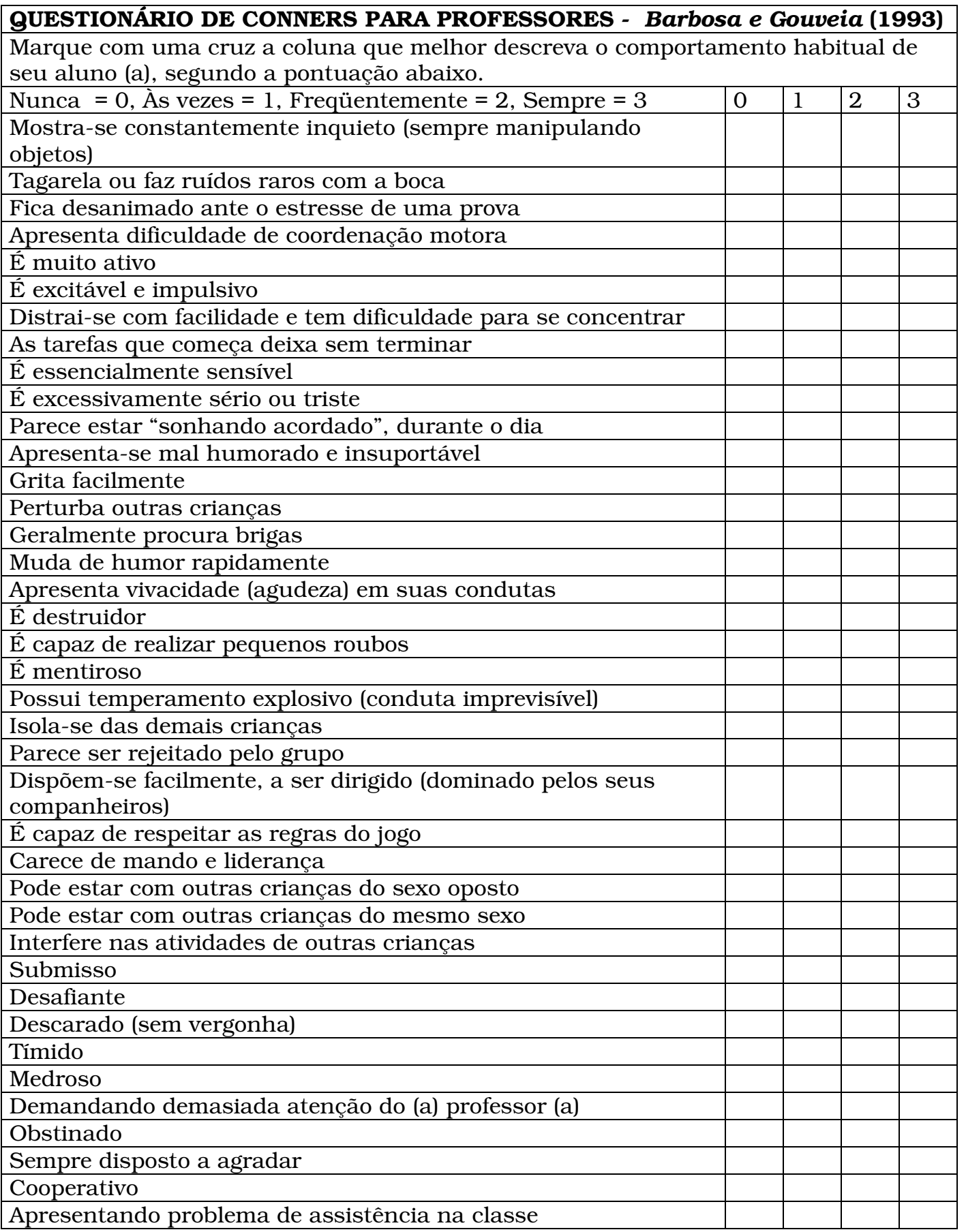




\section{ANEXO F \\ SINAIS DE DISLEXIA (IDA, 2000)}

Faça um X no(s) item (s) correspondente à (s) dificuldade (s) que a criança apresenta:

1. Lentidão na associação grafema-fonema.

2. Dificuldade para a decodificação de palavras simples (leitura isolada de palavras simples).

3. Dificuldade para a soletração oral.

4. Apresenta erros inconsistentes na leitura e na soletração como inversões de letras e palavras, omissões.

5. Confunde palavras pequenas como "para"por "por".

6. Apóia-se em adivinhação e no contexto.

7. Tem dificuldade para aprender novo vocabulário.

8. Pode trocar números de uma seqüência ou confundir sinais aritméticos (+ $-\mathrm{x} /=)$.

9. Pode ter dificuldade em relembrar atos.

10. Pode ser lento para aprender novas habilidades; tenta memorizar sem entender.

11. Pode ter dificuldade em planejamento, organização e administração do tempo, materiais e tarefas.

12. Segura o lápis de forma diferente.

13. Dificuldade na coordenação motora fina (cortar papel, utilizar régua).

Nome da professora: 


\section{ANEXO G}

ESCALA DE AVALIAÇÃo DO NÍVEL SÓCIO-ECONÔMICO FAMILIAR (ASSOCIAÇÃO BRASILEIRA DE INSTITUTOS DE PESQUISA DE MERCADO)

Nome da criança:

D.N.:__ Idade:___ Escolaridade:__ Data:

1. Quem é o chefe de família na sua casa?

( ) o próprio entrevistado

( ) outrem:

2. Qual foi o grau de instrução mais alto que o chefe de família obteve? Qual foi o último ano de escola que o chefe de família cursou?

\begin{tabular}{|l|c|}
\hline \multicolumn{1}{|c|}{ Categoria da Classificação } & No de pontos \\
\hline Não estudou primário completo & 0 \\
\hline Primário e ginásio incompleto & 5 \\
\hline Ginasial completo e colegial incompleto & 10 \\
\hline Colegial completo e universitário incompleto & 15 \\
\hline Universitário completo & 21 \\
\hline
\end{tabular}

3. Na sua casa tem (cada item abaixo):

\begin{tabular}{|l|l|l|}
\hline Item & Não & Sim \\
\hline Aparelho de vídeo cassete VCR & & $($ ) 10 pontos \\
\hline Máquina de lava roupa & & $($ ) 8 pontos \\
\hline Geladeira & & $($ ) 7 pontos \\
\hline Aspirador de pó & & $($ ) 6 pontos \\
\hline
\end{tabular}

4. Quantos (cada item abaixo) existem em sua casa?

\begin{tabular}{|l|l|l|l|l|l|l|l|}
\hline Itens possuídos & Nenhum & \multicolumn{6}{|l|}{$\begin{array}{l}\text { Número de itens possuídos e número de } \\
\text { pontos }\end{array}$} \\
\hline & & $\mathbf{1}$ & $\mathbf{2}$ & $\mathbf{3}$ & $\mathbf{4}$ & $\mathbf{5}$ & $\mathbf{6}$ ou + \\
\hline Carros & & 4 & 9 & 13 & 18 & 22 & 26 \\
\hline TV a cores & 4 & 7 & 14 & 14 & 18 & 22 \\
\hline Banheiros & 2 & 5 & 10 & 10 & 12 & 15 \\
\hline Empregados mensalistas & & 5 & 11 & 21 & 21 & 26 & 32 \\
\hline Rádio & 2 & 3 & 6 & 6 & 8 & 9 \\
\hline A $\geq$ a 89 B 59 a 88 & C 35 a 58 a 34 & E $\leq$ a 19
\end{tabular}

Classe sócio-econômica pelo total de pontos ABIPEME: Total: Classe: 


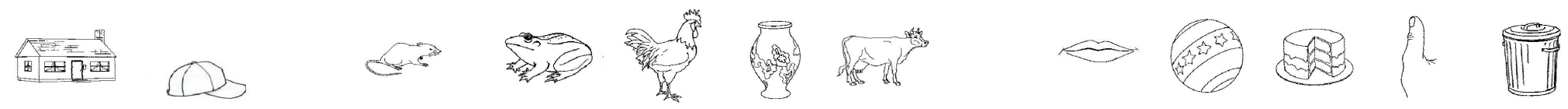

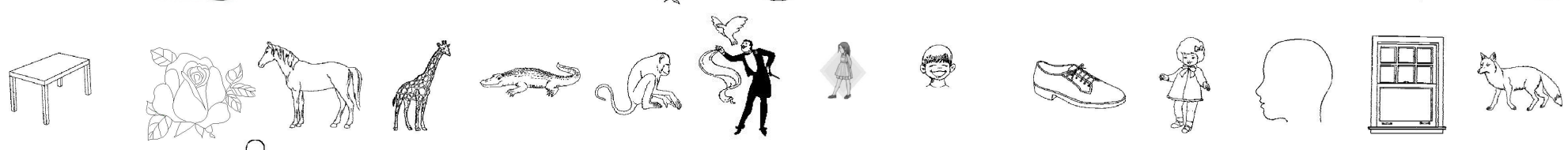

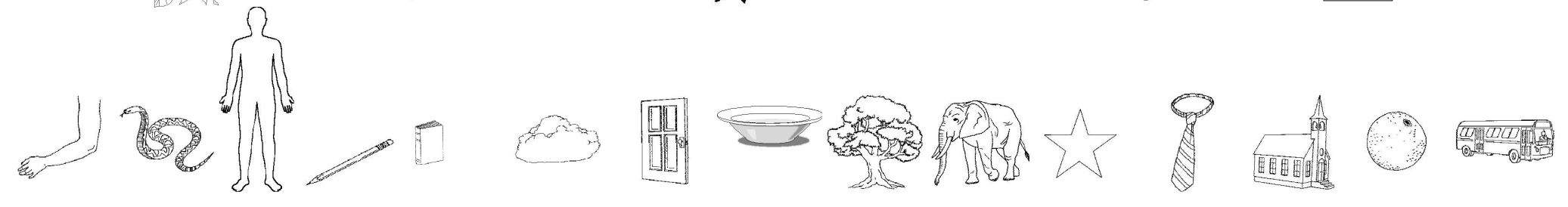
8f 302 I

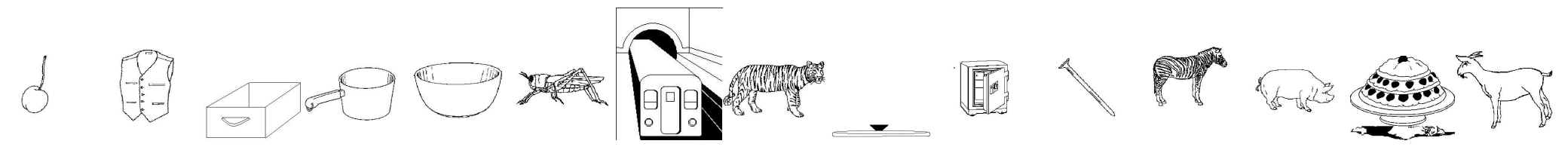

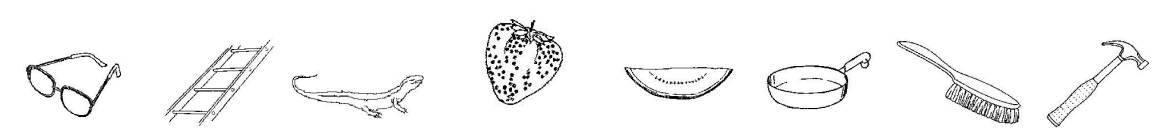




\section{ANEXO I}

Tabela de Nưmeros Causais

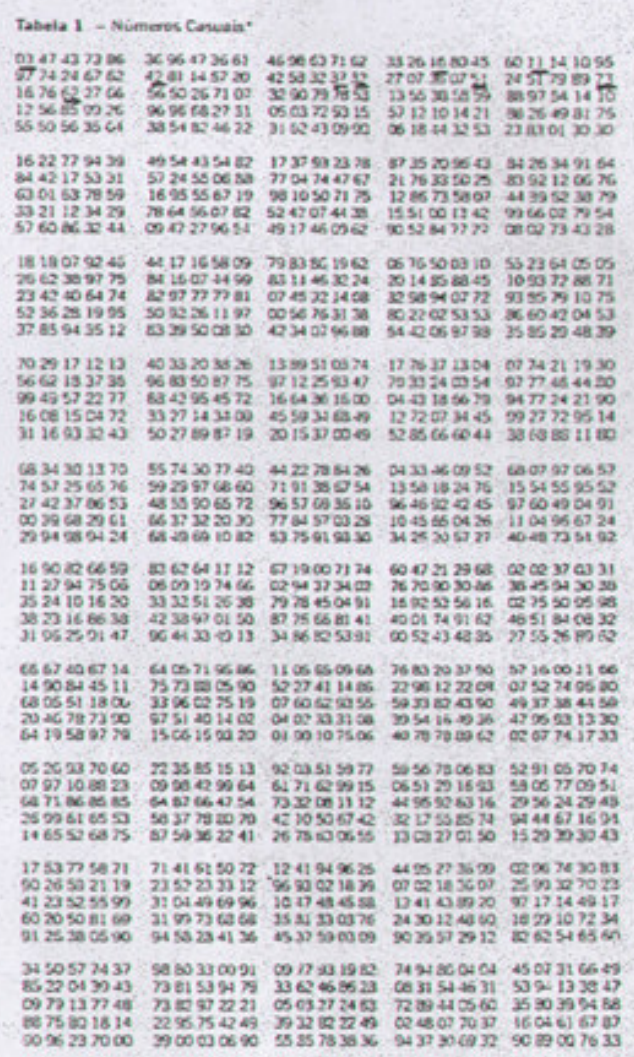

Fisher RA, Yates F. Tabelas estatisticas para Pesquisa em Biologia, Medicina e Agricultura. Såo Paulo, Poligono-EDUSP. 1971. 
10. REFERÊNCIAS 


\section{REFERÊNCIAS}

Adams MJ. Beginning to read: thinking and learning about print. Massachusetts: Institute of Technology; 1994.

Alario FX, Ferrand L, Laganaro M, New B, Frauenfelder UH, Segui J. Predictors of picture naming speed. Behav Res Methods Instrum Comput. 2004;36(1):140-55.

Almeida PM, Wickerhauser H. O critério ABA-Abipeme: em busca de uma solução. Um estudo e uma proposta submetidos à ABA Associação Brasileira de Anunciantes - e Abipeme - Associação Brasileira dos Institutos de Pesquisa de Mercado- abr/jun. 1991.

American Psychiatric Association. Diagnostic and Statistical mental Disorders. $4^{\text {th }}$ ed. Porto Alegre: Artes Médicas. 1995.

Bajo M. Semantic facilitation with pictures and words. $J$ Exp Psychol Learn Mem Cogn. 1998 14: 579-89.

Balota DA, Law MB, Zevin JD. The attentional control of lexical processing pathways: Reversing the word frequency effect. Mem Cognit. 2000; 28(7):1081-9.

Bates E, Burani C, D'Amico S, Barca, L. Word reading and picture naming in Italian. Mem Cognit. 2001;29(7):986-99.

Bates E., D’Amcio S, Jacobsen T, Székely A, Andonova E, Devescovi A. Timed picture naming in seven languages. Psychon Bull Rev.2003;10(2):344-80.

Barbosa GA, Gouveia VV. $O$ fator hiperatividade do questionário de Conners: validade conceitual e normas diagnósticas. Temas.1993;38:188-202.

Barrera SD, Maluf MR. Consciência metalingüística e alfabetização: um estudo com crianças da primeira série do ensino fundamental. Psicol. Reflex. Crit. 2003;16(3):491-502.

Barrow IM, Holbert D, Rastatter MP. Effect of color on developmental picture-vocabulary naming of 4-,6-, and 8-years-old children. Am $J$ Speech Lang Pathol. 2000;9:310-18. 
Barry C, Morrison CM, Ellis AW. Naming the Snodgrass and Vanderwart pictures: effects of age of acquisition, frequency, and name agreement. $Q J$ Exp Psychol. 1997;50(A),560-85.

Bastos DA, Befi-Lopes DM, Rodrigues A. A habilidade de organização hierárquica do sistema lexical em crianças com Distúrbio Específico de Linguagem . Revista da Sociedade Brasileira de Fonoaudiologia. 2006;11(2) 82-9.

Béfi-Lopes DM. Aquisição e desenvolvimento lexicais - algumas contribuições. Acta Semiótica e Lingüística. 2000;8:155-89.

Béfi-Lopes DM, Galea DES. Análise do desempenho lexical em crianças com alterações no desenvolvimento da linguagem. Pró-Fono. 2000;12(2)31-7.

Bennet KJ, Brown S, Boyle M, Racine Y, Offord D. Soc Sci Méd. 56, 2443-2448, 2003.

Berman S, Friedman D, Hamberger M, Snodrass JG. Developmental picture nouns: relationships between name agreement, familiarity, and visual complexity for child and adult ratings of two sets of line drawings. Behav Res Methods Instrum Comput. 1989;21(3),371-82.

Bjork RA, Bjork EL. A new theory of issue and old theory of stimulus fluctuation. In: Healy AF, Kosslyn SM, Shiffrin RM. From learning processes to cognitive processes: Essays in honor of William KE. Hillsdale: Erlbaum. 1992. p.35-67.

Caccamise D, Synder L. Theory and pedagogical practices of text comprehension. Top Lang Dis. 2005;1:5-20.

Cardoso-Martins C, Frith U. Consciência fonológica e habilidade de leitura na síndrome de Down. Psicol. Reflex. Crit. 1999;12(1):209-24.

Cardoso-Martins C, Pennington BF. Qual é a contribuição da nomeação seriada rápida para a habilidade de leitura e escrita?: Evidência de crianças e adolescentes com e sem dificuldades de leitura. Psicol. Reflex. Crit. 2001;14(2):387-97.

Castles A, Coltheart M. Varieties of developmental dyslexia. Cognition. 1993; 47:149-80. 
Castles A, Coltheart M. Cognitive correlates of developmental surface dyslexia: a single case study. Cogn Neuropsychol. 1996; 13:25-50.

Castles A, Datta H, Gayán J, Olson RK. Varieties of developmental reading disorder: genetic and environmental influences. $J$ of Exp Child Psychol. 1999;72:73-94.

Cohen D, Plaza M, Perez-Diaz F, Lanthier O, Chauvin D, Hambourg N, Wilson AJ, Basquin M, Mazet P, Riviere JP. Individual cognitive training of reading disability improves word identification and sentence comprehension in adults with mild mental retardation. Res Dev Disabil. 2006;27(5):501-516.

Chi MTH. Age differences in speed of processing. Dev Psychol. $1977 ; 13: 543-4$.

Cárnio MS, Santos D. Evolução da consciência fonológica em alunos de ensino fundamental. Pró-Fono. 2005;.17(2):195-200.

Cielo CA. Habilidades em consciência fonológica em crianças de 4 a 8 anos de idade. Pró-fono. 2002, 14(3):301-312.

Coltheart M, Curtis B, Atkins P, Haller M. Models of reading aloud: Dual route and parallel - distributed - processing approaches. Psychol Rev. 1993;100:589-608.

Coltheart M, Rastle K, Perry C, Langdon R, Ziegler J. DRC: A dual route cascated model of visual word recognition and reading aloud. Psychol Rev. 2001;108:204-256.

Conlon EG, Zimmer-Gembeck MJ, Creed PA, Tucker M. Family history, self-perceptions, attitudes and cognitive abilities are associated with early adolescent reading skills. J Res Read. 2006; 29:11-32.

Conners CK. A teaching rate scale for use in drug studies with children. American Journal of Psychiatry. 1969; 126:884-8.

Conners FA, Rosenquist CJ, Sligh AC, Atwell JA, Kiser T. Phonological reading skills acquisition by children with mental retardation. Rev Dev Disabil. 2006; 27 (2):121-37.

Cunha JA. Piscoadiagnóstico - R. Porto Alegre: Artes Médicas; 1993. 
Cycowicz YM, Friedman D, Rothstein M, Snodgrass JG. Picture Naming by Young Children: Norms for Name, Agreement, Familiarity, and Visual Ceee4rdsomplexity. J Exp Child Psychol. 1997;65:171-237.

Dahlgren SA. Reading and spelling abilities in children with severe speech impairments and cerebral palsy at 6, 9, and 12 years of age in relation to cognitive development: a longitudinal study. Dev Med Child Neurol. 2006;48(8):629-34.

Démonet JF, Taylor MJ, Chaix Y. Developmental Dyslexia. Lancet. 2004; 363 (1): 1451-60.

Donders FC. On the speed of mental processes. Acta Psychol. 1969; 30: 412-31.

Ellis AW. Leitura e escrita e dislexia: uma análise cognitiva. $2^{\text {a }}$ ed, Porto Alegre: Artes Médicas; 1995.

Ehri LC, Mccormick S. Phases of word learning: Implications for instruction with delayed and disabled readers. Reading and Writing Quarterly. 1998;14:35-164.

Eysenck MW, Keane MT. Cognitive Psychology: a student's handbook: New York: Lawrence Erlbaum; 1990.

Faust M, Sharfstein-Friedman S. Naming difficulties in adolescents with dyslexia: Application of the tip-of-the-tongue paradigm. Brain Cogn, 2003;53(2): 211-17.

Ferrand L. Why naming takes longer than reading? The special case of Arabic numbers. Acta Psychol. 1999; 1000:253-66.

Ferraz PG. Transtornos da aprendizagem: proposta de um sistema tutorial para auxílio ao diagnóstico (tese). São Paulo: Faculdade de Medicina, Universidade de São Paulo:2002.

Fisher RA, Yates F. Tabelas estatisticas para Pesquisa em Biologia, Medicina e Agricultura. São Paulo, Polígono-EDUSP, 1971.

Fletcher JM, Schaywitz SE, Schaywitz BA. Comorbidity of learning and attention disorders. Pediatr Clin North Am. 1999;46:885-97. 
Foster KI, Chambers SM. Lexical access and naming time. Journal of Verbal Learning and Verbal Behavior. 1973;12:627-35.

Fowler AE, Swainson B. Relationships of naming skills to reading, memory, and receptive vocabulary: evidence for imprecise phonological representations of words by poor readers. Ann Dyslexia. 2004;54(2);247-80.

Frith U. Beneath the surface of developmental dyslexia. In Patterson K, Marshall J \& Coltheart M, Editors. Surface dislexia: neuropsychological and cognitive studies of phonological reading. London: Lawrence Erlbaum Associates; 1985.

Gayán J, Olson RK. Genetic and environmental influences on individal differences n printed word recognition. J Exp Chil Psychol. 2003; 84:97123.

Goff DA, Prat C, Ong B. The relations between children's reading comprehension, working memory, language skills and components of reading decoding in a normal sample. Reading and Writing. 2005; 8:583-616.

Golz A, Westerman ST, Westerman LM, Gilbert DA, Netzer A. Does otitis media in early childhood affect reading performance in later school years? Otolaryngol Head Neck Surg. 2006;134(6):936-9.

Goswami U. Early phonological development and the acquisition of literacy. In Neuman SB e Dickinson DK, editors. Handbook of Early Literacy Research. New York: The Guilford Press; 2001. p.11-25.

Goswami U, Ziegler JC, Dalton L, Schneider W. Nonword reading across ortographics: how flexible is the choice of reading units? Applied Psycholinguistics. 2003;24:235-247.

Guimarães SRK. Dificuldades no desenvolvimento da lectoescrita: o papel das habilidades metalingüísticas. Psic.: Teor. $e$ Pesq. 2003;19(1):33-45.

Haddad N. Noções gerais de amostragem. In: Haddad N. Metodologia de Estudos em Ciências da Saúde - como planejar, analisar e apresentar um trabalho científico. São Paulo: Rocca; 2004. 
Halliday LF, Bishop DB. Frequency discrimination and literacy skills in children with mild to moderate sensorioneural hearing loss. $J$ Speech Lang Hear Res. 2005; 48 (5):1187-203.

Hayiou-Thomas ME,Harlaar N, Dae PS, Plomin R. Genetic and environment mediation of the prediction from preschool language and nonverbal ability to 7-year reading. J Res Read. 2006; 29:50-74.

Hinshaw SP. Externalizing behavior problems and academic underachievement in childhood and adolescence: causal relationships and underlying mechanisms. Psychol Bull. 1992;111:127-155.

Hoskyn M. Language Processes and Reading disabilities. In: Wong B, editor. Learning about Learning Disabilities. 3a ed, San Diego: Elsevier Academic Press; 2004. p.93-131.

International Dyslexia Association. Basic factors about dyslexia: what every layperson ought to know (cited 2002). Available from: http://www.interdys.org.

International Dyslexia Association. What is dyslexia? (cited 2002). Available from: http://www.interdys.org.

Johnson CJ, Clark JM, Paivio A. Cognitive Components of Picture Naming. Psychol Bull. 1996;120(1):113-39.

Kail R, Bisanz J. The information-processing perspective on cognitive development in childhood and adolescence. In: Sternberg RG, Berg CA. Intellectual Development. Cambridge: Cambridge University Press; 1992. p.229-0

Kamhi AG. The perspectives on comprehension problems. Top Lang Disord. 1997; 17:62-74.

Katz RB. Phonological deficiencies in children with reading disability: evidence from an object-naming task. Cognition. 1986;22(3):225-57.

Kohn SE, Goodglass $H$. Picture naming in aphasia. Brain Lang. 1985;24:266-83.

Lahey M, Edwards J. Why do children with Specific Language Impairment name pictures more slowly than their peers? $J$ Speech Hear Res. 1996; 39:1081-98. 
Laing E, Hulme C. Phonological and semantic processes influence beginning reader's ability to learn or read words. $J$ Exp Child Psychol. 1999;73:183-207.

Lecours AR, Parente MAMP. Dislexia: Implicações do Sistema de Escrita do Português. São Paulo: Artes Médicas; 1997.

Levelt WJM, Roelofs A, Meyers AS. A theory of lexical access in speech production. Behav Brain Sci. 1999 ;22:1-75.

Littlefield LM, Klein ER. Examining visual-verbal associations in children with and without reading disorder. Reading psychology. 2005; 26:363-85.

Linares-Orama N. Language-learning disorders and youth incarceration. Commun Disord. 2005;38:311-9.

Maluf MR, Barrera SD. Consciência fonológica e linguagem escrita em pré-escolares. Psicol. Reflex. Crit. 1997;10 (1):125-45.

Marmurek HHC, Rinaldo R. The development of letters and syllable effects in categorization, reading aloud, and picture naming. $J$ Exp Child Psychol. 1992; 53: 277-299.

Martinet C, Valdois S, Faylol M. Lexical orthographic knowledge develops from the beginning of literacy acquisition. Cognition. 2004;91:11-22.

Maxwell DL, Saake E. Research and Statistical Methods in Communication Disorders. Baltimore - USA: Williams \& Wilkins; 1997.

Mayes SD, Calhoun Sl, Crowell EW. Learning disabilities and ADHD: Overlapping spectrum disorders. J Learn Disabil. 2000;33:417-24.

McCrory, E.; Mechell, A; Frith, U.; Prie, C.J. A common neural basis for reading and naming deficits in developmental dyslexia. Brain. 2005; 128: 261-7.

McDougall P, Borowsky R, Mackinnon GE, Hymel S. Process dissociation of sight vocabulary and phonetic decoding in reading: A new perspective on surface and phonological dyslexias. Brain Lang. 2005;92(2): 185-203. 
McGregor KK, Friedman RM, Reilly RM, Newman RM. Semantic Representation and Naming in Young Children. $J$ Speech Lang Hear Res. 2002; 45:332-46.

Mckague M, Pratt C, Johnston MB. The effect of oral vocabulary on reading visually novel words: a comparison of the dual-route-cascated and triangle frameworks. Cognition. 2001; 80(3):239-70.

Metsala JL. An examination of word frequency and neighborhood density in the development of spoken-word recognition. Mem Cognit. 1997;25:47-56.

Miller CA, Kail R, Leonard L, Tomblin JB. Speed of processing in children with Specific Language Impairment. J Speech Lang Hear Res. 2001;44:416-33.

Miranda MC. A recordação livre de palauras e figuras em crianças préescolares. Dissertação (Mestrado). São Paulo: Departamento de Psicologia. Escola Paulista de Medicina, UNIFESP, 2000.

Morais J. A arte de Ler. São Paulo: Ed. UNESP; 1995.

Murphy LA, Pollatsek A, Well AD. Developmental dyslexia and word retrieval deficits. Brain Lang. 1988; 35(1):1-23.

Navas ALGP. O papel das capacidades metalingüísticas no aprendizado da leitura e escrita e seus distúrbios. Pró-Fono. 1997;9 (1):45-8.

Nation, K.; Snowling, M.J. Phonological and semantic contributions to children's picture naming skill: Evidence from children with developmental reading disorders. Lang Cogn Process. 2001;16: 241-59.

Negard-Nilssen T. Word-decoding deficits in Norwegian: the impact of psycholinguistic marker effects. Reading and Writing. 2006; 19:265-90.

Nelson K. Language in cognitive development: emergence of the mediated mind. New York: Cambridge University Press; 1996.

National Institute of Child Health and Human Development- NICHIDEarly Child Care Research Network. Pathways to reading: the role of oral language in the transition to reading. Dev Psychol. 2005; 41(2): 428-442. 
Nippold MA. The nature of nomral and disordered word finding in children and adolescents. Top Lang Disord. 1992; 13(1):1-14.

Paula GR, Mota HB, Keske-Soares M. A terapia em consciência fonológica no processo de alfabetização. Pró-Fono. 2005;17(2):175-84.

Partz MP. A avaliação da leitura em Neuropsicologia. In: Grégoire J, Piérart B. Avaliação dos Problemas de Leitura: os novos modelos teóricos e suas implicações diagnósticas. Porto Alegre: Artes Médicas; 1997. p.53-64.

Pennington, B.F., Moon, J., Edgin, J., Stedron, J., \& Nadel, L.The neuropsychology of Down Syndrome: Evidence for hippocampal dysfunctions. Child Development. 2003:74: 75-93.

Perfect CA, Liu Y. Routes of orthography to phonology and meaning: Comparisons across and within writing systems. Reading and Writing. 2005; 18:193:210.

Phillips LH, Rabbit PMA. Impulsivity and speed-accuracy strategies in intelligence test performance. Intelligence.1995;21:13-29.

Piérart J. A fragmentação do conceito de dislexia. In: Grégoire J, Piérart B. Avaliação dos Problemas de Leitura: os novos modelos teóricos e suas implicações diagnósticas. Porto Alegre: Artes Médicas; 1997. p.19-35.

Pinheiro AMV. Contagem de freqüência de ocorrência de palavras expostas a crianças na faixa de pré-escola e séries iniciais. Software produzido pela Associação Brasileira de Dislexia- ABD; 1996.

Pinheiro AMV, Parente MAMP. Estudo de caso de um paciente com dislexia periférica e as implicações dessa condição nos processamentos centrais. Pró-Fono. 1999; 11(1):115-23.

Pinheiro AMV. Heterogeneidade entre Leitores Julgados Competentes pelas Professoras. Psicol. Reflex. Crit. 2001;14(3):537-51.

Pinheiro AMV, Rothe-Neves R. Avaliação Cognitiva de Leitura e Escrita: As Tarefas de Leitura em Voz Alta e Ditado. Psicol. Reflex. Crit. 2001;14(2):399-408.

Pompéia S, Miranda MC, Bueno OFA. A set of 400 pictures standardized for Portuguese: norms for name agreement, familiarity and 
visual complexity for children and adults. Arq. Neuro-Psiquiatr. 2001;59(2B):330-7.

Price CJ, McCrory E, Noppeney U, Mechelli A, Moore CJ, Biggio N, Devlin JT. How reading differs from object naming at the neuronal level. Neuroimage. 2006. 15;29(2):643-8.

Posner MI. Operações Mentais. IN: Jorge ES. Cognição. Rio de Janeiro: Interamericana; 1980. p. 79-106.

Rego LLB, Buarque LL. Consciência sintática, consciência fonológica e aquisição de regras ortográficas. Psicol. Reflex. Crit. 1997;10(2):199-217.

Rey A, Jacobs AM, Schmidt-Weigand F, Ziegler JC. A phoneme effect in visual word recognition. Cognition. 1998; 68:71-80.

Rocca CCA. A interferência da semântica na memória em Síndrome de Asperger (dissertação). São Paulo: Faculdade de Medicina da Universidade de São Paulo; 2001.

Roelofs A. Seriality of phonological encoding in naming objects and reading their names. Mem Cog. 2004; 32(2):212-22.

Romero JF. Atrasos maturativos e dificuldades de aprendizagem. In: Coll C, Palacios J, Marchesi A, Editors. Desenvolvimento Psicológico e Educação. Porto Alegre:Artes Médicas. 2004. p. 53-71.

Roth C. Factors affecting developmental change in the speed of processing. J Exp Child Psychol. 1983;35:509-38.

Rutter M, Maughan B. Dyslexia:1965-2005. Behavioural and cognitive Psychoteraphy.2005; 33:389-402.

Salles JF, Mota HB, Cechella C. Desenvolvimento da consciência fonológica de crianças de primeira e segunda séries. PróFono. 1999; 11(2): 68-76.

Salles JF, Parente MAMP. Relação entre os processos cognitivos envolvidos na leitura de palavras e as habilidades de consciência fonológica em escolares. Pró-Fono. 2002;14(2):175-86. 
Salles, JF Parente MAMP. Compreensão textual em alunos de segunda e terceira séries: uma abordagem cognitiva. Estud. psicol. (Natal); 2004;9(1):71-80.

Santa Maria MR, Linhares MBM. Avaliação cognitiva assistida de crianças com indicações de dificuldades de aprendizagem escolar e deficiência mental leve. Psicol. Reflex. Crit. 1999;12(2):395-417.

Santiago J, Mackay DG, Palma A, Rho C. Sequential activation processes in producing words and syllables: Evidence from picture naming. Lang Cogn Process. 2000;15(1):1-44.

Santos MTM, Navas ALGP. Aquisição e desenvolvimento da linguagem escrita. In: Santos MTM e Navas ALGP. Distúrbios de Leitura Escrita: Teoria e Prática. São Paulo: Ed. Manole; 2002. p. 1-26.

Sattler A. Assesment of Children - WISC-III and WPPSI-R supplement. San Diego: Sattler; 1992.

Scarborough HS. Very ealy language deficits in dyslexic children. Child Dev. 1990; 61:1728-43.

Scheuer CI, Stivanin L, Mangilli LD.Nomeação de figures e a memória em crianças: efeitos fonológicos e semânticos. Pró-Fono. 2004;16(1):4956.

Schneider W, Shiffrin RM. Controlled and automatic human information processing: detection, search and attention. Psychol Rev. 1977;84:1-16.

Seidenberg MS, Mcclelland JL. A distributed, developmental model of word recognition and naming. Psychol Rev.1989; 96:523-68.

Shaywtiz SE, Shaywitz BA. Dislexia (Specific Reading Disability). Biol Psychiatric. 2005; 57:1301-9.

Snodgrass J, Vanderwart M. A standardized set of 260 pictures. Norms for name agreement, familiarity and visual complexity. $J$ Exp Psychol [Hum Learn]. 1980; 6: 174-215.

Snowling MJ. Object Naming deficits in developmental dyslexia. $J$ Res Read. 1980; 11: 67-85. 
Snowling M, Goulandris N, Bowlby M, Howell P. Segmentation and speech perception in relation to reading skill: a developmental analysis. $J$ Exp Chil Psychol. 1986;41(3):489-507.

Snowling M, van Wagtendonk B, Stafford C. Object-naming deficits in developmental dyslexia. Jf Res Read. 1988;11(2):67-85.

Snowling MJ. Developmental Reading Disorders. J Child Psychol Psychiatry. 1991; 32(1): 49-77.

Snowling M, Hulme C, Goulandris N. Word recognition in developmental dyslexia: a connectionist interpretation. $Q J$ Exp Psychol A. 1994;47(4):895-916.

Snowling MJ. Dislexia: Um Distúrbio da Linguagem Escrita. In: Snowling, M.J.- Dislexia. 2a ed. Livraria Santos Editora Ltda; 2004.p.87-104.

Sprenger-Charolles L, Siegel LS, Béchennec D, Serniclaes W. Development of phonological and orthographic processing in reading aloud, in silent reading, and in spelling: A four-year longitudinal study. J Exp Child Psychol. 2003;84:194-217.

Sprenger-Charolles L, Colé P, Béchennec D, Kipffer-Piquard A. French normative data on reading and related shills from EVALEC: a new coputadorized battery of tests (end Grade1, Grade 2, Grade 3, and Grade 4). Eur Rev Appl Psychol. 2005; 55 (3): 157-186.

Stanovich KE, West RF. On priming by a sentence context. $J$ Exp Psychol Gen. 1983;112:1-36.

Stanovich KE, Siegel LS, Gotardo A. Converging evidence for phonological and surface subtypes of reading disability. $J$ of Education Psychology. 1997; 89:114-127.

Steifer LS. Activating representations in permanent memory: Difference benefits for pictures and words. $J f$ Exp Psychology: Learning, Memory and Cognition. 1997; 23:1106-21.

Stivanin L, Scheuer CI. Tempo de latência e exatidão para a leitura e para a nomeação em crianças escolares: estudo piloto. Revista Educação e Pesquisa. 2005; 31 (3):425-33. 
Sternberg RJ. Introdução. In: Sternberg RJ: As capacidades intelectuais humanas uma abordagem em processamento de informação. Porto Alegre: Artes Médicas ; 1992:13-16.

Swan D, Goswami U. Picture naming deficits in developmental dyslexia: The Phonological Representations Hypothesis. Brain Lang. 1997;56:33453.

Taft M. Reading and the mental lexicon. Hove, London: Lawrence Erlbaum Associates; 1991.

Theios J, Amrhein PC. Theoretical analysis of the cognitive processing of lexical and pictorial stimuli: reading, naming and visual and conceptual comparisons. Psychol Rev. 1989;96:5-24.

Trauzettel-Klosinski S, MacKeben M, Reinhard J, Feucht A, Dürrwächter U, Klosinski G. Pictogram naming in dyslexic and normal children assessed by SLO. Vision Res. 2002; 42:789-799.

Trauzettel-Klosinski, S., Dürrwächter, U., Klosinski, G. Brau, C. Cortical activation during word reading and picture naming dyslexic and non-reading-impaired children. Clinical Neurophysiology. 2006;117(5): 1085-97.

Troia GA, Roth FP, Yeni-Komshian GH. Word frequency and age effects in normally developing children's phonological processing. J Speech Hear Res. 1996; 39:1099-108.

Valdois S. As grandes etapas da aprendizagem. In: Van Hoult A, Estienne F. Dislexias: descrição, avaliação, explicação e tratamento. $2^{\text {a }}$ ed. Porto Alegre: Artmed Editora; 2001.

Valerie M, Hulme C, snowling M, Stevenson J. Phonemes, Rimes, Vocabulary, and grammatical skills as foundations of early reading development: evidence from a longitudinal study. Dev Psychol. 2004;40(5): 665-81.

Vellutino F. Scanlon DM. Free recall of concrete and abstract words in poor and normal readers. Journal of Exp Psychol. 1985;39:363-80.

Vellutino F, Fletcher JM, Snowling MJ, Scandlon DM. Specific reading disability (dyslexia): What have we learned in the past four decades? Journal of Psychology and Psychiatry. 2004;45(1):2-40. 
Verucci L, Menghini D, Vicari S. Reading skills and phonological awareness acquisition in Down syndrome. $J$ Intellect Disabil Res. 2006;50:477-91.

Wagner RK, Torgensen JK. The nature of phonological processing and its causal role in the acquisition of reading skills. Psychol Bull. 1987;101:192-212.

Weekes BS. Differential effects of number of letters on words and nonword naming latency. $Q J$ Exp Psychol. 1997;50(A):439-56.

Wechsler D. Wechsler intelligence scale for children - revised - New York: Psychological Corporation; 1981.

Willcutt EG, Pennington BF. Psychiatric comorbidity in children and adolescents with reading disability. Journal of Child Psychology and Psychiatry. 2000;41:1039-48.

Whitney C, Lavidor M. Why word length only matters in the left visual field. Neuropsychologia. 2004;42:1680-8.

Wolf M, Segal D. Word finding and reading in the developmental dyslexias. Top Lang Dis. 1992;13(1):51-65.

Ziegler JC, Perry C, Ma-Wyatt A, Ladner D. Developmental dyslexia in different languages: language-specific or universal? J Exp Chil Psychol. 2003;86:169-93.

Ziegler JC, Goswami U. Reading acquisition, developmental dyslexia, and skilled reading across languages: a psycholinguistic grain size theory. Psychol Bull 2005;131:3-29.

Zoccolotti P, De Luca M, Pace E, Gasperini F, Judica A, Spinelli D. Word length effect in early reading and in developmental dyslexia. Brain Lang. 2005; 93:369-73. 